\title{
THE LEXICON
}

\section{OF PUBLIC SECTOR REFORM IN NEW ZEALAND}

$$
1984-1994
$$

Katherine Jane Quigley

A thesis

submitted to the Victoria University of Wellington

in fulfilment of the

requirements for the degree of

Doctor of Philosophy in Applied Linguistics

Victoria University of Wellington 
Nihil est melius quam vita diligentissima.

James Murray 


\section{CONTENTS}

ABSTRACT $\quad$ xi - xii

ACKNOWLEDGEMENTS Xiii

LIST OF ABBREVIATIONS Xiv

CHAPTER ONE: INTRODUCTION

1.1 Introduction 1

1.2 Rationale for the Study 1

1.3 The Reforms 2

1.3.1 Conclusion 5

1.4 Scope of the Study 5

1.4.1 Domains 5

1.4.1.1 The Treasury 5

1.4.1.2 The Base Domains $\quad 6$

1.4.2 Time-Frame 9

$\begin{array}{lll}1.5 & \text { Definition of Terms }\end{array}$

$\begin{array}{lll}1.6 & \text { Previous Related Work } & 10\end{array}$

$\begin{array}{lll}\text { 1.6.1 Australasian English } & 10\end{array}$

$\begin{array}{ll}\text { 1.6.2 International Lexicography } & 12\end{array}$

$\begin{array}{ll}\text { 1.6.3 International English Dictionaries } & 13\end{array}$

$\begin{array}{ll}\text { 1.6.4 New Zealand English Dictionaries } & 14\end{array}$

1.6.5 Past New Zealand English Lexicographical Studies 16

1.6.6 The Lexis of Public Administration 16 
$\begin{array}{lll}\text { 1.7.1 Research Objectives } & 17\end{array}$

$\begin{array}{lll}\text { 1.7.2 Research Questions } & 17\end{array}$

$\begin{array}{lll}2.1 & \text { Data Sources } & 19\end{array}$

2.1.1 Briefings to the Incoming Government 21

$\begin{array}{ll}2.1 .1 .1 \text { Treasury } B I G s & 21\end{array}$

2.1.1.2 Department of Social Welfare BIGs 22

2.1.1.3 Department of Health BIGs 23

2.1.1.4 Department of Education BIGs 26

$\begin{array}{lll}2.1 .2 & \text { Corporate Plans } & 27\end{array}$

2.1.2.1 Treasury $C P \mathrm{~s} \quad 29$

2.1.2.2 Department of Social Welfare $C P \mathrm{~s} \quad 30$

2.1.2.3 Department of Health $C P$ s $\quad 30$

2.1.2.4 Department of Education $C P$ s 31

2.1.3 Annual Reports $\quad 32$

2.1.3.1 Treasury ARs

2.1.3.2 Department of Social Welfare ARs 33

2.1.3.3 Department of Health ARs 34

2.1.3.4 Department of Education ARs 37

2.1.4 Diagrammatic and Tabulated Summaries of Data Sources 38

$\begin{array}{lll}2.2 & \text { Miscellaneous Sources } & 39\end{array}$

$\begin{array}{lll}2.3 & \text { Ethical Issues } & 40\end{array}$

2.4 Methodological Issues 40

2.5 Definition of Words for Inclusion 41

2.5.1 New Zealand Words 41

2.5.1.2 Australasian Words 43

2.5.2 OED and DNZE Post-datings 44 
2.5.3 Summary 44

$\begin{array}{lll}2.5 .4 & \text { Formatting } & 45\end{array}$

2.6 Identification of Words for Inclusion 45

2.6.1 Recognising Potential Words for Inclusion 45

2.6.2 The Google Search Method 46

2.6.3 The Issue of Multiword Units 51

2.6.3.1 Collocations $\quad 52$

2.6.3.2 Compounds $\quad 54$

2.6.4 The Issue of Proper Nouns 55

2.6.5 The Issue of Abbreviations and Acronyms 56

2.6.6 The Issue of Maori Words 56

2.7 The Glossary: Construction $\quad 57$

$2.8 \quad$ The Glossary: Citations $\quad 58$

2.9 The Glossary: Arrangement of Entries $\quad 60$

CHAPTER THREE: THE LEXIS OF PUBLIC SECTOR REFORM 63

$\begin{array}{lll}3.1 & \text { Introduction } & 63\end{array}$

3.2 The Treasury $\quad 63$

$\begin{array}{lll}3.2 .1 & \text { Overview } & 63\end{array}$

3.2.2 Linguistic Features of the Lexicon 64

3.2.2.1 Multiword Units $\quad 64$

$\begin{array}{lll}\text { i. Nouns } & 65\end{array}$

$\begin{array}{ll}\text { ii. Verbs } & 67\end{array}$

iii. Adjectives and Adverbial Phrases 68

iv. Affixation 68

3.2.2.2 Use of Archaic Lexis 69

3.2.2.3 Maori Loan-words $\quad 71$

3.2.2.4 Transitive Verbs become Intransitive and vice versa 72 
3.2.2.5 Semantic Shift 73

3.2.2.6 Uncountable Nouns, Adjectives and Verbs Become Countable Nouns 73

$\begin{array}{ll}\text { 3.2.2.7 Conversion } & 73\end{array}$

$\begin{array}{ll}\text { 3.2.2.8 Abbreviations and Acronyms } & 74\end{array}$

3.3 The Department of Social Welfare $\quad 74$

$\begin{array}{lll}3.3 .1 & \text { Overview } & 74\end{array}$

3.3.2 Linguistic Features of the Lexicon $\quad 75$

$\begin{array}{ll}\text { 3.3.2.1 Compound Nouns } & 75\end{array}$

3.3.2.2 Other Post-Datings for the OED 77

3.3.2.3 Affixation $\quad 77$

$\begin{array}{ll}\text { 3.3.2.4 Maori Loan-words } & 77\end{array}$

3.3.2.5 Samoan Loan-words $\quad 79$

3.3.2.6 Semantic Shift $\quad 80$

3.3.2.7 Adjective Becomes a Countable Noun $\quad 80$

3.3.2.8 Abbreviations and Acronyms $\quad 80$

3.4 The Department of Health 81

3.4.1 Overview 81

3.4.2 Linguistic Features of the Lexicon 81

3.4.2.1 Compound Nouns 82

3.4.2.2 Post-datings for the OED 83

3.4.2.3 Affixation $\quad 83$

3.4.2.4 Maori Loan-words $\quad 83$

3.4.2.5 Samoan Loan-words $\quad 86$

3.4.2.6 Adjective Becomes a Countable Noun 86

$\begin{array}{ll}\text { 3.4.2.7 Conversion } & 87\end{array}$

$\begin{array}{ll}\text { 3.4.2.8 Abbreviations and Acronyms } & 87\end{array}$

3.5 The Ministry of Education $\quad 88$

3.5.1 Overview 88

3.5.2 Linguistic Features of the Lexicon 88

$\begin{array}{ll}3.5 .2 .1 \text { Nouns } & 88\end{array}$

$\begin{array}{lr}\text { i. Compound Nouns } & 89\end{array}$ 
ii. Single Lexeme Nouns

3.5.2.3 Adjectives and Attributive Uses of Nouns 90

$\begin{array}{ll}\text { 3.5.2.4 Post-datings for the OED } & 90\end{array}$

3.5.2.5 Affixation 90

3.5.2.6 Use of Outdated Lexis 91

3.5.2.7 Maori Loan-words $\quad 91$

3.5.2.8 Samoan Loan-words 93

3.5.2.9 Abbreviations and Acronyms 93

3.6 Discussion and Evaluation of Findings 93

CHAPTER FOUR: THE METAPHORS OF ECONOMIC CHANGE 98

$\begin{array}{lll}4.1 & \text { Introduction } & 98\end{array}$

$\begin{array}{lll}4.2 & \text { Theoretical Framework } & 99\end{array}$

4.3 Identification of Metaphors in the Dataset 103

$\begin{array}{lll}4.4 & \text { Methodology and Validation } & 104\end{array}$

4.5 Metaphors of the New Zealand Treasury 105

4.5.1 Terms of Physical Motion as a Metaphor for Economic Change 106

i. Verbs 108

ii. Nouns 112

iii. Adjectives 114

iv. Adverbs 116

$\begin{array}{ll}\text { 4.5.1.1 Discussion } & 116\end{array}$

$\begin{array}{ll}\text { 4.5.2 Other Treasury Metaphors } & 117\end{array}$

i. MONEY IS WATER 119

ii. THE ECONOMY IS A BATTLEGROUND 125

iii. THE ECONOMY IS A PATIENT 127

iv. THE ECONOMY IS A ROADWAY 130 
v. THE ECONOMY IS A MACHINE

vi. THE ECONOMY IS SUBJECT TO HEAVY WEIGHTS AND SUDDEN SHOCKS

vii. THE ECONOMY IS A GAME

viii. THE ECONOMY IS A HORSE

ix. THE ECONOMY IS A BUILDING

x. THE ECONOMY IS FLAMMABLE

xi. THE ECONOMY IS EDIBLE

i. Verbs

ii. Nouns

iii. Adjectives

\subsubsection{Lexical Innovation}

i. Multiword Units

ii. Borrowing

iii. Affixation

iv. Archaic Words

v. Semantic Shift

vi. Conversion

vii. Abbreviations, Acronyms and Blending 
5.2 Implications for Further Research

5.2.1 Data Sources

APPENDICES

APPENDIX I: GLOSSARY OF NEW ZEALAND TERMS OF STATE SECTOR REFORM

APPENDIX VIII: Words from Te Reo Maori in Department of Social Welfare documents

APPENDIX X: Words from Te Reo Maori in Department of Education documents

APPENDIX XII: Abbreviations and Acronyms in Department of Social Welfare documents 
APPENDIX XIII: Abbreviations and Acronyms in Department of Health documents

APPENDIX XIV: Abbreviations and Acronyms in Department of Education documents

DATA SOURCES

REFERENCES AND BIBLIOGRAPHY 


\begin{abstract}
This is a study of the lexical effects on New Zealand English of the legal, social and economic changes brought about by the fourth Labour government and its successor during the decade from 1984 - 1994, during which period the New Zealand public sector was radically reformed. In order to carry out this study a corpus of approximately five million written words was compiled, consisting of three parallel sets of documents from four domains of use in the public sector.
\end{abstract}

Chapter One provides the rationale for scoping the study both to this particular tenyear period and to the lexis of four particular government departments, namely The Treasury and the Ministries of Social Welfare, Health and Education. A review of previous related work in the field of lexicography, and the aims and specific research questions which motivated the study, are located at the end of this first chapter.

Chapter Two explains the reasons behind the selection of three particular documents for use as data sources: the Annual Reports, the annual Corporate Plans, and the triennial Briefings to the Incoming Government. This chapter also describes the methodology used to determine words for inclusion in the glossary which is located in Appendix I. The advantages and pitfalls of the Google search method are discussed, as are the approaches taken to dealing with multiword units, proper nouns, abbreviations and words of Maori origin. The construction and arrangement of the glossary are explained here, including the basis for selection of citations.

In Chapter Three an overview of each ministry's dataset is given in terms of its linguistic characteristics, and the results of the study are described.

The penultimate chapter catalogues the discovery of a rich vein of figurative language throughout the documents of the New Zealand Treasury, as evidenced by varied and extended metaphors used to express economic concepts. This chapter gives a brief account of metaphor theory and discusses the methodology used for identification of metaphors in the dataset. 
The fifth and final chapter of this study sums up the overall findings and points the way towards useful future research in this field.

A major part of this study consists of the aforementioned lexicon in Appendix I of New Zealand-specific words from these domains and their illustrative citations. This lexicon is a record of the NZE words used in a particular dataset in the public sector of New Zealand. It amounts to approximately 260 entries supported by 660 citations, which were collected via an exhaustive data search of three types of government document over one decade. These terms are not new in the sense that they first appeared in NZE during the decade of this study, but approximately two-thirds of them are new in the sense that they do not appear in any dictionary of English. This collection of terms constitutes a cultural and historical archive, which records the distinctive identity of New Zealand's public sector as it underwent a revolutionary era of profound political and economic change. 


\section{ACKNOWLEDGEMENTS}

I am grateful for the award of a three-year Research Fellowship at the New Zealand Dictionary Centre, which enabled me to undertake this study.

I wish to express warm thanks to Emeritus Professor Graeme Kennedy, as the primary supervisor of this thesis, and to Dr Dianne Bardsley, Director of the New Zealand Dictionary Centre, for her willing advice, especially on matters of methodology. I also acknowledge with gratitude Professors Laurie Bauer and Paul Nation of this university's School of Linguistics and Applied Language Studies, for their help on matters relating to compounds and collocations, Professor Jonathan Boston and Associate Professor Bob Gregory of the School of Government, for their assistance with political terminology, and Mrs Te Ripowai Higgins of the School of Maori Studies for checking and commenting on all te reo entries and definitions in the glossary in Appendix I.

To David King of the New Zealand Ministry of Economic Development, Charles Tallack formerly of the New Zealand Treasury, Colin McGregor of the New Zealand Ministry of Education and Thomas Peters of O'Regan, Arndt, Peters and Evans, for acting as consultants on business-related, economic, educational and legal terms respectively which were encountered during the course of this research, go my sincere thanks. And to Peter Crisp, Assets Librarian at Napier Public Library, goes recognition for his lively interest in the topic and his generous gift of primary source materials.

The congenial company and support of Cherie Connor and Xie Xiaoyan in the New Zealand Dictionary Centre research office, have been appreciated.

Finally but not least important, to my husband and three children, my thanks for their patient understanding, personal support and sacrifices made throughout the years spent on this project. 


\section{LIST OF ABBREVIATIONS USED IN CHAPTERS 1 - 5}

A to J's Appendices to the Journals of the House of Representatives

AR

Annual Report

BIG

Briefing to the Incoming Government

CHE

Central Health Enterprise

$\mathrm{CP}$

Corporate Plan

DFR Departmental Forecast Report

DNZE The Dictionary of New Zealand English (Orsman, 1997)

DoH The Department of Health

DPMC The Department of the Prime Minister and Cabinet

ERO Education Review Office

GAAP Generally Accepted Accounting Principles

GDP Gross Domestic Product

MWU multi-word unit

n. noun

NESB non-English speaking background

NZ

New Zealand

NZE

New Zealand English

NZL

New Zealand Listener

NZPC New Zealand Planning Council

OECD Organisation for Economic Cooperation and Development

OED Oxford English Dictionary

pl. plural

PSR Public Sector Reform

SOE State-Owned Enterprise

SOI Statement of Intent

SSC State Services Commission

UK United Kingdom

USA United States of America

v.i. intransitive verb

v.refl. reflexive verb

v.t. transitive verb 


\section{CHAPTER ONE}

\section{INTRODUCTION}

\subsection{INTRODUCTION}

The aim of this study is to identify the changes in the lexicon of New Zealand English during the period of radical political and economic reform of New Zealand's public sector under its fourth Labour government, as evidenced in documents of the Treasury and the Ministries of Social Welfare, Health and Education. The hypothesis is that the introduction of new concepts gave rise to a need for new terms and usages. The results reveal the effects of social change on language, and specify the particular types of linguistic innovations that arose. It will be shown, for example, that the best part of 300 NZE-specific words were found in the datasets of these four government departments, of which approximately two-thirds do not appear in any dictionary of New Zealand English. It will also be shown that the majority of these lexemes were nouns, and that the nature of lexical innovation at the time was characterised particularly by multiword units.

As background for the study, this chapter provides a brief historical overview of the reforms. Next the scope of this study is outlined, in terms both of time-span and of the particular lexical domains selected. The chapter then surveys the field of lexicographical research to date, and discusses previous related work, before concluding with the research questions which arise from this discussion of the literature, and which have motivated this study.

\subsection{RATIONALE FOR THE STUDY}

The decade from 1984 to 1994 was a tumultuous period of reform in New Zealand's political and economic arenas, about which much has been written. The following 
quotations illustrate how important a time it was for the socio-cultural landscape, and, this study will argue, to the use of the English language in New Zealand.

“... the 1980s represented a policy revolution in New Zealand.” (Easton 1997:263)

“... an astonishing period of policy change, such as Aotearoa / New Zealand has not been through since the imposition of British imperial rule on a land then under tribal law." (James 1992:275)

"The great reform period of 1984 - 92 will be remembered as the privatisation of New Zealand." (ibid. p.233)

"The reforms ... covered almost every facet and corner of national, social, economic and political life." (ibid. p.258)

"In short, New Zealanders were struck by a tidal wave that burst through the colonial, economic and intellectual defences they had erected around themselves....That has set in train a wideranging privatisation of much economic and social activity. The revolution has been fast and deep." (ibid. p.277)

This study aims to explore the effect of this social and political change on the New Zealand English lexicon in the domain of government policy and administration during the period of the fourth Labour Government and beyond. The hypothesis is that this decade of socio-political turmoil and the concomitant legislative innovation provided fertile ground for the spawning of new terms and usages needed to describe the new concepts that were being introduced.

\subsection{THE REFORMS}

The origins of New Zealand's public sector reforms of the mid-1980s date from the early 1970s, when Britain joined the European Economic Community and New Zealand lost its guaranteed market for its primary produce. From 1975 onwards, the New Zealand economy slowed and unemployment, inflation and the deficit rose. "The conditions were ripe for deep change on a wide front. There would have been big change regardless of who held power" (James, 1992:277). 
By 1981, the Labour Party was still in Opposition, but was developing the policies for its shift in direction. "By 1984, officials and many politicians had recognized that whatever the source of New Zealand's economic difficulties, the solution to its critical structural problems must be sought in far-reaching structural reform and liberalization" (Evans et al, 1996:1862). In July 1984 foreign exchange and constitutional crises precipitated an early election. Treasury's analysis of the situation and its dramatic proposals for change in that year's Briefing to the Incoming Government, entitled Economic Management, form part of the dataset for this thesis.

In the words of the Treasury: "By July 1984 the financial system in New Zealand was one of the most heavily regulated systems in the world. During the next nine months a series of liberalisation measures was put in place which has left New Zealand with one of the most open and unregulated financial systems in the world" (1987 BIG I.4: 215). This last assertion is supported by a statistical analysis of 23 OECD countries which measured change in economic freedom between 1975 and 1995. New Zealand emerged as the clear world leader in reform. Its author, an experienced OECD observer, remarked that "Viewed as a whole, the sequence makes up one of the most notable episodes of liberalisation that economic history has to offer" (Henderson, 1996:13).

The actual reforms implemented by Labour when they became the government in 1984 included contracting out of public goods and services, corporatisation of state trading activities, deregulation of the financial markets, floating of the New Zealand dollar, lifting of all foreign exchange, interest rate, price and wage controls, privatisation of many state assets, and the reform of the public service. "Some of these steps ... took New Zealand to a position of orthodoxy among developed countries; in other respects, New Zealand's financial markets moved to a more deregulated position than in any other country. New Zealand appears to have been the first country to remove all monetary policy (reserve) ratio controls on banks in the postwar period" (Evans et al, 1996:1863).

After Labour's second election win in 1987, Treasury published that year's briefing as the two-volume Government Management, which is also part of the dataset for this study. Like the landmark Economic Management of three years before, Government 
Management too remains an important milestone in New Zealand's political history. An American expert on public policy called this "an extraordinary Treasury brief" (Schick, 1996:18) in that it vigorously promoted the adoption of the privatisation model.

The Labour Government then moved on to agricultural subsidies, liberalisation of the labour market, and reductions in both welfare expenditure and the protection of local industry, all of which conflicted with its traditional policies and would normally have been characteristic of its opposition, the National Party. When a landslide defeat for Labour led to a change of government at the 1990 election, National continued the process, and "extended economic rationalism to health, tertiary education, and social welfare policies" (Gregory, 2002:20). This all but ended the well-established notion among New Zealanders of the welfare state.

The business sector saw these changes as opportunities and were supportive; in fact the policies of the New Zealand Business Roundtable were already ahead of the government on these issues. Opposition came from the unions, the unemployed, academics and public commentators. For Kelsey, "moves to divide social from commercial objectives and subject them to market forces were bound to provoke controversy and resistance" (1993:31). Public unease was widespread. In Easton's view, on the domestic socioeconomic front these moves were to usher in 'The Decade of Greed' (1997:249).

The view has also been advanced that "New Zealand is a special case which gets its distinctive character from the range and depth of the reforms and the systematic attempt to redefine and limit the role of the public sector" (Evans et al, 1996:1861). Due to this unique combination, 'the New Zealand model' of public management is now well-known internationally. Working groups from several countries have been sent to observe and make recommendations on which of New Zealand's reforms they might adopt. In the United States in 1993 the Vice-President ran a campaign to 'reinvent government' into one that 'works better and costs less'; this was largely based upon the New Zealand and Australian models of reform in its aim to give managers more autonomy and hold them accountable for their performance. 


\subsubsection{Conclusion}

The sector-wide reform of New Zealand's economy from the mid 1980s onwards was characterised by the ideological coherence of the raft of reforms, its speed and thorough-going sweep. Three important pieces of legislation were passed which together constituted the landmark codification of public sector reform in this country: the State Owned Enterprises Act of 1986, the State Sector Act of 1988, and the Public Finance Act of 1989. By outlining the chronology of the reform process, this section has shown that these statutes did not spring fully formed from nowhere, but can be seen as the logical culmination of a fast-moving wave of change. It is the hypothesis of this study that the scale and speed of these socio-economic reforms must have left their mark on New Zealand English.

\subsection{SCOPE OF THE STUDY}

\subsubsection{Domains}

The public sector as a whole generates a huge amount of potentially rich source material for a corpus study of lexical innovation. Due to the sheer quantity of output it cannot all be seriously considered for a close lexicographical examination. However it was not desirable to too strictly limit the collection of data to what is sometimes termed the core public service, that is, those bodies traditionally called 'ministries' or departments (see the definition of terms in section 1.6 below), because some of the most important philosophical, ideological and economic ideas underpinning the reform process issued out of independent statutory authorities. Therefore it was decided to restrict the scope of the project to studying the lexical consequences of public sector reforms in the three domains of Health, Education, and Social Welfare, along with The Treasury as a representative of a 'control agency'. ${ }^{1}$ The reasons for these decisions follow.

\subsubsection{The Treasury}

\footnotetext{
${ }^{1}$ This was the term used during the time-frame of this study; it has since been replaced by 'central agency'.
} 
The constitutional function of New Zealand's Treasury is to provide independent economic advice to the government of the day, regardless of party politics. A key difference between the Treasury and the other three domains included in this study is that "Treasury may supply advice from time to time across the entire range of the Government's policy; other departments are responsible for more narrowly-based provision.” (Treasury 1987 BIG I.2:76). As far back as 1958 it was said of New Zealand's Treasury that its "influence is greater than that of any other department, because, as the controller of finances, it is at the centre of the administration and its financial decisions and recommendations pervade every aspect of government activity."2

The other two control agencies in New Zealand are the Department of the Prime Minister and Cabinet (DPMC) and the State Services Commission (SSC); at the time with which this study is concerned both were powerful, but the Treasury was preeminent. In fact during the decade examined here, the Treasury assumed extraordinary influence. Therefore it was particularly important to include it as a data source. One could even say that at that time it was the prime, though officially unacknowledged in this capacity, driver of public policy. ${ }^{3}$ In 1989 "the Treasury is the pre-eminent economic advisory body in New Zealand. Its power rests not merely on its role as a control department, but also on the particular rules governing the process of Cabinet decision-making, its political support, its capacity to influence the framework within which policy options are considered, the quality of its staff, and the absence of strong bureaucratic rivals" (Boston, 1989:78). "No other department has the analytical resources to challenge the Treasury across a broad spectrum of policy issues and there is only limited vetting of the Treasury's economic advice" (Boston, 1989:82). As late as 1995 it was still true that "the Treasury is without doubt the largest and most influential supplier of policy advice. It employs almost 200 policy analysts and managers, and absorbs around 15 per cent of the government's total expenditure on policy advice" (Boston, 1995:92).

\subsubsection{The Base Domains}

\footnotetext{
${ }^{2}$ Polaschek p.252 quoted by Boston 1989: 70

${ }^{3}$ Witness the popular placard slogan seen on the streets of the capital during the 1980s: "Eliminate the middle man - elect Treasury direct". (Quoted in Boston 1992:195)
} 
The three other domains of education, health and social welfare were selected for the following reasons.

i. Given the Treasury as a representative control agency, it was desirable to include ministries from other categories, under that classification system which sees government departments divided into policy, purchasing, delivery and regulatory bodies. In this taxonomy Health and Education would come under policy ${ }^{4}$, and Social Welfare was mainly concerned with delivery and transfer of services functions. (Into the regulatory category would fall ERO and the Audit Office, for example). The tendency at the time was to split ministries' policy arms from the purchase and delivery of services and from all regulatory functions, the thinking being that this would achieve clearer policy outcomes and a reduction in self-serving behaviour by government agencies, although at the time of writing the situation has changed again in recent years, with many areas being rejoined.

ii. The sheer size of the Department of Social Welfare, and the core role it plays in national development and social policy, make this spectrum of ministries an obvious one to focus on. In 1987 the Department of Social Welfare, at 6,228 staff and a budget of approximately five billion dollars, (DSW AR 1987:12) was the largest of all government departments in terms of people employed, and was by far the largest spender; by 1990 it was recorded that "The Department of Social Welfare is now the largest core department in the public service with some 8,000 staff based at more than 80 locations around New Zealand" (DSW An Inventory of the Dept...1990:13), and a total budget of over $\$ 10$ billion (Treasury 1990 $B I G$ Ch.8 (a)). To illustrate by comparison just how huge this one department was, in 1984 the Department of Health employed "around 3,600 people" (DoH BIG p.2), so the DSW was almost twice as big. For this reason it was selected as likely to be a fruitful source of data and an interesting point of comparison with the other ministries.

\footnotetext{
${ }^{4}$ Though "Health was more than a policy ministry for most of this period, and even after ... the early 1990 s, retained certain regulatory functions.” (Jonathan Boston, personal communication)
} 
iii. These ministries occupy a central position in the national social fabric. Historically the trio of education, health and social welfare formed the backbone of New Zealand's image as a welfare state, and they continue to affect all New Zealanders' daily lives today. Because of the longstanding concept in this country of the 'Welfare State', an expectation of being 'looked after' in these three areas has grown among the general populace.

iv. Labour's strategy of devolving or decentralizing responsibility for the delivery of governmental services impacted significantly on these social service-oriented departments. Because they lie at the forefront of public concern, these areas result in a dynamic interface between government and the general public. Any changes to the way these service-oriented agencies carry out their work receive wide and often critical coverage in the media, and result in immediate public reaction. Community complaints centre on these areas (New Zealand Planning Council 1979:24).

v. If the government's spheres of economic activity are divided into 'market' and 'non-market' areas, where the former are those organisations exposed to competition, then as non-market or 'spending' ministries, these three domains form a natural triad. Variously termed "the social spending departments" (Jesson, 1989:86) and "the large spending categories of health, education and welfare" (Trebilcock, 1995:10), they differ from the majority of government departments in the way that they function. While it is recognised that none of the 37 core government departments makes a profit, yet "it is useful to distinguish between the 'market' activities of the government (where the output is or could be sold) and 'non-market' activities (those which, at any point of time, governments have decided should be provided collectively on the community's behalf)" (Treasury $B I G$ 1984a II.1.120). As one commentator put it, "such touchstones of the welfare state as health and housing ... were deeply embedded in the popular psyche as essential social services, not commercial profit-making enterprises" (Kelsey 1993:31).

As far back as 1979 it was suggested by the NZ Planning Council that instead of separate funding at national government level for each of these 
three ministries, they should be combined into one national framework and assigned a 'social budget' with which to operate (NZPC, 1979:29). The Treasury floated the same idea in its 1987 Briefing $^{5}$. This proposal however has never been taken up, and these three areas remain the most expensive services from the government's point of view, in terms of percentage of GDP spent per annum.

vi. Perhaps for all of the above reasons, the three departments of education, health and social welfare are often grouped together in both government documents and the secondary source literature of the field, as well as in the public mind. ${ }^{6}$ The Royal Commission on Social Policy conceived in 1986 and charged with discovering what New Zealanders want in a fair society was seen by both "Lange and Palmer ... as focussing on health, education and welfare" (NZL, 12.03.88:18).

\subsubsection{Time-Frame}

The decade of 1984 - 1994 has been selected as affording an intensive, narrowlyfocussed snapshot of the first wave of core reforms to New Zealand's public sector. As such, this project has been conceived of as more a synchronic sampling of data than a diachronic study over a longer time-span. Originally a twenty-year time-frame of 1981 - 2001 was planned, but after consultation with political scientists it was decided that this time scale was too broad to capture the heart of the reforms, and would dissipate the clarity of any possible findings by including data samples from a period much later than that when the original changes took place. Therefore the time frame was cut back to sharpen the focus of the study and best serve the project's intentions.

\subsection{DEFINITION OF TERMS}

\footnotetext{
5 “... (one could envisage a Social Policy Ministry, for example, and Departments of Health, Education and Social Welfare) ..." Government Management I.2.78

${ }^{6}$ Education and health are bracketed together in Evans et al, 1996: 1872 and James, 1992: 151 and 308. Education and social welfare are bracketed together in the Treasury, 1984 BIG 2:2:127. Education, health and social welfare are bracketed together in Gregory, 2002: 20; Kelsey, 1993: 82 and 83; Boston et al, 1996: 9; Jesson, 1989: 12 and 79; the Treasury, 1984 BIG 2:12:249-250; the Treasury, 1987 BIG 1:2:77 and 1:3:125-6, and the Treasury, 1990 BIG 1:2.
} 
Within this thesis, the umbrella term 'state sector' will be used to refer to all the organisations of central government in New Zealand. The term 'public sector', on the other hand, will be taken as referring to the whole of the state sector and, in addition, the local government organisations nationwide. Because the sweeping reforms here under discussion impacted upon the whole of the public sector at both the central and local government levels, this thesis will hereafter refer to the PSR (public sector reform) process.

Another interrelated set of terms relevant to this study is the lexemes denoting an economic continuum which begins with 'commercialisation': the government retains ownership but the body is run according to business principles, through 'corporatisation': creation of an SOE, run like a private company, through 'deregulation': removal of restrictive controls, to 'privatization': the SOE is sold off.

Turning now to linguistic terms, this study will use 'headword' to refer to a glossary entry, 'lexeme' or 'word' to mean the concrete instantiation of a headword in context, and 'word-form' to signify an inflected form of a lexeme.

\subsection{PREVIOUS RELATED WORK}

\subsubsection{Australasian English}

Interest in New Zealand lexis first began with observations recorded in the early postcolonial period, but it was not until the two decades from the mid-1930s to the late 1950s that much was written on the subject. This was the period of work by Arnold Wall, Sidney Baker and Cecil Hull; in the middle of this era too, (1946), Johannes Andersen wrote his early article on Maori words incorporated into the English Language. This pioneering set of publications was mainly concerned with slang and spoken language, and was characteristic of the time in their prescriptive attitude towards the 'correct' use of 'The Mother Tongue' or 'The Queen's English'. Any specifically New Zealand lexis or pronunciation was viewed "by way of negative comparison with the prestige variety of English spoken in England" (Kuiper and Bell, 2000:16). 
Two further decades on, although the study of Australasian varieties of the English language was still in its infancy, a change of tone was evident. The Australian Language Research Centre had been established at Sydney University, and shortly after this important development, W.S. Ramson at the Australian National University published in 1966 the results of his doctoral thesis, an historical study of the vocabulary of Australian English from 1788 to 1898 which was later published as the Australian National Dictionary. In this year too The English Language in Australia and New Zealand appeared, in which G.W. Turner described the vocabulary particular to the growing European settlement in the two countries. Although dated now and largely concentrated on words for flora, fauna, farming and goldmining activities in the Dominions, Turner's book stands alongside Ramson's work and the Macquarie Dictionary as a significant foundation stone on which subsequent development in the field was based.

The theory of semantic change which underlay this period of work by Ramson, Baker, Turner and Morris, was not so much the question of how words change their meaning, but rather how experience changes words. It was this group of early lexicographers who brought the perspective that borrowings, word-formation and semantic change are all responses to pressures caused by change in daily life. "All are adjustments of structure to situation" (Turner, 1966:41).

The last two decades have seen an increasing number of works in this area, as scholarly interest in New Zealand English has taken off apace. This second wave could perhaps be seen as beginning with the research of Tony Deverson and Elizabeth Gordon during the mid- to late 1980s. Three more works on New Zealand English were compiled during the following decade, beginning with Bell and Holmes' New Zealand Ways of Speaking English, which appeared in 1990. This was followed in 1991 by McGregor and Williams' work, which focuses largely on New Zealand literature and on the influence of Te Reo Maori on New Zealand English, and then by Bell and Kuiper's book of 2000. Across the Tasman during this time Burridge and Mulder's work covering the historical development as well as the structure and use of English in Australasia also appeared, an update which built on Ramson's and Wilkes' work on Australian English vocabulary during the sixties and eighties respectively. In 
all of these works however, lexis, rather than being to the fore, forms just a small part of the whole.

\subsubsection{International Lexicography}

On the international lexicographical scene the decade from 1975 to 1985 was termed 'a decade of the lexicon" ${ }^{7}$, when a renewed flourishing of dictionary research brought about an increased awareness of the hitherto somewhat unformed state of theory in the field, and resulted in an intensified scrutiny of where lexicography should belong as a discipline. In 1983 it was written that "there is general agreement that lexicography is a branch of applied linguistics which depends heavily on lexicology"8. Whether or not lexicography ought to be considered a branch of applied linguistics (Svensen, 1993, is for and Wiegand, 1998a, contra ${ }^{9}$ ), Hartmann went on in later years to argue (2001) that there is a new field in the making - that of the learner's dictionary, or pedagogical lexicography. In this work too (Teaching and Researching Lexicography), Hartmann maps the field of lexicography, underlines its multidisciplinary and diffuse nature, and laments that a theory to underpin the practical side of the discipline has been slow to develop. "So is lexicography a practical-professional activity or a theoretical-academic discipline?" (p.11). The answer is that it is both, and that a coherent academic theory which embraces all related aspects of lexicography has not yet been advanced.

The 1980s then were a very important time in the context of an acceleration of lexical studies, dictionaries and metalexicography. This decade brought Ilson's 1985 publication which treats the links between dictionaries and language learning, and his 1986 Lexicographic Description of English with Benson and Benson. 1987 saw Burchfield's edited collection of studies on regional and period dictionaries (classical and others), and 1988 Howard Jackson's thorough and comprehensive Words and Their Meaning. During the 1990s Francis Katamba's English Words provided an accessible overview of etymology, morphology and psycholinguistics as well as

\footnotetext{
${ }^{7}$ Nowakowski, M. 1990. "Metaphysics of the dictionary versus the lexicon" in Tomaszczyk and Lewandowska-Tomaszczyk (eds.). p.3 quoted in Bejoint, 1994: 1

${ }^{8}$ A.M.Al-Kasimi, Ch. 13 "The interlingual / translation dictionary" pp 153 - 162 in Hartmann, 1983: 153

${ }^{9}$ discussed in Hartmann, 2001: $11-12$
} 
referring briefly to dictionaries, and in this decade too the interesting work of Tom McArthur must be mentioned, both his eclectic Language, Lexicography and the Knowledge Revolution, and the revolutionary Longman Lexicon, the first (and only) re-organising of English vocabulary in the tradition of Roget's thesaurus.

More recently, three major academic works have recently appeared in as many years: a second edition of Henri Bejoint's Modern Lexicography: An Introduction in 2000, the very important second edition of Landau's Dictionaries: The Art and Craft of Lexicography in 2001, wherein he updates his 1984 discussion of the state of the profession in the United States, and a new introduction to lexicography by Jackson in 2002. These are comprehensive in their coverage and scholarly in approach. The periodicals Dictionaries and International Journal of Lexicography are important ongoing sources of up-to-date research.

\subsubsection{International English Dictionaries}

The publishing of dictionaries themselves is a separate though related area to this review of the literature. The model for all subsequent dictionaries was set by the Oxford English Dictionary, firstly in its original twelve volumes under James Murray, published between 1888 and 1933, which pioneered the historical approach, characterised by citations arranged in chronological order with the earliest placed first, and the quotations used to illustrate the meanings of words. This work was updated between 1972 and 1986 with the four volumes of A Supplement to the Oxford English Dictionary published under Burchfield, in preparation for Simpson and Weiner's full-scale second edition of 1989 , in twenty volumes. This historical method has formed the basis of the world's best-selling dictionary, the Concise Oxford, and of the one-volume Oxford English Dictionary. Collins on the other hand has taken the opposite approach with its Cobuild dictionary for learners of English, aiming to be corpus-based and with definitions and senses arranged in order of frequency. Nonetheless the $O E D$ 's methodology remains extremely influential, and has inspired a whole genre of historical dictionaries worldwide, including the Dictionary of Old English, the Dictionary of the Older Scottish Tongue and the Middle English Dictionary, among others. It was the work in the UK on the OED which set the standard and the methodology for later Australian and New Zealand scholars also. 
The genre of regional dictionaries of English also can be seen as offspring of the $O E D$ in that they too mainly follow its methodology. Members of this group are the Australian National Dictionary, the Dictionary of Americanisms, the Dictionary of American English, the Dictionary of Canadianisms on Historical Principles, and the Dictionary of South African English on Historical Principles. But as Bejoint (1994:82) has observed, as a group they tend to be "much more encyclopaedic than the $O E D$ : they lay more emphasis on the culture, particularly the historical aspects of the rural culture: they are all 'cultural' dictionaries in the particular sense of historical, nationalist dictionaries." (Further along this spectrum are American college dictionaries, many of which are definitively encyclopaedic).

\subsubsection{New Zealand English Dictionaries}

"The compilation of a native dictionary is a symbolical act of independence from the 'mother country', it is a necessary step to assert the cultural identity of the country ... 'for New Zealanders...the publication of specifically New Zealand dictionaries is part of a continuing development of national awareness, a process that has been underway from about the beginning of the century and that has slowly gathered momentum". 10

The literature in the area of lexicography in general is not vast, and when one narrows the field to that of New Zealand lexicography, it rapidly becomes smaller still. To go back to the beginnings of this field in the southern hemisphere, one looks to Edward Morris' Austral English of 1898, a dictionary of Australasian words, representing the first time that scholarly attention was turned to the language of the new colonies. This can be seen as the logical forerunner of The Australian National Dictionary which appeared nearly a century later, in that both listed only Australian words, and not words of general English. In this respect these two dictionaries are akin to the Dictionary of New Zealand English which would follow later again.

Specifically New Zealand dictionary-making began with Sidney Baker's New Zealand Slang: A Dictionary of Colloquialisms in 1941. From this beginning through to the publication 64 years later of the first Oxford English dictionary written

\footnotetext{
${ }^{10}$ Bejoint, 1994: 83, quoting F.S.Scott's 1986 review of The New Zealand Pocket Oxford Dictionary in Dictionaries 8:317-326.
} 
especially for New Zealand users, New Zealand dictionary-making has come of age. Along the way other general New Zealand dictionaries have been The New Zealand Contemporary Dictionary in 1966, where the only specifically antipodean words are in a brief 'Australian and New Zealand Supplement' at the end, and Elizabeth and Harry Orsman's The New Zealand Dictionary in 1994. There was also Orsman's Heinemann New Zealand Dictionary, which went through two editions before being taken over by Reed and appearing as a third edition under Wattie in 2001. Most recently, 2005 brought the publication of Deverson and Kennedy's The New Zealand Oxford Dictionary.

There have been, in addition, various takes on New Zealand lexis with their own peculiar slant, usually humorous (Cryer's Curious Kiwi Words and the travellers' guides to New Zealand by the Hayward brothers and Leland Jr.) but sometimes serious in intent (New Zealand Spelling Dictionary, 1987). There are also two fairly recent glossaries of Kiwi slang, written by McGill in the late 1980s. The presence of Te Reo Maori words in New Zealand English has recently been documented by many scholars, including Macalister whose work has confirmed the finding by Kennedy and Yamazaki that approximately six in every thousand words of New Zealand English are of Maori origin.

The standard guide to the history and usage of New Zealand English remains Orsman's The Dictionary of New Zealand English, published in 1997. A page-bypage search of this dictionary revealed a total of 127 headwords which fall within the lexical domains of this thesis. A complete list of these words can be found in Appendix III. Some of these date back to last century, for example 'local government' (1842), House of Representatives (1846). Of these 127 entries, 26 have first citations which fall within the time frame of this thesis. Examples are 'language nest' (1984) and 'fiscal envelope' (1994).

In 1990 Lipka wrote of the New Zealand, Australian and South African varieties of English, that "Although they are similar in orthography and grammar to British English, there are noticeable differences in the lexicon and the phonology" (1990:18). Deverson too has noted that "The two most conspicuous features of New Zealand English (NZE) observed in relation to other international varieties of the language are 
its phonology and its lexis....It is much less obvious than in the case of the accent how New Zealand vocabulary should be identified and delimited, and how subsequently it should be analysed in a way which will reveal general patterns and categories...the distinctive New Zealand element in the average educated New Zealander's (active and passive) vocabulary seems unlikely to be much greater than 5\%" (Deverson, 2000:23-24). "For now there can be no doubt that there is a continuing responsibility for lexicographers (and Dictionary Centres) down under and elsewhere to monitor, collect, and describe the usage of their own regions, and to make the information available, in the fine tradition of Morris, Ramson, and Orsman, to those wishing to describe these varieties from outside." (Deverson, 2001:39). So although the percentage of NZE vocabulary which is unique to this country is so small, the present study is an attempt to further our knowledge of it in one domain, namely that of government administration.

\subsubsection{Past New Zealand English Lexicographical Studies}

Past lexical studies in New Zealand English have included Bardsley's on the rural sector and Macalister's on the Maori influence, both completed in 2003, and Connor's on harvesting the marine environment (2010). This study of the lexis of New Zealand's government sector during the period of state sector reform should be viewed as fitting in to the same set, although it is different from those three studies in that it uses a synchronic rather than a diachronic approach. In this respect it has been situated deliberately and clearly in the typology described by Deverson (2000:31), where he suggests classifying "a regional lexis according to a series of synchronic semantic fields...such as indigenous culture, flora and fauna, agriculture, government, and sport...those areas of New Zealand society which are most important to its identity." The government sector has been chosen, and within this the specific domains of Treasury, Social Welfare, Health and Education (for reasons described in sections 1.5.1 - 1.5.1.2 above) and the period of $1984-1994$ (for reasons described in section 1.5.2 above).

\subsubsection{The Lexis of Public Administration}


A third and no less important area is any potential research that has been conducted on the lexis of public administration in the United Kingdom, the United States of America, Canada and Australia, especially in the three content areas of most interest to this study. Lexicographical studies have been undertaken in various specialist subject areas - domains ranging from tramping to the legal profession - but none has been found on the language of the public sector. This reveals a gap in academic research to date, which this thesis aims to fill for New Zealand, by examining in detail a sample of documents from four government departments throughout one of the most important decades in this country's political history to date. It is expected that from this research implications will be able to be drawn for other World Englishes, which will be able to be tested by replication studies in other countries.

\subsection{RESEARCH OBJECTIVES}

\subsubsection{Research Objectives}

The objectives of this study are:

- $\quad$ to compile a specialist lexicon of New Zealand English from the government domain, using a sample of ministries and a range of data sources from 1984 to 1994.

- to identify and discuss effects on the New Zealand English lexicon which arose from the reforms of the public sector, including political, economic, social and cultural influences, which were discussed in sections $1.2-1.4$.

- to ascertain through analysis of this lexis the main characteristics of New Zealand English in the government domain, and to explore and make a preliminary assessment of the worth of this sector as a source of new words in New Zealand English.

\subsubsection{Research Questions}

In order to meet the above objectives, this study purposes to provide answers to the following specific research questions: 
1. Was there any New Zealand-specific lexis used in this country during the period 1984 - 1994 in the public administration of education, health, social welfare and the Treasury by the New Zealand government and its agencies?

2. If there was any lexis unique to New Zealand used in these lexical domains during this timeframe, what words does it consist of?

3. How many of the NZ-specific words (if any) were new, as in not listed in any previous dictionary of English?

4. In which word class do the new words (if any) cluster?

5. How were these words formed, e.g. by semantic shift, compounding, blends, any particular morphemic trends?

6. Are the words distinguished by any other lexical features such as collocational patterns or euphemism ${ }^{11}$ ?

7. Do the words occur in any salient patterns, e.g. distribution by users or contexts of use?

${ }^{11}$ The American Heritage Dictionary of the English Language defines bureaucratese as 'a style of language characterized by jargon and euphemism that is used especially by bureaucrats.' 


\section{CHAPTER TWO}

\section{METHODOLOGY}

\subsection{DATA SOURCES}

In order to investigate the research questions listed in the previous chapter, it was first necessary to identify suitable sources from which to create a corpus and collect data. There is a plethora of different document types produced by government departments annually; from New Zealand's Treasury alone, for example, the following documentation is produced every year: Annual Report, Main Estimates of Expenditure, Supplementary Estimates of Expenditure, Budget Tables, Imprest Supply Bills, Statement of Intent, Appropriation Bills, Supplementary Order Paper, Monthly Reports on the Fiscal Position, Three-year Forecasts, Budget Speech and Supplements, and Economic Strategy ${ }^{1}$. From these options three document types were chosen as data sources for this study. They are, firstly, the three-yearly Briefing to the Incoming Government (BIG), prepared by each public service department prior to an election. Secondly, the annual Corporate Plan $(C P)$, which subsequently underwent two name-changes, first to Departmental Forecast Report (DFR), and later to Statement of Intent (SOI). This document is in effect a statement of intent for the year ahead, against which each department measures itself at year's end. Thirdly, the Annual Report which under the Public Finance Act, every public service department is required to supply to Parliament. These three sets of official documents were identified as the most suitable sources of data for the following reasons:

i. Rather than being full of tables of statistics as the financial statements are, these text types are characterised by long stretches of connected prose, suitable for lexicographical examination.

\footnotetext{
${ }^{1}$ The Treasury, AR 1992: 44
} 
ii. They are produced at regular intervals; a matter of statutory obligation in the case of the Corporate Plans and the Annual Reports, and by convention with the briefing papers.

iii. They are all readily accessible, being tabled in Parliament and as such, publicly available.

iv. They provide a slew of different vantage points, with the Annual Reports looking back in time, the Corporate Plans looking forward, and the Briefing papers designed to provide newly elected ministers coming in to Parliament after a national election with a current snapshot of the present state of their portfolio.

v. Being a mixture of text types, they provide a breadth of genre which is seen as a strength for a lexicographical corpus. (For this reason, it was decided not to use a single document type, such as the Briefings to Incoming Governments alone). All three of these documents are quite distinctive in both length and content, and their styles of written discourse differ markedly. The BIGs are dense volumes, divided into substantial chapters with approximately 480 words per page, and, on average, 312 pages per briefing. Their tone is academic: economic theory and practice leavened with some philosophy.

By contrast the Annual Reports and Corporate Plans are much shorter, at approximately 100 pages each, and have a different focus, being narrowly concerned with meeting that year's proposed targets, budget and tasks, which are often presented as a checklist with items ticked off. These document types typically have only 220 words per page and are divided into brief sections with many headings, subtitles and bullet points. Very unlike the BIGs they are written in a journalistic style, where sentences are often incomplete and photographs or graphics enliven the text - all of this presumably to make the reports more reader-friendly and palatable for public consumption, whereas the targeted readership of the Briefings is a much smaller group, mainly inside the government. The Corporate Plans are almost entirely written with reference to the present or future, and 
contain the Forecast Financial Statements for the year. Predictably, they overlap in content with the Annual Reports, which are mainly written in the past tense, and contain as appendices the Financial Statement and audited accounts for the year.

\subsubsection{Briefings to the Incoming Government}

As mentioned above, a $B I G$ is written by every Ministry every three years as part of the preparation for a national election. Each briefing is then handed over by its ministry to the relevant new minister immediately following their appointment and the formation of a government, to help them become familiar with their new portfolio. This would normally coincide with immediately after the election, though not always, as was seen in 1996 when it took some time to form a coalition.

It should be noted that because the briefings to incoming governments are published triennially, and because they coincide with election years in New Zealand, the result is that for this thesis, typically four sets of briefing papers have been examined for each of the four departments selected for inclusion. These were published, normally one $B I G$ for each election year, as follows:

- 1984 , when the fourth Labour Government came to power

- 1987, when Labour was re-elected

- 1990 , when National won the election

- 1993, when National was re-elected

There were however several exceptions to this, which are detailed in the sections below relating to individual departments. Characteristics of this particular data source insofar as they relate to each particular department in turn, will now be discussed.

\subsubsection{Treasury BIGs}

Within the New Zealand Treasury, overall responsibility for authorship of the BIGs rests with the Policy Co-ordination and Development Unit, a thinktank-like group 
within the Treasury ${ }^{2}$. From one election year to the next, there is approximately a $50 \%$ turnover of staff within this unit ${ }^{3}$. The documents are lengthy, each one like a book in itself, with each book often divided into two volumes, and each volume running to as many as 15 chapters. They offer detailed and in-depth advice to the new, post-election governments, and cover all aspects of New Zealand's economy, from the structure of the financial system itself to specific issues such as export markets for certain types of manufacturer.

For the Treasury, 1984 was a very important year as it signalled a major shift in policy direction. Because of this, even working under the time-pressure of a snap election, the Treasury took it upon itself to produce two Briefings to the Incoming Government that year, which were released on 14 and 30 July. This is a reasonably uncommon occurrence, and did not happen again in this ministry until 1999, another key year for policy formation but one which falls beyond the timeframe of this study. The two briefings put out during the July of 1984 are the longest ever produced by Treasury. At a total of 31 chapters as compared to the next longest (17 chapters in total for the two briefings from 1999), they are almost twice as long as any year's $B I G s$, from the earliest records available online through the following two decades up to the present day. Therefore the findings in this thesis are drawn from a total of five Treasury BIGs, (that is an aggregate of 63 chapters, or 1,562 pages), instead of the four which would usually be published within any one ten-year period.

With the Treasury BIGs in particular, we have a dataset consisting of a decade's worth of government briefs, emanating from the prime mover of public policy, covering the ten years which were at the heart of the first wave of dramatic core reforms to New Zealand's state sector.

\subsubsection{Department of Social Welfare BIGs}

\footnotetext{
2 "PCD's role is to maintain an overview across Treasury policy development, keep abreast of emerging ideas and research and review and challenge existing Treasury thinking. PCD provides analysis and advice on medium-term strategy issues." (NZ Treasury, 2005/2006: 44)

${ }^{3}$ David King, Ministry of Economic Development, formerly of The Treasury, personal communication, 2005
} 
The Department of Social Welfare also produced more than one Briefing to the Incoming Government in one year. In 1984, 1987 and 1993 there was only one produced, but in 1990 there were five. These briefings though are considerably shorter than the Treasury BIGs, varying in size from 10 to 217 pages. They are however fairly dense at, on average, 400 words per page. All have different main titles but share the secondary title of A Briefing Paper for the Minister of Social Welfare. The typical structure of an early (1984) DSW BIG is as follows:

(i) Principal Functions of the Department of Social Welfare

(ii) Social Work and Community Services

(iii) Social Security Scheme

(iv) Important Current Issues

(v) Administration of the Department of Social Welfare

(vi) Advisory Councils, Boards and Committees serviced by the Department of Social Welfare

(vii) Legislation administered in the Department of Social Welfare

(viii) The role and responsibilities of the Department of Social Welfare in the Civil Defence Organisation

(ix) The rates of national superannuation and social security benefits

(x) Department of Social Welfare Offices and Institutions - Auckland Region

The standard structure for later DSW BIGs (1993 in this study) is as follows:

Part A: Environmental Overview

Part B: Issues Related to Outputs

Part C: Issues Related to Departmental Operations

\subsubsection{Department of Health BIGs}

The early BIGs from this Department are in typed, looseleaf, MS form, unpublished and stored in ringbinder folders in the current Ministry of Health archives. Individual volumes are between 36 - 198 pages long, with average number of words per page varying widely according to the typesetting, from approximately 165 - 545 per page. Titles of the DoH BIGs varied widely during the decade of this study, i.e. within this Department at the time there was no uniformly accepted title for this type of briefing paper. Unusually, the DoH produced an extra Briefing Paper in 1989, which as a non- 
election year, was out of step with the 1984, 1987, 1990, 1993 papers issued by other ministries and indeed by the DoH itself during this decade. 1990 was also unusual, in that the DoH produced four different BIGs that year. The 1993 BIG was in two volumes. All have been read and included in this study.

According to the $1987 \mathrm{BIG}$, the intention of a DoH $B I G$ is "to provide the Minister of Health with an appreciation of the current state of the New Zealand health services. It covers the structure of the health services, issues of current concern, the general philosophy and health policies under which the Department of Health presently conducts its business, and the organisational structure of the department." (Preface, p.2).

A typical early (1984) General Briefing Notes for the Minister of Health, as this document type was termed at the time, was organised as follows:

Overview of Health Policy

Annex A: List of Senior Departmental Officers and Organisation Charts

Annex B: Notes from Divisions:

- Division of Public Health

- Scientific Services

- Division of Health Promotion

- Health Education and Information Unit

- Division of Dental Health

- Division of Nursing

- Division of Hospitals

- Division of Hospitals (Mental Health)

- Division of Clinical Services

- Management Services and Research Unit

- Data Processing Division

Annex C: Statutory Boards, Committees and Advisory Boards of the Department of Health

Their content ranges over all types of public and environmental health issues, for example water supplies and sewerage schemes, the elimination of polio and tuberculosis, whether or not the amount of lead in petrol should be reduced, the 
production and marketing of breast-milk substitutes, mobile home parks, hearing screening services and deafness prevention programmes, and a law change to allow undertakers to remove pacemakers. In the later years of the decade Maori health emerges as a major issue of national concern, as do cot death, tobacco advertising and accident and injury prevention, especially in children. For 1990 there are three ringbinders of MSS containing 33 specific briefing papers: one on each subject, and most written by a different staff member. Together these three folders form a sort of adjunct to the main three volumes of BIGs that year. The 33 topics which these briefings to the incoming Minister cover are as follows, in order from papers 1 - 33:

- potential for competition led efficiency gains in the NZ health sector

- Health Information Strategy

- Health/Welfare interface

- primary care

- quality in the health sector

- Accident Compensation Corporation

- Health Research Council

- community-based mental health services

- forensic psychiatry service development

- The Mental Health (Compulsory Assessment and Treatment) Bill

- alcohol abuse policy

- drug abuse policy

- co-ordination of health structures to address alcohol and drug abuse

- HIV/AIDS

- child health

- women's health

- cervical screening programme

- continuing care services for older people

- the promotion and protection of health consumers' rights

- national health goals and targets

- tobacco

- assessment of new technology

- Maori health

- devolution of industrial negotiations to area health boards

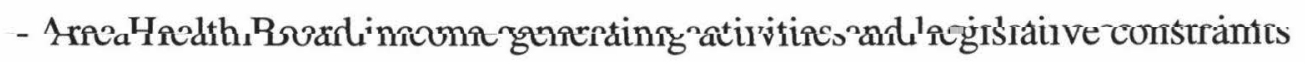


- elected and appointed members of area health boards

- review of the population-based funding formula

- diagnostic related groups (DRGs) and other methods of case mix classification

- therapeutic goods evaluation

- pharmaceutical benefits

- new initiatives in health education

- health workforce

- health sector legislation: Time for Comprehensive Review.

As already mentioned, by 1993 the DoH had moved back to a more usual, twovolume $B I G$ format; the first of these is in six chapters which are concerned with setting the strategic direction and priorities for the health sector, regulating for public health protection and safety, funding the direct purchase of health and disability support services, residual structural reforms, and international issues. Thus the changing focus of the DoH through this decade can be seen in the span of this dataset.

\subsubsection{Education $B I G s$}

The Ministry of Education produced just four Briefings to Incoming Governments over this period, the minimum required by statute. So there is one each for 1984 , 1987, 1990 and 1994. All of these are unpublished MSS, and were read in the Victoria University Library's Official Publications Room (1984 and 1987) and the National Library's Reading Room (1990 and 1994) because the Ministry of Education's archives are not open to the public. The earliest two are cardboard-bound and the later two spiral-bound books, of sizes varying from 46 to 477 pages, with words, typed on a manual typewriter, averaging from $190-370$ per page.

Describing the structures of two of these BIGs will give an idea of the content areas covered by this document type. The earliest BIG looked at, that for the 1984 election, was written in four parts, which consisted of:

- Organisation of the Department and of Education Statutory Authorities; Organisations Representing Controlling Authorities, Statutory Advisory Groups and Employees. 
- Background Information for the Minister (on 65 different topics including, among many others, education of the gifted, the deaf, and Pacific Islanders, computer education, early childhood education, curriculum development, health education, SPELD, school swimming pools, teacher housing and teacher retirement policy).

- $\quad$ The Labour Party Education Policy 1984

- Items of Current Interest (47 different topics including School Certificate scaling, reading recovery, the return of marked School Certificate scripts to candidates, school transport policy, the four term school year, the effects of changing rolls, and honouring the flag).

By the time of the $1990 B I G$, the structure had changed to an introductory chapter outlining the general context, followed by 16 key issues, one the topic of each chapter.

Chapter 1: The Social, Economic and Demographic Context of Education

66

“ 3: Local Management and Community Participation

“ 4: Choice and Entitlement; Zoning

“ 5: Curriculum

6: Cultural Transmission and Retention

“ 7: Achievement, Assessment and Certification

“ 8: Labour Market Responsiveness

“ 9: Teacher Selection, Education and Appraisal

“ 10: Equity of Access to and Outcomes of Education

“ 11: Maori Education

“ 12: Special Education

“ 13: Rural Education

“ 14: Accountability

“ 15: Resource Use

“ 16: Educational Research and Statistics

“ 17: Critic and Conscience

\subsubsection{Corporate Plans}


This forward-looking document type in New Zealand government ministries has gone by various names over the years. The earliest were Management Plan or Corporate Plan, and these began in 1986. A decade later, from the mid-1990's, this document type was called a Departmental Forecast Report, and then from the early 2000's the name changed again to Statement of Corporate Intent. It is this term which is still current in the New Zealand government ministries at the time of writing.

"Statements of Intent and departmental forecast reports for all departments are presented by the Minister of Finance on behalf of other Responsible Ministers to the House of Representatives at the same time as the Budget."4 "The SOI is a public document (intended for Parliament) that describes among other things:

- where the department is heading and what it intends to do for the period ahead

- why it has chosen to do those things

- the organisational capability to implement the chosen strategies

The SOI is intended to give a clear sense that the organisation has a coherent direction and strategy in place, against which it will report progress in the annual report." 5 The first Corporate Plan ever written by the Department of Health, for example, stated that the aim was to produce an annual plan for each financial year. The CPs were to cover the department's objectives, targets, and future agenda of activities, and to give an outline of policy decisions, development and review (1986 DoH CP Foreword, p.1). Because a corporate plan is a future-oriented document, it was described in one department's foreword (1991/92 DoH CP p.8) as a "living document" and "not set in concrete". The implication of this is that as each year progresses, Corporate Plans need to be refined and the outputs regularly reviewed. In this they are completely different from the other two document types used for data collection in this study, the Briefings to Incoming Governments and the Annual Reports.

The Corporate Plans read for this study differed noticeably from BIGs and ARs in several other ways also. First, they were written almost entirely with reference to future time. Second, they were often in note form, consisting of lists of objectives or targets, such as "Participate ...; Complete ...; Delegate ...; Design ...; Get approval

\footnotetext{
${ }^{4}$ www.treasury.govt.nz/soi/ (no page numbers given)
}

5 ibid. 
to ...; Receive ...; Provide ...; Prepare ...; Ensure ...; Improve ...; Define ...; Finalise ...; Formulate ...; Coordinate...;" followed by the corresponding resources needed in time or money (e.g. "3 person weeks", "1 person month", "2 person years", “165 staff days"), and a date by which these actions should be achieved. In 1988 the grammatical structure of these lists changed from the imperative to the future perfect: "To have maintained ...; To have investigated ...; To have developed and implemented ...;". From 1990 onwards the CPs were organised into "Key Results Areas", each with a Goal and an Action.

\subsubsection{Treasury Corporate Plans}

The New Zealand Treasury did not produce any kind of stand-alone, formal plan until 1990. So its four earliest Corporate Plans were read for this study: 1990-91, 1991-92, 1992-93, and 1993-94. These four early plans were all unpublished, and were accessed by interloan from the National Library archives, apart from the first one which does not appear on the National Bibliographical Database and had to be borrowed directly from The Treasury librarian by special arrangement. They are all four manually typed on single-sided pages, two simply stapled and two spiral-bound. In length they range from 49-100 pages. These documents contain almost no te reo. The 1991-92 CP for example uses the lexeme Maori twice in its 54 pages, and no other te reo lexeme.

The structure of the 1993-94 Corporate Plan consists of the following sections:

- Foreword: Minister of Finance

- Section One: The Purpose, Roles, Core Business and Accountabilities of, and Outcomes contributed to by, the Treasury

- $\quad$ Section Two: Key Issues for Treasury 1993-94

- Section Three: Quality Indicators for Treasury Policy Advice Outputs

- Section Four: Ministerial Servicing: Standard Description

- Section Five: Definitions

- Section Six: Treasury Outputs 1993-94

- Section Seven: Ownership and Management Objectives 1993-94

- Section Eight: Financial Performance of The Treasury

- Section Nine: Explanation of Receipts and Payments on Behalf of the Crown 
- Section Ten: Organisational Structure and Management

- Section Eleven: Legal Responsibilities

In 1994/1995 the forecast financial statements for each department were published together in a separate volume of the Estimates as a transitional arrangement. From 1996 onwards, this document type changed its name to the Treasury Strategic Business Plan.

\subsubsection{Social Welfare Corporate Plans}

The very first plan of this department was called the DSW Management Plan and was produced in 1986. Its contents consisted of:

- Introduction by Director-General

- General Organisation

- Regional Structure

- Mission

- Goals

- New Direction in Management

- Planning Timetable

- Annexes

The DSW Corporate Plans vary in length from 16 - 64 pages, with an 8-page update to the 1988 plan published in 1989. They were all read onsite in the Ministry of Social Development library, by special arrangement with the archivist as this centre is not open to the public. From the 1996/97 financial year, the DSW changed the name of this document to Departmental Forecast Report.

\subsubsection{Health Corporate Plans}

There were seven early documents found of this forward-looking type which fall within the timeframe of this study, and these (listed in full in the Data Sources section near the end of the Postmatter to this study) were variously titled Corporate Plan, The Health Management Plan, or Statement of Corporate Intent. The first of these dates from the 1986/87 financial year, and all seven of them through to 1994 were read 
onsite in the Ministry of Health archives. The earliest DoH CPs were unpublished and consist of manually typed pages stapled between two sheets of cardboard. The structure of the first one was as follows:

- Foreword

- Mission

- Statement of Philosophy

- Statement of Business

- Areas of Emphasis

- Divisional Plans: 1. Bureau of Public Health and Environmental Protection

2. Bureau of Medical Services and Drug Control

3. Bureau of Administrative Services

- Appendices

No Corporate Plan was produced for 1989, as this was a major year of restructuring and financial management reforms within the Department of Health, during which a network of area health boards was launched nationwide. The next one produced after this gap in the records was the $C P$ for 1990-91, which was the first $\mathrm{DoH}$ plan to be based on the various classes of the Department's outputs, which were purchased by the Government to contribute towards its outcomes. The first $D F R$ for the Department of Health was published for the 1995-1996 financial year. This ministry then changed the name of this document type from DFR to Statement of Intent from the $1^{\text {st }}$ July 2002.

\subsubsection{Education Corporate Plans}

There were no formal forward-oriented plans produced by this department until 1988 . So the DoE CPs read for this study consisted of the Statements of Intent for 1988/89 and a transitional one for April - September 1989 (the last few months of existence of the Department of Education), and then the first six CPs produced by the new Ministry of Education, which covered the financial years spanning mid-1989 - mid1995. From 1996 onwards this document type for the MoE changed its name to DFRs or Statements of Intent. 
Of the seven documents included in this study then, the early two were unpublished MSS located through the National Library archives. They are manually typed pages simply stapled together, without covers. The lengths of these CPs vary from 4 (the single short, transitional SOI) - 59 pages. To give an idea of their content, the contents of the latest MoE CP read, that for 1994/95, are shown below:

- Vision Statement and Statement of Purpose

- Ministry of Education Mihi

- Government Overview

- Ministry of Education Overview

- Organisational Chart

- Purchase Agreement

- Major Projects

- Ten Point Plan for Maori Education

- Stewardship Interest

- Statement of Projected Performance for 1994/95

- Projected Financial Performance

- Budget Information

- Legislation Administered by the Ministry of Education

- Ministry of Education Managers

- Ministry of Education Addresses

\subsubsection{Annual Reports}

\subsubsection{Treasury Annual Reports}

"The Treasury, like other New Zealand Government departments and state-owned enterprises and Crown entities, is required to produce an annual report containing GAAP-based and audited financial statements. Along with the departmental forecast report or the statement of intent the annual report is a key accountability document. Annual reports are used by Parliamentary select committees to scrutinise a department's performance."6

\footnotetext{
${ }^{6}$ www.treasury.govt.nz/annualreport/ (no page numbers given)
} 
As can be seen from the list of data sources provided at the end of this study, only seven Annual Reports for the Treasury were examined. This was because no earlier ones could be found in their archives. "In all likelihood, the New Zealand Treasury did not produce an annual report before departmental annual reports became mandatory following the passing of the State Sector Act in 1988. Treasury's first annual report, therefore, seems to be for the year ended 31 March 1988."7

The typical structure of an Annual Report from the New Zealand Treasury is as follows:

- Introduction, subdivided into the roles of Treasury, goals for the year, and an overview.

- Organisational Structure

- Statement of Service Performance

- major activities

- policy advice and implementation

- the provision of financial information on the operations of government

- control and accounting for the receipt and payment of public finances

- management of the Crown's public debt and overseas reserves held by Treasury

- actuarial services

- Financial Statements

- Appendix, subdivided into legal responsibilities and human resources.

\subsubsection{Department of Social Welfare Annual Reports}

Unlike the situation with New Zealand's Treasury whose Annual Reports only began in 1987/88, the Department of Social Welfare has a complete set of Annual Reports for the decade $1984-1994$. These documents are full of detail about policy directions for each year, shifts in policy and the reasons for them, and descriptions of the benefits available at the time to groups such as widows, miners, veterans disabled by war, the aged, the ill, abused women, disturbed children and orphans. The average length of the DSW Annual Reports is the same as for those of the Treasury, namely

\footnotetext{
${ }^{7}$ Anand Kochunny, the Treasury, personal communication, 12.12.2005
} 
97 pages, and in this respect the DSW reports are remarkably uniform across the ten years (the variance across the eleven reports is 72 to 120 pages). The average number of words per page is 380 .

In the Annual Reports of 1984 - 1987 inclusive the ratio of body of text to appendices varies between 60:40 and 70:30. These reports have a uniform structure as follows:

- Part I: Introduction

- Part II: Programme I - Administrative Services

- Part III: Programme II - Benefits (and Related Programmes)

- Part IV: Programme III - Social Work Services (and Services for the Disabled, and The Work of Voluntary Agencies)

- Part V: Programme IV - War Pensions

- Part VI: Programme V - National Superannuation

- Appendices I - IV or V: Statistical Data, Financial Statements and Audited Accounts of War Pensions Medical Research Trust Fund and Artificial Limb Board, lists of Membership of Boards and Committees.

With the Annual Reports from 1988 onwards however, although the usual 100 page overall length remains the same, there is more variation of the proportion of text to appendices, from 90:10 in 1988, back to the previous standard of 60:40 in 1989, to an unusual 46:53 in 1990. This was one manifestation of a change in structure of the DSW Annual Reports, in response to new guidelines for departmental annual reporting to Parliament which were issued in 1987. Previously Annual Reports described departmental activity; after 1987 the focus of these documents shifted to what was achieved with the resources used by the Department during the last financial year. The typical structure of a DSW Annual Report from 1987 - 1994 is as follows:

- Part I: Description of the Department

- Part II: Annual Management Plan

- Part III: Programmes and Services

- Part IV: Policy Development

- Part V: Organisational Functions.

\subsubsection{Department of Health Annual Reports}


As with the Department of Social Welfare (but unlike the Treasury), there is a full set of annual reports available for the Department of Health from 1984 - 1994, and all fifteen of them have been read. Apart from the few for a transitional quarter or a halfyear, they are remarkably uniform in length, and match the ARs from the former two ministries in that they are 84 - 96 pages long, carry approximately 390 words per page, and have a text to appendices ratio of $60: 30$ or $70: 30$. The structure of the first $A R$ examined, that for the year ending 31 March 1984, is as follows.

- Introduction by the Director-General of Health

1. Hearing

2. International Health

3. Health Protection

- Environmental Health

- Occupational Health and Toxicology

- Food

- Health Inspection

4. Health Promotion

- Family Health

- Disease Prevention

- Health Education and Information

5. Dental Health

6. Primary Health Care Services

- Medical Services

- Medicines

7. Hospital Services

- Hospital Board Funding

- Hospital Works and Development Programme

- Design and Evaluation Unit

- National and Regional Specialist Medical Services

- Hospitals Advisory Council

- Social Work Services

- National Hormone Committee

- Care of the Terminally Ill

- Mental Health

- Ambulance Services 
8. Nursing Services

- Hospital Nursing Services

- Community Health Nursing Services

- Nursing Education and Manpower Planning

9. Administrative Services

- Management Services and Research Unit

- National Health Statistics Centre

- Health Data Processing

- Health Services Reorganisation: Area Health Boards Act

- Board of Health

10. Scientific Services

- National Health Institute

- National Radiation Laboratory

- National Environmental Chemistry and Acoustics Laboratory

Appendix - Statistical Tables

From 1991 onwards, the structure of the DoH Annual Reports changes markedly in that from that year, they are organised into reporting in classes of outputs, where a statement of objectives for each one is set against the respective statement of service performance. There is another change in the Annual Reports during this decade too, in that from 1989 onwards the reporting year changed, so that instead of these reports following the financial year, in 1989 there was a short report produced for "the transitional quarter April - June". A standard 12-month report for June 1989 - June 1990 followed, but then another change took place, and the next two Annual Reports were half-yearly, for July - December 1990 and January - June 1991. After this rather messy transitional period, during which the Department was being restructured, the three ARs for 1992 - 1994 return to the normal June - June annual format, but the difference in focus and content from ten years earlier is striking when one compares the $1994 \mathrm{MoH} A R$ structure below with that of 1984 listed above:

- Chief Executive's Overview

- Mission Statement

- Outcome Statements

- Management Statements 
- Financial Statements

- Statement of Service Performance

- Ministerial Servicing

- Health and Disability Services Reforms Communication

- Information Services

- Ministry of Health- Financial Performance Measures

- Report of the Audit Office

- Crown Funds - Report

- Crown Funds - Report of the Audit Office

- Management Information

\subsubsection{Department of Education Annual Reports}

The Department of Education, as it then was, produced a full set of Annual Reports for the decade of 1984 - 1994, so in that respect it is like the Departments of Social Welfare and Health. All 16 have been read for this study. There were 16 annual reports for this decade rather than 11 because there was a confused period of three years around the disestablishment of the Department of Education on $30^{\text {th }}$ September 1989 and the creation of the Ministry of Education from $1^{\text {st }}$ October 1989. Extra reports were published for the transitional quarter July - September 1989 (the last three months of the life of the Department), for the last quarter of 1989 (the first three months of the life of the Ministry), for the transitional nine-month period October 1989 - June 1990 (strangely, as this report overlaps with and encompasses the whole period of the preceding one), for July - December 1990 (again unusually, as this halfyear is also covered by the annual report for that year), and for the last six months of 1991. Some but not all of these were included in the Appendices to the Journals of the House of Representatives - section 2.4 below outlines the efforts required to locate those few unpublished papers which were not in the A to J's.

The DoE Annual Reports are between 28 and 108 pages long, and consist of approximately 375 - 430 words per page. Early Annual Reports are structured as follows (this one is taken from the $1984 A R$ and remained similar for the following year; these are the main headings, with subtopics omitted):

- Main Events and Developments during the year 
- Maori Education

- OECD Review

- Early Childhood Education

- Primary and Secondary Education

- Continuing Education

- Teacher Education

- Administration and Supervision

- International Education

- Research

- Buildings

- Finance

- $\quad$ Statistical Tables

\subsubsection{Diagrammatic and Tabulated Summaries of Data Sources}

In summary, the diagram below shows the network of relationships between author domain and data-source documents which was designed for this study.

$\underline{\text { Ministries }}$

Documents

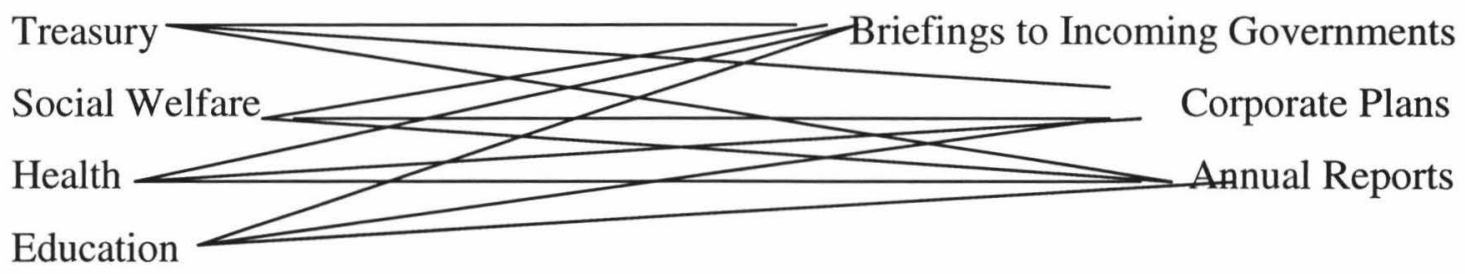

The table on the following page represents the same information in graphic form, namely the arrangement of data sources and domains that was used for this study, and also includes the length of said documents and therefore the size of the corpus. As explained above, there is a combination of four ministries and three document types, one of which was published triennially and two of which were annual. The numbers of pages and words in the table are approximate averages. It can be seen that the dataset yielded a corpus of more than one million words from each of the four government departments over the decade. 


\begin{tabular}{|l|l|l|l|l|}
\hline $\begin{array}{l}\text { Number of } \\
\text { Ministries }\end{array}$ & $\begin{array}{l}\text { Number and } \\
\text { Frequency of } \\
\text { Reports }\end{array}$ & $\begin{array}{l}\text { Number of } \\
\text { Document } \\
\text { Types }\end{array}$ & $\begin{array}{l}\text { Number of } \\
\text { pages per } \\
\text { document }\end{array}$ & $\begin{array}{l}\text { Number of } \\
\text { words per } \\
\text { page }\end{array}$ \\
\hline 4 & Triennial: $5^{8}$ & 1 & 312 & 480 \\
\hline 4 & Annual: 11 & 2 & 100 & 220 \\
\hline $\begin{array}{l}\text { Total } \\
\text { Ministries }\end{array}$ & Total Reports & $\begin{array}{l}\text { Total } \\
\text { Document } \\
\text { Types }\end{array}$ & $\begin{array}{l}\text { Total Pages } \\
\text { Trawled }\end{array}$ & $\begin{array}{l}\text { Total Words } \\
\text { Surveyed }\end{array}$ \\
\hline 4 & 64 & 3 & $\begin{array}{l}6,240(\mathrm{BIGs}) \\
8,800(\mathrm{ARs} / \mathrm{CPs}) \\
\text { Total: } \mathbf{1 5 , 0 4 0}\end{array}$ & $\begin{array}{l}\mathbf{2 , 9 3 6 , 0 0 0}(\mathrm{ARs} / \mathrm{CPs}) \\
\text { Total: } \mathbf{4 , 9 3 1 , 2 0 0}\end{array}$ \\
\hline
\end{tabular}

Total corpus size: $4,931,200$ words

\subsection{MISCELLANEOUS SOURCES}

Rarely, an occasional citation from a source outside the dataset of government documents as set out above has been used in Appendix I. This has been done to better illustrate and support a lexeme for which there would otherwise be only a single citation, or in some cases no citation, from within the dataset of government documents, or when the extra citation illustrates the lexeme in a different sense, for example the only attributive use found of a noun. These alternative sources consist of the newspaper the New Zealand Herald, the magazines the New Zealand Business Review and the New Zealand Listener, the international journal Political Science, and the books by Jonathan Boston (1991; 1995), Brian Easton (1989; 1997), Colin James (1992) and Jane Kelsey $(1993 ; 1995)$. (These publications do not form part of the corpus used for this study; they were read for background reading and the citations found by chance). These supplementary citations have been taken only from within the same timeframe, i.e. the decade which this study targets. The words involved are

\footnotetext{
${ }^{8}$ The expected number in this box would be four, i.e. one BIG for each of 1984, 1997, 1990 and 1993, however as explained above in sections 2.1.1.1 -2.1.1.3, the actual totals for this particular decade were five BIGs published by the Treasury, and eight each by the Departments of Social Welfare and Health. (This reinforces how important these ten years were to government). The lesser number has been chosen here (i.e. 5 instead of 8) to balance out the $A R$ figures, which have been calculated in this table at 11 per ministry though as already seen in section 2.1.3.1, only seven $A R \mathrm{~s}$ are available for The Treasury during this decade.
} 
bulk funding (Easton), Crown-owned company (Boston), DPB (NZL), ESA (NZBR), fiscal envelope (Kelsey), funder/provider split (NZL; Political Science), half-pie (James), ITQ (Easton), kiwi (NZH), LATE (Boston; Kelsey), national award (NZL), Rogernome (Easton), Rogernomics (James; Kelsey; NZH), state house (James), tangihanga (Boston), and Think Big (Easton; NZH).

\subsection{ETHICAL ISSUES}

Because all the documents used for collecting data for this study are in the public domain, it was not necessary to seek ethics approval for their inclusion. No human subjects were used for this study; no one was interviewed for spoken data, as all lexicographical citations need to be found in written form.

\subsection{METHODOLOGICAL ISSUES}

Due to the timeframe of this dataset, most of the documents are not available online, apart from the Treasury Briefings. Again, apart from the Treasury Annual Reports, which were tabled in the Appendices to the House of Representatives, and two of the Department of Education's BIGs, none of the source documents are held by Victoria University's library. Therefore reading of these sources had to take place in the libraries, reading rooms or archives of the four respective Ministries, from which they cannot be borrowed. The exception to this, as already stated in section 2.1.1.4 above, was the remaining Department of Education documents, which had to be accessed through the National Library's Reading Room, as the Ministry of Education does not open its library to the public. Even then several of their Annual Reports took considerable trouble to trace, and one had to be requested from the Alexander Turnbull archives as it was available nowhere else. Another DoE AR was missing from the official records in the Appendices to the Journals of the House of Representatives - the nine-month transitional Annual Report for October 1989 to June 1990 was a slim unbound document which was finally tracked down right at the end of the project, in the W.J. Scott library only.

Apart from the Treasury BIGs then, it is not possible to search these sets of source documents electronically, and even if this had been a possibility, this method would 
not have worked, as which words were being sought was unknown. Therefore there was no alternative but to read the archived hard copies, which in the cases of the earliest reports in the Ministries of Social Welfare and Health, were often yellowing looseleaf papers, typed on a manual typewriter, hole-punched manually and stored in old ringbinder folders. The Treasury documents and some of the later $\mathrm{DoH}$ documents were soft-bound into book form, though still unpublished.

When deciding how best to trawl the selected data sources, the method of sampling for example, every tenth page, was initially considered. However it was thought that in general sampling is not a good way to proceed when it is new words that one is searching for. Rather it is a technique more suited to studies aiming to generalise from the sampled pages - which was not a desired technique for this study. Therefore it was concluded that the best method for trawling the chosen documents was to carefully read every word therein. That way the possibility of missing any word was minimised.

To further strengthen the reliability of the data collection, a double-blind study was carried out, whereby two chapters of a Briefing to the Incoming Government, in this instance one from the New Zealand Treasury dataset, were given unmarked to an experienced lexicographer, to read and trawl for the type of words this study is searching for. The results proved satisfactory in that the colleague marked all the same words as this researcher had previously found and included in this study.

At the end of the project the 90 te reo Maori entries were extracted from the glossary in Appendix I and sent to a Maori Studies lecturer for checking as to the accuracy of definitions.

\subsection{DEFINITION OF WORDS FOR INCLUSION IN THE GLOSSARY (APP.I)}

\subsubsection{New Zealand Words}

There are two possible definitions for New Zealand English: the large group of words which are used both in New Zealand and in other English-speaking countries, and the much smaller subset of these, the words which are restricted in use and understanding 
to within New Zealand. This study has searched for lexical items from the latter category, that which Deverson (2000:24) has described as the "restricted set of words that are known and used by New Zealanders but rarely if at all by other (especially northern hemisphere) speakers, that is, distinctive items called New Zealandisms." Items actually coined in New Zealand are of course far outnumbered by other kinds of lexical innovation such as borrowing. As Benson (1993:101) has observed in the contexts of Australian and Hong Kong English, "Local innovations do not, therefore, in themselves define a local variety of English. But, while other types of lexical innovation tend to reflect openness to outside cultures, it is local innovation which most directly expresses the productivity of the locality itself."

With this in mind, the working definition of the notion of regionalism as to which words were being trawled for, for this study was as follows:

Words which were used in New Zealand's political domain during the period 1984 1994, and which appear from their form and/or semantic content to be likely candidates for being distinctive to New Zealand, or which appear from their context to be used in a new way or to have a new sense distinctive to New Zealand.

Therefore the words this study aimed to collect were New Zealandisms in the sense that either they are used solely in New Zealand, or they originated in New Zealand, or they are words used in other countries which have gained a new and different sense in New Zealand. Orsman summed this up nicely as "words and particular senses of words which are in some way distinctively or predominantly, though not always exclusively, 'New Zealand' in meaning or use." (1995:9). The definition used for this study then, is much broader "than the one used for americanism by Mitford M. Mathews in the Dictionary of Americanisms: words and meanings that were first used in the United States - which excludes words and meanings current in the USA but that did not first appear there" (Bejoint, 1994:82). It is far more similar to the less exclusive definition used for Canadianism by Walter Avis in his preface to $A$ Dictionary of Canadianisms on Historical Principles: 'a word, expression, or meaning which is native to Canada or which is distinctively characteristic of Canadian usage though not necessarily exclusive to Canada' (Avis, 1991:xiii). 


\subsubsection{Australasian Words}

During the course of this research approximately thirty words were found which appear upon investigation to have been, or to still be, used in both New Zealand and Australia, only. The methodological question then arose as to whether to leave these words out of the list as not exclusively "New Zealand", or to include them. It was decided to follow Deverson, who has said that there is a well-documented body of "Australasian" items, which fact does not disqualify them from inclusion in a New Zealand wordlist ${ }^{9}$. George Turner called this our 'areal' variety, and given the close geographical proximity of the two countries, and their relative isolation from the rest of the world, it does seem sensible to include these words. Since early settlement days there has been a history of close cultural, sporting, political and economic ties between Australia and New Zealand. Some international industries look on these two countries as one market and combine their Australasian activities ${ }^{10}$. Deverson labels words used in both countries as "also Aust." and this practice has been followed here.

A second, even smaller, group of words exists which are primarily New Zealand in their usage, but also occur in the documents of New Zealand's former or present dependencies. It was decided to include these words also, since the assumption can reasonably be made that the words were adopted by (or imposed on) these smaller countries in the context of New Zealand's political and legal governance of them. Hence such regional labels in the glossary as Cook Islands, Fiji, Tonga and Western Samoa.

A special case for inclusion has been made for the word "crown", in its senses which have special resonance in New Zealand (crown entity, Crown-owned company), this despite the fact that Google searches show that these lexemes are also used in Canada. It is not unknown for words to occur only in New Zealand and Canada, and nowhere else in the world (for example four-laning a road is a case in point from another domain, that of transport). This pairing reflects the shared British history and similar constitutional status of these two countries: the fact that both share the

\footnotetext{
${ }^{9}$ Deverson, T. "Recognising New Zealandisms", Australex Conference, Victoria University of Wellington, 13 November 2008.

${ }^{10}$ For example the pharmaceutical industry (1990 DoH. BIG R.3.29.Annex B.3)
} 
monarchy and a Westminster system of parliament. In the lexical domains of this particular thesis, the pairing can also arise because of similar pieces of legislation in these two countries.

\subsubsection{OED and DNZE Post-datings}

Although not a primary focus of this study, a by-product of it was a number of postdatings, i.e. citations from two or more decades later than the most recent citation for any word in the Oxford English Dictionary, online edition. Catherine Soanes, coeditor of the New Oxford Dictionary of English, was consulted on this point. Her reply was that all post-datings, even by ten years, would be useful. However because this was not the main aim of this project, a gap of two different decades was settled upon as making a post-dating worthwhile collecting. For example, the word 'woodlot' is last cited in the $O E D$ in 1976, so a New Zealand Treasury usage of it from the 1980s has been discarded. Similarly, 'to conciliate' as an intransitive verb is in the $O E D$ from 1980, so although a 1993 instance was found in the dataset, with a different use and the preposition 'to' in immediate post-position, this word was not included. However where the $O E D$ has for example a 1979 citation, as for 'privatisation', a 1993 usage was collected, on the principle of a two-decade difference. The collection of these post-datings for the $O E D$ can be found at Appendix VI.

Context and punctuation were also looked at when deciding whether or not to include a post-dating. For example the word 'downstream' is last cited in the figurative sense in the $O E D$ in 1963 and is in inverted commas, signalling that at that the was still a new usage not fully integrated into the language; therefore it was thought useful for this study to collect a 1984 citation without inverted commas, showing that this word was by then fully accepted as normal usage. Post-datings for the Dictionary of New Zealand English were also collected, for example the DNZE has citations for wahine up to 1988, so wahine Maori from a health document in 1997 was included. This set of postdatings is listed in Appendix II.

\subsubsection{Summary}

In short, three categories of 'new' words are included in the appendices to this work: 
- words distinctive to New Zealand (and in some cases, distinctive to NZ and Australia), in origin and/or use

- words which appear in the Oxford English Dictionary (OED), second edition ${ }^{11}$ but have gained a new and different sense in New Zealand. This category includes words such as integrated (as in school) which are in the Dictionary of New Zealand English (DNZE) but not in the OED in the New Zealand sense.

- words for which the dataset yields significant post-datings, i.e. two decades or more since the last $O E D$ citation. (Some words are used in New Zealand Treasury documents which post-date the $O E D$ 's most recent citations by more than three centuries, and one by over five centuries). No ante-datings have been collected due to the timeframe of this study: its period of data collection begins after the publication of the two of the three dictionaries used as reference points which contain dates of citations.

\subsubsection{Formatting}

Throughout this study both types of neologism, namely those not listed in The Oxford English Dictionary, The Dictionary of New Zealand English, or The New Zealand Oxford Dictionary, and new senses of existing dictionary entries, will be represented in bold typeface, while titles of publications, general terms and the post-datings collected appear in italic typeface.

\subsection{IDENTIFICATION OF WORDS FOR INCLUSION IN THE GLOSSARY}

\subsubsection{Recognising Potential Words for Inclusion}

New words tend to make their first appearance in written form in inverted commas. Other punctuation such as a different typeface or capitalisation can also function to reveal their newness at the time of writing. They might be accompanied by such phrases as "so-called", which distance the writer from the term. However it is recognised, or identified as a potential candidate for inclusion in this lexicon, and of

\footnotetext{
${ }^{11}$ Including the Additions Series and the Draft Entries online for the new edition
} 
course the main difficulty here is, as Orsman pointed out, "How does one recognise a New Zealandism?" (1980:33), in this study each potential new word has been checked against the $O E D$, second edition, online, including revisions and Additions Series, to ensure that it is not included there. At this point if it is found that the word is one used internationally as well as in New Zealand, that lexeme has not been included as a New Zealandism. However if a word or use of a word does appear in the $O E D$ but the New Zealand government citation in question constitutes an example of it having been used in a new sense, then it has been included in the glossary in Appendix I. If the word is in the $O E D$ and not New Zealand-specific but the citation found in the government dataset is a significant postdating for the word or phrase, then it has been included in Appendix VI.

It must be noted here that in this age of international air travel and especially when dealing with a small population of high mobility such as New Zealand's, it can sometimes be very difficult, if not impossible, to fully trace the history of a word and to be completely certain that it does belong, and solely belong, to this particular regional group.

\subsubsection{The Google Search Method}

In a further effort to ascertain whether or not a particular word is a New Zealandism, the Google search engine has been applied to every potentially relevant word or multiword unit which was not already listed in The Dictionary of New Zealand English or The New Zealand Oxford Dictionary (and even most of these, barring of course the te reo Maori lexemes which are obvious New Zealandisms, were doublechecked). It is recognised that "googling" a word is not without its difficulties and ambiguities, and cannot provide a definitive answer. During the course of this study, the following problems with Google searches have been encountered.

- a lack of dates for some citations on the website references

- the difficulty of ascertaining where some websites originate, if there is no country code in the website address 
- in marginal cases where the ratio of worldwide citations versus New Zealandonly occurrences of a word is approaching 4:3, it could be that the extra $25 \%$ of the international sources are from publications which have been written about New Zealand

- a word which appears to be well-used internationally might have first originated in New Zealand; there is no way of telling this

- unless one performs an advanced search on a multiword unit, one gets thousands of irrelevant results where the two words co-occur randomly within a piece of text, ie not as collocates

- Google does not work well for figurative senses - there is no way of finding these

- Google cannot search for suffixes

- Google cannot distinguish between transitive and intransitive uses of a verb, or between countable and uncountable senses of a noun

- there may be an obscure meaning of a word or phrase which is quite different from the one being searched for, though the phrase is identical. For example in performing an initial advanced search on the financial term "Crown receivable" used by the New Zealand Treasury, the results came up with 68 New Zealand hits and 102 in total on the web. On looking for the additional 34 citations it was found that they came from the field of dentistry (crown receivable as part of an implant) and engineering of wok cooking apparatus (crown receivable as part of the tubular metal base for a wok). As the three phrases are orthographically identical and the search cannot be constrained by semantics, extra time then needs to be taken to patiently refine and narrow the search by using the subtract function (see next bullet point) in an attempt to progressively eliminate all common collocates of the unwanted two senses of the word or phrase.

- from a phrase to be searched, Google deletes all punctuation, which is sometimes critical to distinguishing between senses of a word. To give just one example, performing a Google Advanced Search on the phrase "tagged funding" initially shows a huge proportion of international instances when compared to New Zealand instances, and so this MWU could easily have been discarded from this study at first sight. However a closer look at the hits 
reveals that thousands of them are for tagged "funding" rather than the target "tagged" funding, i.e. they occur in contexts related to blogs and URLs where the noun modified by the adjective "tagged" is a posting on a website, which the writer has tagged or bookmarked "funding". In other words, in the phrase being searched for tagged modifies the gerund funding, as in an endocentric compound, but in the majority of hits yielded by the search engine, tagged "funding" is an attributive phrase modifying a previous noun phrase in the sentence. In cases such as these it can take much time to painstakingly get to the bottom of the matter; the first recourse has been to constrain the Advanced Search further and further, with the addition, or rather subtraction, of the tool "without the words $x$ ". In the particular case of "tagged" funding for example, as the search went on, more and more common antecedents were added to the instructions, until the constraints on the search read "- computer, - blog, posts, - videos, - stories, - articles, - lists, - discussions, - books". At this point the situation resolved, the numbers of international versus NZ hits balanced, and it became clear that the target phrase is used in the sense of specially earmarked funding only in New Zealand and Australia.

Another example of the frustrations associated with the punctuation issue is the phrase "Debtor Crown", used in financial terms by the New Zealand Treasury. None of the following citations were relevant results; all were characterised by a different punctuation mark, none of which Google recognises:

- fullstop: ... a delay granted ... shall benefit the guarantor ... and personal debtor. Crown rights...

- colon: Name of Debtor: Crown Cruises.

- apostrophe: forced to wear the debtor's crown of shame, the green beret, in Rome...

- forward slash: As a debtor / Crown employee for high treason

- comma: Judgement Debtor, Crown Attorney...

So even on an advanced search where one can constrain for the exact word or phrase, punctuation intervenes to muddy the waters. A final example of this, the irritation caused by there being no way of constraining for the ubiquitous full-stop, is the search 
for the descriptor special character as it is applied to schools in New Zealand. An advanced search for the exact phrase "special character schools" still throws up results from UK sources such as "Public utilities may be privately, municipally or state owned without affecting their special character. Schools, hospitals and the like can..." which blur the truth, namely that it is a New Zealand term.

Although not a fault of the Google system itself, it should again be noted here that because very few of the data sources used for this study are available in electronic form (because they date back too far for this), almost none of them are included on the web. Therefore it was not possible to search them electronically, and none of them showed up as sources on any Google searches conducted, except for a few citations from the Treasury Briefings, which are available online.

When one has been engaged in lexicographical work for years, one develops a "feeling" for potentially New Zealand words, which can sometimes be a strong enough "hunch" to carry through an investigation of a word against seemingly very unlikely odds, to an enormously satisfying (or conversely, hugely disappointing) end. One example of this phenomenon is the words funder and provider, which were much used during the timeframe of this study, especially after the passing of The State Sector Act in 1988 which instituted a funder / provider split in New Zealand. It seemed ludicrous to Google funder and provider, as these are both clearly words common to standard international English. Nevertheless the frequency with which these words came up in near proximity to each other in the dataset and in the background literature of the period, gave the writer the strong feeling that there was something special going on here, something unique to New Zealand. It was difficult to settle on the right combination or collocation to search for, and at first private provider was tried, with no success, that is, that phrase is definitely not unique to this country. But when one performs an advanced Google search on funder / provider split, the results show 520 worldwide web instances and 268 New Zealand instances. This is not a promising ratio, and faced with these relative proportions, a New Zealand lexicographer would normally stop at this point and take the matter no further. However with this phrase I felt strongly enough that it was worth pursuing that I checked every one of the international occurrences thrown up. (This was a very time-consuming, methodical process). Little by little, every single source turned out to 
have a New Zealand or an Australian connection. Even the most unlikely references, such as Nordic Studies on Alcohol and Drugs, the International Journal of Mental Health Nursing, and international journals called Governance and Health Care Analysis, turned out to have articles in them written by New Zealand or Australian academics. The website of a British conference on disabilities contained a powerpoint presentation by an Australian. The most difficult source to trawl, and the only one where I thought I had found a definite non-New Zealand use, was an article written by an academic at the American University of Sharjah in the United Arab Emirates. The Google search engine sometimes highlights the phrase being searched for when a text file is opened, but not in this instance. So I read the entire article, looking for these words, and seeing no reference at all to this part of the world, until buried deep in the middle, I found what I was looking for: a small case study had been done on the North Island of New Zealand. And thus without exception, every one of the seemingly daunting and discouraging 520 occurrences worldwide, faded away under painstaking checking, until the 1.94:1 ratio was proved deceptive, and the phrase was found to be of Austral English provenance alone.

A further example of this is the phrase "safe prospect", which when used without an article as an uncountable noun, is a term used by the NZ government, particularly in the health sector, to denote an aspect of social well-being. At first glance on a Google advanced search, the odds against this being NZ-specific appeared overwhelming: 8,190 on the worldwide web as compared to $54 \mathrm{NZ}$ occurrences. It is difficult to explain why I persevered. Even I do not understand why my hunch on this one made me think it was worth pursuing, except that the way it was used in these documents seemed so unusual. However by beginning to read the first ten or so pages of the 8,190 international citations, it became apparent that Safe Prospect is a very common name in the world of horse-racing. By continually constraining the advanced search to read "-horse, -mare, -racing, -stakes and -stud", the total occurrences reduced dramatically. Once I had also added -cyber and -kid, (cyber-safe, kid-safe), 6,490 more hits fell away at one keystroke, leaving a much clearer picture with only a few occurrences left to investigate and gradually eliminate.

Another interesting search concerned the word recapitation, used within the administration of New Zealand's education system to denote the re-addition of Form 
1 and 2 (Year 7 and 8) classes to a primary school which in former days had been a full primary, but had since had these levels removed. Googling this word initially yields a 9:1 ratio of international to New Zealand occurrences - not a hopeful proportion. However using the Google function "Don't show pages that have any of these unwanted words" to progressively restrict the search results, the ratio dropped to 7:1 after the subtraction of -saint, -head, -game (as many computer games seem to feature beheading and miraculous re-heading of the characters) and -dead. After a few more subtractions: -Jesus (to eliminate the number of Catholic schools which appeared to teach about this phenomenon), -beheading, -heads (in the plural, as the original singular subtraction had not been entirely successful in eliminating unwanted occurrences) and -Japan, because it turned out that the yakuza (mafia or gangs) in that country quite commonly prefer this method of revenge, the ratio dropped to $3: 1$, and all the remaining two thirds of "international" citations were found upon closer investigation to be discussing New Zealand.

Thus many hours can be spent investigating a single word, sometimes to the frustration of the researcher, who feels that there must be a better tool. It seems certain that in the future, either a different search method will be developed, or further refinements to Google will be made which will be able to get around some of the issues detailed above. In the meantime however, despite this range of problems with the Google search method, in the absence of any better alternative it was decided to persevere with Googling every lexeme identified as a possible candidate for inclusion in this study. If used intensively and with careful reading of the relevant citations, this tool does offer some indications as to a word's provenance which are sufficiently helpful to warrant its ongoing use.

\subsubsection{The Issue of Multiword Units}

How to deal with multiword strings has long been a thorny issue for lexicographers worldwide, and there is as yet no one accepted approach to the way they are entered in a dictionary. Let us begin this section therefore by clearly defining the terms to describe them which this study will employ. A multiword unit is taken herein as a string of two or more words which acts as a single lexeme. It is used here as the hyperonymic term, or the genus, of which collocations of varying degrees of strength, 
transitional combinations and compounds, can be viewed as hyponyms, or subordinate species.

At one end of a spectrum, we could imagine completely free associations of words, where any meaningful concatenation may occur. At the other end would be that most invariable sequence of words, the frozen idiom. This section will not concern itself with either of these two extremes, but with the middle ground, where almost as many definitions of 'collocation' dwell as there have been writers on this subject.

\section{Multiword Units}

fixed associations

completely

free associations

$\begin{array}{llll}\text { frozen } & \text { obligatory } & \text { optional } & \text { transitional } \\ \text { idioms } & \text { compounds } & \text { compounds } & \text { combinations } \\ & \text { (Opitz 1983) } & \text { (Opitz 1983) } & \text { (Benson, Benson } \\ & & & \text { \& Ilson 1986) }\end{array}$

\subsubsection{Collocations}

Although commonly attributed to Firth (1951, Modes of Meaning), the words collocation and collocability as technical terms were in fact first posited by Palmer almost two decades earlier (Palmer, 1933:7, and cited in Kennedy, 2008:36). A collocation can be defined as a bond of varying strength, from loose to tightly cohesive, between two or more words. These words have a preference for the company they keep; their combination is not entirely free. A collocation then is a cooccurrence of words characterised by "a certain mutual expectancy" (Jackson, 1988:96), their combination a likelihood greater than chance, but not a fixed expression. The quantitative or statistical approach to collocation is widely followed by corpus linguists, and it is accepted that collocates need to occur with more than random probability. However it is still not certain "how frequent the co-occurrence of 
two lexical items should be to be considered as a collocation" (Xiao and McEnery, 2006:105). This notwithstanding, various observations have been made:

"The leading researcher on collocations in the Brown Corpus, Kjellmer (1982:25), noted that a characteristic of collocations was that they were combinations which cooccur 'more often than the frequencies in the corpus of the constituents of the combination would lead us to expect'." (Kennedy, 1998:112)

"If words co-occur in a manner which is so frequent that it cannot be ascribed purely and simply to random collocation, then we may assume that there is some special relationship between those words." (McEnery \& Wilson, 1996:128)

"The double issue of which part of the collocation is more 'basic' than the other and under which the collocation should be entered in the dictionary has not been settled satisfactorily". (Hartmann \& James, 1998:23)

Within this study a collocation is taken as a somewhat fluid association, of the kind not normally included in traditional dictionaries. Without using computational techniques, it is difficult to determine which collocations are statistically significant. That is, are any two collocates, or indeed any number of lexical items occurring within a -5 or +5 span of the node, more tightly-bound than would be expected based on their respective frequencies and on the lengths of the source documents? Without a mutual information index it is impossible to know the exact strength of each collocation's bond, and doing this was beyond the scope of this study.

It has also been often very difficult to determine how tightly-bound a new term is, and therefore whether it should be classified as a collocation or a compound, or whether it is in the process of moving between the two, and therefore falls into the grey area of what have been termed 'transitional combinations' (Benson, Benson \& Ilson, 1986: 254): less variable than collocations but not yet as unchanging as a compound. Because this is a lexicographical work, collocations from the domains studied will not be discussed in any depth herein, although there are some words in the datasets which do stand out clearly as high-frequency collocates with other words. One example from the Treasury documents would be 'performance', which often appears in company such as 'performance management', 'performance review', 'performance target', 'key performance indicators' and so on. 


\subsubsection{Compounds}

Next along our spectrum come compound words, although it should always be borne in mind that none of these categories are as simple or as clearcut as they sound: "Bloomfield (1933) observed that "many forms lie on the border-line between bound forms and words, or between words and phrases"'(Wray, 2002:7). Compounds have been divided into many different types, and called by many names, but clearly that there be component parts to a compound must be a sine qua non of any definition. To quote Bauer, "A compound can be defined, rather loosely, as a lexeme which is made up of two (or more) other lexemes..." (1998:19). Zgusta's definition of a compound word was one "indicated by the absence of space, the hyphen, or a similar device, even if there is no other difference in the form of a compound in contrast to its single parts"(1971:132). For convenience of presentation, this study will describe compounds found open (words separated by a space), hyphenated, and closed (words written solid with no space or hyphen), while recognising that these are not mutually exclusive categories, in that orthography can and does vary with different authors and text types.

A compound then, in this study, is a lexical unit consisting of a set, invariable combination of two or more words which has a single referent or designatum. Sometimes the meaning of a new compound will be opaque, but even if the meaning is derivable from the sum of its parts, (and here again in trying to draw the line between opacity and transparency lexicographers find themselves in a "somewhat indeterminate transitional zone" (Cruse, 1986:40) a compound will have been collected from the source domain documents because it is new, and because it clearly designates a single notion, in exactly the same way as a single-word lexeme does. The words would have come together in the first place because of some semantic link. "In most cases, the individual elements retain their meaning and spelling, although established compounds often develop a history and senses that are unique"(Berg, 1993:68).

This combination of free lexical morphemes via the compounding process is "one of the most productive ways in which new words have been coined, especially in modern times..." (Jackson, 1988: 30), and new combinations are continually appearing. Every 
decade, the proportion of English that is compound nouns increases. "Most compounds are nouns; they are coined because there is a need to 'name' an object or thing that has not been named before. And because the meaning of a compound is usually transparent...it readily commends itself to acceptance by the speakers of the language" (Jackson, 1988:31).

As suggested earlier, words lead lives of infinitely varying gradations of freedom or restrictions, and it is not always easy to draw the boundaries among them and decide what is a compound and what is not. The whole issue of multiword units and how tightly bound, or how frequently occurring, they needed to be in order to be accorded headword status, was a major challenge which emerged early in this project. With some such units it is difficult to decide whether they warrant inclusion at all or whether they are transparent and simply collocations. Examples of this dilemma are joint venture, public accountability, performance outcome, and so on.

Again one could picture a different cline, from single-lexeme compounds (baseload) through to syntactic structures of several lexemes which look compound-like but are strictly not ('unregulated electronic information processing industry'). Opitz has posited a useful distinction in terms between obligatory and optional compounds, with the former referring to compounds where one element, usually an adjective or a noun used attributively, "restricts the denotative range of the other...in an obligatory way so as to require that particular compound in any occurrence of its new meaning..." (Opitz, 1983:61). It is this type of compound, which should be treated as a quasitechnical term and entered in a dictionary, which this study is most concerned with.

\subsubsection{The Issue of Proper Nouns}

A large number of proper nouns occurred in the dataset, such as the names of programmes representing major policy initiatives, for example Well Child / Tamariki Ora and Before Five. It was decided to include these words in the study. Many of the institutions or bodies they describe were created during the timeframe of the study; many of them also have since been disestablished. There is a parallel here with Benson's study of Australian and Hong Kong English, which found that these sorts of names describing social roles and groupings, institutions, political bodies and 
so on - what he calls 'social terminology', is a highly productive category, within which there is "a tendency for items to become obsolete or undergo changes of meaning" (1993:104). Although the present study is neither a history nor an encyclopaedia, if these terms are unique to New Zealand and associated with government processes at the time, it was thought important to record them as part of the entire lexis of the period.

\subsubsection{The Issue of Abbreviations and Acronyms}

For the same reasons it was decided to include acronyms and abbreviations in this study, where they were both indigenous and frequent enough to have formed part of New Zealanders' everyday lexis at the time. Following the style of Orsman's dictionary, these have been listed alphabetically as headwords within the glossary in Appendix I. As observed by Bauer (2002:41), "Every country has its own sets of initialisms and acronyms referring to local institutions." Not all of these were collected, or the appendix would have been swelled to enormous proportions by initialisms including place names, of which there is a particularly large number in the health sector. If an abbreviation was simply a geographical place name plus a description of the service, for example the NHC (National Health Committee), then it was not included. But if the word was politically significant in that it was linked to the process of state sector reform, for example the THA (Transitional Health Authority), then it was included. In summary then, in order to be included in this study an acronym or abbreviation had to be unique to New Zealand, had to be common enough that it would be used in daily discourse at the time, and had to have some point of interest, i.e. the content of the lexeme needed to be more than a topographical reference plus description of service or institution.

The complete lists of abbreviations and acronyms, i.e. not necessarily New Zealandspecific abbreviations and acronyms, but used in the data source documents of the four lexical domains in this study, are a different matter; these can be found at Appendices XI - XIV.

\subsubsection{The Issue of Maori Words}


As to the treatment of Maori words, at first consideration was given to following the policy of the New Zealand edition of the New Collins Concise Dictionary, namely to include in the glossary only those Maori words which are in general use and appear "without benefit of inverted commas, italics, or the need of a translation." However it was decided to include all Maori words found in the government documents, whether or not they are glossed or italicised, so that a complete record could be achieved. In the interests of completeness too, this collection has included Maori proper nouns, for example names of different bodies such as the various iwi-based health providers. The full list of lexemes of Maori origin which occur in the Treasury documents of the period appears in Appendix VII, and words of Maori origin appearing in the Social Welfare dataset can be found at Appendix VIII. Maori words from the Department of Health dataset are listed in Appendix IX, and te reo from the Department of Education in Appendix X.

\subsection{THE GLOSSARY: CONSTRUCTION}

The new words found to be associated with government administration between 1984 and 1994 have been listed together in a glossary in Appendix I. This glossary should be viewed as a record of the New Zealand-specific words used in a particular dataset during a particular period of time in the New Zealand public sector. It is neither a dictionary, nor an index, nor a concordance, but a 'glossary' in the sense defined by Bejoint (1994:27) as a list of specialized terms used in a particular field. As such it could be seen as providing raw material for lexicographers. Accordingly the words are listed, classified into part of speech, and defined, but because the list makes no claim to being a dictionary of any kind, etymology and pronunciation have not been included in this study.

It was decided to arrange the glossary alphabetically, with words from all four government departments in together rather than separated into different lists according to provenance. The reason for this was that it would be both impractical and undesirable to attempt to separate words into sectors, since many if not most of them occur across several domains. 
Given the large number of multiword units found in this dataset, there was an issue of how to enter them. "Modern dictionaries still vary marginally in their use of the alphabetical arrangement, particularly in the positioning of multi-word units." (Bejoint, 1994:14). There is also an American / British divide in that American dictionaries tend to give compounds and phrases separate entries, while British dictionaries traditionally include them under the entry for their headword. This glossary falls more into the British style in that multiword units have been listed firstly at the normal position of their first element, and secondly, the hyphen or the space between the elements is treated as the start of a new internal classification, and the multiword units are listed immediately after their first word. The alternative was to follow strict alphabetical order and treat the multiword units as any other sequence of letters, disregarding the hyphen or space between the words, but this approach "has been heavily criticised ...by structuralist linguists" (Bejoint, 1994:15) and it is thought, does not reflect the way words are stored in the brain.

As already stated in 2.6.5 above, New Zealand acronyms and abbreviations have been

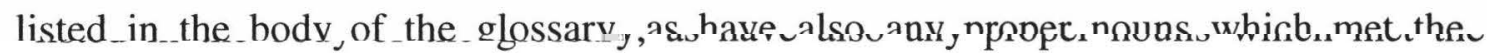
inclusion criteria.

\subsection{THE GLOSSARY: CITATIONS}

Headwords, citations and their sources were copied by hand from book (or, with a small minority of Treasury documents, from computer screen) onto the traditional lexicographical 4" by 6" index cards, and filed alphabetically. The entries in Appendix I have been written to match the style of entries in The Dictionary of New Zealand English. Wherever possible three citations are listed for each headword. However because this study was conceived as a broadly synchronic one, citations here are not used, as they are in the $O E D$, to show the historical development of the senses of the headword. Rather these citations are provided to contribute to the definition of the entry by giving contextual information about the referent, and to show how the word was used by the New Zealand government and its agencies. In cases where there were fewer than three occurrences of a word within the data set, for example if only one citation was found, that word has still been included if the author was satisfied that it was not a nonce-word. In many cases more than three citations have been given 
if this serves a useful purpose, such as to exemplify the use of the word by different ministries, in different contexts of use, in a different lexical combination or with different orthography.

However very many citations have been discarded as superfluous, and when it came to compiling the glossary, and the question of which three best citations to use for each headword out of all the possible candidates in the card-files, many issues were taken into account, and the following set of guiding principles was developed as a rationale for selection. Obviously it is not possible to fulfil every one of these conditions for each word, but the main criteria used are listed here in order of precedence:

Select:

- by date: use the earliest and the latest citations found within the time period (to show the lifespan of the word within the decade).

- by semantics: choose sentences that best define or illustrate the meaning of the word. As these are all New Zealand-specific words and some of them are also either new words or Maori, it has not been uncommon to find citations which actually include a gloss or definition in brackets in immediate post-position, so these have in the main been used where possible.

- by syntax of context: aim for self-contained sentences, without clauses which refer back to a previous sentence. Witness "each quotation must be extensive enough to carry a complete sense by itself" - The Philosophical Society, 1857, (p.10), in its regulations, or instructions to readers. ${ }^{12}$ The government documents in this dataset, particularly the Annual Reports, are frequent users of bullet pointed lists consisting of incomplete sentences. Some of these phrases have been included in the glossary, but they have been discarded in favour of complete sentences wherever possible.

\footnotetext{
${ }^{12}$ Quoted in Willinsky 1994:30
} 
- by part of speech: where the word has been used for example both as a noun and attributively, include both types of citation to illustrate this facet of the lexeme. Think Big is one example of this.

- by number: structure the three citations for each noun to include both singular and plural uses where possible.

- by word form: choose three citations which best illustrate the variety of ways in which the word has been written. This is often variable, and can change with different writers, and across domains of use. With a compound, for instance, if the citations allow, I have shown it as an open compound, hyphenated, and solid. With te reo Maori lexemes, it has been interesting to often find the same word written in four different ways, for example with initial capitals, italicised, in inverted commas, or in regular font fully integrated with its context. The other guiding principle with lexemes from te reo is that I would include citations which show the word being used in both its singular and its plural senses, wherever I have them. The citations for iwi illustrate this. When I have them, I have also included citations for a headword te reo noun which show it being used with both the zero plural marker as in Maori and the English - s plural marker added to the lexeme. An example of this is kohanga reo(s).

- by ministry: try to find citations from three different departments, rather than all from the same ministry / author, which weakens the evidence for a word.

- by source: choose three different source texts, and if possible, different types of source text, e.g. one Annual Report, one Statement of Intent, one Briefing to the Incoming Government. However, if all examples of a word were found in only one domain, that in itself could be significant in that it might indicate restricted use, and so the word has been included, with the best three citations from the single domain according to the other principles in this list.

- by brevity: for conciseness, clarity, and to save space. 
Within each entry, citations are arranged in chronological order within the decade. The main principle of defining has been to write definitions which are substitutable, that is, a 'synonymic paraphrase', "able to replace the lexeme in context with minimum loss of meaning and leaving the syntax as far as possible intact" (Jackson, 1988:135). The second defining principle has been to keep definitions as brief as possible, since in many cases the quotations themselves define the meaning of the word. The main type of definition used is referential, rather than synonym or formulaic definitions.

Part of speech labels used have been drawn from those which Jackson (1985:54) calls "the traditional eight - noun, verb, adjective, adverb, pronoun, conjunction, preposition, interjection." Obviously as this study used a written corpus there are no interjections, nor are there any pronouns, conjunctions or prepositions in the Glossary, as these are not productive word classes. Usage labels such as econ. and field labels such as educ., have been sparingly used: only to mark those few cases where it is certain that a word is confined to one domain. There has been no need with this glossary to employ temporal labels, as the study is basically synchronic (ten years in lexicographical terms is like the blink of an eye or a snapshot), and no need to employ stylistic labels, as all words have been drawn from written public documents so can be assumed to be of reasonably formal register. Regional labels on the other hand have been used, though rarely, as all words can be assumed to be $N Z$ other than those few which are specifically marked as also used in Australia and/or in New Zealand dominions (see section 2.5.1.2 above on Australasian words).

When it came to historical or obsolete headwords, a principled decision had to be made as to whether to use both or only one of these labels, and if only one, which? It was decided to label hist. those entries for which the referent no longer exists. Examples which fall into this category all happen to originate from the education sector: attached intermediate, charter as an intransitive verb used in the early childhood sector in 1990, country service and native school. Labelled obs. have been those headwords whose referent still exists but has been re-named, so the term itself should be seen as obsolete, rather than the entity. Examples of this in this glossary are 
district high school, now known as an area school, and the Free Kindergarten Association, now called the New Zealand Association of Kindergartens. 


\section{CHAPTER THREE}

\section{THE LEXIS OF PUBLIC SECTOR REFORM}

\section{$3.1 \quad$ INTRODUCTION}

When considering how best to classify and analyse the findings of this study, initially various methods were looked at: by style, for example, such as euphemistic words separated from the pejorative, or by notion, for example words to do with welfare reform, or health, or the concept of user-pays. The decision was made to arrange the following analysis into categories according to word formation type.

The following categories are the main ones which will be discussed in this chapter: compounding, semantic shift, conversion or derivation by a zero-morpheme, affixation, abbreviations and acronyms. These processes can all be seen as wordformative patterns of one sort or another. Within this classification system it is recognised that form can differ from function; for example a compound noun might function in a particular context as a modifier. Where this occurs repeatedly, the pattern has been noted in what follows. The structure of this chapter is that an overview of the main features of each ministry's lexis is followed in turn by a detailed examination of each characteristic, with examples.

\subsection{THE TREASURY}

\subsubsection{Overview}

The New Zealand Treasury has been described as having "a certain monastic quality...a palpable culture into which people...were inducted, and to which they were abidingly committed....something like a cult" (Clark, 2004:17). If this is so then it would seem especially likely that this particular organisation within the state sector of New Zealand might have its own preferred lexis. In this chapter it will be seen that 
much of the New Zealand Treasury's lexis as illustrated in their documents written to advise the government does involve both new words and specialised usages of existing words, both of which could cause confusion or non-comprehension for the uninitiated. This section begins with a description in abstract terms of the lexical patterns found in the Treasury dataset. It then proceeds in later sections to give specific examples of each feature described.

An exhaustive examination of New Zealand Treasury Annual Reports, Corporate Plans and Briefings to the Incoming Governments across a ten-year period has shown up some very clear lexical patterns. First among these is the preponderance of multiword units. The vast majority of these function as nouns, of which the majority are written as open compounds. The second most noticeable feature of the New Zealand Treasury's lexicon is the tendency to favour archaic words, again mostly nouns. A total of 84 of these are collected in section 3.2.2.2. Another trend is for Treasury to use existing terms with quite different, new senses. Unsurprisingly, Treasury writings are liberally sprinkled with proper nouns as the names for various government bodies and programmes. Abbreviations and acronyms are also frequent and 76 of these have been listed in Appendix XI. Words from te reo Maori on the other hand are strikingly few - the full list of those can be found at Appendix VII. Use of verbs is changing; in particular transitive verbs are being used intransitively and vice versa. Formerly abstract nouns, adjectives and verbs are all now being used as countable nouns. Conversion from one part of speech to another is also a definite feature of this organisation's bureaucratic language. This section will now look more closely at each of these findings in turn.

\subsubsection{Linguistic Features of the Lexicon}

\subsubsection{Multiword Units}

It became apparent very early in this project that the language used in Treasury documents is noticeably rich in multiword units, or MWUs. It is this characteristic compounding as a form of linguistic innovation - which is the focus of this section. The discussion here is restricted to compounds, and phrasal and prepositional verbs. Forms derived from other parts of speech (for example bundled, 
compartmentalisation, expansionary) have not been included, as these are typically not accorded headword status in a dictionary, but appear as run-on entries under their base lexeme. And because adjective-noun type combinations are not usually included in dictionaries, collocations of this sort will generally not be listed here either.

\section{i. Nouns}

Looking now at the compounds specific to New Zealand English which were found in Treasury publications, the received wisdom that most compounds are nouns was found to be borne out in this dataset. As Bauer has observed in the context of borrowing, "It is relatively easy to borrow new nouns, verbs or adjectives....because [these are] open classes..." (Bauer, 1980:21), although it should also be borne in mind that "there are approximately five times as many nouns in English as there are verbs..."(ibid.), so the borrowing ratio and perhaps also the coining ratio is only in fact in proportion. At any rate, the largest category of compound words found in the New Zealand Treasury dataset was indeed nouns. 121 compound nouns which are either not in the OED or post-date the OED's most recent citation by ten or more years were identified.

However of these, just 15 were of the most important kind: specific to New Zealand. These multiword units included area school, buff report, crown agency, ironsand, Kiwi share, Land Wars, language nest, meatworks, pipfruit (a collective term for apples and pears used within the fruit-growing industry), play centre (written by Treasury sic as an open compound), satellite class, sheepmeats (specific to New Zealand and Australia as a countable noun), sinking lid and solo parent. Within our Treasury a formal policy review sometimes presented to the Minister of Finance for consideration during the parliamentary recess is known colloquially as the Christmas Reading.

Many compounds were found in the Treasury dataset which are not NZE-specific, but are not in the $O E D$ either. These words can be found in Appendix IV, and included: blanket award, bottoming out, cost-recovery, cost squeeze, day-patient, distance education, feed-through, fob price, foundation course, grandfather provisions, old age benefit, sellback, subsector, technical institute, national superannuation, 
universal superannuation and user-pays. Other terms are not so self-explanatory, unless one is an economist: capital flight refers to billions of dollars of mostly illegal outflow from a country (usually done when a devaluation of the New Zealand dollar is anticipated, as happened in 1984), while weak selling describes a situation where New Zealand sellers undercut each other in order to make a sale. A forestry word is clearwood: a high grade of timber, such as that from virgin forest. In farming headworks are part of an irrigation scheme. Turning to the financial sector, we find underpricing, not in the $O E D$ as a verbal noun although there as a transitive verb. Paired terms found include horizontal and vertical equity, price and wage accord, and gift and instrument duty.

As for new senses of existing words, again not specific to New Zealand, but the compound lexeme rollout is used in the Treasury dataset in a figurative sense, which the $O E D$ does not have. This word is listed in Appendix V, New Senses for the OED.

Turning next to the compound post-datings, we find the following terms. They have been recorded here either open, hyphenated or closed, in the form in which Treasury used them. All of these have their most recent $O E D$ citations from the 1960 s or the 1970s, except for the six otherwise specified as being longer postdatings: backbencher (1959), benchmark, crawling peg, credit squeeze, estate duty (1896), featherbedding (1958), feedlot, fringe benefit, inflow (1897), layoff, phase out (sic, as a noun), pressure group, softwood, spot price (1882), standing committee, value-added (n.), wage drift, and wind-up (n., 1869). The crawling peg is a type of exchange rate; spot prices, for oil for example, are what you expect to pay on the open market upon delivery of a barrel today, as opposed to 'real price' long run trends; and wage drift (usually but not always in an upwards direction) is a general movement of wages, usually associated with centralised wage setting systems where settlements in one area feed through into other sectors. Treasury also speaks of ad hoc amendments made to plug loopholes, last cited in the $O E D$ in this sense in 1888. Market forces are a touchstone - last cited in its figurative sense in the $O E D$ from 1871. Woodpulp from the forestry industry is in the $O E D$ as an open compound only, its last citation 1866 , so in the fact that this multiword unit has ended up closed 118 years later, we see here a possible chronological progression in the stages of a compound: the theory that compounds begin life open and gradually come together over time (see Larson 2006 
for a measurement of the rate at which these changes in compounding occur). These and other post-datings for the $O E D$ can be found at Appendix VI.

There was one blend: stagflation. This word, a mixture of stagnation and inflation, is an $O E D$ post-dating which has been used overseas before appearing here. Words formed in this way are also known as telescoped or portmanteau words. Zgusta calls them "unorganic compounds" (1971:136).

In summary then, the compounds outlined in this section are mostly multi-word strings or chains which describe a single concept. Typically, dictionaries do not include adjective/noun type collocations, so this research has shown up the need for principled decisions, first, on how to distinguish between a compound and a collocation, and secondly on what the criteria for basis of inclusion in a glossary of this type ought to be. An example of the lexicographer's dilemma in this regard would be the word regulatory, which occurs often in Treasury briefings. Used as a pre-noun modifier, its most frequent collocates in these documents are capture, changes, environment, framework, instruments, interventions, reform, and review. Another example occurs with customary, as in customary rights and customary title. Whether or not to list each of these collocations as a headword in a glossary of ministry-speak is a difficult call to make. (The reader is referred to Chapter 2 sections 2.6.3 - 2.6.3.2 for a detailed discussion of this issue).

\section{ii. Verbs}

Sheet home (v.t.) is one phrasal verb which in the sense of bringing home a sense of responsibility to someone, seems to be used only in New Zealand and Australia. To draw out, although not NZE-specific, was used in a new sense (as a synonym for to highlight or emphasise) from that in the $O E D$, and to roll back measures in good times that were introduced during a downturn is also not in the $O E D$. Post-datings by some twenty or thirty years have been gathered for the $O E D$ for the phrasal verb lay off (v.t.) and the prepositional verb impact on (v.t.). Compound verbs with postdatings for the $O E D$ (see Appendix VI for all of these citations) were hamstring (v.t.) and safeguard (v.t.). 


\section{iii. Adjectives and Adverbial Phrases}

In New Zealand's tall poppy ${ }^{1}$ industries (this MWU is NZE-specific); we have inshore fisheries, on-stump sale prices in forestry, and the Wool Board operates a floor-price operation rather than a price-smoothing one. In the government sector thorough-going reforms have resulted in policies which provide downstream benefits as flow-on effects. Draw-down periods are restricted and short-run disturbances are to be overcome. Other new and postdating compound adjectives (or nouns used attributively) found in this dataset were downwards, family-friendly, point-to-point and stand-down.

In the realm of adverbial phrases Treasury has revived ad valorem as a rate of subsidy (last $O E D$ citation 1866, so this is a post-dating by 118 years). Examples of adverbial MWU's not in the $O E D$ are meat being weighed bone-in, and in-year, as in "funding is straightforwardly increased to reflect pay awards occurring in-year" (1987:II.6.183). (The reader is reminded that as set out in the Formatting section, 2.5.4 in Chapter 2, bold font signifies words not in the $O E D$, the DNZE or the NZOD, and new senses of existing words, while italics signify postdatings).

\section{iv. Affixation}

"Word formation by use of prefixes, suffixes or other systematic variations of existing morphology is rather more usual than the invention of totally new lexemes" (Opitz, 1983:59). This fact has also been pointed out by Ayto, who wrote that "The breadand-butter routes to the formation of new words in English are compounding and the addition of prefixes and suffixes..." (1990:vi). As Bauer has commented, "Different affixes have been productive at different periods in history, and have left traces behind them in the form of words we still use" (1998:28 - 29).

There are some productive affixes which are widely-used in the discourse of the New Zealand public sector, and these play a role in creating new compounds. Familiar prefixes being used productively to form unfamiliar new combinations are disinflate,

\footnotetext{
1 "Tall poppy" is in the OED only as a person; the Treasury context has "tall poppy industries" and a variation in the comparative form: "taller poppy items".
} 
disinflation, disinflationary, dis-save as a transitive verb, macropolicy, non-OECD, nontradeables as a plural count noun, pre-service and post-audits. Popular Treasury suffixes include -wide (economy-wide, service-wide, system-wide), -driven (resultdriven, roll-driven, visitor driven (open, sic)) and -based, as in needs based (open, sic), school-based and Treaty-based. Another interesting usage, not found in the $O E D$, is -rich as a modified adjective. This is popular in Treasury writing, especially in the context of "employment rich courses".

\subsubsection{Use of Archaic Lexis}

Words last cited over 100 years ago by the $O E D$ are being well-used by the New Zealand Treasury. Most of these are formal, Latinate lexis, though not all. Some are labelled by the $O E D$ "(now) rare", "arch.", "obs.", or "nonceword". Several have only a single source listed in the $O E D$. Nouns are the largest category of such words found in the Treasury dataset; a complete list of them with their most recent $O E D$ citation date follows here, and the Treasury citations for these words can be found in Appendix VI:

abatement (1878), annex meaning final chapter or appendix (1878), appropriation (1858), arbitrage (1882), award as in a national wage award system (1878), brokerage (1884), bundling in a figurative sense (1878), cadetship (1853), civism (1885), collectivity (1884), contraction meaning a lessening in size (1848), Crown in a figurative sense (1844), determinant (1894), determination as in "Nominal Exchange Rate Determination - The Options" (1984:2.5.164), (1882), devolution (1875), disabilities (n.pl.) ("Centralised decision making faces major information disabilities" - 1987:I.1.43) (1849), disaggregation in a non-physical sense (1890), disemployment (1893), disjunction (1864), disjuncture (1865), enabler (1825), entrepot (1883), foreshore (1894), incurrence (1892), inflow (1897), (government) intervention (1868), loophole (1888), shipment (1880), subsidisation (1907), sweep ("These examples give an idea of the sweep of elements involved in the overall wellbeing of society." - 1987:I.3.122) (1877) and touchstone (figuratively) (1871).

Verbs found which conform to this phenomenon are mostly transitive:

advantage (1871), aggregate (1865), alienate "where the Maori owners had freely alienated a fishery" (1855), avail (see section 3.2.2.4 below) (1816), bundle (fig.) 
(1690), capture (fig.) (1882), commercialise (1888), contract as in to contract expenditure, the economy, or the deficit (1878), disprepare (1651), draw out (1861), empower (1869), enable (1888), enhance (1873), ginger (1897), hamstring (1858), refit someone for a purpose (1862), ring-fence (fig.) (1903), stigmatise (1875), sum (1828), unbundle something figuratively (1739), and underpin (1884). The transitive verb disable is used in the Treasury dataset with a different following construction from all those given in the $O E D$; it comes closest to sense 4.a. therein (latest citation 1713) but with Treasury citations describing programmes which are "disabling of taxpayers", or of students, where the indirect object is the person and the item or quality they are deprived of is unstated, this differs from $O E D$ sense 4.a. where the object following the preposition of is the item, not the person. Therefore this lexeme and its 1987 Treasury citations has been listed in Appendix V, New Senses for the $O E D$, rather than Appendix VI, Post-datings for the $O E D$.

Intransitive verbs revived by the New Zealand Treasury and last dated by the $O E D$ last century are appreciate (1882), contract (1891), dull (1871), and transact (1872). Section 3.2.2.4 below has examples of contract and transact in intransitive use.

Adjective examples of this trend are aggregative (1833), bounded (1756), bundled (1868), causal (1881), centripetal (1870), concessionary (1885), contractual (1884), distortive (1823), injunctive (1853), in-kind (1862), inshore (1885), lagged as in "the effects are lagged" (over time) (1602), taxable (1908), thorough-going (1888), and untied (1888).

Three Latin phrases were used in these documents for which the $O E D$ last has nineteenth-century citations: a priori (1882), ad valorem (1866) and in loco parentis (1854).

It is arguable that the data in this section can be explained by the simple possibility that the current process of revising the $O E D$, constantly underway, has not yet reached these words at the time of writing. Yet this would not account for the many words listed above which the dictionary has labelled rare or obsolete. Further, it would seem that this quantity of nouns, verbs, adjectives and adverbs out of a singleauthor (institutional) corpus might constitute a pattern. 
Why would revival of old and little-used lexemes such as these be a feature of Treasury writing? This could be the subject of another, separate study, but some possibilities are that it simply reflects the background and education of Treasury employees in the Policy Development and Coordination Unit - the small thinktank inside Treasury which is responsible for putting out the Briefing papers; that Treasury policy experts are unusually mindful of their audience as government ministers and try to pitch their language accordingly; that they think their subject matter is best served by packaging it in this somewhat low frequency vocabulary; or simply that Treasury is using linguistic conventions established overseas.

\subsubsection{Maori Loan-words}

Lexemes from te reo Maori appear only rarely in New Zealand Treasury documents. In total only 27 terms from te reo were found, which would seem surprising in a New Zealand government corpus of this size (approximately 903,760 words). It is all the more unexpected given the finding of Kennedy and Yamazaki (1999) later confirmed by Macalister (2005), that on average six in one thousand words of New Zealand English is of Maori origin. However that ratio was arrived at by counting tokens, whereas types only were counted in the Treasury dataset, and Kennedy and Yamazaki used a spoken corpus as well as a written. All Maori terms which do occur in the Treasury's Annual Reports and Briefing papers from 1984 - 1993 follow, the less well-known ones being glossed (this list can also be found at Appendix VII):

hapu, iwi, kaiarahi reo (language assistant), kaumatua, kiwi, kohanga reo, kura kaupapa, Maatua Whangai (a Department of Social Welfare programme whereby children 'at risk' are placed within extended family groups instead of in a DSW institution), mana, mana motuhake (a Maori political philosophy which emphasises

Maori control over Maori Affairs), Maori, Maoritanga, marae, pakeha, rangatiratanga (chieftainship over resources), taha Maori, taha Pakeha, tangata whenua, tangi, tangihanga, taonga, te reo (Maori), Te Urupare Rangapu, utu, wairua (spirit), wananga and whanau.

There are also two hybrids: for one, the word Maoridom is used quite frequently throughout the Treasury dataset. As with most of the Maori lexemes listed here, it does not appear in the $O E D$, though it is in the DNZE. Manukau Guardian is 
another interesting usage, which only appears once in the ten-year period: "The appointment of Manukau Guardians, as recommended by the Waitangi Tribunal to provide a Maori overview of the harbour and its environments, is a good example of how consultation can be built into decision making processes." (1987:I.5.343).

\subsubsection{Verbs transitive to intransitive and vice versa}

In the Treasury documents intransitive verbs are used transitively, e.g. float, grow and progress, and transitive verbs are being used intransitively: locate. An illustration of the former is the heading to a Treasury chapter "Grow an Inclusive, Innovative Economy for the Benefit of All”. (Of course to grow crops, for example, has always been in common use; what appears new is the use of these verbs with an inanimate or abstract object). An example of the latter category is "The manufacturing industries which produce goods for local consumption tend to locate more heavily in the urban centres to take advantage of lower distribution costs. Export industries on the other hand tend to locate close to their natural resource base which is often in provincial areas" (1987:I.4.248). It is this type of usage which gives bureaucratic language its special flavour, and it is interesting that it sounds new and fashionable to our ears, a kind of "in-group" jargon which anyone living in New Zealand today would instantly recognise as characteristic of a government department. Because in fact grow is cited transitively and in a figurative sense in the $O E D$ as far back as 1825 , and locate was being used intransitively by the late 1880s. So in fact neither of these usages is new, although they seem so to us today.

Another verb used intransitively by Treasury is transact, as in "to permit individuals to voluntarily transact between one another" (1987: I.3.124) - a usage last recorded by the $O E D$ in 1872 , and labelled "now rare". Along very similar lines is contract (v.i.): "The more flexibly people are able to contract with each other in as unconstrained a manner as possible the more equitable the outcomes are likely to be" (1987:I.4.188). The verb in this form is most recently cited by the $O E D$ from 1891.

An example of a usually reflexive verb being used transitively by Treasury and last cited in the $O E D$ from 1816 is avail: "(tax) avoidance and evasion activities (availed mostly by high-income earners)" (1987: Vol.I Ch.4 p.305). 
To safeguard the payments system and to underpin the Government's priorities and policies are transitive verbs used by Treasury which post-date the $O E D$ 's most recent citations by 55 and 100 years respectively.

\subsubsection{Semantic Shift}

With this phenomenon, significations of words can narrow, or widen. In the Treasury data words were found which had either taken on a new meaning, or an additional meaning, in New Zealand English. Examples of this lexical characteristic are: accredit (v.t.), bundle (n.) and bundled (adj.) as in a bundle of services provided or bundled saving and lending services, cascade (n.) (a policy cascade; price cascades; tax cascades), compete (v.t.), contestable (adj.), creep (n., fig.), culture (n.), delivery (n.), devolve (v.t.), drive (v.t.), driver (n.), ease (n.), impacted (adj.), ratchet (n.), ratioed (adj.), repatriation (n.), roll (n.), scoping (n.), unbundled ("when it comes to unbundling the numerous issues and problems that arise in the course of restructuring"), unwind (v.i. and v.t.), and zoning (n.).

\subsubsection{Uncountable Nouns, Adjectives and Verbs Become Countable Nouns}

In the Treasury data previously abstract or mass nouns, adjectives, and verbs are all now being used as countable nouns in the plural. Examples are:

- Uncountable Nouns: expenditures, externalities, collectivities, (information) disabilities, inflexibilities, ironsands, maturities, rigidities, sheepmeats

- Adjectives: exportables, importables, invisibles, (non-) tradeables, bads.

- $\quad$ Verb: manufactures

\subsubsection{Conversion}

That zero-derivation, or conversion from one part of speech to another with no change in form, is a very productive word-formative process in English, has been commented on by both Lyons (1977:II:523) and Lipka (1990:2). Quirk et $\mathrm{al}^{2}$ describe it as "the

\footnotetext{
${ }^{2}$ 1985:1558, quoted in Lipka 1990:85
} 
derivational process whereby an item is adapted or converted to a new word class without the addition of an affix...not... a historical process, but rather ...a process now available for extending the lexical resources of the language." Conversion is a noticeable feature of this data set. One example of this is trend (n.) being used as a modifier: trend growth rates. As Gordon and Deverson (1998:85) have pointed out, this is another way in which English shows its flexibility. (Trend is also used productively in derived forms, as an intransitive verb: government expenditure trended upwards; the fiscal outlook is trending in a favourable direction).

\subsubsection{Abbreviations and Acronyms}

Predictably, Treasury documents are rich in both acronyms and proper nouns, the latter being in the main the names of Government programmes, which are also often abbreviated. The full list of such words from the Annual Reports and BIGs for the decade 1984 - 1993 appears in Appendix XI.

\subsection{THE DEPARTMENT OF SOCIAL WELFARE}

\subsubsection{Overview}

New Zealand's current Ministry of Social Development had its beginnings in 1972 when as a result of the amalgamation of the Department of Social Security with the Department of Education's Child Welfare Division, the Department of Social Welfare, as it was initially known, was established (DSW AR 1988:7). By the 1980s its work focussed on community welfare and on providing a range of financial services to administer benefits, social work, and counselling services to disadvantaged members of society. This is summed up in its purpose statement (AR 1990:4): “The Department of Social Welfare exists to meet the needs of the people of New Zealand for income support and security; care for, protect and control children when necessary and give support to their families; allocate resources to community groups for approved programmes and services." At the time of this study the Department of Social Welfare comprised the following businesses:

a) the New Zealand Income Support Service

b) the New Zealand Children and Young Persons Service 
c) the New Zealand Community Funding Agency

d) the Social Policy Agency

e) TRITEC (an internal business which supplied information systems to the other businesses) $)^{3}$

Its stated policy goal was "To provide soundly based and well informed advice to Government on the development and impact of social policy" (DSW AR 1988:10).

As mentioned earlier in Chapter 1 (1.5.1.2.ii), the Department of Social Welfare was, and still remains today, one of the largest ministries, "in terms of staff size, level of Government expenditure and number of people served. As at 30 June 1992, the Department's businesses employed 7,104. Social Welfare expenditure for the year ended 30 June 1992 was $\$ 10,008$ million...The total expenditure represented $13.3 \%$ of gross domestic product."4

It should be noted that since the decade under examination here, the Department has undergone two changes of name, first to the Ministry of Social Policy (from 1999) and subsequently to the Ministry of Social Development (from 2002), which is its title at the time of writing. This study will refer throughout to the Department of Social Welfare, since such was the entity at the time.

\subsubsection{Linguistic Features of the Lexicon}

\subsubsection{Compound Nouns}

It is striking that all the words from the Social Welfare dataset which were checked and found to be specific to New Zealand, were nouns, and furthermore, all were compound nouns. This supports the finding from the first lexical domain, that the majority of new words in the Treasury dataset were compound nouns. The 18 DSW, NZ-specific, words follow; those which appear in Orsman's DNZE are in italics, otherwise these NZ-specific lexemes are new.

\footnotetext{
${ }^{3}$ DSW. 1993. Social Welfare in New Zealand: Briefing Material February 1993 for the Hon. Jenny Shipley, Minister of Social Welfare New Zealand, p.2

${ }^{4}$ ibid., p. 3
} 
Children's Boards in New Zealand were established by the CYP Act 1974, their purpose being to deal with offenders under aged 14 outside of the Court system. The Community Services Card provides subsidised health care to low-income New Zealanders, including some receiving the domestic purposes benefit. A crown entity (which is a term also used in Canada) is in New Zealand a government body such as a department or ministry, the Education Review Office, the NZ Qualifications Authority, the Educational Training and Services Agency, and the Careers Service. Crown Receivable and Debtor Crown are financial terms, the former used to represent revenue available to be drawn down from the Crown, the latter undrawn revenue and capital appropriations receivable from the Crown.

A Draft Ministerial (also Aust.) is a policy document produced within a ministry in response to a request from the Minister. A Family Group Conference is a formal meeting, sometimes court-ordered, with legal status and state funding, where, in care and protection cases, a child's family meets with social workers to decide on a careplan. It is noteworthy that this idea initially developed out of Maori community traditions of resolving family problems, and has since received worldwide recognition, was awarded an international prize by the American Humane Society in 2007, and has been adopted for implementation by the United Kingdom and Canada. First-contact processing was a DSW initiative to speed up the processing of benefit applications, and responsibility based processing (also Aust.) was another new system for administering benefits within the DSW, whereby experienced junior and middle management staff were made totally responsible for their work, and all checking of it was eliminated.

Karitane nurse is listed in the DNZE and denotes a person qualified in the nursing of infants. Liable parent has a different meaning in Australasia than it carries in the UK, where it is used in the justice system to denote a parent liable for their dependant's crime. In New Zealand and Australia on the other hand it means a non-custodial parent assessed as liable to pay child support or to contribute to the cost of their former partner's $D P B$. Meshblock, used only in New Zealand, denotes the smallest geographic unit for which data is collected by the NZ Department of Statistics. Periodic detention as a sentence for criminals is also used in Australia, but a play centre for children is a uniquely New Zealand concept. Solo parent is in the DNZE, 
Vote: Social Welfare is a class in the national Budget, and wash up estimates is a term used within Government ministries at the end of the financial year.

Several other compound nouns which are international usages, were collected as meeting this study's criteria for post-datings for the OED. These, with their most recent OED citation date and then the DSW citation date, are: foster home (1886 / 1988), house parent (1964 / 1984) and street kid (n.) (1977 / 1984).

\subsubsection{Other Post-Datings for the OED}

Apart from the compound nouns listed above, other OED post-datings, ranging from 14 to 112 years, collected from the DSW dataset are: ceased (benefits) (ppl.a.) (1927 / 1987)

decentralise (v.t.) (1875 / 1987)

disablement (n.) (1884 / 1984)

portable (pension) (adj., fig.) (1970 / 1984)

receiving (affiliated to theft) (vbl. n.) (1956/1984)

\subsubsection{Affixation}

As in the Treasury dataset, suffixes -based and -rich were found to be frequent in the Social Welfare documents also. Examples of typical contexts are "phone based counselling" (1988 AR 60), "home based support to families under stress" (1988 AR 58), "community-based services" (1989 AR 47), iwi-based (1990 Key Issues for Social Welfare) and "a study into the effects of a fish-rich diet on elderly residents of Montecallo War Veterans Home.” (1989 AR 25).

\subsubsection{Maori Loan-words}

Lexical items borrowed from te reo Maori were found to be more frequent in the published documents of the New Zealand Department of Social Welfare than they 
were in those of the Treasury. Let us look first at the DSW Annual Reports, eleven documents from 1984 - 1994 inclusive, which ranged in length from 72 to 120 pages and averaged out at 97 pages each. Tokens as well as types of Maori words were counted, excluding Maori place-names but including Maori names of reports and collectives. The number of lexemes from te reo ranged from 24 to 82 per Annual Report, and averaged out at 45 Maori tokens in each document. Across the ten years there was neither an overall increase nor a decrease in the use of Maori by the Department of Social Welfare; however there was a peak of such use in the Annual Reports of 1989 and 1990, which at 82 tokens throughout 111 pages and 58 tokens over 80 pages respectively, was an occurrence of Maori $19 \%$ higher than the next highest rate in 1991, and considerably higher than the low of 24 tokens over 88 pages recorded in the Report of 1992. I would suggest that this peak use of te reo was a result of heightened awareness in the wake of the influential report entitled "Puao-teAta-tu": the Report of the Ministerial Advisory Committee on a Maori perspective for the Department of Social Welfare.

To look next at the Briefings to Incoming Governments, in the BIG for 1984, which consisted of 152 pages, just 41 Maori tokens occurred. In the longest Social Welfare BIG, which was 217 pages in 1987, there was the largest total of Maori tokens, at 306 - on average more than one per page. In the two BIGs for 1990, of 116 and 118 pages each, 144 and 47 Maori tokens were found respectively. In the two shorter BIGs from 1990 and 1993 of 11 pages each, Maori tokens occurred five and eight times respectively. At approximately 400 words per page, these figures aggregated average out at a rate of occurrence of te reo Maori in the DSW BIGS of between $0.0006 \%$ and $0.35 \%$, with the median being $0.15 \%$.

When it came to the Corporate Plans for the DSW, the use of te reo was low and confined to occasional single lexemes, until 1990-91 when two whole pages of that year's plan were written entirely in te reo.

It is noticeable that this ratio of Maori: English words in the published documents of the New Zealand DSW, as with that in the documents of the Treasury, is still low in that it does not approach the six in one thousand ratio found by Kennedy and Yamazaki (1999) and Macalister (2005) to characterise ordinary New Zealand 
English. During the ten-year timeframe of this study, when use of te reo by the DSW peaked in the three years 1987 - 1990, at most the rate of Maori words occurring in their documents was half the rate found by Macalister $(0.3 \%$ as compared to his $0.6 \%$ ). Based on this finding I suggest that New Zealand government documents in general, as a genre, contain less than the average proportion of te reo which characterises a wider range of more everyday written genres, and without a doubt, less than does the spoken English in New Zealand.

A list of all Maori words found in the Department of Social Welfare dataset, ie the Annual Reports, the Corporate Plans and the Briefings to the Incoming Governments from 1984 - 1994 inclusive, follows here (this list can also be found at Appendix VIII). As with the Treasury list of Maori lexemes in section 3.2.2.3 above, those words which also appear in Orsman's Dictionary of New Zealand English, Deverson and Kennedy's The New Zealand Oxford Dictionary, or in the OED are here listed in italics; bold font signifies words not in any of these three dictionaries.

Hapu, hui, iwi, kai tiaki, kaumatua, kaupapa, koha, (Te) kohanga reo, Komiti Whakahaere, kowhaiwhai, Maatua Whangai, Maori, Maoritanga, marae, mokopuna, pakeha, Puao-te-Ata-tu, Putea Manaaki, roopu, runanga, taha Maori, Tainui, tangata whenua, tangi, tangihanga, Te Kakano o te Whanau, Te Koputu Taonga, Te Urupare Rangapu, Tihei Mauriora, tikanga Maori, Tuhonohono, whakapakari, whanau, whanaunga, whanaungatanga. The word Maoridom, which occurred fairly frequently in the Treasury documents, was also used, though less often, in the Social Welfare domain.

It can be seen that at 36 Maori lexemes, this total is slightly greater than the total of Maori words found in the parallel dataset from the New Zealand Treasury and listed in section 3.2.2.3 above (27 lexemes from Te Reo in total in that corpus of nearly one million words).

\subsubsection{Samoan Loan-words}

Only one Samoan lexeme occurred within the Social Welfare dataset: So'otaga, the name of a child fostering programme akin to the Maori Maatua Whangai. 


\subsubsection{Semantic Shift}

There was not much evidence of this lexical phenomenon among the papers of the Department of Social Welfare during the ten-year period from 1984 to 1994. Two examples which did occur are Family Home (n.) and residence (n.). Both of these high frequency international terms have taken on a specialised and country-specific semantic load within New Zealand.

In the United States the term "foster family home" is often used, but this has a different meaning to the New Zealand sense of Family Home. The American use of foster family home denotes the home of an ordinary family who take in a foster-child; the NZE use of family home in the DSW documents denotes a purpose-built, large house, staffed by a couple who live there rent-free and who, supported by departmental social workers, care for up to six children or young people who live there and attend local schools.

The NZE use of residence in the DSW domain denotes a secure institution which provides residential, 24-hour supervision and custody for young people referred there under the Youth Justice provisions of the CYPF Act (1989). Every Residence is headed by a Director responsible to the Assistant Director-General Operations. The maximum term under the Act for placement in a residence is three months, or two months with remission.

\subsubsection{Adjective Becomes a Countable Noun}

As in the Treasury dataset, an adjectival form of a lexeme is used in the DSW documents as a count noun: "As the Service worked through the changes and process of redefining its deliverables, ..." (DSW, 1994, AR p.9).

\subsubsection{Abbreviations and Acronyms}

A full list of the New Zealand-specific abbreviations and acronyms found in the DSW documents can be found at Appendix XII. These include abbreviations used to 
describe roles and divisions within the organisation, training programmes and benefits, boards, commissions and committees, and funds and schemes.

\subsection{THE DEPARTMENT OF HEALTH}

\subsubsection{Overview}

New Zealand's Department of Health was originally established in 1901. The changing focus of this department can be seen by how its mission statements changed throughout the decade of this study. In the first CP produced (in 1986), the DoH's "Mission" was "To take a leading role in the development of the health services in New Zealand in order to promote, protect, preserve and restore the health of the people of New Zealand, and to care for and support the sick and disabled, by either providing such services as are needed, or facilitating their provision through others" (p.3). Within three years this had changed to "The mission or overall goal of the Department of Health is to enable all New Zealanders to have access to as comprehensive, equitable, effective and efficient a health system as can be provided within the resources available by way of public funding." (1989a AR:11). The Mission Statement in the front of the 1990 Annual Report reads "The Department of Health is the Government's principal agent and advisor in health and an accepted leader in a world-class health service based on area health boards." By 1994, it had changed again to "The Ministry's mission for 1993/94 was to lead the health and disability sector in promoting health through skilled policy advice, health protection, funding management and monitoring." (AR:2).

The Department of Health became a Ministry during the June 1993/94 reporting year, but as this occurred right at the end of this study's timeframe, it is here referred to as the DoH throughout. Characteristics of the written discourse of this department at the time are that it is especially rich in abbreviations and acronyms, using double the number found in the Treasury dataset and more than three times the number in the DSW documents. It is also significantly richer in Maori borrowings than those other two ministries.

\subsubsection{Linguistic Features of the Lexicon}




\subsubsection{Compound Nouns}

Whether it is seen as forming part of a compound or a collocation, the word "key" in Department of Health documents is often used as a pre-modifier of a head noun, as in "key external variables" (1987 BIG 49), "key results areas" (1990 BIG R.3.5) and "key performance indicators" (1990 BIG R.3.9). Another compound example from the dataset is "performance indicator".

Hyphenation is noticeable in the DoH dataset, particularly in the compounds publicgood research and personal-health demands. Here we see that what starts as a simple adjective / noun collocation becomes semi-closed in order to be able to be used attributively to modify a second noun. Other examples of this phenomenon are "selfhelp approaches", "turn-around times" and "a part-time inservice course". Another common collocation is seen in this dataset to be closing: "areas considered to be 'atrisk' " (note the quotation marks which reveal the novelty of this term, or at least its orthography); "an at-risk situation"; "at-risk localities". 5

One particular to Health as a domain is frequently used in the context of the various Area Health Boards and the formulae they use for charging each other for treating patients whose permanent residence is in a different area: "cross-boundary charges between boards" (1989b AR 79), or "cross-boundary flow arrangements" (1990 AR 26). The subject of a possible law change to making workplaces, restaurants and bars "smoke-free" was also being discussed at the time and is given a lot of space in the DoH documents in this dataset (for example smoke-free buildings, offices, policy and vehicles, $1987 \mathrm{BIG} 166)$. Prefixes qualifying patient are also obviously specific to the Health domain: daypatient, inpatient, outpatient.

Again as in the Treasury documents, the suffix -driven occurred in Health also: "demand-driven services" (1984 BIG 3). Other suffixes used in the Health dataset are as follows: heart-healthy (directions) (1987 BIG 63), union-run (medical practices) (1987 BIG 66), state-funded (dental care) (1987 BIG 82), open-ended (scheme) (1987

\footnotetext{
${ }^{5}$ All examples of hyphenated compounds in this paragraph are from 1985 DoH AR pp $22-25$.
} 
$B I G$ 87), "a world-wide trend" and "a more market-oriented and cost-conscious approach".

\subsubsection{Post-Datings for the OED}

The DoH dataset yielded two significant post-datings for the OED, which are listed in Appendix VI: capitation, by 188 years, and imprest (accounts, in comb.) by 98 years.

\subsubsection{Affixation}

A noticeable prefix in this dataset is multi- as in "multi agency programme" [sic, open] (1984 BIG 13). Others are post-, always in the context of education: "provide basic and post-basic training for school dental nurses" (1987 BIG 81) and "post-basic inservice and refresher courses" (1987 AR 34) and under- ("A relatively minor amount of under-production or inefficiency" (1987 BIG 131).

When it comes to suffixation, as in the Treasury and Social Welfare datasets the suffix -based also occurs in the Health documents examined. For example, "community-based projects" (1986 AR 43), "home-based support services for the elderly” (1987 BIG 29), “a population-based funding formula” (1989 AR 20; 1985 AR 39; 1986 AR 37), and “a zero-based approach" (1990 BIG R.3.7.2). Based as a suffix is particularly common in the DoH dataset in combination with marae: "marae-based courses" (1987 AR 34), "marae based health centres" (1987 BIG 144), "maraebased health schemes" (1984 AR 23), "marae-based programme" (1985 AR 52) and “marae-based projects" (1984 AR 51).

\subsubsection{Maori Loan-words}

By now we have seen that the Treasury corpus of nearly one million words yielded only 27 of Te Reo, and the Social Welfare corpus, 35. The Department of Health corpus contained 67 Maori types, and a significantly higher number of tokens too. This can partly but not wholly be explained by the higher number of programmes and reports with Maori names in this department. However there seems to also be a more receptive attitude towards Te Reo in this ministry's documents of the period; as early 
as 1985 there is evidence of a conscious effort being made not only to make health policy more sensitive to the needs and beliefs of the tangata whenua, but even to include them in its formation. This attitude was also extended to the Pacific Island minorities resident in New Zealand, as evidenced by the use of the Samoan word fono in this dataset. In these respects the Department of Health was ahead of the other ministries.

The Te Reo Maori content in the DoH dataset can be seen to increase markedly after 1984, and remain at that higher level for the next decade. The 1984 BIG of 103 pages contained only three Maori types (nine tokens): Maori (7 occurrences), Oranga Maori (1), and Hui (1). The capitalisation of Hui is noteworthy as it appears oldfashioned now; the initial capital having disappeared over the past twenty years as the borrowing into English became more frequent and the word more commonly understood.

The next $B I G$, in 1987 , though longer at 167 pages still contained disproportionately more Te Reo: 23 types and 176 tokens, as follows (in order of frequency): Maori (122), marae (11), tangata whenua (6), Oranga Maori (4), Te Waiora o Aotearoa (name of a Trust - 4), Waiora (name of a programme - 4), Hui Whakaoranga (3), whanau (3), hapu (2), iwi (2), Te Kohanga Reo (2), Te Wananga o Raukawa (2), hui (1), kaumatua (1), Matua Whangai (1), pakeha (1), Te Koputu Taonga (1), te reo Maori (1), te Taha Hinengaro (1), Te Taha Maori (1), te Taha Tinana (1), Te Taha Wairua (1), te Taha Whanau (1). The $B I G$ that followed only two years later (unusually the DoH produced one in 1989, which was not an election year), was longer again at 192 pages and shows a similar amount of Te Reo content as its predecessor, namely 22 types and 151 tokens, as follows: Maori (112), hui (having already lost its initial capital, five years after its single use in the $1984 B I G-6$ ), Hauora (4), Kaupapa (4), iwi (3), Te Urupare Rangapu (3), Tangata whenua (2), Te Hui Whakaoranga (2), Te Tirohanga Rangapu (2), hapu (1), Ihi (1), kai awhina (1), kaumatua (1), roopu (1), taonga (1), Te Kakano o Te Whanau (1), Te Koputu Taonga (1), Te Wananga o Raukawa (1), tino rangatiratanga (1), Waiora (1), whanau (1), and Whare Rapuora (1). 
By 1993, the final $B I G$ of this study's timeframe, the two volumes which totalled 107 pages contained just five types and 167 tokens, so can be said to be of a comparable level to the preceding two briefings. Again, the most common type by far was Maori at 167 tokens. The others were iwi (4), Te Urupare Rangapu (1), tangata whenua (1) and whanau (1).

With the Annual Reports, the te reo lexemes which occurred in them but were not among the loan-words listed above from the BIGs are as follows: hikoi, kai, Kaitiaki, Kohanga Reo, Maoritanga, Nga Ringa Aroha, Tohunga, wananga, whenua (in the sense of placenta). The hybrid transliteration Minita Maori (denoting a Maori minister of religion) is also noteworthy here. A summary of the te reo content of the Annual Reports follows here:

1984: 13 types and 93 tokens

1985: 25 types and 160 tokens

1986: 13 types and 56 tokens

1987: 4 types and 43 tokens

1988: 10 types and 37 tokens

1989 (a, b and c): 9 types and 131 tokens

1990 (a and b): 9 types and 47 tokens

1991(a and b): 7 types and 36 tokens

1992: 10 types and 30 tokens

1993: 9 types and 27 tokens

1994: 4 types and 31 tokens

The much higher frequency of te reo in the 1985 year is explained by the inclusion in that document of a chapter entitled Maori Health - the other ARs did not specifically cover this topic. It can be seen from the list above that the te reo content of DoH Annual Reports actually fell overall during this decade.

Compared to the $B I G \mathrm{~s}$ and the $A R \mathrm{~s}$, the $C P \mathrm{~s}$ contained little te reo. They yielded only between 1 and 8 types per document, and the number of tokens was very low apart from the lexeme Maori. The only te reo lexeme which occurred in the CPs but not in the other two document types was Te Puni Kokiri. Only one whole te reo phrase (cited 
in Appendix IX) was used in this dataset, and that occurred in the last $C P$ for that decade: that of 1993/94, in the Director-General's Introduction.

In conclusion then it can be seen that in the DoH corpus of roughly one million words, the Maori content began the decade with a very low, barely visible presence, and then jumped significantly in 1984/85, before dropping back again. Overall the DoH dataset contains nearly triple the Maori content of the Treasury dataset, and more than double that of the DSW. However the DoH ratio of Maori is still considerably less than the 5-6 words of Maori origin per 1,000 words of NZE found by Kennedy and Yamazaki (1999) and supported by Macalister (1999). This could be partly because their calculations were based on two corpora: one of spoken NZE as well as written. There is likely to be more Maori in spoken NZE than in written NZE, particularly government documents.

The finding of Kennedy and Yamazaki (1999:41) and Macalister (2001:39) that the lexeme Maori is by far the most frequently occurring word of Maori origin in NZE, is strongly borne out by this study. This will partly be due to the fact that, as pointed out by de Bres (2006:23), there is no readily available alternative to this lexical item. There are also no alternatives to the proper nouns in this DoH dataset which have been listed in this section, namely the titles of departmental reports or programmes. However there was a choice in the first place by the Department to name them thus, and this would appear significant, as would the frequent occurrence in this dataset of other common nouns from Te Reo which do have an alternative available in English.

\subsubsection{Samoan Loan-words}

As mentioned in the previous section, the Samoan word fono, signifying a meeting and similar to the Maori hui, occurred in this domain. The other Samoan loan-word used in the Health dataset was palagi, used adjectivally of patients at Wellington Hospital. These citations can be found in Appendix I.

\subsubsection{Adjective Becomes a Countable Noun}


As with the Treasury and the Department of Social Welfare, the root lexeme deliverable is used in the DoH documents also as a countable noun: "Outputs can be broken down into sub-outputs, deliverables and projects" (1990 BIG R.3.8.4); "Financial processing facilities were provided to the PHCEB with regular monthly reporting on progress against deliverables" (1993 AR 47). Similarly, the adjective susceptible is used as a count noun: "The survey was aimed at measuring the degree of exposure of the nurses to hepatitis B virus and identifying susceptibles for immunisation." (1986 AR 56).

\subsubsection{Conversion}

As described for the Treasury dataset in section 3.2.2.7 above, the lexeme trend, traditionally a noun in English, is used as an intransitive verb in the Health dataset also. An example of its use in context is: "(By way of comparison public funding on health services increased, on average, by around 4.2 per cent per annum in real terms in the decade $1970-80$, and since then has averaged under 1 per cent per annum with the rate of growth trending downwards)" (1984 BIG 2).

\subsubsection{Abbreviations and Acronyms}

The NZ Department of Health dataset is particularly rich in abbreviations and acronyms, and these documents yielded many more of them than did the datasets from any of the other three ministries. DoH abbreviations and acronyms are triple the number which occur in the Department of Social Welfare documents, more than double those used by the Treasury, and outnumber by 31 those of the Department of Education, as will be seen in the next section. Straight acronyms and abbreviations from the DoH dataset which are nothing more than that, have been listed in Appendix XIII. However with some of these it is difficult to decide whether they have become sufficiently integrated into the language to also warrant inclusion as a word, with supporting citations, in Appendix I, the glossary. For example DRG and LGC, as in "They proposed that funding should be on an output basis using the DRG system (a case-based payment system using Diagnostic Related Groups)" (1989 DoH BIG 11) and "The LGC is now proposing one region for Nelson and Marlborough" (1989 DoH $B I G$ 16), have been listed as abbreviations only. PHARMAC on the other hand has 
become so widespread in daily NZE and so important in general discourse outside the domain of health that it has been included as a "word".

\subsection{THE MINISTRY OF EDUCATION}

\subsubsection{Overview}

The Department of Education became the Ministry of Education in 1989. Its statement of purpose as set out in the 1989/1990 Annual Report (p.4) is as follows:

- to provide policy advice to the Government on early childhood, compulsory and post-compulsory education, including employment related education and training;

- to ensure the effective, efficient and equitable implementation of the Government's policies;

- to ensure the optimal use of resources allocated to education.

The dataset of this ministry is characterised by the largest number of Maori words and the second largest number of abbreviations of the four departments in this study. Of all the New Zealand-specific English words found in this dataset, (discounting abbreviations and discounting the Maori and Samoan loan-words, which are discussed below in sections 3.5.2.9, 3.5.2.7 and 3.5.2.8 respectively), the first striking feature is that $94 \%$ of these were nouns. The second significant finding is that of the 45 NZEspecific nouns that occurred in this dataset, 38 , or $84 \%$, were compounds.

\subsubsection{Linguistic Features of the Lexicon}

\subsubsection{Nouns}

\section{i. Compound Nouns}

Multiword unit nouns found in this dataset to be unique to NZE were: activity centre (an institution for disruptive children unable to attend an ordinary school), area school, associate teacher, attached intermediate, basic scale teacher, bulk funding, composite school, contributing school, Correspondence School, country service, 
Crown agency, crown entity, designated character school, district high school, Div A/ Div C, Dutch class teacher, Free Kindergarten Association, intermediate school, language nest, long service leave, Maori warden, model school, Native school, normal school, reading recovery, remote school, resident teacher, retiring leave, satellite class, technical refresher leave, and Tomorrow's Schools.

Mention must be made here of the use of the word "special" by the Department of Education. It is used frequently throughout this dataset with a meaning particular to this domain, namely, to denote entities related to the education of the intellectually disabled. The most common collocations in which it occurs in this dataset are special class, special education, special needs, special pre-school, and special school.

Another cluster of related multiword units in the domain of Education is built around code, referring to the School Accommodation Code of 1970 which set minimum area requirements for certain types of state school facilities such as swimming pools and gymnasiums. As well as code-sized (discussed below under Adjectives), we find code buildings and code facilities.

\section{ii. Single Lexeme Nouns}

The few NZ-specific nouns from the DoE dataset which consisted of a single lexeme include commissioner, a government-appointed crisis manager who is installed to replace the principal and/or the disbanded Board of Trustees in a school which has become dysfunctional, and playcentre, a nationwide form of sessional playgroups for pre-schoolers, run by trained parents instead of professional teachers and founded by New Zealander Gwendolen Somerset. This set also includes the parallel set of terms decapitation and recapitation: the removal of the higher intermediate forms from a full primary school, leaving it as just a Year $1-6$ school instead of a Year $1-8$ school, and the subsequent reversal of this. Integration refers to the process of integrating a private, often religious, school, into the state system of education, and the gerund zoning to a system of limiting enrolments to residents within a defined geographical area around a school.

\subsubsection{Verbs}


Two verbs were found in DoE documents which seem to be unique to New Zealand. One is to bulk fund as a transitive verb, used with the NZ government as the agent and an educational institution as the recipient of the funding. The other is to charter as an intransitive verb. This term, now obsolete, was used up until 1990 in the early childhood sector only. It seems to have occurred only in the lexical context of "an intent to charter" or "an intention to become chartered", and it denoted an arrangement whereby the government would fund the pre-school childcare institution if the institution lodged a charter with it according to required guidelines.

\subsubsection{Adjectives and Attributive Uses of Nouns}

Just the one adjective was found in the DoE dataset to be NZ-specific, although there were nouns used attributively. The adjective contestable is not unique to the domain of Education, being used during this timeframe by the Treasury and the Department of Health also. It refers usually to abstract objects, such as advice, funding and services.

Washup, which also occurred attributively in the Health and Social Welfare datasets, is in attributive use in Education, always in the financial contexts of washup grant, washup payment, washup recoveries, and on a washup basis. Blue Book procedures are those which conform to the Ministry set of policy guidelines for country schools, and code-sized buildings met the standards set by the 1970 School Accommodation Code. Notional roll status is a category assigned to a school by the Ministry of Education, to artificially weight its roll in recognition of an unusually high number of special-needs or NESB children there, and so to compensate for this by qualifying the school for extra funding and/or a higher teacher / student ratio. A notional roll school therefore is a school accorded such status.

\subsubsection{Post-datings for the OED}

The DoE dataset yielded just one significant post-dating: school tuck shops are mentinned several times in the BIG for 1984., thus postdating the OED's mest recent. citation for this lexeme (1885) by 99 years.

\subsubsection{Affixation}


As in the Treasury documents, the suffix -rich occurs in the DoE also, and in the same context: "The department would appreciate knowing what priority might be given to further employment rich programmes" (BIG 1987:111).

\subsubsection{Use of Outdated Lexis}

The first $B I G$ of the DoE for this period contains a section entitled "Education Department Residential Schools for Maladjusted Children”. This section includes the sentence "The Department operates two Residential Schools for Maladjusted Children, Waimokoia School in Auckland and McKenzie School in Christchurch ...”. Later in the same $B I G$, in the section containing the Labour Party's Education Policy, the following sentence occurs (1984 DoE. BIG Sec.3.64): "Approximately 15 experience class teachers (for backward pupils in secondary schools) and 15 teachers of maladjusted pupils for guidance units would be necessary to provide an adequate coverage for these two areas of special education." Also later in this section (Sec.3.169 and 170), "classes for backward pupils" and "special classes for backward children" occur. In the following BIG (1987:74), we find "slow learning boys" and "slow learning students". The adjectives maladjusted, backward and slow learning would not be used nowadays by a government department to describe children who do not fit into a state school setting or are slow learners, as these would be viewed as derogatory labels implying negative value judgements.

At the start of this decade, the Department of Education was still using the English noun plural $-s$ marker on Maori, as in "for the advancement of education to Maoris" (1984 BIG:58). This usage had disappeared from the dataset by 1990 , and sounds somewhat old-fashioned and not politically correct to our ears today.

\subsubsection{Maori Loan-words}

With regards to Te Reo, the dataset from the Department of Education, as it then was, was the richest in this type of loan-word of all four ministries included in this study. It yielded a total of 83 Maori lexemes, as compared to 27 from The Treasury, 36 from the Department of Social Welfare and 67 from the Department of Health. The full list of Maori words used by the Department of Education in these documents during this 
decade can be found at Appendix X. The appendix can speak for itself, but noteworthy among its entries are the hybrids Maoridom, Maoriness and Maori ACCESS or Maccess / MACCESS, the te reo names for the most common school subjects which were being newly coined at the time, and the number of low frequency common nouns which do not occur in any of the other three datasets.

The Ministry of Education is also distinct from the other three ministries in its tendency to use whole Maori phrases rather than just individual lexemes sprinkled through. This is unique in that it does not occur anywhere in the datasets of the Treasury, Social Welfare or Health. The Ministry of Education documents are characterised by whole Maori phrases used especially when the writer is in exhortatory or philosophical mode. This happens most often at the start and end of sections, and particularly in the Secretary of Education's Address and the Chief Executive's Introduction. It is especially frequent in, though not restricted to, the addresses written by Dr. Maris O'Rourke during the early 1990's. Examples of the types of phrases used are:

- He aha te mea nui te ao? He tangata, he tangata, he tangata. (What is the most important thing in the world? It is the people).

- Hutia te rito o te harakeke: kei hea to komako, e ko? (If the central shoot of the flax is removed, where will the bellbird sing?

- Ka rere te manuka, tomokia. (The challenge is upon us now).

- Ko te reo te mauri o te tangata. (The language is the soul of the people).

- Tena koutou katoa ( a ritualised salutation to a group of people)

These phrases are used many times throughout the DOE documents over the ten years of this study. I suggest that their use shows a different attitude to the Maori people and their language on the part of the Department of Education during this time than was pervasive at the other three ministries studied. Although the other three were clearly making strenuous efforts, especially towards the end of the decade, to meet their obligations under the Treaty of Waitangi and to change their earlier ways of thinking and acting in terms of relating to and providing services to the tangata whenua, the Department of Education seems to have been ahead of its time in this respect. This does not mean that there was not a large gap between Maori and pakeha 
children in terms of both school attendance and achievement during this period there certainly was a large discrepancy, and this was recognised as unacceptable and was frequently discussed in the documents of this dataset. (It is noteworthy that this gap, though reduced, still remains today, so this problem has not yet been solved).

Further to using whole Maori phrases as exemplified above, the MoE was also different from the other three ministries studied in that it included in its Corporate Plans whole sections written in te reo. These consisted of the MoE Mihi, the MoE Overview, and the section entitled "Nga Tikanga Tekau o te Tatai mo te Akoranga Maori", and totalled between $1 \frac{1}{2}$ and $3 \frac{1}{2}$ whole pages of solid Maori text per $C P$. These pages are not translated into English. The use of te reo for more than just individual lexemes and a few phrases was not replicated in the dataset of any other ministry studied during this decade, apart from the two pages in the DSW CP of 1990 - 91 mentioned in section 3.3.2.4 above.

\subsubsection{Samoan Loan-words}

Apart from Health, Education was the only other dataset which contained more than one loan-word from a language other than Maori. These documents provided citations for the two Samoan words aiga, a family and fono, a meeting.

\subsubsection{Abbreviations and Acronyms}

The list of the 145 abbreviations and acronyms found in the Department of Education dataset can be found at Appendix XIV. This total is slightly less than that of the Department of Health at 176 , but considerably more than the numbers used by Social Welfare (45) and Treasury (83). Some of these abbreviations and acronyms are still in use today (ASTE); others have fallen into disuse as the examination (SFC), role (STJC), or body they refer to has been either disbanded (IAGNE) or renamed (NZFKU).

\subsection{DISCUSSION AND EVALUATION OF FINDINGS}


This is a study concerned not so much with register ${ }^{6}$ or a diatypic variety of language as with the nature of lexical innovation in a time of social and political change. Benson (1993:102) uses the term 'motivation' to refer to the sociocultural causes of lexical innovation. He recognises that this notion is imprecise in its reference, "being poised somewhere between linguistics and sociology, and it is often difficult to determine for individual items. It is, nevertheless, a useful notion in dealing with general trends." "In terms of motivation, local innovations in lexis seem not to be unique to each variety, but rather the result of the variable operation of general tendencies of lexical innovation in World English under local sociolinguistic conditions" (ibid:107). The motivation of the four government departments examined for this study in using new words or in using existing words in new ways, can be hypothesised from their social, economic and political context in terms of the policy and legal changes being enacted at the time.

So, to encapsulate in brief the findings which have been discussed in detail in this chapter, a short summary of the linguistic features found to be characteristic of the lexicon of each ministry follows.

\section{i. Treasury}

- a preponderance of multiword units, of which the vast majority are nouns

- many (84) archaic words, again mostly nouns (see App. VI)

- $\quad$ new senses for existing terms (see App.V)

- frequent (83) abbreviations and acronyms (see App. XI)

- $\quad$ very few borrowings from te reo Maori (see App. VII)

- transitive verbs are being used as intransitive verbs, and intransitive verbs are being used transitively

- adjectives, verbs and abstract nouns are becoming countable nouns

- there is conversion from one part of speech to another without change of form

ii. Social Welfare

\footnotetext{
${ }^{6}$ As defined by Strang and Halliday, discussed in Lipka, 1990: 16 \& 19
} 
- all the NZE-specific words were nouns, and not only that; all were compound nouns

- more te reo borrowings than in the Treasury documents but still a low number: half the rate found by Macalister (1999): 0.3\% compared to his $0.6 \%$. (see App. VIII)

- $\quad$ some low-level use of semantic shift

- adjectives are becoming countable nouns

iii. Health

- especially rich in abbreviations and acronyms: double the number used by Treasury and triple that used by Social Welfare (see App. XIII)

- significantly richer in te reo borrowings than Treasury or Social Welfare (see App. IX). These include both hybrids and blends. However te reo borrowings in this lexical domain are still well below the $5-6$ words per 1000 words of NZE found by Kennedy and Yamazaki (1999) and supported by Macalister (1999). Kennedy and Yamazaki's and Macalister's findings that the lexeme Maori is by far the most frequently occurring word of Maori origin is strongly borne out by this dataset.

- affixation, both prefixation (multi-, post-) and suffixation (-based) is quite common

- there is some conversion

iv. Education

- $94 \%$ of the NZE-specific words found were nouns, and of these, $84 \%$ were compounds

- the second largest number of abbreviations and acronyms among the four datasets

- the largest amount of te reo Maori of the four datasets (see App. X)

This chapter has shown that the effects of New Zealand's decade of public sector reform can be seen in New Zealand English; they manifested themselves in both new lexis and new uses of existing lexis. True coinages, that is "words fashioned out of the 
blue - words without etymologies" (Burridge and Mulder 1998:124) are rare in any language, and none were found in this study. The most common type of wordformation process in the New Zealand government sector during the decade 1984 1994 was found to be the device of compound nominalization. Lipka has suggested that this device be understood

"as a productive process for the economical expression of the
communicative needs of the speaker of a language. Complete
sentences can be transformed in a rule-governed way into
nominalizations, i.e. complex lexemes. By this process, information-
condensation is achieved, one of the most important functions of
word-formation.... The various kinds of nominalization processes ...
in English ... belong to the most productive devices of word-
formation and are relatively unrestricted." (1990:91-92).

The results as categorised in sections 3.2 - 3.5 above have some similarities with jargon, which has been defined as language "associated with a subject field which is clear to the experts using it, but not to outsiders. Jargon shares with other speciallanguage varieties like slang an in-group orientation which outsiders often criticise" (Hartmann \& James, 1998:78). This has not gone unnoticed by political commentators in New Zealand: Andrew Mason, quoted in Easton (1997:254), said of bureaucratic jargon that "It is the language of power: if you set the terms, others have to grapple with them in order to achieve their own aims." Easton himself wrote of a Treasury paper included in this study that "The 1984 manifesto papered over the differences, relying on what became a characteristic feature of the Labour government, language that was so vague it often had two meanings.” (1997:74).

In the last section of this study, 5.2.2 of Chapter Five, the proposition that lack of familiarity with the new lexis used by Treasury was a factor in members of parliament feeling unable to oppose the new policies, is suggested as a possible area of future research. This theory is supported by James, who wrote (1992:234) that:

"No group felt more keenly the lack of language for the new world into which they were being propelled than the political parties. Their advisers presented the 'privatisation' they were to approve and initiate in the technical language of demographic, economic and budgetary 
necessity. They had somehow to translate that into the language of human need, hope and aspiration. But the old lexicon had gone. Torn from the tranquil moorings of liberal social democracy, the political parties found themselves on the high seas of global ideological change." 


\section{CHAPTER FOUR}

\section{THE METAPHORS OF ECONOMIC CHANGE}

\subsection{INTRODUCTION}

The initial and primary focus of this study was to identify the New Zealand-specific words and uses of words associated with economic change in four domains of government administration. These lexemes are listed in Appendix I. During the course of this lexicographical study however, it became apparent that there was a lot of figurative language in the dataset of government documents. Specifically, the extent to which metaphor was employed by Treasury writers to describe economic change had not been predicted. It is these issues which form the content of this chapter, and in this respect this section covers quite different ground to the previous chapter.

This figurative language did not contribute to the new words listed in Appendix I; this was not because this study's criteria for selection of new words excluded figurative language, but because the figurative language found did not yield any new entries. One finding of this chapter then is that the use of metaphor does not appear to be a route by which new words or phrases enter New Zealand English. It is likely that most metaphors consist of forms and lexemes which are already well-established in a language and are therefore well represented in existing dictionaries. One reason for this is possibly that we are only able to "play" with lexis which has already been around for a long time. Attempts to create metaphors and analogies by using coinages or other new words would likely be unsuccessful as they would entail a double linguistic risk.

The purpose of this chapter then, is to present the range of metaphors used in this dataset. It will be seen that the Treasury in New Zealand during this ten-year period used at least thirteen different metaphorical constructs to represent changes taking place in the national and international economies. 
In this context one metaphor stood out as of striking importance, as measured by both frequency of occurrence and quantity of discrete linguistic instantiations, namely metaphors associated with physical motion. These metaphors are powerful and oftenused tools for talking or writing about economics, which can be found in the business section of any daily newspaper, yet have been little recognised or studied to date. Apart from the physical motion metaphor, a number of others occurred in the Treasury corpus of just under one million words. They are equally colourful and expressive, but are minor players in the discourse of economics when compared to that of physical motion.

\subsection{THEORETICAL FRAMEWORK}

"Lexicographers are not too sure what to do with metaphor. It makes us nervous." (Ayto, 1988: 49, quoted in Moon, 2002: 393)

A lexicographical study is not the place for an in-depth examination of the current state of the field of metaphor studies, but in this section a brief introduction is given in order to contextualise the findings which follow.

Gibbs (1999:47) noted that "Metaphor is undoubtedly one of the most complicated topics in the intertwined domain of language and thought". Therefore the theory of metaphor is complex, and being continually refined as a result of ongoing research. Although the study of metaphor goes back to Aristotle in the $4^{\text {th }}$ century B.C., in some ways it could still be said to be in its infancy, insofar as that no one theory to date can account for all the different kinds of metaphor. Currently there are many different theories of metaphor, and a multiplicity of differing views on how best to anchor any metaphor research in a theoretical framework. It may be that the sheer complexity of how humans use and comprehend figurative language will never be explained by a single theory.

At the time of writing no agreement prevails either as to where the study of metaphor should fit within the traditional theoretical frameworks used for language description. As Moon (2002:391) observes: 
Metaphor is sometimes associated with literary language, but it is an old issue within linguistics and the philosophy of language. In addition to studies of metaphor within semantics, metaphor is an active research area within psycholinguistics and language engineering.

Long and Richards (foreword to Cameron and Low, 1999:x) point out that "While the role of metaphor in language has been a focus of considerable interest in linguistics and other fields since the pioneering work of Lakoff and Johnson and has been the focus of several thousand journal articles, it has received much less attention within applied linguistics."

What is certain is that metaphor as a type of linguistic innovation is based on a perception of similarities, such as Turner's example of banjo for shovel (1966:36). As Moon (2002:397) points out, "there is a long tradition of seeing metaphor essentially as a comparison that implies an underlying simile." But this type of "metaphorical creativity" as Lyons (1977:567) calls it, is not yet understood, nor is it known how metaphor is represented in the brain. So while "the nature and strength of links between metaphor and thought are still only partly understood" (Long and Richards, foreword to Cameron and Low, 1999:xiii), what is clear is that metaphors are not based merely on random likenesses. Ramachandran (2003:9) makes the interesting observation that "metaphors are also directional. Certain directions like sound to touch, or vision to hearing, versus hearing to vision are much more common and there is no way you can explain this except in terms of anatomical constraints in the brain."

The foundation for this suggestion was laid by Lakoff and Johnson's 1980 book Metaphors We Live By, which claimed that metaphor is not simply a matter of linguistic form, but is a surface reflection of basic bodily experience, so that some kind of reasoned transfer (which is of course the literal meaning of the Greek roots meta and pherein) from concrete physical experience to abstract thought has taken place, which has resulted in connections being made in the human brain. This means that not only do we speak in metaphors, but that they actually are how we experience our daily reality. This notion is the essence of the cognitive framework. Thus "Metaphor, or the means by which one thing is described in terms of something else, has been described as a central tool of our cognitive apparatus. It is central to our understanding of how language, thought and discourse are structured....much of our 
experience of life is described in metaphoric terms." (Long and Richards, in Cameron and Low, 1999:x). Kovecses (2005:3) cites AFFECTION IS WARMTH as an example of a primary metaphor, because of the correlation in childhood experience between bodily warmth and the loving embrace of parents.

The trend over the past few decades towards a "strong" cognitive view of metaphor (i.e. that metaphors are patterned on deep conceptual structure in the brain to do with how we store and process thoughts) has resulted in a lack of attention to the surface language of metaphor. However "The fact that metaphor is more than language does not mean that language form is irrelevant to the study of metaphors" (Cameron and Low 1999:12). Applied linguistics is well-placed now to re-focus interest onto the form of figurative language, and to make important contributions to our understanding of how it is used in written texts, and oral discourse.

For Ortony (2001), given that our experience of life is not a series of segmented states but an ever-flowing continuum, metaphor helps to bridge the gap between that experiential continuum and language, which as a system of discrete symbols is incapable of fully describing every aspect of our human experience. Ortony suggests that metaphor fills this deficiency, and to this end he proposes his three theories of compactness, inexpressibility and vividness.

Gibbs (1999: 35) drew distinctions between different kinds of metaphor as follows:

i. $\quad x y z$ metaphors (for example, children are the riches of poor men); these are complex mappings compared to the simple forms A IS B or A IS LIKE B

ii. image metaphors, found in poetry and other literary texts

iii. cross-domain mapping metaphors (that is, of the Lakoff and Johnson sort) It is the latter type with which this study is concerned.

In analysing individual metaphors, Lakoff (1987:283) proposed a Spatialization of Form hypothesis, which "requires a metaphorical mapping, from physical space into a 'conceptual space'.... More specifically, image schemas (which structure space) are mapped into the corresponding abstract configurations (which structure concepts)." So there are metaphors which project "image schemas into abstract domains, 
preserving their basic logic. The metaphors are not arbitrary but are themselves motivated by structures inhering in everyday bodily experience." (ibid:275)

An example of just such a metaphor which was found in the New Zealand government documents and which follows this introduction, is the set of terms such as fall, go up, drop, higher (interest rate), low (reserves), and so on. With this image, which was extraordinarily prevalent in the Treasury dataset, the source domain is verticality, and the target domain, quantity. This particular mapping occurs because "the UP-DOWN schema structures all of our functioning relative to gravity" (Lakoff 1987:276). "There is a structural correlation in our daily experience that motivates every detail in this particular metaphorical mapping....The correlation is overwhelming: MORE correlates with UP. LESS correlates with DOWN. VERTICALITY serves as an appropriate source domain for understanding QUANTITY because of the regular correlation in our experience between VERTICALITY and QUANTITY. Every detail of the metaphor is motivated by our physical functioning" (ibid:277).

Complex metaphors therefore, such as those found in the briefing papers to the incoming governments and which are listed hereunder, function as "conceptual correspondences, or more technically, mappings" (Kovecses 2005:26) between two domains, wherein the source is the more physical kind of domain and the target the more abstract. For example in another metaphor described below, the source domain is WATER and the target domain MONEY. What follows in the next section then, is a catalogue of the complex conceptual metaphors which were found in the published documents mainly of the Treasury, and their linguistic instantiations.

Throughout this chapter metaphors are expressed via small capital letters, according to the convention established by such influential writers in cognitive linguistics as Lakoff and Johnson, and Kovecses. The small capitals should be understood as denoting concepts, not words. "An important point about the kinds of systematic metaphor that Lakoff and Johnson describe is that they link concepts and not individual words." (Moon, 2002:395). That is, it is the concept of money that is linked to the concept of water, not necessarily the lexical items money and water. It is this which poses problems for lexicographers, because while thesauri can categorise 
language according to concept, metaphor entries in dictionaries have to be attached to a lexical headword.

\subsection{IDENTIFICATION OF METAPHORS IN THE DATASET}

This section addresses the question of how the metaphors in this dataset were identified in the first place. In the words of Cameron (1999:105), "Applied metaphor studies cannot avoid the issue of rigorous identification of metaphorical, in contrast to non-metaphorical, language. Identification through defining, by setting up necessary and sufficient conditions for metaphoricity, produces apparently insuperable problems; identification through knowing and describing, in the manner Wittgenstein suggests, would seem a more promising approach.” That said, Cameron nevertheless goes on, having formulated the identification question as "Is $\mathrm{X}$ a metaphor?, where $\mathrm{X}$ is a stretch of language in a particular discourse context" (1999:107), to attempt to produce a definition of metaphor, or a list of necessary conditions for linguistic metaphoricity, as follows.

"A stretch of language is said to be a linguistic metaphor if:

N1 it contains reference to a Topic domain by a Vehicle term (or terms) and

$\mathrm{N} 2$ there is potentially an incongruity between the domain of the Vehicle term and the Topic domain and

$\mathrm{N} 3$ it is possible for a receiver (in general, or a particular person), as a member of a particular discourse community, to find a coherent interpretation which makes sense of the incongruity in its discourse context, and which involves some transfer of meaning from the Vehicle domain" (1999:118).

These principles have been adopted for the purposes of this study. The metaphors described in this chapter meet Cameron's criteria of domain incongruity and potential transfer of meaning. It will be seen that they all "include at least one lexical item (the Vehicle term) referring to an entity, idea, action etc. (the Topic), and that the Vehicle term belongs to a very different, or incongruous, domain from the Topic" (Cameron, 1999:107). It is noted that what Cameron refers to as incongruity between the topic and the vehicle, other writers on metaphor (Ortony, 2001:10) have termed tension, 
which is also a helpful term in trying to explain this as yet not fully understood aspect of language.

\subsection{METHODOLOGY AND VALIDATION}

Having defined the pre-conditions for identifying metaphors in this dataset, the next question is how this was done, and how the process was validated. For this study the researcher examined the texts and decided what was and was not metaphorical. Low (1999:49) has described this method as the most common approach to metaphor identification. Its advantages are "ease and speed" and that "it is possible to be highly responsive to the text being studied and to bring a wide range of experience from areas such as linguistics and literature to bear concurrently on identification decisions. There can, however, be serious dangers with unilateral identification. For example, there is always going to be a measure of subjectivity or randomness in identifying expressions which are not actually referred to...as metaphoric....A second danger involves a recency effect; metaphor researchers are likely to have a heightened sensitivity to metaphors with which they have been working in the recent past. This may lead to consistently over-interpreting expressions which are only peripherally relatable...to the metaphor concerned" (ibid.).

These two possible drawbacks were borne in mind throughout the course of this study. To counter the first one, a validation procedure was applied whereby a sample document from the dataset was given to an experienced colleague to read and mark all the metaphors noticed. The results demonstrated a high level of agreement between the researcher and the second reader as to what was metaphoric, and so confirmed the findings described in this chapter. To counter the second danger mentioned above by Low, the lists of metaphors below underwent several purges of any terms which could be considered only peripherally related to the metaphor of physical motion. These decisions as to which terms to include are discussed in detail below each part of speech list.

Low goes on to expatiate that "There is in fact a whole series of problems relating to familiarity in one form or another. Firstly, there is increasing familiarity with specific words. A jargon term, for example, might be perceived as progressively less 
metaphoric the more it is used within a discourse, and it might become decreasingly tagged....Conversely, frequent repetition of a phrase within a text might serve to increase its salience and to make the speaker or listener increasingly aware of its metaphoric nature.....there is also a very practical implication concerning metaphor identification. This is the fact that the more the researcher reads (and reflects on) the text, the more metaphors tend to be identified. In such a situation, the number of readings and the time spent reflecting on the text themselves become important variables" (1999:50). "It is, however, important to recognise that, whatever the faults of unilateral identification, the alternatives are not problem-free either" (1999:51). This researcher was certainly aware of these possibilities as this data set was trawled, and it is acknowledged that these two eventualities were both potentially applicable to this study. Every effort was consciously made to treat jargon words and high frequency items consistently throughout the data sets. Documents were deliberately read carefully but only once, to avoid an increasing familiarity effect.

\subsection{METAPHORS OF THE NEW ZEALAND TREASURY}

What follows constitutes an account of the metaphors used in the Briefings to the Incoming Government by the New Zealand Treasury during the decade 1984 - 1994. It is interesting that while the Treasury BIGs are relatively rich in such linguistic figures, the Annual Reports and Corporate Plans for the period contain almost none.

The first subsection below deals with by far the most striking image to emerge from a complete reading of this document type across the ten years: the use of the lexis of physical movement to express change in the economic domain. This phenomenon was first noticed, and pointed out in passing, by Kennedy in an article on first language processing in 1978, and Lakoff (1987:321) makes this one brief mention of it: "For example, the MORE IS UP metaphorical model constitutes conceptual scaffolding for, say, discussions about economics - price rises, depressions, downturns, etc." However apart from these two cursory references, no one seems to have taken the idea up or studied it in any depth. As mentioned in the introduction to this chapter, noticing metaphor was not a primary aim of this study, but the extent of it within this one document type from this one Ministry meant that it could not be ignored. Deignan (1999:196) when discussing future possibilities for metaphor research, wrote that 
more genre studies of metaphor which analyse a very specific type of text such as business, law or politics, would be useful. It is hoped that the provision below of empirical data will make a useful contribution to existing knowledge in the field of metaphor research.

\subsubsection{Terms of Physical Motion as a Metaphor for Economic Change}

Detailed and exhaustive lists follow of all the lexical instantiations by which this conceptual metaphor is realised in this data set. The metaphor lists are arranged by part of speech as used in the original context, with the largest category, which as might be expected, is verbs of motion, first, then nouns, adjectives and adverbs in decreasing order of frequency. These words have only been collected if they were used in a metaphorical sense, and if they also occurred in a context relating to economic change, i.e. to money in real terms, or to funding models or systems. Where words to do with motion occurred either literally or metaphorically but in a more general context, i.e. unrelated to economic change, they have not been included in the following lists. An example of this is labour shedding; shedding was not included in the list of nouns of motion which follows because in this context it was labour being shed, not funds or loans.

As lists of discrete lexical items cannot give the full flavour of this metaphor in the way that extended prose does, initially some excerpts are given below, in chronological order of publication, to illuminate the type of written discourse in which the imagery occurs. It will be seen that these examples are densely packed with terms of upward, outward, downward and sideways motion, of opening and closing movements, and of relative speeds. These orientations correlate well with the schema variously categorised by Lakoff as up-down (vertical movement), containment, frontback (on a plane), centre-periphery, and relations (part-whole, etc); metaphorical concepts which "structure our experience of space” (Lakoff 1987:283).

References are to the New Zealand Treasury Briefings to the Incoming Government unless otherwise labelled as from an Annual Report $(A R)$, and give the year of publication, volume if relevant, chapter, and page number. Full bibliographical details 
for each of these documents can be found in the "Data Sources: Composition of Corpus" section at the end of this thesis.

- "This in itself will reduce upward pressure on costs and prices and the output loss that is often associated with the process of disinflation." (1984, Economic Management, Part II:2: 132)

- "A relatively low share price has the effect of raising the firm's cost of capital which in turn reduces its ability to expand and increases the risk of takeover or divestment." (1987, Government Management, Part I:2:100)

- "For example, there is some evidence to suggest that while policies to achieve rapid disinflation will have higher initial adjustment costs, total costs could be lowered because the initial cost can shock people into a faster change to their wage and price setting behaviour, thereby promoting a faster and less costly transition to low inflation." (1987, Government Management, Part I:4:196)

- "Monetary policy actions are assumed to be directed towards offsetting the inflationary pressures of both higher demand and the downward pressures on the exchange rate." (1990, Briefing to the Incoming Government 1990, Chapter 2:26)

- "When the freeze was lifted, there was a rapid resurgence of pent-up wage and price pressures."(1990, Briefing to the Incoming Government 1990, Chapter 5:53)

- "Growing tax revenues and declining unemployment will help close the deficit and offer a more resilient economy in which rapid fiscal progress can be made." (1993, Briefing to the Incoming Government 1993, Chapter 1:25)

- "The September QSBO suggested little upward drift in selling prices, while lower imported inflation, the lagged impact of mortgage-rate falls, and rising productivity suggest the CPI movement should remain comfortably within the 
target range." (1993, Briefing to the Incoming Government 1993, Chapter 2:

42)

i. Verbs

accelerate $v . i$. (90.1.9)

accelerate v.t. (87.I.4.203)

advance v.i. (84.2.14.313)

advance v.t. (91.AR.58)

arise v.i. (87.II.10.272)

arrest v.t. (87.I.4.207)

attract into v.t. (87.I.4.196)

balance v.t. (87.II.10.271)

bind v.t. $(84.2 .4 .154)$

boost v.t. (87.I.6.363)

bottom out v.i. (87.II.1.11)

break away from v.i. (87.II.1.9)

break down v.i. (87.II.6.195)

broaden v.i. (93.2.32)

broaden v.t. (90.1.9)

bundle v.t. (87.II.6.178)

bundle together v.t. (87.II.10.271)

capture v.t. (87.I.2.114)

channel v.t. (84.2.5.163)

close down v.i. (90.2.20)

close off v.t. (87.I.4.202)

constrain v.t. (87.I.4.195)

construct v.t. (87.II.10.294)

contract v.i. \& v.t. (84.1.3.57)

counterbalance v.t. (87.II.6.196)

cram v.i. (87.II.6.196)

crowd out v.t. (84.2.7.176)

curb v.t. (84.2.3.136)

cushion v.t. (84.2.1.104) cut v.t. (90.1.4)

cut back v.t. (90.3.35)

dampen v.t. (84.2.1.104)

decelerate v.i. (87.I.6.391)

decentralise v.t. (87.II.6.193)

decline v.i. (90.2.17)

deliver v.t. (87.I.2.94)

depress v.t. (84.2.3.135)

destabilise v.t. (84.2.7.182)

devolve v.t. (87.I.2.91)

disburse v.t. (87.I.2.91)

disinflate v.i. (87.I.4.204)

displace v.t. (84.2.7.176)

distort v.t. (87.I.4.201)

diverge $v . i$. (84.2.5.165)

divert v.t. (84.2.15.321)

divert into v.t. (87.I.4.196)

double v.i. (87.II.1.11)

draw away v.t. (84.2.4.153)

draw out v.t. (84.2.3.137)

drive v.t. (87.I.6.372)

drive down v.t. (90.9.154)

drive out v.t. (87.I.2.105)

drive up v.t. (84.2.3.137)

drop v.i. (84.2.7.184)

drop v.t. (84.2.6.171)

drop back v.i. (90.2.15)

ease back $v . i$. (84.2.3.140)

ease-out v.t. (87.II.9.262) 
ease up v.t. (84.2.3.137)

emerge $v \cdot i .(84.2 .1 .108)$

enter v.i. (84.2.11.236)

erode v.t. (84.2.5.159)

escape v.t. (90.3.32)

evaporate v.i. (93.5.99)

even up v.i. (87.II.6.196)

exercise v.t. (84.2.3.139)

exit v.t. (93.3.58)

expand v.i. (87.I.6.373)

expand v.t. (87.I.6.366)

fall v.i. (84.1.3.56)

fall back v.i. (93.2.31)

fall behind v.i. (93.1.11)

fall off v.i. (87.I.4.209)

feed through to v.i. (87.II.6.196)

flatten out $v . i$. (84.1.3.55)

float v.i. (84.2.3.137)

float v.t. (87.I.4.197)

flow v.i. (87.II.10.273)

fluctuate $v . i$. (84.2.6.171)

freeze v.t. (84.2.3.140)

go v.i. (87.I.2.93)

grapple v.i. (90.1.2)

grapple with v.t. (93.1.26)

group v.i. (87.I.2.94)

grow v.i. (84.2.4.146)

halt v.i. (87.I.6.365)

halt v.t. (90.2.17)

hamstring v.t. (84.2.1.106)

hold v.t. (84.2.9.208)

hold down v.t. (87.I.2.101)

hold up v.t. (84.1.3.56) impact on v.t. (84.2.4.153)

impede v.t. (87.I.2.90)

increase $v . i$. (84. 2.3.140)

increase v.t. (84.2.3.137)

interpose v.refl. (87.II.10.272)

invert v.t. (87.I.4.204)

lag v.i. (87.II.5.144)

lag behind v.t. (87.II.9.268)

lean against v.t. (90.1.13)

leave v.i. (84.2.11.236)

lengthen v.i. (84.2.11.236)

level off v.i. (87.I.6.366)

level out v.i. (87.I.6.390)

level up v.t. (87.II.5.149)

lift v.t. (84.2.4.154)

loosen v.t. (90.4.44)

lower v.t. (84.2.3.139)

lump together v.t. (90.7.86)

mesh v.i. (87.II.10.289)

moderate v.t. (84.1.3.59)

move v.i. (84.2.1.108)

move away from v.i. (87.I.2.102)

move back v.t. (90.1.8)

move up v.i. (90.4.42)

narrow v.i. (93.1.25)

narrow v.t. (87.I.2.103)

offset v.t. (87.I.2.102)

open up v.i. (84.2.11.236)

outstrip v.t. (90.1.9)

overlap v.i. (90.9.147)

pass v.i. (87.I.2.97)

peak v.i. (87.II.1.11)

phase-in v.t. (87.II.9.263) 


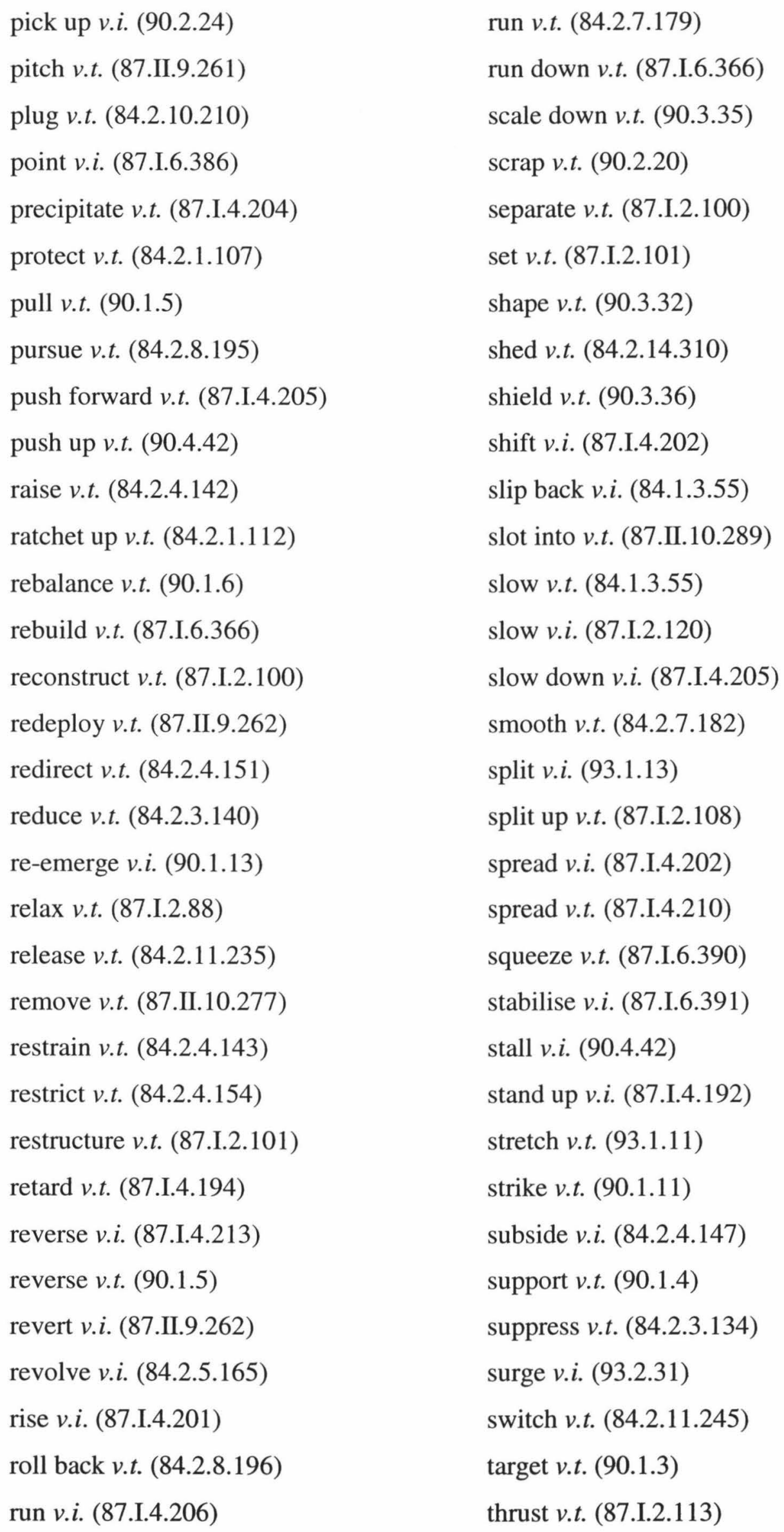


tighten v.t. (84.2.3.137)

tip over v.i. (90.2.29)

transfer v.t. (84.2.13.293)

treble v.t. (87.II.10.269)

trigger v.t. $(01.5 ; A R)$

turn v.i. (87.II.6.177) turn down v.i. (84.2.11.234)

uncover v.t. $(90.4 .42)$

unwind v.i. (90.2.24)

weigh v.t. (87.II.10.273)

widen v.i. (84.1.3.57)

wind down v.i. (90.2.24)

In the above list there is a subgroup of verbs slightly different in that they may not directly consist of active movement, but they cannot exist without movement. They act in a negative sense to stop, slow or redirect physical motion, and for this reason they have been included in the list. These verbs are arrest, curb, constrain, cushion, divert, freeze (v.t.), grapple (with), halt, hamstring, hold, impede, restrain, restrict, retard and stall.

A second subset of the verbs listed above is that involving the notion of balance. To be consistent with the "stopping" verbs just mentioned and because some movement is a prerequisite for all of these words too in order to reach an equilibrium, they also have been included here. These verbs are balance, counterbalance, rebalance, stabilise and weigh. In their semantic notion they are linked to the set of level off, level out and level up, and flatten out, also in the list. A pair to do with cohesion (bind) and dissolution (erode) have also been included in the above list as involving some movement.

In addition to these, there were many other verbs in the Treasury BIGs which could have been construed from their context as related to movement, but in the end were not included in this list because they were not clearcut cases. Examples of such verbs are absorb (84.2.8.198), conceal (84.2.1.104), perform (87.I.2.102), reinforce (84.2.7.181), underlie (v.t.) (90.1.9), undermine (84.2.7.175), underpin (v.t.) (90.1.10) and weaken (v.i.) (90.2.24). Interestingly, several of these have to do with the notion of physical strength of structures. The related notion of tensile strength is another similar domain, and accordingly the word tightness (84.2.4.154) was omitted from the list of nouns which follows (although tightening was included, as the gerund more definitely conveys the feeling of movement). As these examples show, it is sometimes difficult to determine what constitutes motion and what does not, but in the end it was 
decided to draw the line at verbs like these, which indubitably do include some physical movement, but where that is so slight as to be tangential to the word's primary meaning. Cameron (1999:107) discusses the problem of differential metaphoricity, namely the gradedness of metaphor and the fact that some metaphors are more metaphorical than others - as can be seen in this study, the same also applies to the various lexical instantiations within each metaphor.

\section{ii. Nouns}

acceleration (84.1.3.57)

action (84.2.7.177)

adjustment (90.3.32)

bind (84.2.5.167)

blow-out (93.1.9)

blunting (87.I.2.105)

boost (87.I.6.387)

bottoming out (84.1.3.57)

bounceback (84.1.3.57)

break (90.2.28)

break-up (90.9.149)

broadening (90.6.77)

build-up (84.1.3.56)

carriage (meaning “carrying”)(87.I.2.105)

carrier (87.I.2.106)

carry over (87.I.6.388)

clash (84.2.10.212)

collapse (84.2.4.147)

containment (87.I.2.101)

contraction (84.2.5.158)

creep (90.6.80)

crowding out (84.2.7.174)

cut (84.2.7.176)

cut-back (87.I.6.362) cutting (84.2.15.320)

decline (84.1.3.55)

decrease (84.)

deepening (84.2.5.168)

deflation (87.I.4.202)

deflator (87.I.4.208)

delivery (87.I.2.88)

deposit (84.2.4.154)

devolution (87.I.2.92)

disinflation (84.2.2.132)

dismantling (90.3.32)

divestment (87.I.2.100)

downturn (84.2.3.136)

drain (84.2.5.162)

drift (87.II.6.196)

drop (84.1.4.69)

dynamics (84.2.11.235)

dynamism (87.II.5.126)

easing back (84.2.1.104)

elasticity (87.II.9.259)

emergence (90.1.9)

entry (84.2.4.156)

equilibrium (84.2.5.158)

evening out (87.I.4.193) 
expansion (84.2.1.103)

extraction (87.I.2.105)

fall (84.2.4.146)

fall-off (84.1.3.56)

feed-through (93.2.35)

flattening (87.I.4.205)

flexibility (84.2.4.153)

flight (87.II.5.149)

float (84.2.5.167)

floating (84.2.5.168)

flow (84.2.4.145)

fluctuations (84.2.1.105)

freeze (84.2.1.105)

freezing (84.2.5.165)

growth (84.1.3.55)

imbalance (84.2.1.103)

impact (84.2.2.133)

increase (84.1.3.56)

inflation (84.2.3.140)

inflow (84.2.3.137)

input (87.I.2.100)

instability (84.2.7.175)

integration (90.3.32)

lengthening (87.I.4.196)

levelling down (87.II.5.128)

levelling off (87.I.6.367)

levelling up (87.II.5.128)

lift (84.2.1.103)

lowering (84.2.5.161)

manoeuvre (87.II.6.195)

mobility (84.2.15.317)

move (84.2.4.154)

movement (84.2.1.107) narrowing (87.II.10.287)

opening (87.II.9.268)

opening-up (87.II.9.267)

outflow (84.2.4.152)

output (84.1.3.57)

outturn (84.1.4.69)

overlap (87.I.2.107)

overrun (90.3.34)

pace (84.2.12.249)

peak (84.)

pick(-)up (84.1.3.57)

placement (90.1.11)

pressure (84.2.2.132)

progressivity (84.2.10.216)

quadrupling (87.II.1.11)

raising (84.2.3.140)

rapidity $(84.2 .7 .181)$

rate (84.2.3.135)

reconstruction (87.I.2.103)

redeployment (87.II.9.264)

reduction (84.2.5.161)

relaxation (87.I.2.94)

removal (84.2.11.237)

restructuring (90.2.21)

resurgence (84.2.1.103)

retrenchment (84.2.1.107)

reversal (84.2.1.105)

reversion (94.AR.5)

rise (84.2.5.159)

rollback (90.3.34)

rollout $(01.48 ; A R)$

run (84.2.4.147)rundown (84.1.3.56)

separation (87.I.2.88) 
shift (84.2.5.164)

shifting forward (84.2.1.104)

slippage (87.I.4.204)

slowdown (87.I.4.205)

slowing (84.2.7.175)

slowing down (87.I.2.105)

speed (84.2.5.163)

spiral (84.2.5.159)

squeeze (84.2.3.139)

stabilisation (84.2.7.178)

step (84.2.10.217)

stoppage (90.9.152)

streaming (87.II.5.135)

swing (84.2.3.134)

takeover (84.2.13.293) targeting (90.1.9)

tightening (84.1.3.56)

transfer (87.II.10.277)

transition (87.I.2.93)

transmission (87.I.2.105)

turnaround (84.)

upsurge (84.)

upswing (84.1.3.59)

uptake (84.2.3.135)

upturn (84.1.3.57)

volatility (84.2.11.237)

widening (84.1.3.56)

wind-down (87.I.6.377)

wind-up (01.54;AR)

yield (84.2.4.155)

iii. Adjectives; Nouns, Past and Present Participles Used Attributively

accelerated (87.I.4.191)

accelerating (84.2.1.105)

active (84.2.4.154)

arising (87.I.2.96)

attacking (84.2.3.134)

binding (84.2.4.153)

buoyant (84.1.3.56)

centripetal (87.II.4.100)

contractionary (84.2.3.139)

crash (90.6.77)

crawling (84.2.5.166)

cyclical (84.1.3.59)

decelerating (87.I.6.391)

declining (84.1.3.59)

decreasing (87.II.10.270) deep (downturn) (87.I.4.203)

depressing (84.2.1.115)

destabilising (84.2.7.177)

developing (87.II.9.259)

distorting (90.1.8)

down (87.I.6.388)

downward (84.2.5.159)

downwards (84.2.3.141)

driving (84.)

dropping (84.)

dynamic (87.I.2.98)

escalating (84.2.3.135)

expanding (84.1.3.59)

expansionary (84.2.3.141)

falling (84.1.3.61) 
faster (87.I.4.195)

fastest (84.2.8.199)

fixed (84.2.3.134)

floating (84.2.3.134)

flow-on (84.2.4.146)

forward (84.2.5.163)

growing (84.2.5.161)

higher (84.2.5.162)

impacted (84.2.1.107)

increasing (84.2.1.103)

inflationary (84.2.5.159)

inward (84.2.5.163)

levelling off (84.1.3.55)

loosening

low (90.1.7)

lower (87.I.2.103)

lowest (87.I.2.102)

oriented (90.1.9)

output (90.7.86)

outreach $(01.60 ; A R)$

outward (84.2.5.163)

overarching (90.1.8)

portable (87.I.2.92) quick (90.1.3)

rapid (84.1.3.56)

reinforcing (84.2.1.105)

revolving (87.I.2.83)

rising (84.2.5.169)

running (87.I.4.189)

simultaneous (action) (87.I.4.197)

slow (84.2.1.103)

slowing (84.)

spiralling (84.2.3.135)

squeezing (84.2.3.136)

stabilising (84.2.7.177)

stable (84.2.3.59)

stagnant (84.2.15.321)

static (84.1.3.59)

stationary (84.1.3.57)

suppressed (87.I.4.201)

uneven (pace) (87.I.4.209)

upward (84. 2.2.132)

widening (84.2.8.195)

winding down (84.)

wrap-up $(01.50 ; A R)$

In this list the words centripetal, cyclical, revolving, rollback, rollout and spiralling form a subset relaying circular motion: a metaphor within a metaphor. The other feature of this list is that, predictably perhaps, terms of pace are far more evident than in any other part of speech. While the verbs earlier included the six items accelerate, decelerate, lag behind, overtake, pass and run, and the nouns acceleration, pace, rate, slowing down and speed, here the adjectival forms have a far higher ratio of terms related to the pace of physical motion. So although they are a shorter list, they include accelerated, accelerating, decelerating, escalating, faster, fastest, quick, rapid, running, slow, slowing, static, stationary and uneven pace. A similar proportion of terms related to speed can be seen in the adverbial class following. 
iv. Adverbs

at a moderate pace (87.I.4.195)

at a much faster pace (87.I.4.195)

below (84.2.5.162)

dynamically (87.II.10.270)

fast (87.II.9.263)

forward (87.I.2.117)

freely $(84.2 .15 .317)$ quickly (84.2.1.105)

rapidly (84.2.1.105)

sharply (84.2.3.136)

slowly (84.2.11.236)

statically (87.II.10.270)

steeply (84.2.10.217)

upwards (87.I.2.81)

\subsubsection{Discussion}

It could be argued that this metaphor of movement has over time become so embedded in the English language that in its most common representations: words such as go up, fall, grow bigger and reduce, it has become a "dead" metaphor and there is no other way of saying something than by using these words. This is certainly true to some extent. It is obvious that quantity is represented on a vertical plane in the English language (as well as in other languages such as Mandarin Chinese), so these types of words are to some extent inevitable and their use is constrained, without alternatives. To the extent that there are no non-metaphorical synonyms, it is certain that most users have lost sight of the original metaphor as used in this context. Deignan (1999:182) names establishing the point at which dead metaphor is so well established in the language as to be regarded as a literal sense, as one of the main problems which arise in the study of metaphor using naturally occurring data.

So can a metaphor exist if there is not also non-metaphorical usage to describe the same subject matter? As mentioned earlier in section 4.5 of this chapter, there is little or no metaphor in the Treasury Annual Reports or Corporate Plans. Furthermore, metaphor in the Treasury BIGs is not spread evenly throughout the documents, as there are many chapters with no metaphor in them at all. The quotations above are a sample of the quantity and density of metaphorical items found in those sections of the Treasury papers which are concerned with change in economic policies; their pattern of occurrence supports the observation in Cameron and Juurd (2004:108) that "metaphors are not evenly distributed across talk or text, but come in clusters or 
bursts at certain points, and may be nearly totally absent at other points...". The quotations above also illustrate that there is more going on here than long-dead words which used to relate to physical motion. In the frequency of occurrence, in the variety of expressions by which the metaphor is represented, and in the sheer force of the metaphorical lexis of movement, these images go beyond ordinary high frequency words which used to relate to motion but have lost their primary meaning.

I suggest that one of the reasons why these types of phrases using the vocabulary of physical movement are the primary metaphor discovered in the Treasury papers, is that economics as a discipline is sometimes graphical, and policymaker economists tend to use expositional diagrams to illustrate data (rather than conceptual diagrams like the supply/demand curve $)^{1}$. It is possible that the economists employed in writing these document types were conceptualising economic changes as represented by lines and movements on a graph.

The second explanation I propose here is that economics is often concerned with changes and rates of change. There is a mathematical basis to economics in that velocity and relative rates of change have to do with physics; the maths behind this physics is all calculus. Hence perhaps because of this link - that economics and the physics of motion are both concerned with change and rate of change - similar conceptual structures have led to the adoption of the same lexis.

\subsubsection{Other Treasury Metaphors}

Apart from the huge and omnipresent image of physical motion as a metaphor for economic change, there were a dozen other, less frequent, metaphors found in the documents of the Treasury, and these follow in this section. It will be seen here, however, that the concept of physical motion continues to be a common thread through several of the following metaphors, though they all have quite different metaphorical realisations, and each set of imagery is distinct from the others. The continuation of physical movement is perhaps most obvious in the first of what

\footnotetext{
${ }^{1}$ Charles Tallack, Senior Analyst, NZ Treasury, personal communication, 06.09.07
} 
follows, MONEY IS WATER, and in THE ECONOMY IS A MACHINE metaphor; it also occurs though in the schemata of the battleground, the game and the roadway.

It is noted that Moon, in deciding which metaphors to include in a dictionary, developed for herself a 'rule of ten', whereby she "only dealt with metaphors if there were at least ten lexical realizations that reflected the mapping fairly clearly..." (2002:395). Cortazzi and Jin (1999:162) "set a minimum number of five tokens before considering accepting candidate conceptual metaphors..." Adopting this type of principle was considered here, but instead it was decided to include all conceptual metaphors found in the documents examined, in the interests of providing a complete list, which may be helpful for future research. In fact most of the metaphors discovered were fairly productive, and almost half of the subsidiary ones which follow do meet or exceed Moon's 'rule of ten'; the last seven metaphors had fewer than ten realisations in this dataset. Furthermore only the final four metaphors listed here do not meet Cortazzi and Jin's minimum of five tokens. In this section the metaphors have been arranged in order from the most frequent to the least frequent. In these twelve more minor metaphors we can see the various instantiations of each base metaphor working together to represent often abstract and demanding subject matter through a single figurative concept.

In this section, each metaphor has been named for its most specific concept (following Lakoff and Johnson, 2001:7), which should be read as encompassing the other metaphorical concepts which are entailed within that name. For example, the metaphorical construct found in the dataset and listed below as THE ECONOMY IS A PATIENT, should be understood as entailing, each one in sequence, the other, unspecified concepts, of THE ECONOMY HAS VARYING STATES OF HEALTH, and THE ECONOMY IS A LIVING ENTITY. These three are sub-categorisations of the same metaphorical construct, thus we see that a whole system of interdependent metaphors characterised by a chain of entailment relationships can be, and is in this dataset, expressed by a correspondingly coherent system of linguistic instantiations for those concepts.

Not every occurrence of these metaphors has been listed here, as the most productive ones had very many instances. In the few cases where the same word was used in the 
same way, only one citation has been selected by way of an example. Within each metaphor, its various lexical realisations have been ordered alphabetically, with the headword highlighted by italicised bullet points, the citations following. In cases where several different lexical instantiations of the one conceptual metaphor occur within the same sentence or consecutive sentences, as can occur when a writer has an image in mind and continues it throughout the proposition s/he is making, these citations have been listed under the first occurring headword. In these cases too, where an image has been continued throughout two consecutive sentences, rather than splitting them and listing under their respective different headwords or lexical realisations, the sentences have been kept together, so as to preserve the original integrity of the metaphor and the full force of its image.

\section{i. MONEY IS WATER}

Cash as the physical object notes and coins, and as the more abstract entity in bulk, is often conceptualised as liquid, through the systematic borrowing of lexical items from the source domain and lexical set of plumbing and irrigation in order to express different aspects of monetary transactions. This conceptualization is not specific to English, but occurs in other languages such as Mandarin Chinese, Japanese, and Spanish.

\section{- Anchor}

These will be greatly facilitated if the monetary authorities can identify a useful 'intermediate target' which will act as an 'anchor' for nominal magnitudes in the system. (87.I.4.217)

Given a floating exchange rate, the role of nominal anchor must be played by a monetary aggregate. (87.I.4.217)

\section{- Cascade}

margin-on-tax cascade (84.2.10) 
price cascades (84.2.10)

tax cascades (84.2.10)

\section{- Channel}

The Prime Minister's Department provides an additional channel for advice and dialogue on economic questions. (84.2.2)

... has simply channelled the costs through other mechanisms...(84.2.8)

...this will enable resources to be more rapidly channelled into activities yielding high returns ... (84.2.11)

Administrative methods of allocation are likely to channel scarce capital resources in less preferred directions. (84.2.14)

\section{- Churn}

Instead there is a lot of recycled income or income churning among middle income earners. (87.I.3.185)

\section{- Dampen}

This effect would tend to dampen the recovery of consumption as disposable incomes rise. (87.I.6.374)

...and accepting that this will dampen our low-growth economy. (90.1.2)

- Downstream

...reduced cashflow for downstream traders ... (84.2.10) 
There are several policies designed to compensate forest growers for the downstream benefits they provide through the protection of land prone to erosion. (84.3.34)

Within the state sector, responsibility for allocation of funds should be moved as far downstream as possible. (87.II.5.150)

\section{- Drain}

...the resulting balance of payments deterioration drains cash out of the economy ... $(84.2 .3)$

...designed to spread the monetary effects of the tax drain to the Government in September and March... (84.2.4)

\section{- Drop (of Water)}

It is in fact by resisting "sharing" that the minority maintains its existence: it is like a drop of water constantly threatened by the presence of a sponge. (87.II.8.225)

\section{- $E b b$}

...voluntary compliance which is reported to be at a low ebb. (87.I.4.192)

\section{- Filter}

-secondary schools in New Zealand operate more finely as filtering devices...in consequence the path through to university and teachers college for those who get through the filter is exceptionally smooth; (87.II.6.187)

\section{- Flow}


High levels of assistance to manufacturing industries through import licensing and high tariffs have encouraged a flow of resources into some of our least efficient industries. (87.Intro.2)

The cash flows in and out of the Public Account have not in the past been managed in the sense that a private firm would... (87.I.2.92)

Viewed in this context free transfer of the SOEs deprives the Crown of the dividend flows from the assets. (87.I.2.115)

...empowering...through maximising information flows... (87.II.2.42)

...the broader economic costs that flow from economic distortions ... (84.2.14)

The national benefit requires that resources flow as freely as possible among different activities ... (84.2.15)

Trade is a process in which, through voluntary contracting, scarce resources flow to their most highly valued uses. (87.1.15)

Through voluntary contracts, either based on barter or facilitated through money, ownership titles to resources are transferred, ensuring that resources flow towards those who value them the most. (87.1.15)

... where individual firms are unable to prevent some of the benefits from their investments ...from flowing to competing firms. (84.2.15)

... capital flowing more freely across international borders. (93.3.53)

... flow-on effects arising from the troubles of particular financial institutions. (84.II.4.146)

\section{- Liquid}


This class of outputs concerns the operational management of the Crown's net liabilities portfolio and the central management of its liquid funds. (93.AR.40)

\section{- Liquidity}

the degree to which tighter liquidity would have reduced the cash drain through the OET accounts. (84.2.4)

...difficulties of ....adjusting liquidity management settings soon enough. (87.I.4.204)

...the liquidity management system that has evolved relies heavily on flows to and from the public account... (87.I.4.216)

- liquidity risk: this involves ensuring that the Crown can always finance its cash flows at reasonable cost and in a timely manner. (1991-92.CP.35)

Transactions to meet liquidity requirements i.e. new issues and debt servicing. (1991-92.CP.36)

- Log-jam

The removal of the above constraints has the potential to break the log-jam of change and produce better labour-market outcomes. (90.9.151)

\section{- Log-rolling}

Such flexibilities as do exist in the system, for example in respect of funding for buildings, do not exist at the local level and thus reinforce pressure group politicking, and the chance that priorities will be determined by 'log rolling' at the centre rather than by any assessment of demands relative to available funds. (87.II.4)

- Muddy (the flow) 
...the idiosyncracies of personal interaction will tend to muddy the flow of academic analysis. (87.I.Annex.400)

- Navigate

...with parents belonging to lower socio-economic groups or belonging to ethnic minorities less able to navigate the committee politics involved... (87.II.5.147)

\section{- Pump priming}

Depending on the policies followed to achieve full employment this may involve costs in the form of reduced choice (in a managed labour market) increased inflation (as a result of 'pump priming') or attacks on collective bargaining rights (to reduce the cost of labour). (87.I.Annex 440)

- Stagnant

Higher taxes on a stagnant economy will only damage the economy further. (90.1.9)

- Stream

... a premium above the present value of the future income stream...(84.2.13)

The SOE Unit was represented on and serviced the SOE Steering Committee, which provides an independent stream of advice direct to the Minister and comprises private and public sector members. (91.AR.57)

A further four departments are scheduled to come on-stream by 1 July 1991. (90.AR.58)

- Strip (liquid) 
... subsequent sales...were successful in stripping these liquid assets out of the banking system (84.2.3)

- Trough

Since the trough of the recession in mid-1991 ... (93.3.48)

\section{ii. THE ECONOMY IS A BATTLEGROUND}

- Aggressive

... a policy that is so aggressive that reversal is thought highly probable... (87.I.4.196)

- Captive

A reserve asset ratio system was in place to provide a captive market for government securities and to assist with monetary control. (87.I.4.215)

- Capture

Avoidance of Capture (subheading, 87.I.1.48)

...a proportion of the gains will be captured by the Government in a competitive selling process. (87.I.2.114)

- Clash

...the current clash between policies ... (84.2.1)

- Combat

increases in expenditure...to combat recession...(84.2.7) 
- Danger

In general government policy faces the danger of two types of capture: capture from external sources - that is, lobby groups; capture from internal sources - that is, its own bureaucracy. (87.I.1.44)

The dangers are obvious ... (84.2.3)

- Force

...forces pulling strongly in different directions ... (84.2.1)

- Militate

The information costs underlying centralised decision making therefore militate against its successful execution. (87.I.1.43)

- Predatory

... given ...the risk of EC acting in a predatory manner. (87.I.2.108)

- Spear

The Maori Development Corporation could play a spear-heading role in this process. (87.I.5.342)

- Sword

The state is a double edged sword. (87.I.1.44)

Industry assistance is a double-edged sword. (87.I.4.240)

- Takeover 
The retention of any form of public ownership is likely to shelter the organisation against takeovers... (87.I.2.117)

- Target

We are off target. (90.1.2)

- $\quad$ Threat

... pressures for domestic wage and price increases...would further threaten our international competitiveness. (84.2.3)

- Trap

...we are particularly worried that the cumulative effect of a variety of targeted schemes could act as a trap for low income assistance recipients. (87.I.Annex.446)

iii. THE ECONOMY IS A PATIENT

- Cause

... tackle the root cause of the difficulties by reducing the fiscal deficit...(84.2.3)

...inflation diverts attention from causes to symptoms ... (84.2.3)

\section{- Chronic}

...chronic imbalances between government expenditure and revenue can seriously disrupt and destabilise the economy ... (84.2.7)

- Disable 
... any inwardness in the educational source is potentially disabling of students.

(87.II.5.146)

- Inject

the potentially destabilising influence of injections of liquidity into the financial system...(84.2.7)

Any such cash injections would have to be reversed when the crisis subsided. (84.2.4)

... insufficient debt was sold to negate the effects of the injection from the fiscal deficit. (84.2.7)

...the latter works through injecting additional cash into the financial system ... (84.2.4)

The more actively involved Ministers become in monitoring, the greater is the likelihood of non-commercial objectives being injected into the commercial decision making of the business. (87.I.2.100)

Additional resources injected into an existing system may help in countering the symptoms but not the cause of conflicts and failure. (87.II.5.143)

- Pain

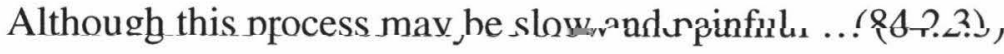

- Pick Up

However, export volumes are expected to pick up. (90.2.24)

- Recovery 
The economy has experienced a relatively modest and uneven recovery... (90.2.17)

However, the recovery has been weak and tentative... (90.2.17)

- Remedy

The remedy for this fiscal problem lies in improving the overall balance in policy strategy. (90.1.2)

- Sclerosis

These are fundamental, but they must be supplemented by action to overcome the sclerosis that has built up through the regulation of many markets of the economy... (84.II.1.107)

- Side-effects

...so as to minimise the risks of policy reversals with all the undesirable side-effects on private sector decisions which such uncertainties about policy intentions arouse. (84.2.7)

- Suffer

The economy is suffering from serious imbalances internally and externally. (84.2.3)

- Symptoms

... to try to suppress symptoms by direct controls rather than by attacking causes directly. (84.2.3)

...high levels of unemployment... are a symptom of the more general difficulties the economy has faced. (84.2.11) 
- Weak

The weak state of domestic activity... (90.2.19)

\section{iv. THE ECONOMY IS A ROADWAY}

- Barrier

...minimise...barriers to exit from the present state system; (87.II.5.152)

Further, the greater the cost barriers erected around private schools the less competition they pose to state schools. (87.II.5.130)

- Collision

There are inevitable collisions in the economic traffic if the signals are jammed or confused. (84.2.1)

- Fuel

...fuelling excessive monetary expansion ... (84.2.7)

- Gate

It is not known to what extent subject decisions are taken by Maori children themselves, and to what extent teachers act as 'gate-keepers' guiding children to subjects they, the teachers, deem suitable. (87.II.8.230)

This suggests that schools at forms $6-7$ provide a narrow gateway...to educational opportunity. (87.II.6.188)

- Path 
Either pretence can be immensely damaging to an individual's initial path in the world beyond school. (87.II.5.145)

...schools...owe it to their students...to make school a path not a barrier to the outside world. (87.II.5.146)

An international survey suggests that young people in education predominantly see it in terms of a pathway to work. (87.II.5.121)

Thus chance, bad choice, earlier errors or problems or shortage of resources are less likely to trap individuals into a particular pathway. (87.II.6.169)

Schools need...to...provide a pathway to the necessary skills, knowledge and abilities that will enable reasonable progress to be made in the wider society. (87.II.10.290)

- Redirect

This may mean establishing mechanisms to redirect government intervention from main institutional to other sources of education; (87.II.2.42)

- Signal

However, as described, educational qualifications are used as signalling devices in the labour market... (87.II.5.124)

the desire to get price signals correctly aligned as soon as possible to redeploy resources... (87.I.4.196)

..changes in relative prices are signals to producers and consumers to change the pattern of their resource use. (84.2.4)

- Signpost 
Its strengths seem to lie in signposting and providing the basic skills and attitudes that young people will need in the world beyond education. (87.II.5.144)

Those who lack such orientation most need to have the system explained and the way forward signposted to them so that they can develop for themselves appropriate strategies for success. (87.II.5.145)

Therefore, to justify state support, the school's side of the partnership lies in providing the core curriculum and, where necessary, clear signposts as to its relevance and use. (87.II.5.145)

Thus, unless secondary schools can...offer a well signposted way to the valuable social and economic skills... (87.II.10.280)

- Steer

... the self-steering ability inherent in society to reach optimal solutions through the mass of individual actions pursuing free choice without any formal consensus. (87.II.2.41)

- Traffic Lights

In a similar way to traffic lights, the major virtue of the price mechanism is its simplicity in both signalling information and co-ordinating behaviour. (87.1.16)

- Vehicle

...consultative processes will provide a vehicle for furthering their particular interest... (84.2.2)

- Way (forward) 
This brief attempts to open out the issues for the Government in order to lead to more constructive consideration of the best way forward. (87.II.1.vii)

\section{v. THE ECONOMY IS A MACHINE}

- Automatic

...administered exchange rate regimes with a high degree of automaticity in their operation (e.g. some forms of crawling peg) may also fail to be sufficiently flexible... $(84.2 .5 .165)$

- Dismantle

... the dismantling of existing policies... (84.2.11)

- Engine

That argues that openness to trade will remain an extremely important engine of growth. (93.3.48)

- Fulcrum

... provide the fulcrum on which monetary policy is made effective... (87.I.4.219)

- Machinery

$\ldots$ the machinery for...executing policy... (84.2.1)

Cabinet has the overall responsibility for control of the government machinery, ... (84. 2.13)

- Mechanism 
In both cases the outcome of these different adjustment mechanisms on the real factors in the economy (for example, consumption and output) is identical once the adjustment is fully worked out. (84.2.5.158)

The mechanism of domestic monetary contraction described above is therefore prevented from operating. (84.2.5)

...whether the mechanisms for change in education policy, which worked well in more leisurely times, are up to the sudden gear shifts that are increasingly required if the system is to adapt to the fast changing and increasingly varied needs of society. (87.II.1.4)

... introducing a credit offset mechanism whereby taxpayers can offset tax on inputs against tax on their outputs. (84.2.10)

Other mechanisms allowing greater freedom could also be devised. (84.2.13)

The particular mechanisms adopted, which are operated by the producer boards, cause problems of their own; (84.2.15)

The mechanisms through which opportunism and incentive problems generally work in the state are in fact more subtle and complex than are widely appreciated. (87.I.1.43)

They may do this either by putting automatic mechanisms in place which give the system self-stabilising properties consistent with price stability... (87.I.4.211)

- Momentum

Once inflation has gathered momentum, it is difficult to stop... (84.2.3)

- Ratchet 
...the structural expenditure ratchet...will remain (84.2.6)

A notable feature of this trend in government expenditure as a proportion of GDP has been a "ratchet" mechanism whereby increases in spending in election years have not been fully reversed in subsequent years. (84.2.8)

- Supertanker

Like a supertanker, the economy ... (84.2.1)

- Track

The system tends to run on its own track... (87.II.1.18)

vi. THE ECONOMY IS SUBJECT TO HEAVY WEIGHTS AND SUDDEN SHOCKS

- Burden

A reduction in the fiscal deficit would put pressure on the relatively sheltered parts of the economy such as the public sector...spreading the burden away from the exposed sectors. (87.I.4.237)

- Exposed

... with the exposed sectors taking an undue share of the pressure on the whole economy. The correct response in such circumstances is to ... increase the pressure on the sheltered sectors... (90.4.44)

- Impacts

Excluding activities from the economy-wide programme to reduce assistance or even shielding them from its most significant impacts... (87.I.4.252) 
This resulted in a steeply inverted yield curve, with long term rates substantially below money market rates, which is usually an indication that the system is under pressure. (87.I.4.204)

Particularly important is the relative pressure on those exposed to international competition and those protected from it. (90.4.40)

- Protection

Also important are the protections afforded by regulations. (90.1.7)

- Shelter

...reducing the costs imposed from the more sheltered sectors of the economy. (90.1.7)

... principally by ensuring that these sectors and activities which are currently sheltered or protected are exposed more openly to market pressures. (87.I.4.203)

...some of the most highly assisted industries have been somewhat sheltered from the impact of the liberalisation programme. (87.I.4.247)

...from exposing sheltered areas of the economy to some form of price competition... (87.I.4.251)

- $\quad$ Shield

Past approaches tended to shield New Zealanders from change in world prices. (90.3.36)

- Shocks 
A firm fiscal stance will minimise the risks around the outlook and help reduce the economy's vulnerability to shocks. (93.2.31)

The vulnerability to terms-of-trade shocks should diminish as exports become more diversified and firms differentiate the products they produce. (93.3.52)

\section{vii. THE ECONOMY IS A GAME}

- Counter(Moves)

The Government may seek to counter the counter moves of the advantaged and of the employer and tertiary recruiters, thus leading to further rounds of the game and eventually to a totalitarian state. However, before we get to that stage, the game can be seen to produce higher and narrower bastions of privilege... (87.II.5.127)

Attempts to disable the advantaged... will merely lead to counter moves... takeover of the public school agenda, and hence to an expensive game played out largely with public money... (87.II.10.280)

- Player

Private sector players are likely to have better incentives to carefully monitor any investment proposal they fund, and the quality of investment decisions is likely to be better if left to them. (87.I.4.235)

- Round(One)

The state's choice is not the end of the story, it is only round one. .... If the state resists such counter moves there will be further rounds of the 'game'. For this reason, state intervention which seeks or is likely to disable the choice by a particular group of its educational agenda is liable to meet resistance by that group and may be sidetracked or turned around. (87.II.2/38)

- Rules (of game) 
It is important to consider the nature of the conflict between rapid and significant change and another feature of progressive adjustment, namely that there be consistency in the rules of the game. (87.I.4.251)

- Tactics

...it is difficult to force the pace of change simply by concentrating on the former, particularly if this turns into disabling tactics against some of the latter. (87.II.5.128)

\section{viii. THE ECONOMY IS A HORSE}

- Fetter

unfettered markets (84.2.1)

- Harness

It is desirable that the resources of the tax system and the social-welfare system are harnessed to exploit their complementarity. (90.11.180)

harnessing markets (84.2.1)

- Rein

Government expenditure has not been reined in to make room for the 1982 tax cuts. (84.2.3)

..to keep a tight rein on these policies...

- Spur

...competition provides a strong spur to innovation and better performance. (93.1.16) 
- Stubborn

Inflation has proved stubborn. (87.I.4.190)

\section{ix. THE ECONOMY IS A BUILDING}

\section{- Ceiling}

For example, controls on conditions of employment and staff ceilings may make it difficult to attract the employees required to improve performance. (84.II.13.284)

...the problems caused at upper levels by delays in adjustments have recently been compounded by the imposition of a ceiling on their adjustments. (87.I.2.66)

The retention rates from form 3 to form 5 are of special interest because, while a ceiling of 90 percent enrolment appears to have been operated for non-Maori students, for Maori students there has been an effective ceiling of less than 70 percent. (87.II.8.230)

- Floor

To put a floor under wages, either by a minimum wage law or some concept of a "minimum living wage" in wage negotiations is probably a particularly inequitable form of labour market intervention. (84.II.11.240)

By placing a floor under the wages which people will accept, benefits can also reduce the number of jobs on offer. (90.4.48)

Effectively, these policies impose a wage "floor" in the labour market. (90.9.152)

\section{- Window}


The next 10 years provide a window of opportunity to secure a significant reduction in debt. (93.1.25)

\section{THE ECONOMY IS FLAMMABLE}

- Ignite

If demand rises too fast then other prices may rise as well, igniting inflation. (93.2.42)

- Overheat

Macroeconomic conditions may firm, reducing the risks of overheating. (93.2.40)

This would ensure that fiscal policy helps prevent domestic demand overheating. (93.2.44)

\section{xi. THE ECONOMY IS EDIBLE}

- Cake

While the share of the national cake going to the household sector has not significantly altered over the period reviewed, marked changes in the distribution of income have occurred within the household sector. (84.I.6.94)

\section{xii. EDUCATION IS A TREE}

- Graft

...the graft of multicultural education onto mainstream education will not automatically take, because it involves inserting...into... (87.II.7.207)

\subsection{METAPHOR IN OTHER MINISTRIES}


It has now been noted twice in this chapter (sections 4.5 and 4.5.1.1) that although the Treasury BIGs are so rich in metaphor, the Treasury Annual Reports and Corporate Plans for the same period contain almost none. It is also interesting that the same three document types, during the same time period but from different ministries, namely the BIGs, the Annual Reports and the Corporate Plans from the Departments of Social Welfare, Health and Education, contain very little metaphor. The Education documents contain none at all, and the Health and Social Welfare documents use a very little of it, as follows. (Possible reasons for this are discussed in the next section of this chapter).

\subsubsection{DOH Metaphor}

As with the NZ Treasury dataset, so with the NZ Department of Health - it was physical motion which again proved the most common metaphor used to describe economic change. However the metaphor was far less common in the $\mathrm{DoH}$ than in the Treasury documents, and was clustered in the section entitled "Trends in Health Expenditure". This location is significant because it correlates to the finding in a previous section (4.5.1.1) that the Treasury metaphors clustered in areas of written discourse which dealt with economic change. The lexemes used to instantiate this metaphor in the DoH BIGs are listed below (again, only instances from economic contexts where these words were used to describe financial patterns or transactions have been collected).

i. Verbs

accelerate v.i. (87.31)

carry forward v.t. (87.113)

deflate v.i. (84.3)

expand v.i. (84.13)

fall v.i. (87.32)

import v.t. (84.17) increase v.i. (84.3)

keep pace v.i. (87.35)

lower v.t. (84.6)

reduce $v . i$. (87.33)

rise v.i. (87.31)

stabilise v.i. (87.33) 


\section{ii. Nouns}

decrease (87.33)

driving force (84.2)

freeze (87.40)

growth (84.2)

increase (87.31)

iii. Adjectives

high (87.31) input (87.35)

reduction (87.33)

rise (87.31)

shift (87.35)

rapid (87.31)

The only other metaphors used by the New Zealand DoH in its BIGs from 1984 1994 are those of water ("Once again this could threaten the overall effective use of tax payers' dollars that are channelled into the public funding of health care" 1990 R.1.32; "the flow of funds..." 1993 BIG I.45; "Providers are likely to behave with greater fiscal responsibility if they are accountable for the flow-on costs they generate" 1993 BIG I.23; "cashflow" 1987 BIG 41), battlegrounds ("professional capture" 1984 BIG 131), medicine ("an injection of extra funding” 1990 R.1.11; "some CHEs may also need to have their balance sheets strengthened by some combination of equity injections or debt writeoffs by the Crown" 1993 BIG I.31), and buildings ("Ninety-one new ceilings were created, to support the activities of different groups in the community..." 1987 BIG 145).

Throughout the DoH BIGs of the decade, the above four metaphors occurred very rarely. Only one instance of each lexeme has been quoted above but in total, no lexeme occurred more than three times in the one million word DoH corpus.

\subsubsection{DSW Metaphor}

The documents from the Department of Social Welfare contained a small amount of the physical motion metaphor, in the 1987 Briefing Papers in particular, in the section entitled "Generic Income Maintenance Issues", which discusses benefit adequacy, benefit indexation, and benefit wage relativities. This finding lends weight to the 
theory advanced in this chapter that the metaphors listed herein are particular to the domain of economics and finance.

\subsection{DISCUSSION}

Since Lakoff and Johnson and the emphasis on "A is B", the perception has been widespread that the most typical sort of metaphor is those where both component parts, Topic and Vehicle, are nouns. In this study however, from the data above it can be seen that the primary metaphor discovered, that of physical motion, mainly consists of verbs. This would suggest that in text types to do with finance and economics, verbal metaphors are more common.

By contrast, of the dozen less common metaphors found and listed above, most are nominal, and do fit the Lakoff and Johnson model. A breakdown of all the linguistic instantiations of these twelve metaphors shows that their ratio of nouns to verbs to adjectives and adverbs stands at 121:47:25. Of these dozen minor metaphors, ten were primarily nominal and only two were instantiated more by verbs (THE ECONOMY IS A HORSE and THE ECONOMY IS FLAMMABLE). It is noted that these two fall within the five least common of the twelve minor metaphors; thus it is possible that their relative infrequency and resultant small sample size could be responsible for this result. The conclusion then would be that while this part of the study bears out the Lakoff and Johnson model of "A is B" where both parts of the metaphor are nouns, by contrast texts to do with the realm of economics tend rather towards verbal metaphoricity, and within this are presented overwhelmingly through the lens of the metaphor of physical movement.

As mentioned in the introduction to this chapter, it is interesting that the comparative studies of the three-yearly Briefings to the Incoming Governments and the annual Corporate Plans and Annual Reports from three other New Zealand ministries, namely the Departments (as they then were) of Social Welfare, Health and Education, across the same time frame, yielded almost no metaphor at all (the exceptions are catalogued in the previous two sections, 4.6.1 and 4.6.2). So although the Treasury study was replicated exactly by reading a second, third and fourth million words of text from the same three document types and the identical publication years at single 
and three-yearly intervals across a decade, though from different government departments, the result was a near complete dearth of any figurative language.

This raises the question of what the Treasury metaphors do. What is the effect of using metaphor in general and these metaphors in particular? I suggest that one key reason for there being a wealth of metaphor in the Treasury papers and almost none in the corresponding sets of Education, Health and Social Welfare papers is that whereas those three ministries are mainly writing about concrete entities such as people, Treasury is writing about abstract entities such as economic theories, the financial markets and rates of exchange: content which places considerably more demands on the reader. To take one department as an example, the DSW documents from the period are mainly concerned with the need to increase the cultural sensitivity of their own workforce and policies, intervention programmes for orphans and abused children, the various benefits available for single parents, widows, returned servicemen and invalids, and how many beneficiaries are abusing the system. This is all somewhat more concrete and easier for a reader to relate to than papers which discuss solely abstract ideas such as which economic policies the government should adopt.

It seems likely therefore that Treasury economists resort to the metaphorical concepts listed in this paper in order to make their subject-matter more easily understood by their readers, namely the new Minister for their portfolio, and the incoming government. Ortony $(2001: 20)$ has said that "Metaphors are necessary as a communicative device because they allow the transfer of coherent chunks of characteristics - perceptual, cognitive, emotional and experiential - from a vehicle which is known to a topic which is less so." Cameron and Juurd (2004:114) have observed that clusters of metaphor arise "when a conceptual, or root, metaphor was needed to talk about something...", and this finding is borne out by the present study. Lakoff and Johnson too contended that metaphor is not just a poetic or rhetorical device, but "is principally a way of conceiving of one thing in terms of another, and its primary function is understanding" (1980:158). Gibbs made the same point (1999: 44): "Many scholars now recognise that metaphor is essential for how people communicate about abstract, difficult-to-talk-about ideas, .... In this way, metaphor is indeed necessary and not just nice or ornamental". It is clear then that "metaphors 
have a function of organising systematic concepts" (Cortazzi and Jin, 1999:161). Describing the economy as a machine with moving parts, as a building with floors, ceilings and windows or as a cake to cut and share out, transforms the theories into physical images and by creating these pictures in the reader's mind, makes the actual concepts easier to grasp.

Secondly, it also seems possible that the Treasury writers during this period of radical economic reform chose the metaphors they did, whether consciously or not, because they suited their purpose in seeking to persuade the government to follow the courses of action which Treasury was recommending. Cameron and Juurd (2004:115) also, have claimed that some metaphorical clusters function to persuade "through rhetorical repetition." Talking about money as flows of water or traffic implies that it is possible for the government to control and direct such flows. Conceptualising running the economy as fighting a war or as wrestling a stubborn animal needing to be reined in to submission, also creates the impulse to adopt the recommended tactics to control and dominate it. Framing the national economy as an unwell patient, or as a vulnerable entity exposed to outside pressure and liable to crack under sudden shocks or heavy weights could well incline the government to protect, shield and shelter it. Describing the economy as at risk of overheating and catching fire warns the government of possible danger if they do not take action to lower the temperature. And if managing the economy is playing a game, then the government has a chance to win if it employs the right strategies.

In conclusion, it is suggested that the thirteen tropes described in this chapter, and most especially that of physical movement, are commonly but to some extent unconsciously used by writers of economic and financial texts. It has been the aim of this chapter to draw conscious attention to the figurative lexis and therefore the mental schemata we use to describe this domain of the human experience. 


\section{CHAPTER FIVE}

\section{CONCLUSIONS}

\subsection{SUMMARY OF RESULTS}

\subsubsection{Introduction}

"Over the last six years, New Zealand has undergone a period of economic reform unprecedented in its own history and unusual in that of any other country" (1991 DoE. AR 25). The initial hypothesis of this study was that social and economic change must impact on a language, and once completed, must leave some trace behind. This case study of language change resulting from change in society has had as its central focus the nature of lexical innovation. Using the documents of the government sector during the decade 1984 - 1994, there is some evidence that changes in this particular society were reflected in its words. In basic terms, the most significant findings relating to the actual nature of this linguistic change were that:

1. it was largely composed of innovating via multiword units, and

2. these were, in the vast majority of cases, nominal: strings of nouns modifying other nouns.

The other major finding of this study, one unrelated to linguistic change in purely morphological terms, was that:

3. a significant amount of metaphor is used in the domain of finance to describe economic change.

These and the other main trends which emerged from the study are summarised in more detail below. 


\subsubsection{Results}

\subsubsection{Lexical Innovation}

Lexical expansion typically occurs in a language by a limited number of ways. To summarise, the word formation processes whereby new words are coined which have been found in this dataset and discussed in the foregoing chapters have included:

\section{i. Multiword Units}

This study has had two major findings with regard to the NZE neologisms searched for in this dataset: that compounds were the most frequent type of neologism used, and that there was a noticeably high proportion of collocations. These findings support the theory that innovations specific to any one variety of English are most likely to occur at the interface between grammar and lexis, or "where the regular meets the chaotic" (Schneider, 2007:86). As two or more lexemes become more and more strongly bound together with increasing frequency of use, what began as collocational preferences become lexicalised, and a firm combination results, restricted to those words only, so that no other word can be substituted. Thus a new phraseological unit enters the language. It has been suggested (Schneider, 2007:81) that this particular process is "extremely characteristic" of post-colonial varieties of English, which are marked "by the emergence of new constructions, new habits of word combinations which are meaningful (only) in a given speech community" (ibid: 88). As Schneider has said, what remains after a regional variety of written English has been stripped of its place names and personal names? "Not very much, but something inconspicuous but nevertheless powerful and consistent: preferences tendencies to use specific words in combination with specific other words consistently perhaps more frequently than elsewhere..." (2007:91). "individual varieties differ from each other first and foremost in their combinatory preferences,...in the frequency of their lexicogrammatical choices, collocations, ..." (2007:92).

- The compounding process proved to be highly productive in this dataset and by far the most common of the word formation processes found therein. 
- The percentage of the lexemes specific to NZE which were found in this study which were compounds was $58 \%$.

- The percentage of the lexemes specific to NZE which were found in this study which were nouns was $95 \%$.

\section{ii. Borrowing}

ii. i From the indigenous language, te reo Maori.

Borrowed lexical items can

a) be adopted by necessity to describe an entity for which no exact English equivalent exists (e.g. mana motuhake), or

b) be used for political, stylistic or personal preference reasons as an alternative to the existing English term (e.g. the choice to use kohanga reo instead of language nest), or c) be used in combination with an element of English to create a new term, either in two separate lexemes as a compound (e.g. Manukau guardian, tangihanga leave) or bound into one word as a hybrid (e.g. Maoridom).

- All three types of borrowing from te reo Maori occurred in this dataset.

- New Zealand government documents in general contain less than the average proportion of te reo Maori which characterises a wider range of more everyday genres both written and spoken.

Witness the Department of Social Welfare dataset as an example: its million word corpus read for this study contained $0.3 \%$ te reo Maori, as compared to the $0.6 \%$ found by Macalister (1999) in his written corpus. Overall, the amount of te reo Maori in the total five million-word corpus of this study was well below the $5-6$ words per 1,000 words of NZE found by Kennedy and Yamazaki (1999) and supported by Macalister (1999). This will be in part due to the inclusion of a spoken corpus in those calculations, and partly due to the nature of government documents, which, this 
study has shown, tend to use more neutral and international English than indigenous borrowings.

- The percentage of the lexemes specific to NZE which were found in this study which were of Maori origin in one of the three ways listed here was $90 / 256$ words, or $35 \%$.

Note that this figure counts only lexemes of te reo Maori origin, that is it excludes headwords which are English but only exist to refer to Maori concepts, e.g. customary rights, native school. So the proportion of NZE English in this study which is influenced by the Maori people and language is actually higher than $35 \%$.

ii. ii From the Samoan language.

Only three of this type occurred in the dataset: aiga, fono and Sootaga, which together constituted only $1 \%$ of the NZE words found.

iii. Affixation: both prefixation and suffixation were noticeable, in all the four domains.

iv. Revival of archaic or obsolete words: this was especially noticeable in the Treasury domain.

v. Semantic shift: taking an existing word and using it with a different sense, which can be either narrower or wider than the original, occurred in the lexis of two of the four domains: Treasury and Social Welfare.

vi. Conversion: taking an existing word and changing its part of speech without changing its form was evident in the lexis of two of the four domains: Treasury and Health.

vii. Abbreviations, acronyms and blending: these are all reductive processes which are not usually as common as the expansionist types of word formation listed above in 
5.1.2.1 $\mathrm{i}$ - vi. However as a whole they were frequently used in all four lexical domains of this study.

- Of these three only abbreviations and acronyms were found to be used very productively in this dataset (for these see Appendices XI - XIV).

There were only two blends: Rogernome and Rogernomics, created on analogy with Reagonomics and Thatchernomics. It is noted here that while clipping is another such reductive process, no clippings were found in this corpus.

\subsubsection{The Metaphors of Economic Change}

The discovery of a large amount of figurative language in the documents of the New Zealand Treasury was described in Chapter 4. The major findings from this part of the study were that:

- 13 different metaphorical constructs were identified in the context of written text about changes occurring in national and international economies.

A coherent system of interdependent metaphors characterised by a chain of entailment relationships is expressed in this dataset by a correspondingly rich, detailed and coherent system of linguistic instantiations for these concepts. Apart from the metaphor of physical movement which is detailed below, the other 12 metaphors found were named as follows:

- MONEY IS WATER

- $\quad$ THE ECONOMY IS A BATTLEGROUND

- THE ECONOMY IS A PATIENT

- $\quad$ THE ECONOMY IS A ROADWAY

- THE ECONOMY IS A MACHINE

- $\quad$ THE ECONOMY IS SUBJECT TO HEAVY WEIGHTS AND SUDDEN SHOCKS

- THE ECONOMY IS A GAME

- THE ECONOMY IS A HORSE

- THE ECONOMY IS A BUILDING 
- THE ECONOMY IS FLAMMABLE

- $\quad$ THE ECONOMY IS EDIBLE

- EDUCATION IS A TREE

These twelve metaphors were found to be mainly nominal. In that respect they support Lakoff and Johnson's “A IS B" model where both components of the metaphor are nouns.

- The construct of physical motion was by far the most common metaphor used in contexts describing economic change.

- Unlike Lakoff and Johnson's "A IS B" model where both the topic and the vehicle are nouns, in the contexts of finance and economics, verbal metaphoricity is more common, and within this, discourse is framed primarily through the metaphor of physical motion.

In the dataset from the New Zealand Treasury 202 verbs of physical movement were found, as compared to 145 nouns, 75 adjectives and 14 adverbs all used to convey this particular metaphorical construct.

Suggested extrapolations from the above findings, evidenced in Chapter 4 above, were that:

- Metaphor is more likely to be used in discourse which treats abstract entities (and therefore makes more demands of the reader) than in contexts about concrete entities.

- Metaphors are used by writers as an aid to persuading the reader to their way of thinking and to their recommended courses of action.

\subsubsection{Post-Datings for the $O E D$}

Finding post-datings for the $O E D$ was not a primary aim of this study. However many were discovered as a by-product of the research, and these are listed in full at Appendix VI. The most significant ones are highlighted here. 
i. Nonce-word: Educatee is labelled a nonce-word in the $O E D$, where it has just two citations from 1815 and 1857. A postdating was found in this dataset by 130 years.

ii. Obsolete: The noun defeasance in the sense of discharge of an obligation and bundle (figurative use), grow in the sense of to cause to increase or enlarge, refit and scope as transitive verbs are all labelled obsolete in these parts of speech and senses in the $O E D$. However postdatings for these words in these uses were found in this dataset by $439,297,520,125$ and 185 years respectively.

iii. Archaic or rare: enable (in the sense of to empower) as a transitive verb is labelled archaic in the $O E D$. Yet an occurrence of this word used in this way was found in this dataset. Five words are labelled rare in the $O E D$ for which citations were found in this dataset, including one by 123 years - see Appendix VI for details.

iv. Single source: In the $O E D$ distortive has only two citations from a single source, and the adjective lagged has a single citation from 1602. Postdatings for both of these were found in this dataset.

v. Three centuries or more: In this dataset three postdatings of three centuries have been found for the $O E D$, one of four centuries and one of over five centuries - see Appendix VI for a list of these and their citations.

\subsection{IMPLICATIONS FOR FURTHER RESEARCH}

\subsubsection{Data Sources}

It could be that there is some lexis distinctive to New Zealand English in the political domain during the era of public sector reform in New Zealand which is yet to be identified and catalogued because it does not appear in official government sources. This project has confined itself to an intensive study of ministerial publications written for both public and intra-government consumption, and has not considered evidence from national and local media such as newspaper and magazine political columns. Many of these articles were vociferous in their opposition to the 
government's policies. It is likely that their discourse, being one of sometimes passionate and despairing dissent, contained less of the formal lexis used by government bodies to publicise and promote their policy aims, and more of the colloquial, and perhaps derogatory, lexis used by the general public at the time to talk about what was happening. It is also likely that newspapers contain more te reo Maori than do these government documents: Macalister has estimated the te reo content of newspapers at 9:1,000 words, i.e. greater than his finding of 6-7:1000 across a mixture of oral and written sources (2010: personal communication).

So while linguistic innovation appears to be limited in formal writing, it is possible that non-official, less formal data source types closer to spoken New Zealand English might prove to be more highly productive in their use of new terms. For these reasons it is suggested that a methodical examination of "counter-culture" type publications as well as more mainstream media's regular features and columns dedicated to discussing social and cultural change, might yield more lexemes unique to New Zealand English than has this study. In the field of education, the New Zealand Education Gazette would be one publication which would be worth analysing.

Given then, that new words usually enter the language in spoken form before they appear in written sources, it would also be worthwhile in future to search a set of oral data, such as the Wellington Corpus of Spoken English. As mentioned earlier, (Chapter 1, section 1.7.4) Deverson has remarked that the content of an average, educated NZE native speaker's vocabulary which is specific to this national variety is no more than $5 \%$. By contrast the percentage found in this study of published government documents was more like $0.0075 \%$. Part of this difference is of course due to the difference between spoken and written English, but because of the very nature of official discourse, which by necessity has to be fairly neutral, bland, and "international", this document type is not recommended as a fruitful source, at least of New Zealand English, in future.

\subsubsection{Further Research Questions}

While this study has been almost a synchronic one in lexicographical terms, future diachronic projects could usefully examine both the provenance and the life 
expectancy of these and other lexemes. Whence did these NZE lexemes come into our language, and how long did each one last before becoming obsolete, as happened within this ten-year period to several of the words catalogued in this Glossary.

Lexicographical research of this nature has the potential not only to capture change in language in the context of rapid conceptual innovation, but also to shed light on parallel social change. This research study has thrown up other interesting issues which, though linked to the lexicography of these domains, has been beyond the scope of this project but might usefully be explored in future. Did the use of an exclusive new lexis disenfranchise the general public from the public sector reform (PSR) debate? Was there less opposition to PSR within government because the management jargon used made it difficult for economically illiterate bureaucrats to argue against it? (A well-established theory, discussed in recent literature). Has the use of new words for new concepts in PSR assisted its introduction and acceptance by the New Zealand public? These questions and more could be considered by sociolinguists who are interested in this episode from New Zealand's history. 
APPENDICES 


\section{APPENDIX I}

GLOSSARY OF NEW ZEALAND WORDS USED IN THE ADMINISTRATION OF THE PUBLIC SECTOR IN NEW ZEALAND, 1984 - 1994

It should be assumed that the words which follow in this glossary, being NZ-specific lexical items, are either not in the Oxford English Dictionary or not there in the same sense in which they appear here. Any exceptions to this are specified within the entry as being in the $O E D$, e.g. ironsand. Words marked with an asterisk appear in Orsman's The Dictionary of New Zealand English (1997). Words marked with a $\dagger$ appear in Deverson and Kennedy's The New Zealand Oxford Dictionary (2005). Of the 258 entries in this word-list, 87 (33\%) appear in Orsman and 106 (41\%) in Deverson and Kennedy. These are largely the same words, i.e. the two sets mostly overlap, although not always. It was still important to include these words in this glossary, so as to provide a complete record of all New Zealand lexis in this dataset. Furthermore, this data set has provided some ante- and post-datings for such words, and so amplifies our knowledge of how and when they have been used.

Finally, the reader is reminded that throughout this study, no claim has been made that the following words first appeared in NZE within the timeframe of this study, i.e. post-1984. Because the study is almost synchronic, no research could be carried out into when the following words entered the NZE lexicon - to do so would have been outside the scope of the research questions as outlined in Chapter 1. In summary then this glossary provides a full record of all the NZ-specific lexis which occurred within the dataset of this study. It consists of approximately one-third words which already appear within dictionaries of NZE, and two-thirds words which do not appear in any dictionary to date. It is in the latter sense that these approximately 150 lexemes could be termed "new" words; not necessarily in the sense of first appearing in NZE between the years of 1984 and 1994. 


\section{Abbreviations Used in Appendix I}

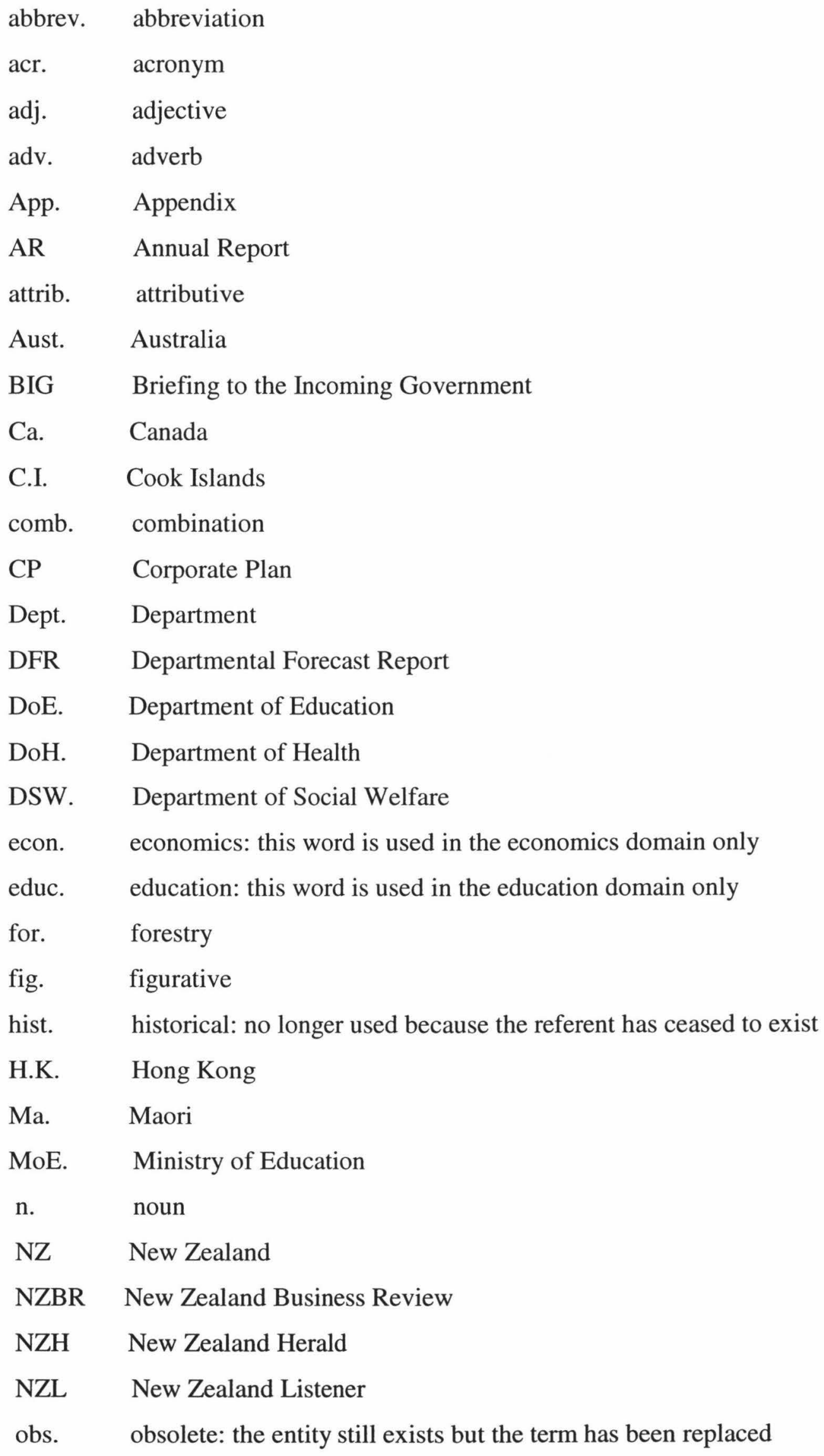


OED Oxford English Dictionary

p. past

pl. plural

ppl. participial

prep. preposition

R.1,2,3 Ringbinder Folder 1, 2 and 3 (of the DoH Briefing Papers, 1990)

Sa. Samoan

Sec. Section

sing. singular

T. Treasury

U.K. The United Kingdom

U.S. The United States

v.i. intransitive verb

v.t. transitive verb

ACC $†$ n. abbrev.

the New Zealand Accident Compensation Corporation.

1987 DoH. BIG 26 It can be affected by location...income, age, cause of illness or disability (whether covered by ACC or not). 1987 DoH. BIG 135 The ACC scheme impinges on New Zealand's health care system and Vote:Health in various ways. 1987 DoH. BIG 135 Although the ACC Board was replaced and large increases in employers' levies imposed, no substantive changes were made to the scheme, its application or the basis of its funding. 1994 T. AR Sec.5 The Treasury provided advice on the proposed annual ACC employer and earner premiums; the ACC motor vehicle levy, and the Government's ACC contribution on behalf of non-earners. Advice was also provided on the level of payment by the ACC to Vote:Health for the public health costs of accidents. A range of ACC policy matters with fiscal implications required Treasury input.

$\operatorname{ACCESS} * n$. and attrib.

the name of a programme which provides unemployed people with an entitlement to training and gives them a choice as to what form that training will take. (see also Maccess). 
n. 1990 T. $B I G 8 \mathrm{~b} 13780 \%$ of public expenditure in this area is on schemes targeted to the unemployed such as ACCESS, where the cost per person is higher than for most other training schemes. 1994 T. AR Sec.5 During the year the Treasury, in conjunction with other departments, provided advice on options for mainstreaming Mana Enterprises, vocational training, the Maori housing portfolio, Maori Access, and certain residual payments made on behalf of the Crown by the Ministry of Maori Development. attrib. 1987 DSW. BIG 21 This direction is being explored in other areas of government activity e.g. the Labour Department is performing a similar brokerage role in providing training through the ACCESS schemes - decision making and resource allocation is now made at the local level through Regional Employment ACCESS Committees and Maori ACCESS ... 1987 T. BIG II.1 9 A recent move that breaks away from the dominant pattern of state provision is Access training. 1988 DoE. AR 22 The major finding of the health research report was that the poor health of Access trainees inhibited their readiness for work.

accredit $* \dagger$ v.t.

to formally credit a high-school leaver, based on the year's work, with the equivalent of a pass in the university entrance test.

1987 T. BIG II.5 135 Until 1987 most successful candidates were accredited by their schools and the remainder sat an external examination conducted by the University Entrance Board.

\section{activity centre $n$.}

an institution for a maximum of 20 teenagers and a minimum of two full-time teachers, used as a last resort to admit disruptive youth who have been suspended and are subsequently unable to return to an ordinary secondary school.

1984 DoE. BIG Sec.2.3 An activity centre generally has the characteristics of a minischool. 1986 DoE. AR 55 Six additional activity centres are to be set up in Invercargill, Gisborne, Wellington, New Plymouth, Rotorua and Porirua; $1990 \mathrm{MoE}$. AR 15 A deadline of 1 November 1990 and 30 December 1990 was originally set for the Review of Education Regulations and the Review of Activity Centres respectively but these have been delayed as a result of a revised review work programme.

aiga $\dagger n$. 
[Sa.] (extended) family.

1989 MoE. AR 27 The department advertised that whanau / aiga support persons would be welcome at interviews, and a procedure was established for appointment letters to open and close with Maori phrases.

ANZCERTA $n$. acr.

Australia and New Zealand Closer Economic Relations Trade Agreement. (also Aust.) 1987 T. BIG I.4 197 For example the response to trade liberalisation under closer economic relations with Australia (ANZCERTA) has been very positive, in contrast to the predictions of many commentators at the time of its introduction. 1987 T. BIG I.4 246 The widening of the free trade agreement with Australia (ANZCERTA) ... The ANZCERTA agreement was signed in March 1983.

Aotearoa $* \dagger n$.

[Ma] New Zealand.

$1994 \mathrm{MoE}$. AR 9 The first ever report on the performance of our schools New Zealand Schools 1993 / Nga Kura o Aotearoa was also published in June, and will be an annual event from now on.

area school $* \dagger n$.

a rural state school providing both primary and secondary education.

1984 DoE. BIG Sec.2.123 An area school catering for approximately 161 Primer 1 to Form 7 pupils may be required in the long term. 1985 DoE. AR 43 The programme of upgrading accommodation at area schools has virtually ended and the opening in February 1985 of the new area school at Whangamata brings to 35 the number of such schools catering for the educational needs of the more isolated rural areas. $1990 \mathrm{MoE}$. $B I G 166$ Area schools provide education from new entrant to form 7 and receive pupils from form 1 from contributing primary schools in the wider district.

aroha $* \dagger n$.

[Ma.] compassion, fellow feeling, warmth, love.

1991 MoE. AR 89 Mihimihi, karakia, manaaki, atawhai, aroha (cultural support) on behalf of, and within, the Ministry of Education. 
associate teacher $* n$. and attrib.

an experienced teacher who supervises trainee teachers' teaching practice in his or her classroom.

1988 DoE. AR 5 An associate teacher allowance is now paid for childcare staff supervising trainees on practical assignments as part of pre-service training.

ASTU n. acr. and attrib.

Advanced Studies for Teachers Unit, a division of the Department of Education.

1984 DoE. AR 23 The teaching staff includes 14 ASTU tutors, 13 pre-school, 75 primary, and 295 secondary teachers, and the administrative staff 73 [sic].

\section{atawhai $n$.}

[Ma.] care, fostering, nurture.

1989 MoE. AR 89 Mihimihi, karakia, manaaki, atawhai, aroha (cultural support) on behalf of, and within, the Ministry of Education.

attached intermediate $n$. (hist.)

co-educational classes for 11 and 12 year-old children (in their $7^{\text {th }}$ and $8^{\text {th }}$ years of schooling), which were attached to a single-sex, private, secondary school at the time of its integration into the state system.

1985 DoE. AR 50 In 1984, 21 were attached intermediates. 1985 DoE. AR 51 Includes ordinary and special classes at full and contributing schools, intermediate, attached intermediates and area schools. 1989 MoE. $A R 41$ Includes teachers at full and contributing primary schools, intermediates, board special schools, attached intermediates, teachers of special classes, special needs teachers, and primary teachers at Correspondence School.

\section{basic scale teacher $n$.}

a teacher in the early years of his/her career, who has no management responsibilities and who is on the first rung of the salary scale.

1985 DoE. AR 9 The phased implementation of staffing improvements for kindergartens continued with the approval of a further 10 basic scale teacher equivalents from 1 February 1985. 
Before Five $n$. and attrib.

educ. the name of a policy statement launched in March 1989 which involved farreaching reform of the administration of education and set out the Government's recommendations for pre-school education in New Zealand.

n. 1989 DoE. CP 7 Separate bills will be required to implement the proposals contained in 'Before Five' and 'Learning for Life'. 1990 T. AR 37 Provide advice to support the implementation of Tomorrow's Schools, Before Five and Learning for Life. 1990 MoE. AR 6 The introduction of Before Five, Tomorrow's Schools and Learning for Life has produced a change process of considerable breadth and depth. attrib. 1989 C DoE. AR 8 As part of its Before Five early childhood care and education reforms, Government has made a commitment to progressively increase funding to kindergarten associations over five years.

\section{blocks away spraying $n$.}

a method of disinfecting the interior of an aircraft (normally bound for New Zealand or Australia) with a pesticide either while airborne or immediately prior to departure once the aircraft is in motion on the runway.

1984 DoH. $A R 18$ In liaison with Ministry of Agriculture and Fisheries staff, departmental staff assisted with the training of airline cabin staff so that "blocks away" spraying (spraying of the aircraft before departure for New Zealand) could be extended.

Blue Book $n$. attrib.

educ. a set of policy guidelines published by the Department of Education.

1987 DoE. BIG 118 Review of 'Blue Book' Procedures - Organisation of Education from F1 Upwards in Rural Areas 1987 DoE. BIG 141 The original 'Blue Book' procedures were introduced in 1972 to cover the translation of the then district high schools to area schools or form $1-7$ schools.

\section{Budget night legislation $n$.}

laws to be passed the day the Budget is introduced.

1989b DoH. AR 17 Budget night legislation was introduced giving the Crown power to import medicines. 


\section{Budget Secret adj.}

which cannot be released and must be kept confidential until after the budget is announced as it contains material (often new initiatives) related to the budget.

1991 T. $A R 30$ Many papers, preparatory to publication, are designated "Budget Secret" and have a restricted circulation.

\section{buff report $n$.}

this appears to have been a one-off term coined probably on the basis of the colour of paper on which it was printed, to refer to a particular government document which was published in October 1986.

1987 T. BIG I.2 65 Recently, a number of the proposals set out in the Minister of State Services' October 1986 'buff report' came into effect - 'ranges of rates', performance pay, the facility for enterprise unit bargaining, and the assignment of dispute resolution and arbitration to the private sector arbitral institutions. $1987 \mathrm{~T}$. $B I G$ I.2 94 Implementation of remaining buff report proposals on pay fixing, ... 1987 DoE. BIG 124 A report commonly known as the "Buff Report" was issued in October 1986 and outlined the development of a new philosophy and structure in state pay fixing.

\section{bulk fund v.t.}

of the government, to allot an annual lump sum to an educational institution, out of which it must meet its expenses.

1992 MoE. AR 18 Although universities have been bulk funded for many years, polytechnics, and colleges of education have, since 1990, been bulk funded along with universities through a coherent system based on equivalent full-time student (EFTS) numbers. 1993 DoH. BIG 22 The government now funds purchasers to buy health and disability support services directly, rather than subsidising some individual entitlements and bulk funding some services, as it did in the past.

\section{bulk funding $* \dagger n$. and attrib.}

a system of funding teachers' salaries from a lump sum given to each school, used by extension to domains other than education.

n. 1990 MoE. BIG App.2:16 There is a policy commitment to introduce bulk funding of teachers' salaries by 1992 and legislative provision has been made. 1990 MoE. BIG 
202 Early childhood institutions now receive bulk funding for operational expenses based on actual attendance. $1991 \mathrm{MoE}$. CP 15 A sample of schools opting-in to bulk funding will be selected for a planned evaluation of the scheme. attrib. 1997 Easton 207 The bulk funding alternative was to have the school receive a lump sum, out of which it would pay teacher salaries and other expenses.

\section{carried underexpenditure $n$.}

an unspent amount of a budget which is carried over into the next financial year.

1985 DoH. AR 41 The ability of boards to use carried underexpenditure on items of non-recurring costs resulted in less demand for scarce capital resources and in reductions in operating expenditure due to appropriate purchases of equipment and materials.

CCMAU $\dagger$ n. abbrev.

the Crown Company Monitoring Advisory Unit.

1993 T. AR 56 During the year the Government decided that the SOE Unit would become part of the new Crown Company Monitoring Advisory Unit which was established on 1 July 1993. 1994 T. AR Sec.3 The Crown Company Monitoring Advisory Unit (CCMAU) was established on 1 July 1993 from the State-Owned Enterprises Advisory Unit and the Crown Research Institutes Steering Committee. 1994 T. $A R$ Sec.5 The Treasury worked throughout the year with the Crown Company Monitoring Advisory Unit on resolving issues arising from the establishment of Crown Health Enterprises (CHEs).

CER † n. abbrev.

Closer Economic Relations. (also Aust.)

1984 T. BIG II.10 85 It should be noted that CER will have an effect on the domestic tobacco industry and is making restructuring inevitable. 1987 T. BIG I.6 361 The gradual removal of import licensing and the continuation of liberalisation signalled in industry plans - and under CER has prompted some adjustment through rationalisation of production and a shift to importing some product lines. 1994 T. $A R$ Sec.5 The Treasury also worked with the Ministry of Transport on CER border issues such as passenger facilitation, pre-clearance options and cabotage. 
charter v.i. (hist.)

to sign an agreement with the Ministry of Education that the Ministry would fund an Early Childhood Education service, if that service was licensed by the MoE. The licensing and compliance with the government regulations ensured that services met regulatory requirements.

1990 MoE. BIG App. I:4 However, during the transitional period kindergartens, playcentres, family daycare schemes as well as childcare centres licensed under the Childcare Centre Regulations 1985 have received bulk grant funding on the basis of an application of intent to charter. 1990 MoE. BIG App. I:7 The implementation of the bulk grant fund to all early childhood services which have indicated an intent to charter is well in hand and a system of payment is up and running. $1990 \mathrm{MoE}$. BIG App. I:7 Early childhood services which have indicated an intention to become chartered, have until March 11991 to negotiate their charters with the Ministry of Education.

\section{CHE / Che $* \dagger n . /$ acr.}

a Crown Health Enterprise.

1993 T. AR 72 Twenty-three CHEs were established as planned on 1 July 1993. 1993 DoH. BIG 6 Improving the structures for Crown-owned providers (CHEs), including giving them clear goals. 1994 T. AR Sec.5 In particular, advice was provided on the adjustment pressures being faced by the Regional Health Authorities and the Crown Health Enterprises and strategies for managing these pressures.

\section{CHIFS n. acr.}

the Community Health Initiatives Funding Scheme, established in 1985, to encourage self-help and community development approaches.

$1985 \mathrm{DoH}$. AR 6 The recommendation for more flexible funding to support marae and community-based health initiatives encouraged the Department of Health to set up the Community Health Initiatives Funding Scheme (CHIFS). 1987 DoH. BIG 121 The original CHIFS proposal envisaged an increase in the fund annually from $\$ 100,000$ in year one to $\$ 300,000$ in year three. In the second year of operation the 230 CHIFS applications totalled over one and a quarter million dollars. Approval has been given for the CHIFS Programme Committee to increase its representation of people who have experience of community development and self help activities. The main reason 
for declining applications in both 1985/86 and 1986/87 was that the applications were for services which are explicitly excluded in CHIFS criteria. 1989a DoH. AR 54 This reflects the nature of CHIFS as a small-scale scheme for small community groups and projects.

\section{Children's Board $n$.}

a group of skilled persons with non-mandatory powers, in an informal setting, available to assist children and their families to overcome personal and social difficulties.

1984 DSW. BIG 38 The Children and Young Persons Act 1974 provided for the establishment of Children's Boards throughout New Zealand. The purpose of the Boards is to ensure as far as possible that children, namely those under 14, who offend are dealt with outside the Court. 1987 DSW. BIG 123 Children's Boards are an alternative to the Children and Young Persons Court. The Children's Boards are targeted to serve children aged $0-13$ years and their families. Children's Boards are established in each Social Welfare District.

\section{children's health camp $n$.}

residential facilities for malnourished children, supported by the proceeds from a surcharge on special postage stamps. cf Children's Health Camps Act 1972; Children's Health Camps Board Dissolution Act 1999.

$1984 \mathrm{DoH}$. BIG 4 ...assistance and seeding funding to outside organisations (e.g. plunket, children's health camps). $1985 \mathrm{DoH}$. AR 20 The committee appointed in late 1983 to consider how the resources of the children's health camp movement might best be used to improve child health continued with its task. $1987 \mathrm{DoH}$. BIG 72 - the Children's Health Camps Board: to operate 7 health camps which provide short term residential care for children aged 5-12 years who are physically, emotionally or socially disadvantaged; 1990 DoH. BIG R.3.27.App.I.7 There should be no adjustment to the funding formula for health camps.

\section{Christmas Reading $n$.}

a NZ Treasury document reviewing macroeconomic policy settings, presented in December to the Minister of Finance. 
1984a T. BIG 2:2 126 These are currently formally reviewed about twice a year once in the development of the budget strategy and again in a review of policy which Treasury has sometimes seen as useful to present for consideration by the Minister of Finance during the parliamentary recess (known colloquially as the Christmas Reading).

code $n$. and attrib. Beyond Code, code-sized, non-code

educ. a term used with reference to the (School) Accommodation Code 1970, which set out the minimum building facilities, calculated in square metres, required for a school, and to which a school is entitled. Beyond code was the space over and above the "Code" - this occurred in schools with falling rolls. (also Aust.)

attrib. 1984 DoE. BIG Sec.2.24 This compares to an assessed total value of "code" buildings of $\$ 3500$ million [sic]. 1984 DoE. AR 46 The programme of upgrading accommodation at area schools has virtually ended with the letting of contracts at Panguru and Whangamata for the bulk of the code facilities. 1985 DoE. AR 45 The department has for many years made finance available to schools through subsidy schemes for non-code facilities such as swimming pools and assembly halls in primary schools. 1985 DoE. AR 44 Grant-in-Aid Scheme for Beyond Code Facilities 1987 DoE. BIG 137 Until now available funding has been largely taken up with bringing existing schools up to code standards. code-sized adj. 1984 DoE. BIG Sec.2.23 No responsibility is accepted for extensions to code-sized gymnasiums.

\section{commissioner $n$.}

educ. a Ministry of Education employee on a temporary posting to manage a school experiencing difficulties.

1989 DoE. $A R 5$ No school received such an insufficient response from parents that a commissioner was required to be appointed to run the school. $1990 \mathrm{MoE}$. AR 41 One commissioner has been appointed to Mangakino Primary School. 1993 MoE. AR 9 They do a remarkable job and most boards of trustees continued to govern schools well with only five commissioners appointed in the year and 13 since 1989.

\section{community services card $\dagger n$.}

a card held by low to middle income earners entitling them to reduced charges for some medical services. 
$1993 \mathrm{DoH}$. BIG 28 Since the introduction of the interim targeting regime for user charges, doctor visits have increased for adults and children in families with community services cards and reduced for children in families without cards. 1993 DoH. AR 23 The Department provided ongoing advice on issues related to eligibility for the Community Services Card and the High Use Health Card and recommended amendments to the relevant regulations. 1994 DSW. AR 32 Output Class: Assessment for the Community Services Card

\section{composite $\operatorname{school} n$.}

usually located in a rural area, a school which provides primary, intermediate and secondary education at the same location. Not all composite schools are area schools. (also Aust.)

Note that this term is also used in Britain and Canada but with a different referent there it denotes a usually large school for children of mixed abilities which provides both an academic and a vocational curriculum.

1984 DoE. BIG Sec.1.12 Education boards also control composite schools and appoint teachers to the schools under their control. 1984 DoE. BIG Sec.4.2 The setting up of a staffing protection scheme requires amendment of the Composite School Regulations because of the existence in the regulations of a procedure for termination (last on- first off) held by all parties not to be in the best interests of the schools nor of their pupils. 1984 DoE. BIG Sec.4.50 Composite School Regulations Amendments.

\section{contestability $* n$.}

the quality of being able to be competed for. (also Aust.)

1987 T. BIG I.2 63 Limited tenure on the other hand can impose strong incentives to perform and achieve results within a certain period by the increased contestability of the position of departmental head. $1992 \mathrm{MoE} . A R 7$; the introduction of contestability to the Early Childhood Development Unit's activities; 1993 DoH. BIG 24 Contestability should also encourage a wider range of providers.

contestable $\dagger$ adj.

able to be competed for, open to competition. (also Aust.) 
1987 T. BIG I.2 76 The Government requires access to high quality advice on all aspects of its policy; that advice should be contestable both internally and externally that is, the Government should have access to the views of professional experts outside the public sector, and to competing views within it on all areas of government activity. $1991 \mathrm{MoE}$. AR 66 Applications for the contestable equity funds were sought from the 37 tertiary institutions for the 1991 academic year. 1993 DoH. BIG 34 RHAs anticipate these services would progressively become contestable over a period of about three years - with the objective of improving the quality, quantity and price of services.

\section{contributing school $* n$.}

a primary school for the first six years, after which it "contributes" its pupils to an intermediate or secondary school, as opposed to a "full primary" school which retains its 11 and 12 year old pupils for another two years.

1984 DoE. BIG Sec.2.1 The present schedule of accommodation for primary schools does not differentiate between contributing and non-contributing schools. $1990 \mathrm{MoE}$. $A R \quad 41$ Five applications have received Ministerial approval to provide form 1 education in a contributing school for bilingual reasons as per Section 150 (4) of the Education Amendment Act 1989. 1991b MoE. AR 11 Schools may now apply directly to the Minister of Education for approval to cease to be a contributing school.

\section{control agency $n$.}

the Treasury, the State Services Commission, or the Department of the Prime Minister and Cabinet.

1987 T. BIG I:2 73 As well as these sectorally oriented departments there are a number of others - Treasury and the SSC, commonly designated as 'control agencies', and the Audit office, which occupies a constitutionally distinct role reporting to Parliament... 1987 T. BIG I:2 73 The role of the control agencies is discussed in a later section. 1987 T. BIG I:2 93 The greater the reform the smaller is the role for central control agencies.

\section{Correspondence School *† $n$. and attrib.}

a Wellington-based, government-funded school which sends lessons by mail to those unable to attend a regular school. Originally for children, especially of primary age, 
living in remote parts of New Zealand, but now also for adult prisoners, and for secondary students whose school does not offer a subject they wish to study.

n. 1988 DoE. $A R 12$ The Correspondence School purchased two INVICON teacher operated video booths so that teachers can make short individualised video tapes to illustrate teaching points to students. attrib. 1988 DoE. AR 12 The Government approved a new policy to provide financial assistance to parents supervising full time

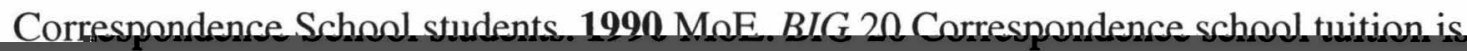
available for children tutored at home and where the school is unable to provide a teacher in a particular subject area.

country service $* \dagger n$. and attrib. (hist.)

a compulsory period of time spent teaching in a rural school.

1990 MoE. BIG 163 There was a country service bar on the basic salary scale. A teacher needed to obtain a country service position to advance beyond this step. There was provision for a paid household shift to a country service teaching position and back to an urban one on the same salary scale.

crown agency $n$. and attrib.

a generic term used to describe a range of public sector organisations such as the ACC, Transit NZ and tertiary institutions, which are neither departments, SOEs nor local authorities.

n. 1989 MoE. AR 21 Negotiation and Monitoring of Contracts with Crown Agencies 1990 T. AR 66 ...having a detailed knowledge of the Public Finance Act and the various financial performances incentive regimes established for Crown agencies as a part of the reforms... 1990 DSW. AR 73 The Board must regard its new status as a Crown Agency as providing it with a challenge to provide the country's amputees with a service of even higher standard... 1992 DoE. AR 90 The recommendation, following the Maori Education Foundation Review in 1991, to establish the Foundation as a Crown agency is to be included in the 1993 legislative programme. attrib. 1990 T. BIG 792 There are potentially significant gains from clarifying accountabilities in the Crown agency sector.

crown entity $\dagger n$. 
a generic term for five different types of entity legally separate from the Crown, namely statutory entities, Crown entity companies (see Crown-owned company), Crown entity subsidiaries, school boards of trustees, and tertiary education institutions. (also Ca.)

1993 T. AR 71 The most significant part of the 1992 Bill was the inclusion of a large number of bodies as Crown entities in schedules to the Public Finance Act. 1993 MoE. AR From 1 July 1993 the Learning Media Group of the Ministry will become a crown entity. $1993 \mathrm{MoE}$. CP 38 Advice will be given to the Minister on the quarterly reports of service performance provided by Crown entities within 21 days of receipt of the report from each Crown entity.

\section{Crown-owned company / CROC n. / acr.}

an unofficial term for a certain type of crown entity, incorporated under the Companies Act 1993. (also Ca.)

1994 MoE. AR 16 The Learning Media Group was established as a Crown owned company from 1 July 1993 and all the assets and liabilities have been transferred to the Crown at net book value. 1995 Chen in Boston (ed.) 112 They have not liked the profit-making orientation of Crown-owed companies (CROCs) in general, and stateowned enterprises (SOEs) in particular, which were created to perform previous state trading functions. 2001 T. AR 74 ...monitoring and advising ministers about SOE and CROC performance against these objectives and targets.

\section{Crown Receivable $n$.}

money available to the government. (also C.I. and Ca.)

1993 DSW. AR 95 Crown Receivable represents revenue available to be drawn down from the Crown.

\section{Crown Research Institute / CRI $n$. / abbrev.}

a government-owned research facility.

1993 T. AR 71 In conjunction with the Crown Research Institutes' Implementation Steering Committee, the Treasury assisted in resolving implementation issues associated with the establishment of the 10 Crown Research Institutes (CRIs). 1994 T. $A R$ Sec.5 The Unit, in conjunction with the Treasury, advised Ministers on the strategic and financial implications of draft Business Plans and Statements of 
Corporate Intent for CRIs, and on the performance of CRIs in regular monitoring reports. Share-holding Ministers used this advice in their discussions with CRI boards on their strategic approach to the business.

customary rights $\dagger n . p l$.

usually used in a Maori context, the traditional rights to fish in certain areas etc, as opposed to legal rights.

1987 T. BIG I.5 322 There is also the possibility that, regardless of the Treaty, Maori customary title and rights may be able to be recognised in common law. The Court of Appeal has yet to give a ruling on these possibilities but they indicate the extent to which orthodox approaches to the legal relevance of the Treaty and Maori customary rights are coming under question.

\section{Debtor Crown $n$.}

money payable by the government.

1991 DSW. AR 39 Debtor Crown represents undrawn revenue and capital appropriations receivable from the Crown.

\section{decapitation $n$.}

educ. the removal of Forms 1 and 2 classes from a full primary school. (See recapitation).

1984 DoE. BIG Sec.3.54 A similar situation could eventuate in the Western Suburbs with a drop in Wellington secondary school rolls and a decapitation of the full primary schools in Karori/Wilton/Kelburn.

\section{designated character school $n$.}

educ. a legal term for a state school with a special character established under section 156 of the Education Act 1989, which teaches the New Zealand curriculum but is recognisably different in its aims, purposes and values from an ordinary state school. For example, a Maori immersion school whose character is based on delivering te reo medium education in accordance with local custom, tikanga and history. A group of parents with 20 or more children may make an application to have such a school recognised. 
1990 MoE. BIG 46 The Ministry will review Kura Kaupapa Maori and Designated Character Schools to examine the speed of expansion of these choices. $1990 \mathrm{MoE}$. $A R$ 41 Two convenors have been appointed for forums for designated character schools. 1991 MoE. AR 70 Nineteen community forums were approved covering the establishments of Kura Kaupapa Maori, designated character schools, school closure and recapitation.

\section{district high school $* \dagger n$. (obs.)}

originally a term for a rural primary school with some secondary courses added, subsequently a term used for a rural high school.

1984 DoE. BIG 6 The Department of Education is at the centre of the administrative pattern of the education service, with education boards and school committees looking after the local interests of primary, intermediate, and district high schools, and boards of governors, boards of managers, and secondary school councils administering secondary schools, and councils administering teachers colleges and boards administering community colleges and technical institutes.

\section{Division A / Division B / Division C / Division K $n$. and attrib.}

intake "divisions" or classes of teacher training. Division K trained kaiarahi reo teachers.

1984 DoE. BIG Sec.4.53 Review of Division C Training. 1987 T. BIG II:5 138 To become secondary teachers, individuals must be selected for enrolment in a secondary teachers training course. These are divided into division B and division C. Division B training provides for trainees to undertake two years of professional studies at teachers' college and study at a university or technical institute towards an approved subject qualification. Division C training provides a one year full-time course for university graduates, or those with other acceptable qualifications. 1988 DoE. AR 8 Forty Te Atakura Maori language specialists graduated from a one-year Division C secondary teacher training programme in Whangarei, Auckland, Palmerston North and Christchurch at the end of 1987. 1989 MoE. AR 45 Division A, Speech and Pacific Island Supplementary Training students and exchange teachers. 1989 DoE. $A R$ 8 A two year equivalent full-time off campus field based programme known as Division ' $\mathrm{K}$ ' will be provided by three teachers' colleges, and involve correspondence units, local seminars, school based training projects and block courses. 


\section{Domestic Purposes Benefit / DPB *†n. / abbrev.}

1. a financial benefit paid in regular instalments by the government to unemployed solo parents. 2. the recipients of such a benefit.

1. 1984 DSW. AR 22 Domestic purposes benefits current prior to 1 April 1983 continue to be paid under the earlier provisions which required maintenance paid by the husband, or wife, or the father or mother of the children to be diverted to the department. 1987 T. BIG II:3 61 The state's regulatory involvement is minimal, but it plays a major funding role through the Domestic Purposes Benefit for solo parents not in paid employment. 1988 DSW. AR 55 DPB sections, where identified have 610 staff, including wage workers. 1990 DSW. AR 43 The rise in liable parent numbers reflects the growth in the number of DPB clients. 1990 DSW. Key Issues for SW 27 ....as Figure 16 shows more than 80 percent of DPB spending goes to households in groups one, two and three. 1990 DSW. Key Issues for SW 30 A dollar taken from DPBs would create more hardship than a dollar taken from other benefits. 2. 1991 DSW. AR 68 The number of Liable Parents of current DPBs. 1997 NZL 26.0737 Similarly, the Quarterly Review of Benefit trends indicates that $73 \%$ of DPBs have been on it for less than five years.

\section{draft ministerial $n$.}

a reply to a letter sent to a Minister, drafted by the Minister's department and sent across to the Minister to consider. (also Aust.)

1992 DSW. AR 31 - 100 draft ministerials completed (target 130) ... In 1992, draft

ministerials were generally more complex which contributed to the lower than average expected timeliness performance. 1993 DSW. AR 75 The percentage of Draft Ministerial Replies delivered within 20 working days.

\section{Dutch class teacher $n$.}

educ. a teacher working in a team and sharing a class.

1985 DoE. AR 49 Includes advisers, psychologists, speech and reading teachers, and teachers not employed under staffing schedules such as visiting teachers, itinerant teachers, museum and zoo teachers, REAP teachers, pool relief teachers, physiotherapists, Dutch class teachers, occupational therapists, refugee centre teachers, community centre teachers. 
EDRU n. abbrev.

the Electricity Distribution Reform Unit.

1991 T. AR 58 The Electricity Distribution Reform Unit (EDRU) and the Trans Power Establishment Board (TPEB) were established early in the 1990/91 financial year to implement the (then) Government's policies for reform of the electricity industry. 1992 T. AR 92 The EDRU continued to facilitate and co-ordinate the reforms in the electricity distribution industry in addition to a number of other tasks for the Crown.

EFTS $n$. acr. and attrib.

equivalent full-time students. (also Aust. and Fiji).

n. 1992 MoE. AR 12 An 8.5\% increase in funded EFTS is expected to result in an extra 9,765 EFTS places for 1992. $1993 \mathrm{MoE}$. AR 48 Negotiation for the allocation of approximately 127,000 EFTS to be completed within 90 days. attrib. 1990 MoE. BIG App.3:3 The EFTS unit is thus able to provide a standard counting unit across all tertiary providers. 1991 MoE. AR 66 The Equivalent Full Time Student (EFTS) funding formula was introduced on 1 January 1991. The funding of all tertiary institutions was calculated on the EFTs formula, and in accordance with approved government policy. 1991 MoE. CP 32 EFTS Negotiations - the negotiation with tertiary institutions of the number of equivalent full time student places for which they will receive funding in the financial year. 1992 MoE. $A R 18$ Tertiary institutions negotiate in advance, on a rolling triennium, their projected EFTS numbers with the Ministry.

EMDTI / EPTI n. abbrev.

the Export Market Development Taxation Incentive / the Export Performance Taxation Incentive.

1987 T. BIG I:4 247 For non-traditional exporters, the Export Performance Taxation Incentive (EPTI) phased out this year, and the Export Market Development Taxation Incentive (EMDTI) will phase out in 1990.

ESA $n$. abbrev.

an electricity supply authority.

1990 T. AR 32 Provide advice on restructuring and regulatory reform and possible privatisation of the electricity industry including Electricity Supply Authorities 
(ESAs). 1992 NZBR 11 Whilst it may be argued that this is justified given the current regulatory framework in the electricity industry, it denies consumers the price reductions that can be achieved should the corporation apply similar cost-saving measures to ESAs to those which it has itself implemented.

Family Group Conference / FGC $\uparrow n$. / abbrev. and attrib.

a formal meeting, sometimes court-ordered, in care and protection cases, for members of a family group to discuss with social workers a future care-plan for a child or young person. Designed to divert young offenders from the formal judicial system. Initially developed out of Maori community traditions of resolving family problems; since adopted by the UK and Canada, and awarded an international prize by the American Humane Society in 2007.

n. 1990 DSW. Key Issues for $S W 68$ The new Act requires that a Family Group Conference be held if a care agreement between an agency and parents is to be longer than 28 days. 1991 DSW. CP 36 The Department will provide Youth Justice Family Group Conferences at or below the unit cost of $\$ 1,010$. 1994 DSW. CP 267,500 FGCs held (including additional FGCs for the same child or young person) attrib. 1994 DSW. AR 12 All ongoing FGC plans must be reviewed.

Family Home $n$. and attrib.

a large house in a normal community, generally purpose-built, for approximately six children in the care of the Department of Social Welfare and staffed by selected foster parents who live there rent-free, receive board payments and have exclusive use of 2 bedrooms for themselves.

n. 1984 DSW. BIG 40 For example, children and young persons requiring shelter care (i.e. those who are in need of care and protection, rather than those who have offended or who have behavioural problems) are placed in foster care or Family Homes and kept out of institutions whenever possible. 1988 DSW. AR 46 Over $50 \%$ of children in departmental care are in the care of foster families in private foster homes or in one of the 164 departmental Family homes. 1990 DSW. An Inventory of the Dept... 14 In support of its social work services, the Department also has a number of family homes located around the country. attrib. 1985 DSW. AR 40 The former client group of Reception Centres is now most adequately catered for within the family home programme. 


\section{Family Support $\dagger n$.}

a financial benefit paid by the I.R.D. to low income families.

1987 T. BIG I:2 81 The Family Tax Rebate is an example of a previous tax expenditure which has since been replaced by Family Support and shown as direct expenditure; 1987 T. BIG I:2 289 Family Support and the Guaranteed Minimum Family Income already provide income support for low wage earners with dependants. 1987 T. BIG 293 Family Support was introduced to assist families on lower incomes;

\section{first-contact processing $n$.}

a system used by the DSW for the processing of benefit applications.

1993 DSW. AR 6 'First-contact' processing is now occurring in most district offices, resulting not only in efficiencies but also in greater customer satisfaction and confidence in the administration of their benefit. 1994 DSW. AR 45 The overachievement of the timelines standard reflects the significant improvements in benefit processing times achieved as a result of improved work practices, including first contact processing, multiskilling and best practice initiatives.

\section{fiscal envelope ${ }^{* \dagger} n$}

a government strategy announced in December 1994 "to secure a full and final settlement of Treaty grievances" by Maori tribes against the Crown, whereby a sum of $\$ 1$ billion gross over a decade was set aside to be used for cash payouts or to buy land and resources back from the state.

1995 Kelsey \& O'Brien 11 The government claims the fiscal envelope will resolve all outstanding grievances in a durable, but fiscally responsible, way.

\section{fono $n$.}

[Sa.] in the languages of Samoa, Niue and Tokelau, a meeting. A term with meaning similar to the Maori hui.

1989a DoH. $A R 95$ - fono for Pacific Island women; $1993 \mathrm{MoE}$. AR 24 Major initiatives included a national fono and a stress management programme. $1994 \mathrm{MoE}$. $A R 101$ - a national Fono for Pacific Island staff.

Free Kindergarten Association $\dagger n$. (obs.) 
a body (now named the New Zealand Association of Kindergartens) offering morning and afternoon sessional pre-school education for children aged $3-5$, licensed and funded by the New Zealand government.

1984 DoE. BIG 30 There are 52 free kindergarten associations composed of persons interested in the movement, and in July 1983 these controlled 539 recognised kindergartens attended by 40,895 children. 1984 DoE. BIG 30 The New Zealand Free Kindergarten Union Incorporated is the national body, elected by the associations, and recognised by the Minister as representing all associations in the discussion of all matters relating to kindergarten policy. 1984 DoE. BIG 30 The associations establish and maintain recognised free kindergartens, which have professionally trained staff.

\section{funder/provider split $n$.}

a guiding principle, instituted by the 1988 State Sector Act and used by government in its restructuring of public service departments, thereby separating the funding arm from the service-providing arm of an organisation. (also Aust.)

1994 Political Science 46.2220 Its report advocated the fashionable separation of funding and provision, with the providers (i.e. hospitals) run on business lines. 1997 NZL. 26.0737 As it is, we are told that: welfare damages people, welfare provides incentives to have children, welfare should be privatised, a funder/provider split in welfare is advisable, welfare is not a government but a community responsibility, the state has little role in providing solutions and so on.

gazette $v . t$.

to place an entry about in the New Zealand Gazette.

$1990 \mathrm{MoE}$. BIG 76 If the requirements of the Act are met and the private provider is gazetted, then Government will fund the institution and this will be in addition to the financial support which the institution's students attract.

\section{General Medical Services benefit / GMS n. / abbrev.}

a benefit paid by the government to low income families to assist with doctors' fees.

$1984 \mathrm{DoH}$. BIG 4 One major form of Government assistance in the primary medical field which has been the subject of public debate over the past year has been the General Medical Services benefit. 1987 DoH. BIG 41 The introduction of a new scale of child GMS benefits in September 1985 had an impact on benefit payments in that 
year and more so in 1986/87 when the new benefits were payable for a full year. 1987 DoH. BIG 66 The capitation fees are higher than annual average GMS per patient to assist with this... 1989 DoH. BIG 2 The General Medical Services benefit (GMS) has been increased with effect from 1 January 1989, and prescription charges have been increased with effect from 1 February.

\section{gift duty $* \dagger n$.}

a tax payable on gifts of money and property over a certain value.

1984 T. BIG I.4.78 Other direct taxation receipts (land tax and estate and gift duty) are forecast to remain static. 1984 T. BIG II.10.218 The only wealth-based taxes imposed in New Zealand are land tax and estate and gift duties.

\section{Guaranteed Minimum Family Income / GMFI $n$. / abbrev.}

a DSW scheme which tops up the income of families in paid work to ensure that they receive more than they would if they were totally reliant on the benefit system.

1987 T. BIG I:4 304 The dispersion of EMTRs was reduced significantly for market income earners (leaving aside the guaranteed minimum family income (GMFI) scheme, which affects only a small number of families). 1987 T. BIG I:4 304 On the other hand, it can be argued...that Family Support and GMFI, to the extent that they are delivered through the tax system, continue to confuse the appropriate tax unit and impose higher administrative and compliance costs; ... 1990 DSW. Key Issues for SW 44 The present GMFI will continue but be administered by Social Welfare rather than IRD.

\section{Guaranteed Retirement Income $n$.}

a DSW scheme to provide income support for the elderly.

1990 T. AR 76 In particular, work was undertaken on land tax, fuel excises, resident interest and dividend withholding taxes, alcohol and tobacco excises, the funding of Guaranteed Retirement Income, and the timing of PAYE payments. 1991 T. AR 48 Analysis and advice was provided to the Government, in conjunction with the Department of Social Welfare, on options available for the reform of GRI and then for the administration of the reformed scheme.

\section{half-pie $* \dagger$ adj.}


half one thing and half another; a blend.

1992 James 161 The National Government is attempting to drive the model further into private sector practices, creating half-pie state-owned enterprises (with a social as well as a commercial objective) out of the area health boards to run hospitals...

hapu $* \dagger n$.

[Ma.] a Maori sub-tribe. (The Puao-te-Ata-tu report restricts this denotation to those descended from a common ancestor).

1986 DSW. AR 9 Indeed, efforts by Maori people to strengthen iwi, hapu and whanau ties represents a mounting resolve of the Maori community to accept responsibility and authority for its own families by utilising the strength of the extended family. 1987 T. $B I G$ I:5 332 In some cases payment to the tribe as a whole may also reflect the fact that it is often impossible to determine, after the passing of so many years, which particular whanau (families) or hapu (sub-tribes) may have been the main losers when confiscations of tribal land occurred. The precise recipient of payment in each case (iwi or hapu) will depend on the issue and evidence, and the Tribunal can be expected to offer guidance on a case by case basis. $1990 \mathrm{DoH}$ BIG R.3.6.42 To encourage Maori people to achieve their highest level of health by supporting whanau, hapu, and iwi.

\section{Hauora $n$.}

[Ma.] physical health, well-being; the name of a DoH report.

1989a DoH. AR 5 The recently published report on Maori health Hauora shows that in many areas the health of Maori people is improving faster than that of non-Maori.

\section{hikoi $* \dagger n$.}

[Ma.] an organised group walk, often with the purpose of making a political protest or statement.

$1985 \mathrm{DoH}$. $A R 7$ One of the successful activities undertaken by the trust was a fund raising hikoi (walk) to Rotorua.

\section{Homebuilders / homebuilders $n$.}

a DSW funding programme to assist families to remain together in the one house. 
1987 DSW. BIG 34 Homebuilders will fund voluntary agencies to provide comprehensive homebased support to 'at risk' families so as to enable them to remain intact and to deal constructively with the problems they are facing. $1988 \mathrm{DSW}$. AR 57 Homebuilders funds voluntary agencies to provide comprehensive homebased support to 'at risk' families to enable them to remain intact. 1990 DSW. Key Issues for SW 69 ...confusing boundaries between Child and Family Support Services, Homebuilders, Family Services and Youth Services lump sum funding; 1992 DSW. AR 20 Steps were also taken to rationalise into one Children and Young Persons and their Families Programme (CYP \& F), the homebuilders, emergency housing, youth services, family services and child and family support services programmes.

\section{hui $* \dagger n$. and attrib.}

[Ma.] a gathering, meeting.

n. 1988 DSW. AR 41 ...convening a hui of national trainers to develop cross-cultural communications skills courses; 1989 MoE. AR 23 Key Maori women have been identified to run regional hui during 1989. $1994 \mathrm{MoE}$. $A R$ - two National EEO hui were held to discuss progress on EEO activities; attrib. $1992 \mathrm{DoH}$. AR 79 Two hui reports were published - Hui Hauora Tane and Hui Hauora-a-Iwi.

\section{Hui Whakaoranga $n$.}

[Ma.] a DoH meeting held in 1984.

1987 DoH. BIG 143 In 1984 the Department of Health hosted the Hui Whakaoranga, a National Maori Health Planning Workshop, inviting Maori people and health providers to meet together to discuss a Maori view of health and consider what initiatives and policies would be appropriate to improve Maori health. From the Hui Whakaoranga a number of recommendations were proposed which have provided guidance to the department and the health services on the range of policies and initiatives that need to be set in place to support Maori development. The major recommendations of Hui Whakaoranga are included in Appendix F. 1989 DoH. BIG 67 Recent efforts of the department and health services to develop their partnership with Maori people have stemmed to a large degree from Te Hui Whakaoranga, the Maori health planning workshop held at Hoani Waititi Marae, Auckland, in March 1984. ... Hui whakaoranga was an historic event for the health services of New Zealand. 
imprest supply n., attrib. comb.

relating to money paid in advance. (also Aust, C.I., Fiji, H.K. and Western Samoa)

1994 T. AR Sec.5 Imprest supply for 1993/94 was revised during the year and was also provided for the 1994/95 year with the relevant Imprest Supply Bills being introduced on time.

Individual Transferable Quota / ITQ $n$. and attrib.

first implemented in New Zealand, in 1983 as a system for deep sea fishing and in 1986 extended to inshore fishing; now also used in Canada, the U.S. and Iceland.

n. 1984b T. BIG 10.88 An ITQ is the right to catch a certain amount of fish from a certain species and fish stock within a given period; this right may be bought and sold like any other commodity. 1984b T. BIG 10.88 Firstly, a limited quantity of ITQs could simply be allocated to existing fishermen. 1987 T. BIG I.1 30 A more recent example where the Government has sought to improve the husbandry of a scarce resource is the introduction of individual transferable quotas to fishing. 1990 T. BIG 10160 These include amending or creating property rights (the Individual Transferable Quota for fish is an example), subsidy, government provision, or nuisance taxes. attrib. 1987 T. BIG I.5 335 There would still need to be consideration given to fisheries that remain outside the ITQ system such as shell fish.

\section{industry plan $n$.}

an industry development plan, covering $30 \%$ of New Zealand's manufactured goods output as at 1987 , including some of the most highly assisted industries.

1987 T. BIG I.4 197 An example in the industry policy area is given by industry plans, where some commentators perceive that a concession has been granted, despite the fact that some activities covered by plans are undergoing reform which is more rapid than that within non-plan areas. 1987 T. BIG I.4 252 The industry plan for apparel is due to be re-examined in early 1988. 1987 T. BIG I.6 361 The gradual removal of import licensing and the continuation of liberalisation signalled in industry plans - and under CER has prompted some adjustment through rationalisation of production and a shift to importing some product lines.

\section{integrate $v . i$.}


of a private school, to relinquish its independent status and join the state school system.

1984 DoE. BIG Sec.2.39 Agreements have been signed and 258 schools have integrated. 1984 DoE. BIG Sec.2.39 There now remain 132 Private Schools receiving 'State Aid' and of these only one has tentatively indicated an interest in integrating.

\section{integrated $* \dagger$ adj.}

used of a formerly private school which has now become part of the state education system while still maintaining its special character.

1985 DoE. AR 39 When maximum rolls for individual integrated schools are being considered a particular concern is the possibility that pupils are being drawn from non-integrated state schools to integrated state schools. 1987 T. BIG II:4 102 Of those enrolled at board controlled schools, 32,420 (8 percent) were at 'integrated' schools, that is, private, mainly Catholic, schools which, by an agreement and Act of 1975, are integrating into the state school system. $1989 \mathrm{MoE}$. AR 81 The Ministry does not own the land and buildings of integrated schools, and therefore, they are not included in the Ministry's accounts. 2001 T. AR 59 - the Government's response to the Review of the Education Review Office; the secondary school property guide; and guidelines for the establishment of integrated and special character schools

\section{integration * $n$. and attrib.}

the process of integrating private schools, many of them Catholic, into the state system of education.

n. 1987 T. BIG II:1 9 The private sector is very small and, with the integration of many Roman Catholic schools, has grown smaller in recent years. $1993 \mathrm{MoE}$. AR 19 During early 1993, officials studied and reported on possible changes to the criteria for the integration of private schools. attrib. 1986 DoE. AR 43 The integration agreements for St. Ita's School, Rakaia, and Erskine College, Wellington, were cancelled at the end of 1985 after the schools had closed.

\section{intermediate school $* \dagger n$.}

an urban school for Years 7 and 8, i.e. 11 and 12-year old children only; a school attended for the two years between primary and secondary school. 
1987 DoE. AR 24 As a result of that decision, junior high schools, established during the 1920 s, were transformed into intermediate schools. 1987 DoE. $A R 25$ Intermediate schools were staffed, therefore, by a mixture of primary generalist teachers and secondary specialist teachers. 1987 DoE. $A R 26$ Although rolls in intermediate schools have declined steadily during the past decade, positions for teachers of home economics and workshop crafts in some areas of the country have been difficult to fill.

\section{invalids benefit $n$.}

a DSW benefit payable to those unable to work because of a disability.

1998 Feb. DSW. Public Discussion Document 22 At the moment, there are no workrelated requirements for people on sickness and invalids benefits, and for most people on DPB or widows benefit.

\section{ironsand $* \dagger n$.}

a black sand rich in iron found on many NZ beaches.

1987 T. BIG I:5 324 Other conflicts of this nature have developed since 1840 through various legislative enactments reserving river beds, inland waters such as Lake Taupo and minerals such as petroleum, ironsands and geothermal energy to the exclusive ownership of the Crown.

iwi $\dagger n$. and attrib.

[Ma.] a Maori tribe.

n. 1987 T. BIG I:3 132 Rather it involves the agreement that an iwi will act as the Crown's partner and agent in delivering social assistance in a way that is more efficient than other approaches have proved. 1988 DSW. AR 15 In keeping with the findings of 'Puao-te-Ata-tu', the Department moved away from institutional care of pre-adolescent children in favour of alternative community and iwi based programmes. 1990 T. $A R$ Provide advice on how to improve the delivery of services to Maori through an increased role for Iwi... 1990 DoH. BIG R.3.6.42 To encourage Maori people to achieve their highest level of health by supporting whanau, hapu, and iwi. 1994 MoE. $A R$ The target was reduced in supplementary estimates to $\$ 16.2$ million to reflect consultation with iwi. attrib. $1988 \mathrm{DSW}$. AR 41 The iwi authorities have shown dissatisfaction with the difference between the recommendations of 
'Puao-te-Ata-tu' and the legislation. 1991b MoE. AR 56 An iwi visit programme is fully funded for all Ministry staff and two visits were undertaken during the reporting period.

JOS n. acr.

Job Opportunities Scheme.

1987 T. BIG I:4 290 The Job Opportunities Scheme (JOS) is generally in line with the structure outlined above, providing subsidies which aim to compensate employers for perceived productivity differences among job seekers; ... Some incentive features of JOS could be improved.

kai $* \dagger n$.

[Ma.] food.

1988 DoH. AR 26 Waiora Productions received $\$ 40,000$ for a video on kai (food).

kaiarahi reo $n$. and attrib.

[Ma.] an assistant teacher and fluent speaker of the Maori language, selected by education boards with the involvement of representatives of the Maori community.

n. 1987 DoE. AR 5 Twenty-five more kaiarahi reo (Maori language assistants) were appointed to work in the junior classes of schools receiving kohanga reo children. 1989 DoE. AR 8 Government has approved the redeployment of existing resources to permit the teacher training of up to 25 Kaiarahi Reo annually. $1992 \mathrm{MoE}$. $A R 88 \mathrm{~A}$ contract for the support of kaiarahi i te reo Maori in primary schools is currently in operation. attrib. 1988 DoE. AR 7 The department reviewed the kaiarahi reo scheme towards the end of the 1987 school year and also assessed the learning needs of Maori pupils and school programmes using both Maori and English for instruction. 1988 DoE. AR 7 The review confirmed that kaiarahi reo teachers have an important contribution to make in maintaining the oral Maori competence of pupils from Te Kohanga Reo centres (Maori language nests). 1990 MoE. BIG 102 Division AK is training people in Kaiarahi Reo positions to become primary teachers.

\section{kai awhina $\dagger n$.}

[Ma.] a caregiver, helper or mentor. 
1989 DoH. BIG 69 - Traditional healers and kai awhina in the health services. 1991b MoE. AR 9 With the appointment of a Group Manager Maori, the Ministry's Ten Point Plan for Maori Education is being systematically actioned resulting in increased kaiawhina, kura, wananga and publications. $1992 \mathrm{MoE}$. AR 14 A retargeting of Maori Language Factor Funding has created 97 new Maori language assistant positions called kaiawhina $\mathrm{i}$ te reo. The kaiawhina are to be employed on an annal basis and are to increase and maintain Maori language immersion.

\section{kai tiaki $* \dagger n$.}

[Ma.] a guardian, caretaker, steward or manager. (The Puao-te-Ata-tu report defines this as a caregiver or someone who knows and can speak for a child, somewhat like a godparent).

1987 DSW. BIG 10 The Advisory Committee's recommendations affirmed...the right of the whanau/hapu/iwi to be consulted by the professionals and involved in the court process and to have a kai tiaki speak as an advocate. 1992 MoE. AR 32 The Advisory Officer Maori is based in this space and acts as Kaitiaki. 1994 DoH. AR 25 Section 74a of the Health Act 1956, which relates to the NCSP, was amended to enable regulations to be made to establish a national kaitiaki group.

\section{kakapo $* \dagger n$.}

[Ma.] an endangered bird native to New Zealand, a flightless ground parrot.

1991 MoE. $A R 11$ It is like the Kakapo and the Chatham Island Robin; a national treasure on the brink of extinction, too valuable to us, our history and our unique New Zealand society to be allowed to go.

\section{karakia $* \dagger n$.}

[Ma.] an invocation, a prayer chanted or sung.

1991 MoE. AR 89 Mihimihi, karakia, manaaki, atawhai, aroha (cultural support) on behalf of, and within, the Ministry of Education.

\section{Karitane nurse $* \dagger n$.}

a nurse trained in infant care who "lives in" with a family to help with a newborn.

1984 DSW. AR 7 A Karitane nurse or other suitable help may be engaged in multiple birth cases or where supportive assistance is necessary. 


\section{kaumatua $* \dagger n$.}

[Ma.] a Maori elder, male or female.

1984 DoE. AR 10 The department, working in association with local kaumatua and marae committees, has organised 29 marae courses since 1976. 1987 DoH. BIG 149 The membership of this committee is different from other standing committees in that there are Kaumatua, Maori and non-Maori western trained health providers upon it. 1990 MoE. BIG 112 The establishment of Te Kohanga Reo and Kura Kaupapa Maori are examples of such initiatives, while Te Reo o Te Tai Tokerau project, in which northern kaumatua (Maori elders) were involved in the evaluation of oral School Certificate Maori (Peters and Marshall 1988, 1989), or the selection by iwi or home marae of Te Atakura teacher trainees provide examples of effective partnership.

\section{kaupapa $* \dagger n$.}

[Ma.] a plan, policy, proposal, purpose or scheme.

1987 DSW. BIG 134 Kaupapa of Community Organisation Grants Scheme (COGS) 1989a DoH. AR 4 At the same time, the corporate plan and mission statement are being refined, a kaupapa (statement of guiding principles) has been developed and a number of important human resource management measures implemented. 1989 MoE. AR 23 The courses encouraged the setting up of regional networks for Maori women in education, the development of a draft kaupapa / statement of aims for Maori women in education, and the identification of priority areas for the training of Maori women teachers.

kiwi $* \dagger$ 1. n. 2. attrib. comb.

[Ma.] 1. name for the NZ dollar. 2. kiwi share an agreement between the NZ government and Telecom to ensure free local telephone calls for domestic households. 1. $1987 \mathrm{NZH} 16.05 \mathrm{He}$ believes the kiwi needs to come down by 15 to 20 per cent, if export industries are to remain competitive. 2. 1990 T. BIG 791 Social concerns could be met by direct social-policy intervention or by mechanisms such as "Kiwi share". 1990 T. AR 41 Specific parameters may be set down for the sale, such as requirements for legislation, a Kiwi share, or maximum/minimum levels of foreign or domestic ownership, in response to issues or concerns raised in the scoping report. 1990 T. CP 25 - Completion of the sale of Telecom which involves monitoring the settlement process and Kiwi share obligations. 
koha $* \dagger n$.

[Ma.] a customary contribution or donation, often but not always monetary.

1987 DSW. BIG 124 This transfer of resources would cover personnel and administrative costs, replacement koha, and ongoing whanau development costs. 1988 DSW. AR 43 In 1987/88 \$1.3 million was allocated within the Department's general operating allocation for koha to support children living apart from their parents. 1989 DSW. AR 32 In the years 1987/1988 and 1988/1989, \$1.3 M was allocated for Koha placement.

kohanga (reo) $* \dagger n$. and attrib.

[Ma.] first established in 1981, a type of childcare centre for pre-schoolers which provides immersion in Maori language and culture.

n. 1984 DSW. AR 56 Te Kohanga Reos or "language nests" are licensed as childcare centres. 1994 MoE. AR 39 Payments to nga kohanga reo on agreed dates. 1987 T. BIG 346 For Maori people, this form of ECS has a distinctive language and cultural function and much of the increase in public resources flowing to ECS in recent years has been for the establishment and operation of these Kohanga. attrib. 1984 DoE. AR 7 The Kohanga Reo (language nest) movement in particular has been greatly helped by the foundation. 1985 DoE. AR 22 A booklet providing guidelines for primary schools enrolling kohanga reo children has been produced.

\section{Komiti Whakahaere $n$.}

[Ma.] a series of SW meetings held to discuss a government report; a steering or organising committee.

1988 DSW. AR $41 \ldots$ and attending Komiti Whakahaere hui to provide administrative services and feedback on work completed as a result of 'Puao-te-Ata-tu'.

\section{kowhaiwhai $n$. $* \dagger$}

[Ma.] a scroll pattern used as an ornamental border in Maori art.

1987 DSW. CP 1 The Kowhaiwhai on the cover tells us of the path along which we have come and the long road ahead.

kuia $* \dagger n$.

[Ma.] a respected, old or senior woman. 
1988 DoE. AR 7 Kaumatua and kuia actively participated in the developments. 1990 MoE. BIG 18 In kohanga reo, however, the kuia or an elder with expertise in Maori language and cultural perspectives is the essential element in the educational process and the identification of appropriate teachers in kohanga reo is seen to be the role of the Maori community.

kura $\dagger n$. and attrib.

[Ma.] a school.

n. 1991b MoE. AR 60 Two kura were established during the reporting period bringing the number of kura to 13. $1994 \mathrm{MoE}$. $A R 9$;ensured co-ordinated development for present and future kura by signing protocols with Te Runanga Nui o Nga Kura Kaupapa Maori; attrib. 1990 MoE. BIG App.8:2 Objectives identified in the kura charters, the community, learning environment, teachers, facilities, property, funding, and the progress of the children will all be taken into account. $1991 \mathrm{MoE}$. $A R 12 \mathrm{In}$ addition, the Ministry has seconded a full time Project Officer to determine how the successful facets of the kura development can be enhanced within existing resources.

\section{(kura) kaupapa (Maori) / KKM *† n. / abbrev.}

[Ma.] first established in 1989, a Maori immersion primary school.

1987 T. BIG II:4 102 There are 11 bilingual board run primary schools mainly in rural areas, and two kaupapa Maori private schools. 1990 MoE. BIG 208 A further five KKM are to be established in 1990 - 91. 1991 MoE. AR 70 Nineteen community forums were approved covering the establishments of Kura Kaupapa Maori, designated character schools, school closure and recapitation. $1994 \mathrm{MoE}$. AR 90 The Government approved funding for five additional kura kaupapa Maori to be established in 1994.

\section{Land Wars $* \dagger n$.}

a term used for the early conflicts over the seizure of Maori land by British troops.

1987 T. BIG I:5 327 A survey of historical research suggests that the most substantial breaches of the Treaty arising from unjustified confiscations may have occurred in parts of Taranaki, Waikato and perhaps the Tauranga/Bay of Plenty areas in the aftermath of the Land Wars of the 1860s. 1987 T. BIG I:5 333 The Land Wars destroyed the independent military base of the tribes. 1987 T. BIG II:8 219 The Land 
Wars, land sales and the drastic decline in the Maori population must have combined to cause considerable cultural decline and malaise in the late nineteenth and early twentieth century.

\section{language nest $* \dagger n$.}

an English translation of kohanga reo, the Maori immersion pre-school.

1987 T. $B I G$ II.3 76 ...successful 'local' initiatives, for example playcentres and the Pacific Island and Maori language nests. 1987 DoE. $A R 48$ The project will set up a home-based programme linked to established Pacific Island early childhood "language nests". 1988 DoE. AR 7 The review confirmed that kaiarahi reo teachers have an important contribution to make in maintaining the oral Maori competence of pupils from Te Kohanga Reo centres (Maori language nests). $1990 \mathrm{MoE}$. BIG 40 The significant developments have been in the extension of training by the state, the growth of kohanga reo and other language nests, increased state support, and coordination of the former Department of Social Welfare functions under the Department of Education.

liable parent $n$. and attrib.

a separated parent liable for the financial upkeep of his/her children who live with the other parent. (also Aust.) (This is a different sense from the same term used in the U.K. where it means a parent liable for a dependant's crime).

n. 1984 DSW. AR 22 Since 1 April 1981 a solo parent applicant for domestic purposes benefit has been required to identify the liable parent of each dependent child in his or her care. 1986 DSW. AR 30 At 31 March 1986, 43,411 liable parents were required to contribute toward the cost of current domestic purposes benefits. attrib. 1984 DSW. BIG 57 A system for recovering contributions from non-custodial parents towards the cost of paying a domestic purposes benefit was introduced from 1 April 1981 in the form of the Liable Parent Contribution Scheme. 1984 DSW. BIG 101 This section is responsible for the administration of maintenance and liable parent contribution collection activities carried out by the Department. 1987 DSW. BIG 175 Lack of equity in payment rates of LPC between low and high income earners. 1989 DSW. AR 43 The rise in liable parent numbers reflects the growth in the number of DPB clients. 1990 DSW. Key Issues for SW 58 Non-custodial parents contribute to the support of their child through the LPC scheme, but in practice, only about 41 
percent of amounts due are recovered. 1990 DSW. An Inventory of the Dept... 76 The average LPC assessment is low, at just over $\$ 30$ weekly per family.

\section{link course $n$.}

a part-time vocational training course for high school students. (This term is used in the U.K. with the meaning of a 'foundation course' in NZ, i.e. a bridging course to link school with a tertiary institution).

1987 T. BIG II:5 142 Link courses, to give secondary students 'hands-on' experience of vocational courses through part-time attendance at polytechnics, are being developed.

\section{Local Authority Trading Activity / LATA $n$. / acr.}

a commercial undertaking run by a local or regional council.

1987 T. BIG I:2 96 In relation to the product markets in which SOEs and local authority trading activities (LATAs) compete, section 4 discusses the issue of barriers to entry and market dominance. 1987 T. BIG I:2 117 Like SOEs the trading activities of local authorities (LATAs) are major commercial undertakings and significant users of the economy's resources. 1987 T. BIG I:2 117 For example, the Harbours Act constrains the way in which a harbour board can use the proceeds from the sale of its property and LATAs come under the Higher Salaries Commission jurisdiction.

\section{Local Authority Trading Enterprise / LATE $\uparrow n . /$ acr.}

a company or other organisation in its own right owned or controlled by the local authority and functioning as a business enterprise, i.e. carrying on an undertaking for profit.

1991 Boston et al 274 Provision was made for trading activities to be "corporatized" and formed into local authority trading enterprises (LATEs) at the option of authorities... 1993 Kelsey 49 Corporatisation provided an obvious opportunity to trim the ARC's sails by forcing it to transfer to a Local Authority Trading Enterprise [LATE] and subsequently to sell its transport and rubbish services, commercial forestry holdings and the ports of Auckland.

\section{long service leave $n$.}


an additional holiday payable to an employee who has worked for the same company continuously for a long period of time. (also Aust.)

1984 DoE. BIG Sec.3.117 Labour will commence consultation with teacher unions on long service and refresher leave provisions. $1993 \mathrm{MoE}$. AR 41 The Ministry has accounted for long service leave and retirement leave for the first time. $1994 \mathrm{MoE}$. $A R$ 27 The provision for long service leave represents the amount owing to those employees who had completed 20 years service as at 30 June 1994.

\section{Maatua Whangai $n$. and attrib.}

[Ma.] a preventive DSW programme run in conjunction with Maori communities and the Department of Maori Affairs, to foster Maori children and young people 'at risk' within the whanau (extended family network) rather than placing them in DSW institutions.

n. 1984 DSW. BIG 45 Developments have occurred in the area of community involvement with the formulation by the Departments of Maori Affairs and Social Welfare, and the Maori community, of the Maatua Whangai, or foster parent programme. $1987 \mathrm{DSW}$. CP 8 Complete planning to divert resources to Maatua Whangai and related purposes by November 1987. 1990 DSW. CP 34 -strengthening Matua [sic] Whangai to ensure that children continue to be cared for within their kin groups. attrib. 1988 DSW. AR 48 Some districts, particularly those with strong Maatua Whangai support, made considerable progress in implementing the recommendations of 'Puao-te-Ata-tu' for Maori children. 1989 DSW. AR 32 The devolution of the maatua whangai resource to iwi authorities for contracted results, negotiated at the iwi and district or regional level. 1990 DSW. CP 45 The Matua [sic] Whangai way of working - whakapakari whanau or family decision-making - has been acknowledged in the directions taken by the CYP \& F Act.

\section{Mana / mana $* \dagger n$.}

[Ma.] authority, prestige.

1987 T. BIG I:5 332 Accordingly, the objectives of many claimants seem to be twofold: to redress the injury done to tribal mana when an injustice occurred and to help re-establish a tribal economic base. 1987 T. BIG II:8 223 Further, this status, Benton considers, carries with it the implication of the right to a deciding vote in the disposition of resources and the regulation of social affairs: fundamental to the 
acceptance of this argument being the notion of Maori seniority in relation to all newcomers, and the understanding that the Treaty transferred administration to the Crown with sovereignty and associated Mana being retained by the Maori people.

manaaki $\dagger n$.

[Ma.] generosity, hospitality.

1991 MoE. AR 89 Mihimihi, karakia, manaaki, atawhai, aroha (cultural support) on behalf of, and within, the Ministry of Education.

\section{MANA Enterprises $n$.}

the name of a programme.

1987 T. BIG I:5 324 Examples of such programmes include MANA Enterprises (which extends loan finance to support relatively small-scale Maori business ventures) and Maatua Whangai... 1990 DSW Key Issues for SW...20 A notable success has been the MANA enterprise scheme (operated through the Iwi Transition Agency). 1994 T. AR Sec.5 During the year the Treasury, in conjunction with other departments, provided advice on options for mainstreaming Mana Enterprises, vocational training, the Maori housing portfolio, Maori Access, and certain residual payments made on behalf of the Crown by the Ministry of Maori Development.

mana motuhake $\dagger n$.

[Ma.] self-determination; a political belief and movement associated with indigenous rights.

1987 T. $B I G$ II:8 226 A view which contrasts with the preceding one of sharing of Maori language and culture, including elements of compulsion, is one which accords with mana motuhake (a Maori political philosophy emphasising Maori control over Maori Affairs) and the spirit of the Treaty of Waitangi.

\section{Manukau Guardian $n$.}

a Maori leader appointed by the Minister of Maori Affairs to look after the traditional interests of the tribes surrounding the Manukau Harbour and its environs.

1987 T. BIG I:5 343 The appointment of Manukau Guardians, as recommended by the Waitangi Tribunal to provide a Maori overview of the harbour and its 
environments, is a good example of how consultation can be built into decision making processes.

Maori $* \dagger n$. and attrib.

[Ma.] belonging to the indigenous race of New Zealand.

1984 DoE. BIG Sec.3.82 Some schools invite community Maori culture tutors to train their Maori cultural groups. 1987 T. BIG II:8 225 Race against time sees the Maori language as not just for Maori people and criticises official recognition of the Maori language in the Maori Affairs Amendment Act 1974 'as the ancestral tongue of that portion of the population of New Zealand of Maori descent.' $1994 \mathrm{MoE}$. AR 96 The responsibilities of this position include ensuring staff (particularly Maori staff) are able to improve Maori language fluency and understanding of tikanga;

\section{Maori Access / MACCESS n. / acr.}

the name of a programme.

1990 MoE. BIG 44 Alternative provision was available in Access and Maccess courses initially under the Departments of Labour and of Maori Affairs but now under the Education and Training Support Agency and the Iwi Transition Agency. 1993 T. $A R 68$ During the year the Treasury, in conjunction with other departments, provided advice on options for mainstreaming Mana Enterprises, vocational training, the Maori housing portfolio, MACCESS, and certain residual payments made on behalf of the Crown by the Ministry of Maori Development.

\section{Maori warden $\dagger n$.}

a uniformed volunteer who patrols city trouble-spots, advises Maori youth and generally assists the public.

1993 MoE. $A R 11$ - two school attendance trials set up in partnership with Maori wardens; 1994 MoE. AR 93 A pilot truancy intervention programme, operated by the Rotorua branch of the New Zealand Maori Wardens' Association under the auspices of the Wardens' National Office, was set up in Rotorua with funding provided by the Ministry.

\section{Maoridom $* \dagger n$.}

a general term for all Maori people. 
1984 DoE. BIG Sec.3.85 The advent of the te kohanga reo movement is one aspect of a renaissance in Maoridom which has increased the numbers of students in primary schools learning Maori and heightened the interest of teachers in learning the language also. 1987 T. BIG I:5 344 The Government should not endeavour to impose its own preferred organisational structures on Maoridom. 1988 DSW. CP 7 The current debate on partnership with Maoridom may lead to new roles for the Department in 'mainstreaming' services for Maori people and devolving functions to the iwi, as defined in He Tirohanga Rangapu (Partnership Perspectives, Department of Maori Affairs, April 1988).

Maoriness $* \dagger n$.

the quality or attributes of being Maori.

1990 MoE. BIG 141 The essence of Maoriness - te iwi wairua - is doomed if Maori alone are expected to sustain it.

\section{Maoritanga $* \dagger n$.}

[Ma.] a general term for all things Maori.

1985 DoH. AR 6 - the need to recognise the significance of Maoritanga (Maori culture) and to include it in health and education training programmes; 1987 DSW. $B I G 11$ Positions are advertised in Maori as well as English and interview panels for such positions involve a person or people knowledgable in Maoritanga. $1990 \mathrm{MoE}$. $B I G 63$ The Department of Education also contributed by promoting Maoritanga and taha Maori through its syllabuses and curriculum materials.

marae $* \dagger n$. and attrib.

[Ma.] a meeting-house and its courtyard, the centre of tribal life.

n. 1984 DoE. $A R 10$ Marae have played an increasing part in the educational and cultural life of the education system. attrib. 1984 DoE. AR 10 The department, working in association with local kaumatua and marae committees, has organised 29 marae courses since 1976. 1987 T. BIG II:3 68 The centres are generally located in marae complexes, church halls or community centres.

\section{meatworks $n$. $* \dagger$}


a meat-processing factory where animals are killed for subsequent packing, freezing and human consumption (also Aust.)

1987 T. BIG I.6 369 With agricultural stocks having also fallen, following the buildup caused by the meatworks strike in early 1986, real gross national expenditure fell by 0.8 percent.

\section{meshblock $n$.}

the smallest geographic unit for which statistical data is collected and processed by Statistics New Zealand.

1989 DSW. AR 53 During the year, the Statistics Unit has been working to relate social welfare district boundaries to population meshblocks used by the Department of Statistics.

mihimihi $n$.

[Ma.] formal greetings associated with making introductions.

1991 MoE AR 89 Mihimihi, karakia, manaaki, atawhai, aroha (cultural support) on behalf of, and within, the Ministry of Education.

\section{Minita Maori $n$.}

[Ma.] the Minister of Maori Affairs; a Maori minister of religion.

1985 DoH. AR 8 The whenua (placenta) and diseased body parts are now made available for families, and the importance of local Tohunga, traditional healers, and Minita Maori (Maori Ministers of Religion) is clearly recognised.

Mode A $n$. and attrib.

a phase of the Government's financial management reforms.

n. 1989b DoH. AR 33 There has been NO provision made for accrued annual leave, as the department continues, in 1989/90, to be appropriated in Mode A, that is in cash terms only. $1990 \mathrm{DoH}$. AR 33 It has to be remembered, however, that throughout $1989 / 90$ the Department was appropriated on the basis of and operated under Mode A. attrib. $1990 \mathrm{DoH}$. AR 5 In my view these two requirements are inappropriate for a Mode A department. 1991 DoH. AR 26 Under Mode A appropriation the Department reported trust and imprest accounts that are not part of the balance sheet when reporting as a Mode B appropriated department. 
Mode B $n$. and attrib.

a phase of the Government's financial management reforms, effective from 1 July 1990, this included the stipulation that all financial delegations to incur cost should match the specific budgets within each cost centre.

n. 1989a DoH. AR 68 In line with developments indicated by the Public Finance Bill, departmental resources were shifted to the development of organisational outputs for implementation when the organisation moves into mode B (appropriation on an accrual basis referred to in the Bill as an appropriation for the incurrence of costs). 1990 DoH. BIG R.3.8.3 Under Mode B, all fixed assets are a corporate resource so that where priorities change, assets can be reassigned as appropriate. 1992 T. CP 38 Review of arrangements made by departments to ensure successful migration to Mode B. attrib. 1990 DoH. BIG R.3.8.4 The 1990/91 financial year is the first time the Department of Health has been appropriated on a Mode B basis through output classes. 1991 DoH. AR 7 This annual report, therefore, represents the successful completion of the Department's first Mode B cycle. 1994 DoH. AR 15 The Ministry of Health complies with Treasury instructions for a mode B department.

\section{$\operatorname{model} \operatorname{school} n$. and attrib.}

educ. similar to a normal school in that it is associated with a teachers' college and provides pre-service teaching practice for trainee teachers, a model school was often called a country model school and was originally a small, one or two teacher school located in a rural area, which modelled the norm for country service where all levels were taught in one classroom.

n. 1984 DoE. BIG Sec.4.54 There are 22 normal schools and nine model schools established in teachers college centres. 1984 DoE. BIG Sec.4.54 In the case of the model schools established on the outskirts of teachers college centres, many have become larger suburban schools and no longer adequately perform their original function. attrib. 1984 DoE. BIG Sec.4.55 They could also argue that a reduction in the status of normal and model positions would adversely affect the quality of teacher training.

\section{mokopuna $* \dagger n$.}

[Ma.] grandchild(ren). 
1987 DSW. BIG 10 Similarly, before Puao-te-Ata-tu, grandparents or relatives who cared for their mokopuna did not qualify for assistance from the Department. 1990 MoE. BIG 18 Te Kohanga Reo is an example where whanau have accepted responsibility for the education of their mokopuna. $1992 \mathrm{MoE}$. $A R 90$;initiatives to increase the attendance of mokopuna and tamariki;

\section{NAFMAC $n$. acr.}

National Fisheries Management Advisory Committee.

1984b T. BIG 1087 Following a review last year by the National Fisheries Management Advisory Committee (NAFMAC) - a joint officials/industry grouping officials have been reviewing the policy options available to sensibly restructure the New Zealand inshore fishery.

national award $* \dagger n$. and attrib.

standard wage and working conditions for an industry, set by an employment court (also Aust.)

n. $1990 \mathrm{~T}$. BIG 447 Of particular concern is the system of national awards, which is unresponsive to the particular circumstances of individual businesses and their workers. attrib. 1987 NZL 14 February 12 Instead, a new set of constricting forces is being "imposed" on the FOL: the Government's new industrial relations legislation, confident big business developing a penchant for lockouts and refusal to negotiate, the threat of contestability, the erosion of the 40-hour week, a fight to banish the national award system.

\section{national superannuation $* \dagger n$.}

a government pension paid in regular instalments to New Zealanders, currently from the age of 65. (also Aust.)

1984 T. BIG I.6 94 This series is not entirely satisfactory as it does not include the effect of changes in the composition of the labour force (e.g. changes in the numbers on unemployment benefit) and does not adequately deal with the transition in 1977 from the old age benefit / universal superannuation to national superannuation. 1998 T. $A R 18$ At the request of the Royal Commission we also made a significant contribution to the modelling and costing of various options for National Superannuation. 


\section{native school $* n$.}

a school for Maori pupils. (hist.)

1987 T. BIG II.8 217 Walker sees the development of Native Schools in a less charitable light, as a 'campaign against Maori culture' based on the 'pakeha's assumed superiority over the Maori (which) was built into the institutions of the new society, including education.' 1990 MoE. BIG 1 A Native schools system for Maori children had been instituted in 1858 - with an amendment in 1867 making provision for instruction in English only.

\section{Nga Ringa Aroha $n$.}

[Ma.] loving hands; name of a DoH assistant nurse training programme and transf. to the nurses themselves.

1985 DoH. AR 6 The department has supported this innovative project since its inception and, in 1984, seconded a public health nurse for 12 months to co-ordinate a training programme for 3 women selected by the local community to become Nga Ringa Aroha - 'those with loving hands'. ... Since completing the training programme, 2 of Nga Ringa Aroha have become employed as health assistants by the department. .... As well as promoting a Maori view of health, the Nga Ringa Aroha aim to prevent health problems and to strengthen links and understanding between health professionals, health services, and the local community.

\section{nga taonga katoa $n . p l$.}

[Ma.] all treasured possessions (both tangible and intangible).

1990 MoE. BIG 60 In this context culture is defined as the languages, histories, customs, traditions, beliefs and values that make up the shared experiences, roots and possessions (nga taonga katoa) of particular communities that are handed down from one generation to the next.

nga toi $n . p l$.

[Ma.] the arts.

1992 MoE. $A R 25$ The Framework specifies seven essential learning areas which describe in broad terms the knowledge and understandings which all students will learn: language and languages / te reo, nga reo; mathematics / te pangarau; science / te 
taiao; social sciences / te tikanga-a-iwi; the arts / nga toi; health and physical wellbeing / te tinana, te wairua, te hinengaro; and technology / te putaiao.

normal school $* \dagger n$. and attrib.

educ. a primary school set up to establish and maintain a connection with a College of Education for the purpose of providing periods of practical classroom teaching experience for trainees as part of pre-service teacher education.

n. 1984 DoE. BIG Sec.4.54 However, they did concede some tightening of travel organisation for both students and staff could save costs in the area of teaching practice and two boards, Wanganui and Wellington were prepared to disestablish one normal school each. 1984 DoE. BIG Sec.4.55 Already there has been one instance of a Principal's position at a normal school becoming vacant which gave rise to some debate about that particular school's future and the possible adverse effect this could have had on the number and quality of the applicants. attrib. 1984 DoE. BIG Sec.4.55 They could also argue that a reduction in the status of normal and model positions would adversely affect the quality of teacher training.

\section{notional roll attrib.}

educ. a category assigned by the Department of Education to schools which have large numbers of children with exceptional special education needs.

notional roll school 1984 DoE. BIG Sec.3.34 It would appear that the establishment of a 1:20 ratio in junior classes would be a very appropriate time to review the place of notional roll schools and also the staffing of schools with grading rolls of between 150 and 187: 1984 DoE. BIG Sec.3.34 Notional roll schools are schools approved by the Minister (45 at present) which have their rolls weighted by $10 \%, 15 /$ or $20 \%$ for staffing purposes and also receive an additional cash grant. notional roll status 1984 DoE. BIG Sec.3.34 One issue to be considered is whether the extra staffing generated by notional roll status should be reduced or even continued when the 1:20 ratio is introduced into the junior classes. 1984 DoE. BIG Sec.3.35 Staffing in schools for Reading Recovery is supplied in various, ad hoc, ways through the Guaranteed Staffing Component, notional roll status, Regulation 31(d) special needs teachers and teacher relief days from the districts inservice resources. 1984 DoE. BIG Sec.3.81 in 1976 notional roll status was accorded to a number of schools that had large numbers of children with exceptional educational needs because of multi-ethnic rolls. 
NWASCO $n$. acr.

National Water and Soil Conservation Organisation.

1984b T. BIG 334 ...the National Water and Soil Conservation Organisation (NWASCO) provides for protection grants of up to 70 percent of planting costs...

NZDMO $n$. abbrev.

New Zealand Debt Management Office.

1989 T. AR 26 NZDMO comprises Portfolio Management, Research and Settlements teams. 1993 T. $A R 80$ The New Zealand Debt Management Office (NZDMO) is responsible for managing the Crown's debt, overall net cash flows, and interest bearing assets. 1994 T. AR Sec. 3 The New Zealand Debt Management Office (NZDMO) is the Crown's treasury...NZDMO has portfolio management, research, systems development, relationships management and settlement teams in Wellington and a small team in London.

OET n. abbrev.

overseas exchange transaction. (also Fiji and Tonga)

1984a T. BIG 123 The deterioration in the OET balance will contribute to a tightening in monetary conditions in late 1984 and into 1985, but the slowing in the rate of growth of the money supply is not expected to be sufficient by itself to depress spending, as happened in 1982. 1984a T. BIG 583 Funds are borrowed externally to fund the deficit in our overseas exchange transactions (OET's). 1984a T. BIG 4148 ...the OET balance is the net cash balance with the rest of the world, measured over same period.

official visitors (scheme) $n$.

a system whereby people appointed by the government visit psychiatric hospitals to talk to patients and check on conditions; to negotiate on patients' behalf and report back to government. (also Aust.) (The term official visitor is also used in India and the appointment process is similar but in that country the term is used for those who visit prisons).

1984 DoH. AR 48 Following a recommendation made in 1982, over 20 official visitors were appointed by the Minister of Health in 1983-84. 1985 DoH. AR 47 Consideration is being given to extending the roles of both district inspectors and 
official visitors..... A number of new official visitors were appointed during 1984, bringing the total to 22. 1989a DoH. AR 30 The recommendations of the Mason Report have highlighted the department's role in relation to both "special patients" and the work of official visitors and district inspectors as advocates for committed patients.

oranga $n$.

[Ma.] livelihood, living; health, welfare.

1987 DoE. BIG 36 These include learning which ... helps students to develop their sense of well-being, oranga, and their responsibility for the well-being of others.

Pakeha $* \dagger n$. and $a d j$.

[Ma.] a European New Zealander.

n. 1987 T. BIG II.8 227 It is important to appreciate the size of the educational attainment differences that currently exist between Maori and Pakeha. adj. $1987 \mathrm{~T}$. BIG II.10 291 However the attainment gap between Maori and non-Maori students has remained wide and in some ways has widened whilst the commanding heights of the educational system have remained predominantly in Pakeha hands. 1987 T. BIG II.8 222 The more Pakeha New Zealanders grow up knowing Maori culture and history (for which they must be familiar with the language) the more will adult New Zealanders relate warmly to one another as Pakeha and Maori come to show each other mutual respect. 1987 T. BIG II.8 223 There would also be the practical difficulty of deciding who would speak for the Pakeha partner.

palagi $* \dagger n$. and attrib.

[Sa.] a white person, a European.

1986 DoH. CP 62 Study the relationship of Pakeha/Palagi patients to Wellington hospital services.

pangarau $n$. and attrib.

[Ma.] mathematics.

n. 1992 MoE. AR 25 The Framework specifies seven essential learning areas which describe in broad terms the knowledge and understandings which all students will learn: language and languages / te reo, nga reo; mathematics / te pangarau; science / te 
taiao; social sciences / te tikanga-a-iwi; the arts / nga toi; health and physical wellbeing / te tinana, te wairua, te hinengaro; and technology / te putaiao. $1993 \mathrm{MoE} . A R$

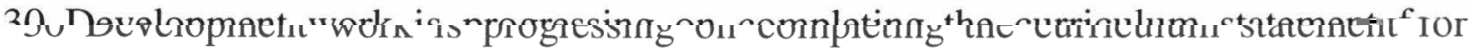
mathematics (pangarau); science (putaiao) and te reo Maori for use in Maori medium education. 1994 MoE. AR 94 Three Maori curriculum statements are being developed: Pangarau, Putaiao and te reo Maori, and development is on target. attrib. $1994 \mathrm{MoE}$. $A R 95$ Pangarau and Putaiao draft curriculum statements are being published while te reo curriculum statement draft is being made ready for publication.

\section{$\operatorname{PAP}$ n. abbrev.}

Priority Areas Programme (Scheme).

1987 DoH. BIG 119 The programme administers two schemes, the Priority Areas Programme (PAP) Scheme and the Community Health Initiatives Funding Scheme (CHIFS) both of which represent new ways of working in health development ... Most districts have developed PAP initiatives in schools and work schemes. 1987 DoH. BIG 120 Approval was given under the 1987/88 New Policy round to fund an additional 14 (full time equivalent) positions under the PAP scheme. $1987 \mathrm{DoH}$. BIG 146 At 24 June 1987, there were 25.75 community health workers employed under PAP. 1989 DoH. BIG 116 Emphasis has been on time-limited projects; all PAP projects include a built-in evaluation component. 1993 DoH. BIG I.115 The Priority Areas Programme was established in 1985 when 91 staff positions were allocated to Health Development Units / area health boards.

\section{$\operatorname{PAT}$ n. abbrev.}

\section{Progressive Achievement Test.}

1987 T. BIG II.4 108 The 'PAT' (Progressive Achievement Tests) have been developed by the New Zealand Council for Educational Research and are administered by schools in order to assess levels of individual students' performances and assist teachers in planning. 1987 T. BIG II.5 140 PAT tests show some statistically significant declines in attainment levels in listening comprehension, mathematics and reading tests from the late 1960s, through the 1970 s and into the 1980s. 1987 T. BIG II.10 278 However such sources as the 'PAT' tests designed by the New Zealand Council for Educational Research suggest some decline over time in 
skills although the problem appears to be concentrated more at intermediate and secondary levels.

periodic detention $\dagger n$.

a non-custodial sentence handed down by a court for a minor offence, consisting of a certain number of hours' unpaid work in the community. (This is a slightly different sense from the same term used in Australia where it means a sentence of imprisonment served at a detention centre on a number of days each week).

1984 DSW. AR 82 Sentenced to periodic detention ... 1989 DSW. AR 87 Sentenced to periodic detention ...

\section{PHARMAC $n$. acr.}

New Zealand's Pharmaceutical Management Agency, responsible for assessing drugs and their generic substitutes and deciding which treatments should be subsidised by the government.

$1993 \mathrm{DoH}$. AR 1 The Department also undertook work with the RHAs to arrange for the transfer of the Drug Tariff section and its responsibilities to the RHAs under a new organisation called the Pharmaceutical Management Agency limited (PHARMAC). 1993 DoH. BIG 35 PHARMAC (the Pharmaceutical Management Agency) negotiates with pharmaceutical suppliers on behalf of the four RHAs. ... PHARMAC is developing strategies for obtaining lower prices for drugs, and for reviewing the relative subsidies for different drugs on the schedule.

\section{pipfruit $n . \dagger$}

a collective term for apples and pears.

1984 T. BIG II.2 15 Dairy (for export), sheepmeat, wool, beef, all pastoral, pipfruit, kiwifruit, vegetables, other crops...

\section{PIT n. acr.}

parentally income tested, a term used in the context of the government paying student allowances (in NZ) to 16 - 25 year-olds and the youth allowance (in Australia) to 17 20 year-olds, but on a sliding scale according to parents' income thresholds. (also Aust.)

1990 DSW. Key Issues for SW 42 PIT (Parentally Income Tested) 
play centre $* \dagger n$. and attrib.

a national system of parent-run educational sessions for pre-schoolers founded by Gwendolen Somerset and based on the philosophy of free play.

1984 DSW. AR 85 Community kindergarten or play centre. 1984 DoE. $A R 17$ The playcentre movement has continued to achieve notable success with its education programme for parents as well as its work with children under 5 years. 1984 DoE. $A R$ 17 It confirmed the value of playcentre work for helping people realise latent abilities. 1987 T. BIG II. 19 For most people, the choice is greatest at pre-school where there is a variety of options including kindergarten, play centres and private day care. 1990 MoE. BIG 17 The playcentre training uses community evening classes, professional educators and field-based trainers to provide a comprehensive and quality training for parents towards a qualification.

Plunket $* \dagger n$. and attrib.

the common name for the Royal New Zealand Plunket Society Inc., a nationwide association of clinics staffed by district nurses who carry out a series of well-child checks on all infants born in New Zealand, during the pre-school period from the age of six weeks to five years.

n. 1984 DoH. BIG 4 ...assistance and seeding funding to outside organisations (e.g. plunket, children's health camps). attrib. 1987 DoH. BIG 72 - the Plunket Society: to provide child health nursing services to $0-5$ year olds, to run family support units, and through the South Auckland Plunket Contract, to have sole responsibility for the provision of child health nursing services for $0-5$ year olds in South Auckland; in comb. Plunket nurse $n$. 1987a DoH. AR 26 The measures included provision for the appointment of a paediatric specialist to coordinate all activities relating to infant health, and an additional 4 public health and 15 Plunket nurses.

POBOC n. acr. and attrib.

Payment on Behalf of the Crown. (also C.I.)

n. 1990 DoH. BIG R.3.8.3 The appropriation can also be made for capital contribution and for Payments on Behalf of the Crown (commonly known as POBOCs). 1993 DSW. AR 58 The majority of POBOC's were expended to budget or within 5\% of budget ... As knowledge was gained of the POBOCs, a detailed review was undertaken, resulting in a new POBOC structure being approved for 1 July 1993. 
attrib. 1992 MoE. AR 6 The Ministry's internal library service, POBOC forecasting, and the curriculum and teacher development contractual process have been reviewed. 1993 DoH. AR 17 There was, however, unappropriated POBOC expenditure. 1994 MoE. AR 39 Administration of discretionary POBOC funding

PR n. abbrev.

position of responsibility, an official term used in the New Zealand education system to designate certain positions within a school. (also Aust.)

1984 DoE. BIG Sec.2.4 The report recommended that in activity centres the director's salary be at PR2 level. 1984 DoE. BIG Sec.2.4 Approval was given this year for payment of all directors at the level of PR2. 1987 T. BIG II.5 139 However, the 'position of responsibility' (PR) system gives some flexibility. Every school is allocated a certain number of PR points to be allotted to teaching posts at the discretion of the board within guidelines laid down by the Department. PR posts carry both status and salary increments.

\section{PSU n. abbrev}

pupil session unit, a Treasury term used in the administration of education in New Zealand, related to teacher: pupil ratios.

1987 T. BIG II.3 65 There is a government commitment to lower this under the PSU (pupil session unit) scheme to values of 1 to about $12-15 \ldots$ Currently there is a shortage of kindergarten teachers; this has delayed implementation of the PSU scheme.

\section{Puao-te-Ata-tu $n$.}

[Ma.] the name of an influential report commissioned by the DSW and published in September 1988.

1987 DSW. BIG 10 Similarly, before Puao-te-Ata-tu, grandparents or relatives who cared for their mokopuna did not qualify for assistance from the Department. 1988 DSW. AR 42 The Department held public meetings throughout the country to promote and discuss 'Puao-te-Ata-tu', and the news media provided extensive coverage of 'Puao-te-Ata-tu'. 1988 DSW. AR 47 The Social Security Amendment Act 1987 extended the criteria for eligibility for Orphans Benefit, as a result of recommendations in Puao-te-Ata-tu. 1989 DSW. AR 13 The Social Welfare 
Commission was established as part of the implementation of Puao-te-Ata-tu (the Report of the Ministerial Advisory Committee on a Maori Perspective for the Department of Social Welfare)." 1990 DSW. Key Issues for SW 64 Puao-te-Ata-tu, the Report of the Ministerial Advisory Committee on a Maori Perspective for the Department of Social Welfare, also challenged the way in which this Department developed and delivered social services, and questioned whether the methods were appropriate or effective in meeting the needs of a culturally diverse client group.

\section{public health nurse $\dagger n$.}

a nurse who works in schools and the community, educating and assessing.

$1985 \mathrm{DoH}$. AR 21 The essential features of the contract are that the care of pre-school children is the responsibility of the Plunket Society's district nurses; and public health nurses concentrate on the health of school children. 1987 DoH. AR 26 Public health nurses continued to provide an important health screening service for school entrants.

putaiao $n$. and attrib.

[Ma.] science.

n. 1993 MoE. $A R 16$ In addition to the Achievement Initiative: te reo Maori, work commenced on the development of draft curriculum statements for the Maori versions of the curriculum statements in science (putaiao) and mathematics (pangarau). 1994 MoE. AR Three Maori curriculum statements are being developed: Pangarau, Putaiao and te reo Maori, and development is on target. attrib. 1994 MoE. AR 95 Pangarau and Putaiao draft curriculum statements are being published while te reo curriculum statement draft is being made ready for publication.

\section{Putea Manaaki $n$.}

[Ma.] a fund established by the DSW to give small grants to rural community selfhelp initiatives.

1988 DSW. AR 41 ; the introduction of the rural special needs initiative (Putea Manaaki) for family and community self-care; 1987 DSW. BIG 12 Called Putea Manaaki, this funding is for rural areas with high Maori populations that are poorly served by social agencies, or areas which have a high Maori population and a high incidence of unemployment and/or other social problems. $1988 \mathrm{DSW}$. AR 44 The finance allocated to the Small Scale Preventative Projects Fund and Putea Manaaki 
programme will also be used for that purpose ... Putea Manaaki was established in 1987 to fund small scale community welfare initiatives, with an emphasis on rural Maori needs.

rangatiratanga $* \dagger n$.

[Ma.] sovereignty.

1987 T. BIG I.5 325 For example if partnership in respect of fisheries is confined purely and simply to receipt of a prescribed share of rentals, that would seem to be a one-sided and uneven arrangement, a very pale reflection of the 'rangatiratanga', or chieftainship over resources that is pledged in the Maori text. ... Though rangatiratanga implies an important role in the management of issues affecting the tribe, the ceding of general government is one of the clearest points in the Treaty, and no specific or general role in national issues is reserved for the chiefs and tribes. 1987 T. BIG II.8 224 According to the Maori text of the Treaty (as translated by Professor Kawharu) it was chieftainship (rangatiratanga) that was retained by the Maori people. 1989 DoH. BIG 70 The Treaty guarantees Maori people "tino rangatiratanga" (selfdetermination), the protection of all their precious taonga and all the rights and privileges of British subjects. $1991 \mathrm{MoE}$. $A R 13$ The growing confidence in tino rangatiratanga and self-determination is focusing towards an alternative delivery system that is controlled by Maori people themselves.

reading recovery $* \dagger n$. and attrib.

educ. developed in Auckland during the 1970s and implemented nationwide from 1982 when 15 tutors, selected from each education board, were trained in a 1 year course, a system whereby children at risk of reading failure are identified after one year of reading instruction and withdrawn from class for half an hour a day of individual instruction with a specially trained teacher for $12-14$ weeks.

n. 1986 DoE. AR 19 The 10 additional tutors of teachers of reading recovery, trained at the University of Auckland in 1985 to assist in maintaining the programme, took up positions at reading recovery centres at the beginning of 1986. attrib. 1984 DoE. AR 21 For reading recovery programmes to be successful, experienced teachers must be trained in the techniques. 1989 MoE. $A R 10$ New Zealand reading recovery procedures, initially developed by Dame Marie Clay, in association with advisers and 
education officers in the Department of Education, have now been taken up in several centres in Australia and the United States of America.

REAP $n$. acr. and attrib.

Rural Educational Activities Programme, an educational resource established in 13 isolated and sparsely populated districts throughout New Zealand between 1979 and 1982 in order to help provide equity for rural students.

n. 1984 DoE. AR 22 Meetings have been held with all the national organisations associated with REAP to seek their views. 1984 DoE. AR 22 At present the management committees of the REAPs have advisory powers only. 1984 DoE. AR 22 The 13 rural education activities programmes (REAP) use the equivalent of 92.6 teachers. attrib. 1990 MoE. BIG App.2:18 The review of the Rural Education Activities Programme (REAP) has been completed, and the Government has decided to defer any substantive decisions until early in the new year.

\section{recapitation $n$.}

educ. the restoring of Form 1 and 2 (Year 7 and 8) classes to a primary school which previously catered for this level of schooling but then had it removed. (See decapitation). (also Aust.)

1990 MoE. BIG 41 For these reasons, amongst others, a National Task Force on Recapitation has been set up to examine the issues and to report by the end of November 1990. $1990 \mathrm{MoE}$. AR 41 In such matters as the recapitation of contributing primary schools and the closure of schools, the procedures required by the legislation and the previous minister of Education led to several schools becoming impatient. 1993 MoE. AR 6 Later in the year, additional funds for five kura kaupapa Maori, recapitation, private schools, and integration were provided and ACCESS was moved to the Training Opportunities Programme (TOP).

recovered p. ppl. adj.

educ. applied to children who have successfully passed through the Reading Recovery Programme and have returned to mainstream reading classes.

1984 DoE. BIG Sec.3.35 In 1984, there are 409 schools operating Reading Recovery giving a potential for 4090 children to be "recovered". 1984 DoE. BIG Sec.3.35 A more realistic figure for 1984 might be 3000 children "recovered". 1984 DoE. BIG 
Sec.4.48 These figures are based on an average 10 children per teacher 'recovered' each year.

\section{remote $\operatorname{school} n$.}

a rural school classified as such by the Government and paid maintenance money loaded by an increasing percentage depending on its distance from the nearest town. 1990 MoE. BIG App.2:9 A remote school is one which is more than $30 \mathrm{~km}$ from a population centre of 2000 or more.

\section{residence $n$.}

a DSW residential institution providing short term care and custody services for young people referred under the Care and Protection and Youth Justice provisions of the Children, Young Persons and Their Families Act (1989).

1990 DSW. An Inventory of the Department and its Programmes 14 Each Residence is headed by a Director who is responsible to the relevant Assistant Director-General Operations. 1990 DSW. An Inventory of the Department and its Programmes $23 \ldots$ to propose measures which may be used by the Department to divert children and young persons from residences into appropriate care and control in the community. 1990 DSW. AR 41 Residences (previously referred to as institutions) provide residential care facilities for young people, where all other care options have been explored but found inadequate. $1990 \mathrm{DSW}$. Key Issues for SW 71 The provision of services to young people whose non-offending behaviour requires 24 hour supervision in a relatively secure setting, has traditionally been a role taken by residences. 1990 DSW. Key Issues for $S W 72$ The maximum "term" under the Act for placement in a residence is three months (two months with remission). $1991 \mathrm{DSW} . A R 16 \ldots$ in particular the decision not to place young people in residences outside of the region if at all possible; 1993 DSW. AR 44 The local Residents Association believed this practice was in conflict with the proposed use of the residence stated in the District Scheme.

resident teacher $n$. and attrib.

a Correspondence School teacher posted to live in other parts of New Zealand to service pupils in a rural area who are enrolled with the Correspondence School, by visiting the pupils and parents in their homes. 
1984 DoE. BIG Sec.3.101 Many pupils live in remote and inaccessible areas and, at present roll numbers for each resident teacher, they can only be visited once a year. 1984 DoE. AR 23 Two resident teachers took up duties in 1984 in the Wanganui and Napier districts. This provides complete coverage of the North Island by the resident teacher service for the first time, so that families will receive more personal advice. $1985 \mathrm{DoE} A R 14$ The establishment of 2 new resident teacher positions to cover the Wanganui-Taranaki and the Hawkes Bay areas completed a national coverage of the resident teacher service.

\section{resigning leave $n$.}

in the New Zealand public service, entitlement upon resignation to either paid time off work or the equivalent in a cash payout, accrued on a sliding scale by an employee of long service (normally 20 years or more).

2001 T. AR 109 Provision is made in respect of the Department's liability for annual leave, long service leave, retirement leave and resigning leave.

\section{responsibility based processing $n$.}

a system whereby experienced junior and middle management staff are made totally responsible for their work, and all checking of their work is eliminated. (also Aust.) 1987 DSW. AR 191986 saw the successful piloting in two district offices (Tauranga and Nelson) of a new management system for administering benefits, called responsibility based processing. 1987 DSW. AR 20 An evaluation of the two pilot schemes in Tauranga and Nelson clearly established that responsibility based processing works to the advantage of both staff and clients ... By 31 March 1987, responsibility based processing had been introduced into most Social Welfare offices. 1988 DSW. AR 13 The most successful example of delegation leading to improved service delivery is the Responsibility Based Processing (RBP) system.

\section{retiring leave $n$.}

an amount payable to an employee upon his or her retirement. (also Aust. and Ca.)

1984 DoE. BIG Sec.3.117 Retiring leave for teachers has been actively sought by the Teachers Unions and the Combined State Unions for some years now. $1994 \mathrm{MoE} . A R$ 25 Add portion of Retiring Leave not now subject to Fringe Benefit Tax $1994 \mathrm{MoE}$. 
$A R 27$ The provision for retiring leave represents the amount owing to those employees who were eligible to retire as at 30 June 1994.

\section{ROBOC $n$. acr.}

Receipt on Behalf of the Crown.

1990 DoH. $A R 37$ Debtors exclude amounts due on behalf of the Crown (ROBOCs). 1991 DoH. AR 26 Receipts Made on Behalf of the Crown (ROBOCs) 1992 T. $C P 80$ The process is fiscally neutral within the Crown and involves the Crown selling assets to the new entity, while simultaneously investing in the new entity i.e. the Crown pays for the shares by way of a POBOC and receives a ROBOC from the entity for the (same) value of net assets purchased from the Crown. 1994 DoH. AR 49 Total Vote:Health and Vote:CHE ROBOCs 1994 MoE. AR 74 ROBOC GST adjustment

\section{Rogernome $* n$.}

an advocate of the policies of then Minister of Finance Sir Roger Douglas.

1997 Easton 39 The 1984 Labour caucus contained a number of committed environmentalists, few of whom were Rogernomes committed to commercialisation solutions.

\section{Rogernomics $* \dagger$ n.pl.}

a popular term given to the financial policies of Sir Roger Douglas, Minister of Finance in New Zealand during the 1980s.

$1987 \mathrm{NZH} 16$ May Rogernomics finally became an officially approved word this week when the Labour Government use it to advertise the achievements of its Minister of Finance, Roger Douglas. Three months before an election in which it will be a key issue, New Zealand Herald economics reporter Simon Collins asks: "Is Rogernomics working?" ... Layoffs, which once seemed evidence of the failure of Rogernomics, are now being claimed by the Government as a sign of successful “restructuring". 1992 James 234 We have passed through Rogernomics - and National's extension of that into Rogernomics-plus - into post-Rogernomics. 1993 Kelsey 10 In the early years of Rogernomics, high interest rates had forced many small businesses to close. 1993 Kelsey 96 The architects of Rogernomics showed no such indecision. 


\section{roopu $n$.}

[Ma.] group.

1987 DSW. BIG 124 In addition, many positions allocated to Maatua Whangai within this Department would disappear, and other mechanisms need to be developed to maintain the links between social workers and tribal roopu. 1989 DoH. BIG 40 Nominations were called for in October-November 1988 from tribal authorities, national Maori health groups and other roopu a iwi. 1989a DoH. AR 49 To have facilitated the setting up of a new Maori Health Ministerial Committee with the support of roopu-a-iwi authorities and links to area health boards.

\section{runanga $* \dagger n$.}

[Ma.] assembly, council.

1988 DSW. AR 15 - working relationships with tribal runanga had to be established and plans co-ordinated with changes to the Maatua Whangai programme; $1992 \mathrm{MoE}$. $A R 87$ The Group Manager Maori is to begin discussions about the plan with appropriate external government and non-government agencies including iwi, runanga, tribal trusts, National Maori Congress and other groups.

\section{Runanga Matua $n$.}

[Ma.] a Ministry of Education advisory group.

1989 DoE. CP 5 A seven member Runanga Matua will ensure that Maori concerns are embraced as part of the changes. 1990 MoE. AR 57 Runanga Matua, an independent advisory body to the Minister on Maori policy matters, is serviced by the Ministry.

\section{safe prospect $n$. (uncountable)}

the ability to plan with reasonable confidence for the future - a term used in NZ (and one Aust. citation was found) to describe an aspect of social well-being.

1989 DoH. BIG 12 The Royal Commission's report emphasised themes of voice, choice and safe prospect.

\section{satellite class $n$.}

a classroom for children housed within the grounds of a regular school but separately administered, staffed and/or with a different purpose from the rest of the school. (also 
Aust.) (This is a different sense from the same term used in the U.S. where it means a class in a distant geographical location from the school).

1987 T. BIG II.4 102 Intellectually handicapped children attend special schools or satellite classes at regular schools. 1989 MoE. $A R 15$ The establishment of satellite classes for students with intellectual disabilities in secondary schools has been a major move towards educating these young adults with their peers. $1991 \mathrm{MoE}$. AR 65 For the 1991 school year, satellite classes of special education schools were funded on a percentage split agreed between the base and host schools.

\section{section 29 panel $n$.}

a group consisting of two commissioners and three departmental heads from the State Services Commission, convened to make high-level appointments in the public sector. So named because it is Section 29 of the State Services Act 1962 which specifies this requirement.

1987 T. BIG I.2.66 Appointments to high-level positions are made by an augmented SSC, in the form of a 'section 29 panel', consisting of two commissioners and three departmental heads.

\section{section 51 notice $n$.}

a gazetted notice about an amendment to the Health and Disability Services Act 1993 which concerned the prices paid to authorised midwives and doctors. (also Aust.)

1993 DoH. BIG 36 The Section 51 notice for maternity services expires on 1 April 1994.

\section{septic closet $n$.}

a toilet with a handbasin. (also Aust.)

1990 DoH. BIG I.44 - sewage tanks and septic closets;

\section{sheepmeats $n . p l$.}

a commercial term for mutton; the collective noun is used elsewhere but not in the plural. (also Aust.)

1984 T. BIG I.2 These exports, while not currently competing in the markets where New Zealand sells beef, have been to countries ... where New Zealand might expect 
to sell sheepmeats. 1984 T. BIG II.14 308 The precise extent of this subsidy will depend principally on prices realised for wool and sheepmeats.

\section{sheet home v.t.}

to cause to realise, to attach blame or responsibility for. (also Aust.)

1990a T. BIG 8115 The mechanisms for sheeting home the costs of accidents to the individuals and employers responsible should be examined.

\section{sinking lid $* \dagger n$.}

a form of cost-cutting in the public sector; a policy of reducing the number of civil servants by not replacing those who died, retired or resigned.

1984 T. BIG II.9 209 The shortcomings of the current system can be attributed to a number of factors:... an undue weight on across the board measures such as the sinking lid on staff numbers and less than full compensation for inflation which, it can be argued, are counterproductive in their effects on management practices. $1986 \mathrm{DoH}$. $A R 3$ The department has for several years operated with a restricted staff in response to the previous Government's sinking lid policy.

SMP n. abbrev. and attrib.

supplementary minimum prices, paid until 1984 by the New Zealand Government to farmers via the Meat Board and the Wool Board.

n. 1984 T. BIG II.9 77 The quantities produced of each commodity receiving SMPs in recent years have reflected relative SMP levels rather than international market prices. 1987 T. BIG I.4 246 The changes to date have included the abolition of Supplementary Minimum Prices (SMPs), ... attrib. 1984 T. BIG I.4 74 The major factor affecting spending is SMP payments, which are forecast to drop from $\$ 504.8$ million in $1983 / 84$ to $\$ 336.0$ million in $1984 / 85$. The $1983 / 84$ outturn includes an additional \$150 million brought forward from 1984/85, while the 1984/85 forecast includes additional "lump sum" payments arising from the termination of the SMP scheme.

\section{SOE $* \dagger$ n. abbrev.}

State-Owned Enterprise: a limited liability company owned by the state but which operates as a commercial business. Formed from the government's earlier trading 
operations under the State Owned Enterprises Act 1986, there were originally nine created; by 1994 there were 15 .

1987 T. BIG II.8 223 It is true that Mr Justice Cooke stated at one point in the Appeal Court judgement on the State Owned Enterprise case that 'The Treaty signified a partnership between races.' 1990 T. BIG 789 The financial performance of SOEs has improved significantly following corporatisation. 1993 T. BIG 365 State-owned enterprises (SOEs), for example, have assets totalling around $\$ 13$ billion.

\section{solo parent $* \dagger n$.}

a parent raising offspring alone.

1984 DSW. AR 30 Beneficiaries with limited cash assets who require funds urgently for essential needs such as spectacles and dentures, may receive an advance of their benefit of up to $\$ 250$ for married couples and solo parents, ... 1985 DSW. AR 22 Since 1 April 1981 a solo parent applicant for domestic purposes benefit has been required to identify the liable parent of each dependent child in his or her care 1987 T. BIG II.1 15 A further pressure, partly arising from a feminist critique, is for childcare facilities to allow both spouses and solo parents to work. 1990 DSW. Key Issues for $S W 24$ A solo parent household ...

\section{Sootaga $n$.}

[Sa.] a version of the DSW programme of fostering Maori children within extended family networks, modified for the Samoan population in New Zealand.

1984 DSW. BIG $148 \mathrm{We}$ are currently finalising details of a proposed Samoan adaptation of the Maatua Whangai programme to be known as Sootaga. 1987 DSW. $B I G 61$ The So'otaga programme (a partnership between the Department and the Auckland Samoan community) is to be expanded through the employment of two additional social workers. 1990 DSW. CP 38 - practical community liaison through special funding programmes (So'otaga and the Pacific People's Development Fund), newsletters and other activities;

\section{Special Area $n$.}

a rural location designated by the NZ government as needing a subsidy in order to attract a doctor to live and practise there (see Special Area Medical Officer). 
1987 DoH. AR 25 There will now be 16 salaried medical officers employed in 12 special areas, providing free medical care to residents of rural areas of special need. 1988 DoH. AR 29 The Te Kaha Special Area was renamed Te Whanau-a-Apanui Special Area in January 1988, to better reflect the tribal affiliations and boundaries of the special area. 1990 DoH. BIG I.App.106 Under certain circumstances loan money is available to purchase a motor vehicle for use in the Special Area.

\section{Special Area Medical Officer / Doctor $n$.}

a rural G.P. who lives and works in one of several government-designated regions (see Special Area).

$1987 \mathrm{DoH}$. AR 25 As a result of a conference of special area medical officers, new guidelines for employment and practice equipment are being developed with the employing area health hospital boards and district offices of the department. 1989b DoH. AR 32 Loans to Special Area Doctors 1990 DoH. BIG I.App.106 Special Area Medical Officers (SAMOs) is a scheme whereby salaried medical officers provide free medical care to residents of "special areas" which are usually isolated locations where it would be difficult to attract doctors. ... The SAMO establishment as at 31 March 1989 was 16. 1990 DoH. BIG I.App.106 Residents in a Special Area receive free medical care from the SAMO.

\section{special character attrib.}

a legal term as defined in the Education Act 1989, to designate an integrated state school with its own special character which is genuine, meritorious and in some way unique as defined in the Private Schools Conditional Integration Act 1975. In most cases the special character is religion-based; approximately $75 \%$ of integrated schools have a Catholic special character.

2001 T. AR 59 - the Government's response to the Review of the Education Review Office; the secondary school property guide; and guidelines for the establishment of integrated and special character schools

\section{special class $n$.}

a class for intellectually disabled pupils.

1985 DoE. $A R 17$ This education has taken place in special schools, school groups and in special classes and units in regular schools, or through the special needs section 
of the Correspondence School. 1987 DoE. BIG 71 It is more appropriate to relocate intellectually handicapped students presently educated in segregated schools into special classes or units in high schools, intermediate, and primary schools. $1989 \mathrm{MoE}$. $A R 41$ Includes teachers at full and contributing primary schools, intermediates, board special schools, attached intermediates, teachers of special classes, special needs teachers, and primary teachers at Correspondence School.

\section{special patient $n$.}

a person subject to an order made under the Mental Health Act 1992 or the Criminal Justice Act 1985 for detention in a psychiatric hospital.

$1986 \mathrm{DoH}$. AR $42 \mathrm{~A}$ new concept of 'maximum period of detention as a special patient' for 'under disability' patients was also introduced. $1987 \mathrm{DoH}$. BIG 80 - the granting of leave to special patients under section 47 of the Mental Health Act 1969, and the granting of leave to committed patients who, immediately before becoming committed patients, were special patients; 1987 DoH. AR 29 The recommendation of the Commission of Inquiry into the Donaldson case proposing an 'alert' system for special patients has been implemented by the Wanganui Computer Centre Amendment Act 1986. 1988 DoH. AR 35 The manager of the Mental Health Programme has specific legislative responsibilities relating to the care of special patients, who enter the health service via the criminal justice system. 1989a DoH. $A R$ 30 The recommendations of the Mason Report have highlighted the department's role in relation to both "special patients" and the work of official visitors and district inspectors as advocates for committed patients.

special pre-school $n$. and attrib.

a pre-school for intellectually handicapped children.

1985 DoE. AR 10 Following the department's evaluation of special pre-school groups for educationally handicapped children attending playcentres and kindergartens, negotiations have been proceeding on policy and administrative changes with the New Zealand Free Kindergarten Union, the New Zealand Free Kindergarten Teachers' Association and the New Zealand Playcentre Federation.

\section{special $\operatorname{school} n$.}

a school for intellectually handicapped children. 
1984 DoE. AR 46 Several special schools catering for intellectually handicapped children were also upgraded during the year. 1985 DoE. AR 18 Two important characteristics of special education have been the co-operation between parents and teachers and the sense of identification parents have felt with the special school. 1985 DoE. AR 42 Remodelling and other improvements were also carried out at Blomfield and Rosehill Special Schools.

SSC n. abbrev.

State Services Commission.

1987 T. BIG I.2 65 The SSC is the legal employer of public servants; departments are not.

state house $* \dagger n$.

a government-owned house used for rental accommodation to low-income earners.

1992 James 137 The number of state houses built or bought more than doubled.

state primary $n$. (state school $* \dagger$ )

a government-owned and run primary (elementary) school, part of the state education system.

1987 T. BIG II.1 13 State primary class sizes have reduced dramatically over the last 20 years:

\section{sub-output $n$.}

a sub-class of output, i.e. a good or service produced by a department and purchased by the government to achieve their outcomes. (also Aust., Fiji and Western Samoa)

1990 DoH. BIG R.3.6 Sub-output: Tobacco smoking

TAC $†$ n. abbrev.

total allowable catch - a term used in the fishing industry for an amount set by the government.

1984b T. BIG 1088 The setting of the TACs, which are the sum of the ITQs and hence also related to particular species and stocks, determines the speed at which the various fish stocks will be built up again and future economic surpluses secured. 


\section{tagged funding $n$.}

money earmarked for a particular purpose and unable to be spent on anything else. (also Aust.)

1984 DoH. BIG 3 The introduction of the Accident Compensation schemes and later the channelling of "tagged" funding to hospital boards in the form of community care funding were the main factors leading to growth in the 1970s.

taha Maori $* \dagger n$. and attrib.

[Ma.] 1 the Maori side or viewpoint in general; 2 name of a subject taught in NZ schools.

1 n. 1985 DoE. AR 21 First-hand experience of Maori culture as a living thing has encouraged a number of schools to build taha Maori into their day-to-day practices and administrative procedures. 1987 T. BIG II.8 225 Apart from specific teaching of Maori language and culture, taha Maori is a "Maori dimension" which is meant to permeate the school...1987 DSW. BIG 61 To date the Pacific Island community within New Zealand would be somewhat justified in noting the apparent discrepancy between the Department's obvious focus on taha Maori and the comparatively limited attention accorded to other minority cultures. 1987 DoH. BIG 150 ;support for the introduction of Te Taha Maori into the training of health workers; 21987 T. BIG II.4 109 The Curriculum review seeks to develop non-racist and non-sexist materials at all school levels and taha Maori particularly at primary level. 1987 T. BIG II.6 206 The New Zealand Curriculum Review proposes both elements: it contains recommendations for including taha Maori and for eliminating racism and sexism. attrib. 1992 MoE. AR 89 - the effectiveness of taha Maori programmes in mainstream education;

taha Pakeha $* \dagger n$.

[Ma.] the pakeha way of seeing things.

1987 T. BIG II.8 218 Walker notes that Ngata, the greatest Maori leader of this century saw facility in English as the means of gaining access to taha pakeha (European culture).

tall poppy attrib. * in DNZE as $n$. and v.t.; not as attrib. or in the comparative form. $\dagger$ in NZOD as $n$. and in comb. (a different one to below); not in comparative form. 
so successful as to attract attention, and sometimes hostile notice. (also Aust.)

1984 T. BIG 2.14308 The motivation for this expansion factor rule is to ensure that a somewhat faster rate of adjustment to import competition is faced by the most highly assisted ("tall poppy") industries as revealed by the size of tender premia. $1984 \mathrm{~T}$. $B I G 2.14310$ Instead of the proposed annual increments of between 2.5 percent and 5 percent of domestic production (less exports) the rates could be increased to, say, a minimum of 5 percent of the market with higher rates for taller poppy items as revealed by tender premia.

tamariki $* \dagger n . p l$.

[Ma.] children.

1992 MoE. AR 90 ;initiatives to increase the attendance of mokopuna and tamariki;

\section{tangata whenua $* \dagger n$.}

[Ma.] literally the people of the land; the indigenous race of New Zealand, the Maori. 1987 DoE. $A R 12$ The first is that, for the first time in our history, a committee of Maori and Pakeha have acknowledged clearly and unequivocably that the culture and values of Maori as tangata whenua must be an integral part of the required curriculum for all New Zealanders, not something tacked on to courses of study that are in all essential respects derived from Pakeha culture. 1987 DoH. BIG 70 This programme acknowledges the Maori as the tangata whenua, and aims to promote a bicultural approach. 1990 T. $A R 68$ The Treasury sought to meet its objectives in this area by providing staff with an introduction to bicultural issues and by developing an approach to policy work which encourages the recognition of a special relationship between the Crown and the Tangata Whenua.

tangi $* \dagger n$.

[Ma.] a funeral, a death ritual, sometimes of three or more days.

1987 T. BIG II.8 $226 \mathrm{We}$ are doing that in the wananga, in the homes, at the tangi, wherever we meet.

\section{tangihanga leave $n$.}

a paid leave from employment entitlement to attend and participate in the ceremonies, rituals for the dead and grieving process which accompany a Maori funeral. 
1990 DoH. BIG R.3.3.App.C.2 - bereavement / tangihanga leave approval 1991 Boston et al 68 These included existing provisions for maternity leave, sick leave, retiring leave, childcare facilities, flexible hours, tangihanga leave, permanent parttime work, and other matters.

taonga $* \dagger n$.

[Ma.] (a) treasure; an item, possession or token (tangible or intangible) precious to its owner.

1987 T. BIG I.5 321 On this basis, the Tribunal has suggested that 'taonga' ('other properties' in the English text) should be read to include cultural as well as physical 'treasures'. 1989 DoH. BIG 70 The Treaty guarantees Maori people "tino rangatiratanga" (self-determination), the protection of all their precious taonga and all the rights and privileges of British subjects. 1993 MoE. BIG 29 The Waitangi Tribunal agrees with the Maori regard for their language as a taonga, and has judged it to be protected by virtue of the Treaty of Waitangi.

\section{tariff $n$.}

the official list of approved drugs which are subsidised by the NZ government. (also Aust.)

1985 DoH. AR 34 The implementation of this decision in the Drug Tariff was challenged in the High Court by the manufacturer of the dearer product, Gaviscon. 1990 DoH. BIG R.3.29.6 Supply of these items through the tariff means that the New Zealand public as a whole is paying considerably more than would occur if they were sold through the ordinary highly price competitive non-tariff system.... The tariff is the list of pharmaceutical and allied products which are approved and partly or fully paid for by the government when prescribed for patients by medical practitioners. 1991 DoH. $A R 40$ An update to the Drug Tariff and 5 amendments to the Tariff were published during the year.

\section{te Ao Maori $n$.}

[Ma.] the Maori world.

1986 DoE. $A R 24$ Important aims of the draft syllabus are the development of an understanding of nga tikanga Maori through which te reo (the Maori language) asserts 
itself, and the gaining of a deeper understanding of, sensitivity to, and respect for, te Ao Maori (the Maori world).

Te Atakura $n$. and attrib.

the programme for fluent Maori speakers to train as secondary school teachers of Maori language.

1987 DoE. BIG 59 An example of such an issue is the provision of adequate resources to enable to accommodation of teachers from the Te Atakura Scheme, who will enter schools in 1988, and in subsequent years. 1988 DoE. AR 8 Forty Te Atakura Maori language specialists graduated from a one-year Division $\mathrm{C}$ secondary teacher training programme in Whangarei, Auckland, Palmerston North and Christchurch at the end of 1987. 1991 MoE. AR 12 Consequently, colleges of education offer bilingual programmes for experienced teachers, and the Atakura training programmes for secondary teachers acknowledges [sic] the Maori language and cultural attestation of home marae and iwi in the recruitment of Maori trainees.

\section{Te Koputu Taonga $n$.}

[Ma.] the name of a DSW programmme.

1984 DSW. BIG 147 In Otara we are part of a project known as Te Koputu Taonga which aims to increase parenting skills and improve family life among mostly Maori families in the area. $1987 \mathrm{DoH}$. BIG $145 \mathrm{Te}$ Koputu Taonga translated literally means a "store house of precious things". When established it was extremely innovative in that it developed an administrative structure in which several government departments (Health, Social Welfare, Education, Labour, and Internal Affairs) and the local Manukau City Council could work together, sharing skills, resources and a common philosophy to train local people as community workers.

\section{te reo (Maori) $* \dagger n$.}

[Ma.] literally the language; the Maori language.

1986 DoE. $A R 24$ Important aims of the draft syllabus are the development of an understanding of nga tikanga Maori through which te reo (the Maori language) asserts itself, and the gaining of a deeper understanding of, sensitivity to, and respect for, te Ao Maori (the Maori world). 1987 T. BIG II.8 236 The Waitangi Tribunal, in its finding on te reo Maori, said that it suspected that attitudes disparaging of Maori 
culture and history exist somewhere in the education system. 1990a DoH. AR 55 The Department's eye-testing provisions were extended through the employee agreement and a Te Reo Maori allowance was introduced to recognise staff who use the Maori language in their jobs.

\section{te tinana, te wairua, te hinengaro $n$.}

[Ma.] educ. health (the Maori term for the school subject). Literally: the body, the soul and the mind; physical, spiritual and emotional respectively.

1992 MoE. AR 25 The Framework describes seven essential learning areas which describe in broad terms the knowledge and understandings which all students will learn: language and languages / te reo, nga reo; mathematics / te pangarau; science / te taiao; social sciences / te tikanga-a-iwi; the arts / nga toi; health and physical wellbeing / te tinana, te wairua, te hinengaro; and technology / te putaiao.

\section{Te Tirohanga Rangapu $n$.}

[Ma.] the name of a discussion white paper by Koro Wetere, Minister of Maori Affairs, in April 1988 on the devolution of the Department of Maori Affairs.

1989 DoH. BIG 67 More recently the Government's objectives outlined in the two discussion papers $\mathrm{He}$ [sic] Tirohanga Rangapu and He [sic] Urupare Rangapu released by the Minister of Maori Affairs.

\section{Te Urupare Rangapu $n$.}

[Ma.] a major government policy statement published in November 1988, the outcome from the Tirohanga Rangapu (see above) that saw the devolution of the Department of Maori Affairs. This heralded an unprecedented partnership between government and Maori by promising devolution of responsibility and some measure of self-governance to iwi.

1989a DoH. $A R 5$ The Government's Maori affairs policy was enunciated in $T e$ Urupare Rangapu in November 1988. 1990 T. AR 32 The Treasury worked to strengthen both the Ministry of Maori Affairs and the Iwi Transition Agency (ITA) on the practical application of the objectives spelt out in Te Urupare Rangapu and in the development of the Runanga Iwi Bill. 1990 T. AR 68 In all these policy and related activities the Treasury has had the objective of being supportive of the Te Urupare Rangapu principles and the Principles for Crown Action on the Treaty of Waitangi... 


\section{technical refresher leave $n$.}

educ. a government scheme for teachers at technical institutes who may apply after five years' full-time service, and subsequently for a second time after a further ten years' service, for a paid break to return to industry to update their knowledge and skills.

1984 DoE. BIG Sec.3.135 Labour will also upgrade staff training provisions through improvements in technical refresher leave provisions. 1984 DoE. BIG Sec.3.135 The Technical Refresher Leave scheme (TRL) was introduced in June 1974 for selected technical institute tutors to enable them to return to industry and commerce on full pay to make themselves conversant with current techniques and practice in the areas in which they are teaching. 1984 DoE. BIG Sec.3.135 There is a 2 percent per year additional staffing entitlement available to technical institutes, which enables them to appoint relievers when permanent tutors are on technical refresher leave.

Think Big / think big $* \dagger n$. and attrib.

a policy of New Zealand's conservative government in the early 1980s, characterised in particular by energy generation schemes, later often deemed wasteful and excessive.

n. 1989 Easton 120 A major public debate took place and the National Government made Think Big a centrepiece of its 1981 election manifesto. attrib. 1987 T. BIG II.1 8 If the return is, in fact, negligible, as the US findings appear to suggest, the Net Present Value of about $-\$ 1,500$ million would be comparable to the sum of losses in Net Present Value terms of several of our recent 'Think-Big' industrial projects. 1987 NZH 16 May Deregulation of the finance sector has forced companies there to accept lower profit margins, while the wind-down of "think big" projects and changing labour practices are believed to have caused a productivity increase in the construction industry of around 20 per cent.

\section{tikanga $* \dagger n$.}

[Ma.] traditional practices; customary way of doing things.

1986 DoE. $A R 24$ The major emphasis in the syllabus is on speaking the Maori language, and understanding elements of tikanga Maori (Maori behaviour, attitudes, and values). $1993 \mathrm{DoH}$. $A R 76$ These included a cultural awareness programme that familiarised staff with marae protocol, customs, tikanga and other aspects of Maori 
lore and marae life. $1994 \mathrm{MoE}$. AR 96 The responsibilities of this position include ensuring staff (particularly Maori staff) are able to improve Maori language fluency and understanding of tikanga;

\section{tikanga-a-iwi $n$.}

[Ma.] social science.

1992 MoE. $A R 25$ The Framework specifies seven essential learning areas which describe in broad terms the knowledge and understandings which all students will learn: language and languages / te reo, nga reo; mathematics / te pangarau; science / te taiao; social sciences / te tikanga-a-iwi; the arts / nga toi; health and physical wellbeing / te tinana, te wairua, te hinengaro; and technology / te putaiao.

\section{Tohunga $* \dagger n$.}

[Ma.] a Maori healer, either physical or spiritual.

$1985 \mathrm{DoH}$. AR 8 The whenua (placenta) and diseased body parts are now made available for families, and the importance of local Tohunga, traditional healers, and Minita Maori (Maori Ministers of Religion) is clearly recognised.

\section{Tomorrow's Schools $n$. and attrib.}

a Government policy document published in August 1988 by David Lange, then Minister of Education. Subtitled 'The Reform of Education Administration in New Zealand", it resulted from the 20,000 responses to the Picot Report.

n. 1989 DoE. $C P 2$ The Government in 'Tomorrow's Schools', 'Before Five', and 'Learning for Life', has announced its policy position for the far-reaching reform of the administration of education. 1989 DoE. $A R 17$ The administrative costs for the Implementation Unit overseeing the transition towards Tomorrow's Schools is [sic] also reflected in the programmes. $1990 \mathrm{~T}$. AR 37 Provide advice to support the implementation of Tomorrow's Schools, Before Five and Learning for Life. attrib. 1989 DoE. CP 15 Undertake Tomorrow's Schools grants payment. 1989 DoE. AR 7 Publication of “Tomorrow's Schools” Working Group Reports. 1990 MoE. CP 29 To begin to remedy the deferred maintenance of the Tomorrow's Schools asset base. 1990 T. BIG 8b 133 Although the Tomorrow's Schools' administrative reforms are likely to bring about improvements in educational outcomes, problems of choice, efficiency and equity remain. $1990 \mathrm{MoE}$. BIG App.8:3 The project monitored and 
evaluated teacher/school consultation with parents, whanau, and the broader community during the pilot implementation of the Curriculum Review recommendations and subsequently during implementation of the Tomorrow's Schools reforms.

\section{training benefit $n$.}

a DSW benefit payable to people enrolled on training courses.

1998 DSW. Public Discussion Document Feb. 20 The Government pays some money directly to individuals for training (eg to almost 32,000 people on training benefit).

Treaty (of Waitangi) $* \dagger n$. and attrib.

the Treaty of Waitangi, New Zealand's founding document, signed in 1840.

n. 1987 T. BIG I.5 319 The Treaty has attracted very considerable public interest in recent years. 1987 T. BIG I.5 347 However, this does not mean that the Crown has a Treaty-given right to impose a system of law that is consistently alien to Maori practices and beliefs. 1987 T. BIG II. 8222 The promises in the Treaty of Waitangi of equality in education as in all other human rights are undeniable. attrib. 1987 T. BIG I.5 320 The argument for doing so is that Treaty issues cannot be shelved until, one by one, they are addressed by the Tribunal or the Courts.

\section{Triple(-)S attrib.}

relating to a "special sessional scheme", a DoH programme under which general practitioners may claim an hourly fee for participating in approved health promotion and health education activities.

n. 1984 DoH. AR 30 - details of the "Triple S Scheme". This is an alternative method to the fee-for-service / general medical services benefit method of remunerating general practitioners; 1990 DoH. BIG I.App.102 Functions such as student health services, health centre managers, the Triple "S" Scheme and the emergency locum scheme are included in these subsidies. attrib. 1989a DoH. AR 22 To have analysed results of a survey of Triple-S participants, and formulated any necessary changes to guidelines.

\section{tuatara $* \dagger n$.}

[Ma.] an endangered lizard-like reptile, indigenous and unique to New Zealand. 
$1992 \mathrm{MoE} . A R 58$; a senior science resource on the tuatara;

\section{Tu Tangata $n$.}

[Ma.] "Stand Tall", the name of a Maori social and political initiative developed and led by the Secretary of Maori Affairs, Kara Puketapu, in the mid 1970s. This was the precursor to Te Urupare Rangapu.

$1984 \mathrm{DoE} . A R 7$; and support for the various educational and training programmes under Tu Tangata. 1984 DoE. AR 12 The fourth general objective is being defined and developed largely by the Maori people themselves in the Tu Tangata movement. 1987 DoE. AR 13 One consequence of the greater assertiveness of Maori leaders under Tu Tangata has been to spark similar movements among various groups who identify as ethnic minorities in the larger New Zealand community.

\section{Tuhonohono $n$.}

[Ma.] the name of a DSW programme.

1987 DSW. BIG 34 This is particularly the case for Tuhonohono - Neighbourhood family support services programme. 1987 DSW. BIG 133 Tuhonohono was developed in 1984 to provide funding for neighbourhood and whanau development which supports families. 1988 DSW. AR 43 Tuhonohono provides financial grants to assist neighbourhood and whanau development by implementing projects to assist and support families with dependent children. 1989 DSW. AR 34 Tuhonohono funds were mostly reallocated to the new CWIF programme.

UE $* \dagger$ †. abbrev.

University Entrance (examination).

1987 T. BIG II:8 231 While Maori participation rates at university level are undoubtedly very much lower than Pakeha rates, Maori students with UE are, according to Nash, more likely to proceed to university than non-Maori students with UE. 1987 T. BIG II:8 235 Secondly, working class pupils are less likely to enter the upper class even when they do attain UE.

\section{union health centre $n$.}

a low-cost medical centre, originally part-funded by various Workers' Unions. 
1989 DoH. BIG App. 2 - union health centres in Wellington, South Auckland, West Auckland and Christchurch. 1989 DoH. BIG App. 3 The funding of all the projects is time-limited, with a maximum of three years for projects such as the union health centres..... The report on the Union Health Centres is currently being peer-reviewed before publication and the evaluation of the first 3 womens' [sic] health centres is nearing completion and will be published.

utu $* \dagger n$.

[Ma.] revenge to restore balance and regain mana.

1987 T. $B I G$ I:5 346 For example, the right to make war and enslave opponents was abandoned as was the seeking of revenge or utu.

\section{Vote $\dagger n$.}

the money allocated in the Budget for each government department.

1984 T. BIG II.10 227 A second step would be to allocate tax expenditures, where possible, to particular departmental Votes.

in comb. Vote analysis the setting and management of the budget at a national level.

1993 T. AR 71 During 1992/93 the Treasury continued to develop its approach to Vote analysis to take account of current and future directions in public sector financial management.

Vote Minister the government minister responsible to Parliament for the money voted for his/her particular area when Parliament has passed the budget. 2001 T. AR 5 This exercise triggered a dialogue between Finance Ministers and Vote Ministers on the fiscal implications of emerging risks and policy options in several significant areas, including health and social services. 2001 T. DFR 8 CCMAU's Executive Director enters directly into purchase agreements with Vote Ministers to provide advice independent of the Treasury on issues arising from the ownership of Crown companies.

1993 DoH. BIG 43 This spending is currently being "unbundled" from Vote: Health, and will in future be appropriated in Vote:ACC. 1989 T. AR 29 The costs of and proceeds from privatisation recorded through Vote:Capital Participation are also not recorded in these accounts. 1994 DoH. AR 48 Vote:CHE POBOCs 1984 T. BIG I.4 74 The increase of 10.6 percent in Vote:Defence reflects some major underexpenditure in 1983/84 which was in part related to the Defence review 
conducted last year. 1987 T. BIG II.6 180 Little information is available about education and training funded outside Vote:Education. 1984 T. BIG II.9 208 Other packages have included assistance to employment and funding for Vote:Energy. 2001 T. DFR 22 From 2000/01 the Treasurer and Finance Votes have been combined into a single Vote, Vote Finance. 1987 DoH. BIG 114 Additional funding is provided for direct expenditure from Vote:Health for major items of specialist equipment. 1989 DSW. AR 25 Includes $\$ 6,662$ formerly paid from Vote:Housing. 1984 T. BIG I.4 75 Other factors contributing to the low forecast are the effect of the "tail-end" of the 3 percent exercise on universities and a transfer of the Young Persons Training Programme to Vote:Labour. 1990 DSW. An Inventory of the Dept 70 GRI expenditure is now charged to Vote:Senior Citizens. 1987 DSW. BIG 17 For example: the costs of recent moves towards community care in the areas of mental health and criminal justice are largely being borne through Vote:Social Welfare without an equivalent transfer of funds from Votes:Justice and Health. 1984 T. BIG I.4 74 This is influenced by the decision to abolish Vote:Stabilisation and pay the subsidy on milk (the only remaining item in the Vote) directly from Vote:Agriculture and Fisheries (which is included in the function Land Use). 1994 T. AR 5 The Treasury reports against 15 Output Classes, encompassing Vote:Treasury (output Classes 1 - 9), Vote:State-Owned Enterprises (Output Classes 10,11,13 and 14), Vote:Crown Research Institutes (Output Class 12) and Vote:Crown Health Enterprises Monitoring (Output Class 15).

\section{Waiora $n$.}

[Ma.] spiritual health, well-being; the name of a DoH programme which used community-based activities and television to encourage and promote a positive image of Maori people.

$1985 \mathrm{DoH}$. AR 7 The Waiora programme evolved from the work of Te Koputu Taonga and is the most ambitious initiative in the Maori health area. Waiora means total wellbeing. 1987 DoH. BIG 145 Waiora Programme This programme has been developed by a group of young Maori people who wish to assist their people achieve Waiora (total wellbeing). 1989 DoH. BIG 121 Grants have been made to the Maori Women's Welfare League and to Waiora in recognition of the fact that the Maori population is at special risk from heart disease and need the resources to address these problems in specific ways. 
wairua $* \dagger n$.

[Ma.] the soul, spirit.

1987 T. BIG I:5 321 This seems to be consistent with what we understand to be the Maori approach to interpretation, under which the wairua or spirit of what is said is more important than the actual words. 1990 MoE. BIG 141 The essence of Maoriness - te iwi wairua - is doomed if Maori alone are expected to sustain it.

\section{Waitangi Tribunal $\dagger n$.}

a commission established to hear Maori grievances against the NZ government dating back to the Treaty of Waitangi.

1987 T. BIG I.5 320 It has been given legal status in various statutes, especially the State Owned Enterprises, Conservation and Environment Acts and the Treaty of Waitangi Act which established the Waitangi Tribunal. 1987 T. BIG II.8 219 Dr Bruce Bigg's evidence to the Waitangi Tribunal gave similar figures: in 191390 percent of Maori school children could speak Maori, 26 percent in 1953 and less than five percent in 1975. 1987 T. BIG II.8 222 The Tribunal was in no doubt that the education system is failing Maori children.

\section{wananga $n$.}

[Ma.] 1. a Maori tertiary educational institution. 2. a meeting.

1. 1987 T. BIG II. 6180 - the confederation of Ngati Raukawa, Ngati Toarangatira and Te Atiawa have established Te Wananga o Raukawa as a contemporary interpretation of the traditional wananga (school of higher learning); 1987 T. BIG II.8 220 At the university level, Maori people have also felt the absence of an institution geared to their own needs, and they established their own university at Otaki - Te Wananga o Raukawa. 1993 MoE. $A R 16$ The Minister announced that two new wananga (Maori tertiary institutions) were to be established in 1993. 2. $1985 \mathrm{DoH} A R$ 9 Departmental representatives attended the $21^{\text {st }}$ birthday celebrations of Manu Ariki in Taumaranui and have subsequently participated in several wananga (seminars) organised by the society.

$\operatorname{wash}(-) \mathbf{u p} n$. and attrib. 
an audit and settling of accounts; the final changes to financial estimates (Budgets and actuals) that Treasury and the Minister of Finance are able to make, because minor, without going through Cabinet. (also Aust.)

n. 1990 MoE. AR 15 That work has now been carried out and overpaid and underpaid early childhood centres were subjected to a 'wash-up' in June 1990. $1991 \mathrm{MoE} . A R$ 67 Grant washups relating to 1989 grants were paid out as schools completed their financial statements and forwarded audited copies to the Ministry. attrib. $1990 \mathrm{DoH}$. $B I G$ R.3 App. Fig.1 "Wash up” Appropriation bill + Estimates 1990 MoE. BIG App.I:4 It is delivered to the management of chartered services four times a year on an advance/washup basis. 1990 DSW. Key Issues for SW 97 The last chance the Department has to make adjustments, without having to take a special case to Parliament (which was necessary last financial year) is the Wash Up Estimates ... Last year, decisions on Wash Up Estimates were made by Government in February (four months before the end of the financial year). 1990 MoE. AR 39 A wash-up payment is to be made in January 1991. 1991 MoE. AR 65 Early childhood services received a 25\% washup grant for June 1990, 100\% funding for July 1990 to May 1991, and an advance for June 1991. 1994 MoE. AR 83 Grants Washup Recoveries

\section{whakapakari whanau $n$.}

[Ma.] a work philosophy within the NZ Department of Social Welfare whereby families are encouraged to make their own decisions.

1989 DSW. AR 33 The promotion of whakapakari whanau or family decision making as a social work practice, in which whanau or family make decisions and are empowered to take more responsibility for their own members. 1990 DSW. Key Issues for SW 111 Similarly, the adaptation within the Department of the Maori process of whakapakari whanau / family decision making provided a model for the family group conferences under the CYP \& F Act 1989. 1990 DSW. CP 45 The Matua Whangai way of working - whakapakari whanau or family decision-making has been acknowledged in the directions taken by the CYP \& F Act.

\section{whakapapa $* \dagger n$.}

[Ma.] genealogy, family tree.

1985 DoE. AR 23 Each applicant is now required to provide a whakapapa (genealogy) and a statement of support by an elder of the whanau (family). 
whanau $* \dagger n$. and attrib.

[Ma.] (extended) family.

1984 DSW. AR 37 The programme is seen as building on the promise shown by Te Kohanga Reo in association with the whanau system. 1987 T. BIG I.5 332 In some cases payment to the tribe as a whole may also reflect the fact that it is often impossible to determine, after the passing of so many years, which particular whanau (families) or hapu (sub-tribes) may have been the main losers when confiscations of tribal land occurred. 1987 T. BIG II. 368 These were established by Maori people and provide ECS in a whanau setting and aim for the children to become familiar with Maori language and Maori cultural values. 1987 DSW. BIG 133 It enables support to be given to urban whanau (multi-tribal and multi-cultural) and developmental and preventive activities. 1988 DSW. AR 14 Extension of orphans benefit provisions to include the claims of unsupported children so payment can be made to whanau members looking after these children. 1993 DoH. $A R 75$ Interviewees continue to be encouraged to bring support or whanau groups to interview.

\section{whanaunga $n$. pl.}

[Ma.] relatives.

1987 DSW. BIG 124 In 1986, in a deliberate policy change, the focus shifted to strengthening the tribal network of iwi-hapu-whanau, in the belief that the pulling together of the people as whanaunga, as tribal members, is in the long run the strength of this programme.

\section{whanaungatanga $\dagger n$.}

[Ma.] family ties, relationship.

1987 DSW. BIG 133 (c) to foster a sense of belonging and whanaungatanga.

\section{whanau wananga $n$.}

[Ma.] a local school of learning, whether whanau, hapu or iwi-based, sometimes very formal and using experts in history, tikanga and whakapapa.

1987 T. BIG II.3 68 The method of learning is community oriented, in the form of whanau wananga. $1990 \mathrm{MoE}$. $A R$;a feasibility study for establishing a whare wananga in or near Kaitaia; 
whare kura $* \dagger$ (though in both with an earlier, more general meaning) $n$.

[Ma.] a Maori immersion high school.

1993 MoE. AR 32 A whare kura (kura kaupapa Maori secondary school) is being piloted at Hoani Waititi Marae, with milestone reports due in 1993/94.

\section{Whare Rapuora $n$.}

[Ma.] a Maori health unit in the MidCentral Health region which offers marae-based accommodation within the whare for any number of whanau (relatives) of the patient who need to stay.

1989 DoH. BIG 162 Since the Cabinet directive in September to sell surplus assets, one of the properties in Glen Innes, has been removed from the list (after discussion with the Treasury) - in late July 1988, a Whare Rapuora was established in the building and was operating successfully from this location.

\section{whare wananga $* \dagger n$.}

[Ma.] houses of higher learning; Maori tertiary institutions.

1990 MoE. BIG App.8:3 Recent initiatives for the further development of iwi-based tertiary institutions, Whare Wananga, have been accompanied by requests for research and development support from the Ministry. 1991 MoE. AR 13 Legislation now allows for the establishment of state-funded whare wananga. $1993 \mathrm{MoE}$. BIG 36 Over the last three years the Government has begun funding whare wananga;

wharenui $* \dagger n$.

[Ma.] a meeting-house, often named after a highly respected ancestor.

1984 DoE. AR 10 A growing number of schools and teachers colleges have established wharenui or marae; they are also being established at universities and technical institutes. 1984 DoE. BIG Sec.4.24 Provision of a marae or whare nui at educational institutions;

whenua $* \dagger n$.

[Ma] placenta.

1985 DoH. $A R 8$ The whenua (placenta) and diseased body parts are now made available for families, and the importance of local Tohunga, traditional healers, and Minita Maori (Maori Ministers of Religion) is clearly recognised. 
zoning $* \dagger$ (defined in these two dictionaries as relating to secondary schools only, this system is now used by many primary schools in New Zealand) vbl. $n$. and attrib. out of zone, zone attrib., zoned adj.

a system whereby a school (secondary or primary) adopts an "enrolment scheme" which limits its pupils to those residing within a defined geographical area or zone around the school.

n. 1990 MoE. $B I G$ vii_Z Zning for ses@ndary, schools illustrates the way, in which choice is effected and the tensions which arise when the state constrains choice. attrib. 1987 T. BIG II.5 139 Zoning procedures (under which a geographical zone within which students have absolute right of attendance - is indicated) exist at 53 percent of surveyed schools in 1985 (as against 42 percent in 1973). There are thought to be some 22 areas operating zoning schemes.... Where zoning existed, proximity of residence was only used as a selection criteria in 20 percent of out of zone cases in 1985 (43 percent in 1975). Sixty-nine percent of zoned schools said they did not use this as a criterion. $1990 \mathrm{MoE}$. BIG 41 Zoning policy served a variety of purposes over the forty-five years since World War II. $1991 \mathrm{MoE}$. CP 21 This has resulted in changes to zoning and enrolment policies for state schools and the decision to restore funding for independent schools to a level equivalent to a $20 \%$ salary grant. 


\section{APPENDIX II}

ANTEDATINGS AND POSTDATINGS FOR THE DNZE (Orsman, 1997)

The years in the right-hand column are the dates of citations listed in Appendix I of this thesis. As all these words, and citations for them, can be found in Appendix I, the citations are not repeated here.

\begin{tabular}{|c|c|c|}
\hline Aotearoa & postdating by 1 year & 1994 \\
\hline ACCESS & $\begin{array}{l}\text { antedating by } 1 \text { year } \\
\text { postdating by } 3 \text { years }\end{array}$ & $\begin{array}{l}1987 \\
1994\end{array}$ \\
\hline accredit & postdating by 11 years & 1987 \\
\hline bulk funding & postdating by 5 years & 1997 \\
\hline CHE & postdating by 5 years & 1997 \\
\hline contestability & postdating by 7 years & 1993 \\
\hline contributing school & postdating by 2 years & 1991 \\
\hline Correspondence School & postdating by 2 years & 1990 \\
\hline district high school & postdating by 7 years & 1984 \\
\hline DPB & postdating by 6 years & 1997 \\
\hline gift duty & postdating by 20 years & 1984 \\
\hline half-pie & postdating by 3 years & 1992 \\
\hline hapu & postdating by 8 years & 1987 \\
\hline hui & postdating by 4 years & 1994 \\
\hline integrated & $\begin{array}{l}\text { antedating by } 2 \text { years } \\
\text { postdating by } 12 \text { years }\end{array}$ & $\begin{array}{l}1987 \\
2001\end{array}$ \\
\hline integration & postdating by 18 years & 1993 \\
\hline iwi & postdating by 3 years & 1994 \\
\hline kakapo & postdating by 2 years & 1991 \\
\hline karakia & postdating by 43 years & 1991 \\
\hline kaupapa & antedating by 2 years & 1987 \\
\hline kohanga reo & postdating by 1 year & 1994 \\
\hline kowhaiwhai & postdating by 1 year & 1987 \\
\hline
\end{tabular}




\begin{tabular}{|l|l|l|}
\hline kura kaupapa & antedating by 2 years & 1987 \\
\hline language nest & postdating by 2 years & 1990 \\
\hline mana & postdating by 3 years & 1987 \\
\hline Maoritanga & postdating by 2 years & 1990 \\
\hline national superannuation & postdating by 4 years & 1998 \\
\hline playcentre & postdating by 2 years & 1990 \\
\hline Rogernome & postdating by 11 years & 1997 \\
\hline taha Maori & postdating by 3 years & 1992 \\
\hline taha Pakeha & postdating by 2 years & 1987 \\
\hline tall poppy & antedating by 7 years & 1984 \\
\hline tamariki & postdating by 12 years & 1992 \\
\hline whare kura & postdating by 22 years & 1971 \\
\hline whare wananga & postdating by 5 years & 1991 \\
\hline $\begin{array}{l}\text { whenua (in sense of } \\
\text { placenta) }\end{array}$ & postdating by 165 years & 1985 \\
\hline zoning & & \\
\hline
\end{tabular}

\section{Errata in DNZE}

The word GST is listed in Orsman's dictionary, but it is not New Zealand-specific.

The word mainstreaming (used in education of special-needs children) is also listed in Orsman with a NZ citation from 1993, but the OED has this categorised as "chiefly U.S.”, and lists American citations for its use in this sense from 1973 to 1991. 


\section{APPENDIX III}

\section{WORDS FROM THE PUBLIC SECTOR DOMAIN \\ WHICH APPEAR IN THE DICTIONARY OF NEW ZEALAND ENGLISH}

Words from the domains covered by this thesis, i.e. economics, education, health and social welfare, which appear in the DNZE, are listed here with their earliest citation date (for the same sense and part of speech of the word as that in Appendix I) as given in that dictionary.

Words the first citation for which dates from within the timeframe of this thesis, are marked with a $\S$ symbol.

Words from the $D N Z E$ which also appear in the dataset for this study are marked with an asterisk.

\begin{tabular}{|c|c|c|}
\hline Aotearoa & 1857 & \\
\hline ACCESS & 1988 & $\S$ \\
\hline accredit & 1966 & \\
\hline accrediting & 1919 & \\
\hline area school & 1945 & \\
\hline aroha & 1815 & \\
\hline associate teacher & 1987 & $\S$ \\
\hline black budget & 1930 & \\
\hline bulk funding & 1991 & $\S$ \\
\hline $\mathrm{CHE}$ & 1992 & $\S$ \\
\hline contestability & 1986 & $\S$ \\
\hline contributing school & 1932 & \\
\hline Correspondence School & 1924 & \\
\hline district high school & 1877 & \\
\hline dole bludger & 1983 & \\
\hline domestic purposes benefit, DPB, dpb & 1972 & \\
\hline fiscal envelope & 1994 & $\S$ \\
\hline gift duty & 1909 & \\
\hline GST & 1985 & $\S$ \\
\hline half-pie & 1911 & \\
\hline
\end{tabular}




\begin{tabular}{|c|c|c|}
\hline hapu & 1843 & \\
\hline hikoi & 1984 & $\S$ \\
\hline House of Representatives & 1846 & \\
\hline hui & 1846 & \\
\hline integrated (of schools) & 1989 & $\S$ \\
\hline integration (of schools) & 1975 & \\
\hline intermediate school & 1933 & \\
\hline internal assessment & 1972 & \\
\hline ironsand & 1769 & \\
\hline itinerant teacher & 1921 & \\
\hline iwi & 1820 & \\
\hline joint family home & 1950 & \\
\hline kai & 1840 & \\
\hline kai tiaki & 1908 & \\
\hline kakapo & 1843 & \\
\hline karakia & 1832 & \\
\hline Karitane nurse & 1924 & \\
\hline kaumatua & 1820 & \\
\hline kaupapa & 1989 & $\S$ \\
\hline kindy & 1959 & \\
\hline kiwi (meaning the NZ dollar) & 1985 & $\S$ \\
\hline kiwi share & 1990 & $\S$ \\
\hline koha & 1982 & \\
\hline kohanga reo & 1982 & \\
\hline kuia & 1820 & \\
\hline kura kaupapa (Maori) & 1989 & $\S$ \\
\hline Labour & 1916 & \\
\hline Land Wars & 1971 & \\
\hline language nest & 1984 & $\S$ \\
\hline language nursery & 1983 & \\
\hline lease in perpetuity, perpetual lease & 1892 & \\
\hline local body & 1935 & \\
\hline local government & 1842 & \\
\hline mana & 1843 & \\
\hline
\end{tabular}


Maori

1834

Maori Land Court

1931

Maoridom

1860

Maoriness

1877

Maoritanga

1843

marae

1769

mokopuna

national award

1817

1898

national superannuation

1935

native school

1839

normal school

1876

outdoor education

1973

outside education

$1986 \S$

overstayer

1976

pakeha

1814

playcentre

1944

Plunket

1909

post-primary

1919

private school

1944

public servant

1948

Public Service

1890

Public Trust (Office), Public Trustee

1870

rangatiratanga

1837

reading recovery

1979

Rogernome

$1991 \S *$

Rogernomics

$1985 \S \quad *$

runanga

1843

School C(ertificate)

1932

School Trustees Association / Bill

$1991 \S$

(on) section

1930

sinking lid

$1984 \S \quad *$

Social Credit

1959

SOE

$1986 \S *$

sole charge

1944 


\begin{tabular}{|c|c|c|c|}
\hline sole teacher & 1888 & & \\
\hline solo father & 1987 & $\S$ & \\
\hline solo mother & 1977 & & \\
\hline solo mum & 1978 & & \\
\hline solo parent & 1972 & & $*$ \\
\hline solo parenthood & 1989 & $\S$ & \\
\hline solos & 1986 & $\S$ & \\
\hline State aid & 1879 & & \\
\hline State Forest & 1885 & & \\
\hline State highway & 1936 & & \\
\hline state house & 1942 & & $*$ \\
\hline state housing & 1946 & & \\
\hline State-Owned Enterprise / SOE & 1986 & $\S$ & \\
\hline state school & 1882 & & $*$ \\
\hline state tenant & 1982 & & \\
\hline superannuitant & 1938 & & \\
\hline taha Maori & 1984 & $\S$ & $*$ \\
\hline taha Pakeha & 1983 & & $*$ \\
\hline tall poppy & 1992 & $\S$ & $*$ \\
\hline tamariki & 1804 & & * \\
\hline tangata whenua & 1877 & & $*$ \\
\hline tangi & 1817 & & $*$ \\
\hline tangihanga & 1846 & & \\
\hline taonga & 1820 & & $*$ \\
\hline te reo (Maori) & 1837 & & $*$ \\
\hline think big & 1981 & & $*$ \\
\hline tikanga & 1858 & & $*$ \\
\hline Tohunga & 1804 & & $*$ \\
\hline Treaty (of Waitangi) & 1840 & & $*$ \\
\hline tuatara & 1820 & & $*$ \\
\hline U.E. & 1963 & & $*$ \\
\hline utu & 1820 & & $*$ \\
\hline
\end{tabular}


wairua

whakapapa

whanau

whare kura

whare wananga

whenua

zoning

(127 headwords)
$1815 *$

1904 *

1938 *

1971 *

1971 *

1820 *

1953 * 


\section{APPENDIX IV}

\section{WORDS IN THE CORPUS WHICH ARE NOT IN THE OED}

\section{allocative adj.}

1984 T. BIG II.10 211 Pursuit of particular allocative or distributional objectives should be effected through specific tax measures only if they are clearly the most efficient instrument.

blanket award $n$. and attrib.

1987 T. BIG I.4 283 To some degree they also encourage the retention of blanket awards, irrespective of their suitability in a particular industrial environment. ... Clearly the effect of union registration rules in supporting inefficient bargaining structures are [sic] reinforced by bargaining rules and in particular blanket award coverage.

\section{blitzkrieger $n$.}

1994 Political Science 46.2 217 At one stage the blitzkriegers advocated a much more privatised health system on both the supply and demand side than did the advocates of the 1974 White Paper. 1997 Easton The Commercialisation of New Zealand 251 It was easy for the blitzkriegers to discount any pressure groups opposed to them, no matter how competent, on the basis that they were acting out of self-interest.

\section{bone-in adj.}

1984b T. BIG 16 Analysis of total meat production (000 tonnes bone-in weight)...

\section{bottoming out $v b l . n$.}

1984 T. BIG I.3 57 In part this reflects the effect of climatic factors on the profile of lamb production following the record year in 1982/83 and in part the bottoming out of the rundown in the beef herd.

\section{bounded rationality $n$.}


1987 T. BIG I.1 11 Uncertainty about the future and about the consequences of certain actions derives from what may be called the bounded rationality of individuals. Bounded rationality is the inability of humans to comprehend fully the nature of their environment, to anticipate or devise strategies to cope with change and to communicate effectively with each other. ... Given the existence of bounded rationality, people must plan on the basis of a largely uncertain future, and they are forced to adapt to change and adopt strategies that minimise risks.

\section{brain gain $n$.}

1988 The Dominion 13 Instead of a brain drain, Australia is currently experiencing a brain gain.

\section{bumper-sticker $n$. and attrib.}

1987 T. BIG I Annex 398 Though it is easy to express generalised goals for social policy such as 'the achievement of a fair distribution' or 'giving everyone a fair chance', it is very much harder to translate such bumper-sticker thoughts into coherent policy.

\section{call option $n$.}

1992 NZBR 17 Interestingly, where departures from these features occurred, political problems arose (e.g. the sale of New Zealand Steel to Equiticorp in return for shares in the latter and the put and call options on the sale of Petrocorp to Fletcher Challenge).

\section{capital flight $n$.}

1984 T. BIG I 7 Believed to represent mostly illegal capital flight, this amounted to an outflow of US $\$ 45$ billion over 1981-83.

\section{casemix $n$.}

1990 DoH. BIG R.3.27.1 That committee chose a population-based system for allocating funds in preference to the main alternative, a casemix funding approach (that is payment for cases treated).... The committee considered that a formula based on casemix was too closely related to the supply of existing services to be equitable, although equity was one of the stated aims. 1990 DoH BIG R.3.28.2 Although not 
without limitations (see below) DRGs are the best known and most used method for describing casemix as a measure of hospital throughput.

casualized $p p l$. adj.

1995 Yeatman in Boston (ed.) 136 For example, feminists currently have to decide their position on the extension of enterprise bargaining, and its implications for women workers, especially those in low-paid and often casualized jobs.

CBU (completely built up) n. abbrev.

1987 T. BIG I.4 307 Preassembled (CBU) and unassembled (CKD) car imports are currently subject to a normal tariff of 5.5 and 27.5 percent respectively.

\section{change manager $n$.}

1989 NZL 04.0318 But what they said is, "What we really want is a change manager in there."

\section{charge-out attrib.}

1992 NZBR 21 Vigorous competition in domestic and international toll calls is putting downwards pressure on effective real unit charge-out rates in these areas while unit line rental charges for residential customers cannot be increased faster than the rate of inflation under the conditions imposed by the government at the time of the sale.

\section{child support $n$.}

1998 Feb. Public Discussion Document 18 About 140,000 parents currently pay child support through Inland Revenue Child Support.

\section{clearwood $n$.}

1984b T. BIG 14 Although the data available are limited, it appears that prices for higher grades of timber such as clearwood are likely to be firmer and less volatile than lower grades. Because of past harvesting of virgin forests, the proportion of the world's forests which are capable of producing clearwood is decreasing.

\section{commercialiser $n$.}


1997 Easton 140 At best it could be claimed that surveys of the economic profession showed that even if commercialisers were not in the centre of any 'mainstream', and although there were few advocates in 1980, the support did increase over the decade. 1997 Easton 250 The New Zealand commercialisers imitated what they thought foreigners were arguing, rolling over like puppy dogs whenever they were praised by them.

\section{comparable worth $n$.}

1987 T. BIG I.4 286 Over the last few months the idea of 'comparable worth' or 'equal pay for work of equal value' has received considerable publicity. Advocates of reform in this area see comparable worth as a fairly natural 'next step' to supplement the provisions of existing equal pay legislation. 1987 T. BIG I.4 287 Any assessment of equity gains should therefore be weighed carefully against the costs that comparable worth regulation may impose.

\section{compartmentalisation $n$.}

1984 T. BIG II.2 124 For example, a problem with the most recent Cabinet Committee structure is the compartmentalisation of the expenditure review process broadly into current (other than staff) expenditure, capital expenditure and staff.

\section{concessionality $n$.}

1984b T. BIG 773 This will reduce the concessionality of its lending, and thus improve the efficiency of resource allocation.

contractionary adj.

1984 T. BIG II 7182 Traditionally, it would have been presumed that policies to reduce the fiscal deficit would have a contractionary effect on the economy, at least in the short-term. 1987 T. BIG I 6391 The overall stance of fiscal policy in the OECD is expected to remain relatively contractionary.

\section{contractualism $n$.}

1995 Martin in Boston (ed.) 48 Underlining the proposition that 'contractualism' is dominant is the invitation (in Section $72 \mathrm{E}$ of the Act) for the CAA to contract out its activities after appropriate procedures. 


\section{contractualist $a d j$.}

1995 Boston back cover And one of the most distinctive and controversial features of New Zealand's reforms is the emphasis on contractualist modes of governance, including the use of new kinds of contracting within the public sector.

\section{contractualization $n$.}

1995 Yeatman in Boston (ed.) 135 Thus, marketization, privatization, devolution and contractualization are all technologies of government which fit the modern regime of regulation, where government works by means of the self-regulating capacities of citizens as these are informed by the normalizing effects of professional expertise, among other things.

\section{core business $n$.}

1994 T. AR 4 The links between the Treasury's 1993/94 outcome statements (impacts or consequences for the community), outputs (services provided by the Treasury), core business, and examples of other agencies which contribute to the same outcomes, are shown below: 1999 Sunday Star Times 10.01 Somehow, in today's climate, a camping ground is not regarded as "core business".

cost recovery $n$. and attrib.

1984b T. BIG 441 One problem is that without full cost-recovery there is no inbuilt test of the efficiency with which the service is provided. With full cost recovery, MAF would compete on equal terms with the private sector and the level of consumer demand would usually provide a good indication of its level of efficiency. ... In general, pricing below the cost of supply has several adverse effects: a) it results in additional purchases which users would not have made at the higher, cost-recovery, price level and which must therefore be worth less to them than the cost of supply.

\section{cost squeeze $n$.}

1984 T. BIG II.3 139 The imposition or tightening of foreign exchange controls may inhibit the capital outflow for a time, but this is at the expense of prolonging the cost squeeze on the exposed sector.

\section{counter-indemnity $n$.}


1990 T. $A R 42$ The existing Government guarantee on the Bank's other borrowings will continue, but Fletcher Challenge has given the Crown a counter-indemnity against default.

CPI (Consumers' Price Index) n., abbrev.

1987 T. BIG I.6 360 A surprisingly high June quarter CPI movement took the annual point-to-point rate of consumer price inflation to 18.7 percent. $1990 \mathrm{~T}$. BIG 556 The most commonly used measure of the general price level (and hence inflation) in New Zealand is the Consumers Price Index (CPI).

\section{day-patient $n$.}

1990 T. BIG 8b 120 Aggregating across all AHBs, the total number of patient admissions and attendances as out-patients or day-patients has declined between 1987 and 1989.

\section{deprotection $n$.}

1992 James 170 In tandem with import deprotection went internal deregulation.

\section{disinflate $v . i$.}

1987 T. BIG I.4 204 Nevertheless, despite some easing of conditions during 1986, which has resulted in an undesirable delay in disinflating, monetary policy has been restrictive enough to put the real economy under some pressure. 1990 T. BIG 554 Slowly-adjusting inflation expectations, and slow rates of growth, are also typical of the experiences of most other OECD countries that disinflated earlier in the 1980s.

\section{dispreferred $a d j$.}

1987 T. BIG II.5 149 Freeing those who have been forced to consume a particular educational agenda supplied through a particular school, although it is their dispreferred option, may enable all schools to better meet the needs of their clients.

\section{distance education $n$.}

1987 T. BIG II.9 262 Some New Zealand tertiary institutions would seem well placed to market 'distance' education, that is either to accept overseas students on a 
correspondence basis or to 'sell' teaching programmes to overseas institutions and governments.

\section{distortionary adj.}

1984 T. BIG II.14 299 The most direct approach of all would be an appropriate subsidy on manufacturing employment, financed in the least distortionary way. 1987 T. BIG I.4 288 Furthermore, a minimum wage has distortionary effects in the labour market which are likely to hinder long term employment prospects and harm the very workers that the policy is designed to assist.

\section{doubtful debt $n$.}

1993 T. AR 23 There is no provision for doubtful debts.

ECS n. abbrev. and attrib.

1987 T. BIG II.3 45 Educational professionals working in this area tend to consider the relevant age range as $0-8$, but, for our purposes, it is convenient to use five as the cut-off age as institutional early childhood services (hereinafter ECS) for the 0 - 4 age group are very different from those for the five-plus group. 1987 T. BIG II.3 46 For Maori people, this form of ECS has a distinctive language and cultural function and much of the increase in public resources flowing to ECS in recent years has been for the establishment and operation of these Kohanga. 1987 T. BIG II.3 60 Such arrangements could be applied to the individual or to ECS institutions.

EEO n. abbrev.

1991 Boston et al. 68 The wider significance of this lay in the fact that many of these employment conditions were directly relevant to the issue of equal employment opportunities (EEO).

\section{employment-rich adj.}

1987 T. BIG II.6 180 Access is intended to run at a level of 12,000 trainees in any month, Maori Access at a level of 3,500 - 4,000 and the foundation and employment rich courses at $3,500-4,000$.

EMTR n. abbrev. 
1987 T. BIG I.4 303 Chief amongst these were the narrowness of the income base; high and variable effective marginal tax rates (EMTRs); some lack of clarity about the appropriate tax unit; and disparities in the form and delivery of family assistance. 1987 T. BIG I.4 304 The dispersion of EMTRs was reduced significantly for market income earners... On the other hand, it can be argued ...that the abatement of Family Support leaves many middle-income families subject to a quite high EMTR (48 percent) over a wide range of income;

\section{envelope committee $n$.}

1984 T. BIG II.9 206 The reviews could be carried out in various ways depending on their size and area e.g. by an envelope Committee e.g. one dealing with Industry Assistance;

ERA n. abbrev.

1984b T. BIG 213 The effective rate of assistance (ERA) is a measure which indicates the relative strength of the incentives for the employment of resources in an activity provided by government assistance. ... Factors which will influence the extent to which differences in ERA will affect resource movements include the ease with which resources can be transferred from one activity to a more highly assisted one and the responsiveness of demand (and hence price) to an increase in the output of assisted activities.

\section{factor cost measure $n$.}

1987 T. BIG I.4 209 During the next year, however, with indirect taxation acting to restrain inflation, the market price measure is expected to rise by 1 percent less than the factor cost measure. ... The result is that the factor cost measure suggests a clear downward trend in underlying inflation since 1985/86, but the market price measure, which moves broadly in line with the politically sensitive consumer price index, will not reflect this until 1988/89, when it should fall off in an exaggerated way.

\section{family-friendly adj.}

2001 T. DFR 15 The EEO programme includes work on motivation and organisational commitment, development of a Maori language policy and investigating more family-friendly policies. 


\section{feed-through $n$.}

1993 T. BIG 235 This reflected a faster feed-through of wood price increases into consumer prices and an increase in hire purchase charges as more firms began to charge interest. 1993 T. BIG 242 An encouraging feature is that there appears to have been little feed-through of large increases in wood prices into general cost and price movements.

\section{flat playing field $n$.}

1988 The Dominion 18.0813 The market-led theoreticians who seek to provide flat playing fields for all investors oppose nearly all forms of subsidies as a government interference in the market.

\section{floor-price attrib.}

1984b T. BIG 979 The Wool Board, for example, has tended to operate a 'floorprice' operation rather than a 'price-smoothing' operation.

\section{flow-on $a d j$.}

1984 T. BIG II.4 146 The payments system is sometimes likened to a form of social capital, like law and language, which cannot be allowed to disintegrate because of flow-on effects arising from the troubles of particular financial institutions.

\section{fob price $n$.}

1984b T. BIG 12 The average fob price for the Brazilian product in 1983 was US $\$ 831$ per tonne, a drop of US\$372 from the 1981 price level. This is about two thirds the average fob price of New Zealand lamb.

\section{foundation course $n$.}

1987 T. BIG II.6 180 From 1987-8, a significant addition to attendance at tertiary institutes, will be students on Access and employment rich or foundation courses.

\section{GAAP $n$. abbrev.}

1996 Evans et al 1868 After a decade of effort, a central government fiscal surplus finally was achieved on an accrual accounting (GAAP) basis in the 1993/94 financial year. 2001 T. DFR 28 The output class includes advice on the application and 
development of Generally Accepted Accounting Practice (GAAP) as it applies to the Crown.

\section{grandfather provisions $n . p l$.}

1987 T. BIG II.9 260 In the short-term fee increases are unlikely to have much effect as 'grandfather' provisions can be made for existing students and, where such arrangements are not made, students and their families are likely to make substantial sacrifices in order to ensure completion.

GST $n$. abbrev. and attrib.

1987 T. BIG I.4 306 The introduction of GST on 1 October 1986 marked arguably the most fundamental reform of New Zealand's tax system. ... Even so, care is required to ensure that the GST base, unlike the wholesales tax base which it replaced, is not eroded over time. 1989 T. $A R 17$ - a planned increase in the rate of Goods and Services Tax (GST), preceded by provision for a transitional mechanism for a GST rate change.

\section{headworks $n$. pl.}

1984b T. BIG 544 Current policy, approved in October 1982, is for irrigation scheme headworks and off-farm distribution works to receive a 70 percent grant.

\section{heart-healthy $a d j$.}

1987 DoH. BIG 63 Priorities will include liaising with the new non-governmental group "Heartbeat" in relation to their activities, in particular to encouraging the food industry and relevant government departments to modify their products in 'hearthealthy' directions.

\section{high-rolling adj.}

1997 The Daily Telegraph 07.08 They did not care to foresee that the reforms would create a new class of high-rolling consultants and business executives for whom greed was good...

\section{horizontal equity $n$.}


1984 T. BIG II.10 211 This is commonly referred to as horizontal equity and implies that all individuals on the same income also face the same marginal tax rate. $1987 \mathrm{~T}$. $B I G$ II.2 32 Where differences in educational access, process or outcome are not regarded as fair, they pose equity issues: fairness between different socio-economic groups (vertical equity); redistribution of resources over an individual's lifetime (horizontal equity);...

\section{horizontally equitable adj.}

1984 T. BIG II.10 212 Similarly, a tax system which is not horizontally equitable will also generate economic inefficiencies of the type referred to in (a) above.

\section{hub and spoke pattern $n$.}

1987 T. BIG I.4 257 Similarly while airline regulators are charged with maintaining efficient air services, it is unrealistic to expect them to be aware of the broader efficiency gains that could be achieved by restructuring air routes using the hub and spoke pattern.

\section{instrument duty $n$.}

1984 T. BIG I.4 79 Smaller changes are expected in instrument duty (as a result of a relatively buoyant property market), the energy resources levy (higher use of natural gas) and motor vehicle fees and charges (strong growth in new vehicle registrations).

\section{intersectoral $a d j$.}

1987 DoH. BIG 62 Other countries have tried a number of ways of ensuring this "intersectoral co-ordination" and the programme will also attempt to consider how this should be done in an effective and constructive manner.

\section{in-year adj.}

1987 T. BIG II.6 183 Given the level of academic and non-academic staff in place, funding is straightforwardly increased to reflect pay awards occurring in-year.

\section{labour shedding $n$.}


1984 T. BIG I.22 The 1982/83 economic contraction resulted in severe destocking and labour shedding. 1987 T. BIG I.6 362 Therefore it is possible that labour shedding associated with this tier of adjustment may be on a smaller scale.

\section{light-handed regulation $n$.}

1996 Evans et al 1889 Continuing study of them will provide insights as to the longterm viability of New Zealand's “light-handed regulation”. 1998 Evans 30 Open entry is one of the key distinguishing features of light-handed regulation.

M1, M3 (econ.) $n$.

1984 T. BIG II.4 146 In the British case, while M3 was tending to increase at rates above the targetted range, other indicators of monetary policy were telling a different story; e.g. M1 was growing slowly, interest rates and the exchange rate (floating) were high. 1987 T. BIG I.4 218 This suggests that their demand for primary liquidity is unlikely to bear a strong or stable relationship to either the size of their own balance sheets or an aggregate such as M3 (the broad measure of money supply). 1990 T. BIG 560 For example, some evidence is emerging of a reasonably close relationship between the long-run growth rates in the broad money aggregate (M3) and in nominal GDP.

\section{macropolicy $n$.}

1984b T. BIG 15 In other words the problems of agriculture are not just those of marketing and of assistance; there are macropolicy problems as well. 1984 II.5 169 Choices may be pre-empted to some extent by the current precarious exchange market situation, but we see the essential agenda for discussion as being the sequence of macropolicy and market liberalisation moves, and the communication of their implications to the public and to labour market participants in particular, which would facilitate the smooth introduction of a floating regime.

mbd (econ.) n. abbrev.

1984 T. BIG I 7 The seasonal decline in demand since then has not been matched by a corresponding reduction in OPEC output, which stands at around 18.2 million barrels per day (Mbd). 
MMP n. abbrev.

1994 Political Science 46.2 233 The introduction of MMP may well be seen as an attempt by the public to replace the policy blitzkrieg with a return to incrementalistpluralism...

MTN (econ.) n. abbrev.

1991 T. AR 55 Finally, the Government's Medium Term Note programme, which has been in place since 1986, was modified and extended. 1994 T. AR 5 NZDMO met the Crown's foreign-currency financing needs through a combination of medium-term note (MTN) issuance and public borrowing. ... A total of NZ\$1,000 million was raised through the Government's MTN programme.

\section{old age benefit $n$.}

1984 T. BIG I.6 94 This series is not entirely satisfactory as it does not include the effect of changes in the composition of the labour force (e.g. changes in the numbers on unemployment benefit) and does not adequately deal with the transition in 1977 from the old age benefit/universal superannuation to national superannuation.

\section{old long stay $n$.}

1990 DoH. BIG R.3.27.13 As compared with the old formula, the proposals differ in regard to supplements, in that they advocate dropping the supplements for old long stay, Pukeora Home, and the New Zealand Disability Resource Centre. $1990 \mathrm{DoH}$. $B I G$ R.3.27.App.I.4 Responsibility for patients currently categorised as old long stay should be allocated to boards on the basis of meaningful domicile where this exists and then in proportion to boards' populations, placing financial responsibility, where possible, in the hands of the current board of treatment. 1990 DoH. BIG R.3.27.App.I.11 The OLS area will require substantial work.... We need a plan from Linda Jacobs on how to assess which category and which domicile OLS patients fall into.

on-stump (for.) adj.

1984b T. BIG 338 In addition, there is a need to increase on-stump sale prices so that investment by private growers is not discouraged and so that appropriate forestry processing investment is undertaken. 
paraprofessionalism $n$.

1987 T. BIG I.4 269 Non-certified individuals are not prevented from offering routine services - 'paraprofessionalism'.

post-audit $n$.

1984 T. BIG II.13 284 The infrequent post-audits that have been done have shown disturbing results. ... Typically post-audits are carried out only after the organisations have run into serious problems, e.g. Air New Zealand and Railways;

post-basic adj.

1987 DoH. BIG 81 Provide basic and post-basic training for school dental nurses.

price-smoothing $a d j$.

1984b T. BIG 979 The Wool Board, for example has tended to operate a 'floor-price' operation rather than a 'price-smoothing' operation.

recrewing $v b l . n$.

1992 T. $A R 81$ The Treasury negotiated on behalf of the Crown a satisfactory settlement of the ANZECs/SCNZ dispute relating to the reflagging and recrewing of the New Zealand Pacific.

\section{rent-seeker $n$.}

1992 James 339 Government employees became 'rent-seekers' (that is, obtained control over what they did and levied a charge on society for the existence of that control) and the existence of such monopoly rents in the public sector encouraged its expansion.

rent-seeking adj.

1991 Boston et al 260 Admittedly, multi-purpose departments sometimes engage in rent-seeking behaviour, or seek to expand their budgets more than is justified, or supply demonstrably self-seeking policy advice.

restorative justice $n$. and attrib. 
200528.06 The Dominion Post A1 Most victims who took part in restorative justice programmes were pleased they had done so, while there was also a small reduction in re-offending by offenders who took part, Justice Minister Phil Goff said yesterday. ... Restorative justice brought parties together in a way that allowed victims to confront their offenders, explain the impact the offending had on them and participate in deciding an appropriate penalty. 2005 28.06 The Dominion Post A3 Community Magistrate Mary Symmans refused interim name suppression and ordered a restorative justice conference for Berry and the victim's family.

risk premia (econ.) n. pl.

1984 T. BIG II.14 308 When tender premia reach defined low levels, an automatic switch to licence on demand, followed by licence exemption, will be made. $1984 \mathrm{~T}$. $B I G$ II.14 310 Instead of the proposed annual increments of between 2.5 percent and 5 percent of domestic production (less exports) the rates could be increased to, say, a minimum of 5 percent of the market with higher rates for taller poppy items as revealed by tender premia. 1990 T. BIG 228 As a result, risk premia built into interest and exchange rates should decline.

\section{sellback $n$.}

1987 T. BIG I.4 220 Since monetary policy considerations at any one time are influenced by any transactions the Reserve Bank is expected to carry out on its own account (for example sellbacks), the quantity of Treasury bills issued may differ from the Government's own immediate needs.

\section{selldown $n$.}

1992 NZBR 18 While in some cases a selldown may be undertaken over a period of years, the government does not expect to retain part shareholdings in the long term because of the commercial and financial exposure that would result. 1992 James 214 He was speaking from experience: as chair of Fletcher Challenge he had to preside over a selldown to reduce debt.

SES n. abbrev. attrib.

1987 T. BIG II.8 236 The question which the work of Lander and others on educational differences between classes in New Zealand raises is whether Maori 
under-achievement is due to factors relating to their ethnicity or to the fact that, by and large, they belong to lower SES groups. 1987 T. BIG II.8 240 The outcome of research to date indicates that SES and other environmental matters do not entirely explain Maori under-achievement.

\section{soft legislation $n$.}

$199731.10 \mathrm{NZL} 50$ Attracting foreign investment, settling low tariff levels, bringing in soft legislation to promote trade is all well and good, but any moves towards deregulation also attract white-collar crime.

sole parent $n$. and attrib.

1989 DSW. AR 41 Departmental support for sole parents includes giving information, referral to other agencies, and access to other departmental services. 1989 DSW. AR 45 Increases in numbers of sole parent beneficiaries and liable parents reflect this social change. 1993 DSW. AR 70 ... an update of the profile of sole parents with 1991 Census data...

\section{stump sock $n$.}

1989 DSW. AR 101 Meanwhile, the development of the local stump sock facility, based in Christchurch, has continued with the construction of a machine for teasing a 'brushing' surface on to stump sock.

\section{suboutput $n$.}

1991 T. AR 19 The Treasury Corporate Plan January - June 1991 lists some 40 outputs and 116 suboutputs. 1992 T. $A R 41$ One sub-output was substantially completed within the agreed timeframe, but one aspect of it was deferred with the agreement of Ministers.

\section{subsector $n$.}

1984 T. BIG II.1 107 We have protected subsectors of the economy at the expense of general welfare.

\section{technical institute $n$.}


1987 T. BIG II.1 14 The real cost per full-time equivalent university and technical institute student has been on a decreasing trend through the early to mid 1980s.

\section{tight prior $n$.}

1997 Easton 94 The practical failure of an analytic approach dominated by a tight prior is evident in a row between Richardson, the Minister of Finance between 1990 and 1993, and Wyatt Creech, who was Minister of Revenue at the time. 1997 Easton 162 The tight prior remained the benchmark, not itself subject to evaluation.

\section{transition education $n$.}

1987 T. BIG II.5 142 The Curriculum review seeks further developments in this direction whilst the inquiry into the curriculum for forms $5-7$ seeks the development of 'transition education' for those forms.

\section{TWI $n$. abbrev.}

1996 Evans et al 1867 Given its influence, the Reserve Bank adopts an unpublished target band for the trade-weighted exchange rate (TWI) which is designed to ensure that aggregate inflation stays within the $0-2$ percent range.

user-pays $n$. and attrib.

1984b T. BIG $549 \mathrm{We}$ are of the opinion that contributions should be distributed according to benefits (i.e. 'user pays'). 1987 T. BIG II.6 165 Those who feel that the broader advantages of tertiary education are liable to be directed to the wider public good by the students who are their direct beneficiaries, should refer to the content and tone of the recent student campaign against 'User Pays' in tertiary education... 1990 DoH. BIG R2.3 It is favoured as a "user-pays" approach but opposed as a "tied tax" with limited Parliamentary scrutiny. 1995 Martin, John in Boston (ed.) 48 Its funding comes from a mix of 'user-pays' and general taxation (for the purchase of policy advice).

\section{yield curve $n$.}

1987 T. BIG I.4 204 This resulted in a steeply inverted yield curve, with long term rates substantially below money market rates, which is usually an indication that the system is under pressure. 1987 T. BIG I.4 205 This is confirmed by survey and 
anecdotal evidence, while the resultant flattening of the yield curve suggests that the money markets do not feel themselves to be under pressure. 


\section{APPENDIX V}

\section{NEW SENSES AND USES OF WORDS IN THE OED}

\section{aggregate $n$.}

1996 Evans et al 1866 The monetary aggregates were indicating that policy was lax, while the interest and exchange rate data and demand patterns were indicating that policy was particularly tight.

(not in OED in this econ. sense, nor as a n.pl.)

\section{annualise v.t.}

$1994 \mathrm{DoH}$. AR 15 The rate of return for this financial year was 10.8 percent annualised.

(OED labels "rare", last citation 1808; new sense)

\section{$\operatorname{bad} n$.}

1997 Easton 36 Typically private market decisions result in an over-supply of public bads, so there is ongoing political pressure for measures to decrease the total production of environmental bads. ... Because increases in the gases result in increases in air temperatures (global warming) which is judged detrimental, they are economic bads. 1997 Easton 14 Note that in doing this, the government need not have any less commitment to treating the pollution as an economic bad, nor any less of a commitment to reduce pollution. 1997 Easton 36 But the emitters of the bads do not pay for their discharges, and so do not take into consideration in their business decisions or profit calculations any impact of the emissions on the environment. (B 3, not in OED in this econ. sense)

\section{bail-out $n$.}

$1992 N Z B R$ i Nevertheless, the gains were always likely to be limited by the difficulties involved in...making the competitive environment genuinely neutral, when continuing government ownership brings with it the possibility of future state bail-outs;

(OED has only bailout from an aeroplane, labelled U.S. and rare) 


\section{baseload $n$.}

1984 T. BIG I.3 55 The 10 percent growth in baseload manufactured exports estimated for 1983/84 largely offsets a decline of a similar magnitude in the previous year. 1984 T. BIG I.3 60 Baseload imports (defined as total imports less major project and large government imports) declined by 8 percent in 1982/83 as a result of a sharp decline in domestic output in response to lower domestic demand.

(OED has electr. engin. sense only, and as an open compound and hyphenated, not closed)

\section{best-practice $n$.}

1987 T. BIG II.5 150 Careful targeting of resources ... to foster school-based initiatives based on best-practices ... may help overcome this problem.

(not in OED as a count noun or hyphenated, only as a mass noun and open compound)

\section{bundled ppl.a.}

1984 T. BIG II.4 143 Likewise, in the market for housing mortgage finance it is common, worldwide, for specialist institutions such as Building Societies to cater for mortgage demand by offering "bundled" saving and lending services (for instance, a savings programme or an established relationship in exchange for access to a mortgage loan at some future date. 1987 T. BIG I.3 133 However, significant difficulties may arise with the elements bundled together in such a private contract. (not in OED in fig. or econ. senses)

buyout $n$. and attrib.

1987 T. BIG I.6 388 This assumes little carry over of the effects of the US dairy herd buyout scheme into the $1986 / 87$ September year, ...

(not in OED in attrib. use)

\section{cadetship $n$.}

1987 T. BIG II.5 135 Students entering technician cadetships, teaching, nursing and other professions may do so from form 6 but not form 5 and subject to suitable exam results.

(new sense from those in OED) 
capture $n$.

1987 T. BIG I.2 75 The conflicting objectives that arise in the combination of policy advice provision and policy implementation within the one organisation tend also to produce a phenomenon known as 'producer capture'. 1991 Boston et al xi The analysis in Chapter 9 raises doubts about some of Labour's changes, especially those made as a result of the preoccupation with bureaucratic capture. 1993 Kelsey 64 Treasury claimed this was necessary to eliminate ministerial capture by self-serving bureaucrats.

(new sense from those in OED)

\section{cascade $n$.}

1984 T. BIG II.10 223 ... inherent difficulties which include: price cascades (the effect of taxed inputs adding to the cost of the subsequently taxed outputs, as shown in Table 1); 1984 T. BIG II.10 226 To the extent that tax cascades and margin on tax effects are eliminated by either a final sales tax or a VAT, significant gains in revenue (up to 30 percent) can be made for no CPI effect. 1992 James 162 That was a major policy cascade from the deregulation of the financial markets.

(new sense from those in OED)

\section{cascade $v . t$.}

1995 Boston 81 In health care, for instance, there is a cascading series of contracts between funders, purchasers and providers... 1995 Davis and Gardner in Boston (ed.) 140 Yet amid the cascading stream of contracts from Parliament down to the most humble public servant and private contractor, one group has conspicuously escaped being caught in the flow. 2003 Drabble Hawkes Bay Today 31.07 If you love language, you are not going to believe these: "boundarylessness" and "to cascade (information) to staff".

(new senses from those in OED)

\section{charter $n$.}

1989 NZL 04.03 19 Under 'Tomorrow's Schools' there will be a charter to lay down the values and to assess results against, so there should not be room for a great deal of misunderstanding. $1989 \mathrm{DoH}$. BIG 35 It is envisaged that boards will develop their own charter. This charter will be a strategic plan for health service goals and 
objectives for the next $5-7$ years.... The National Health Council is working towards the development of a National Health Charter. 2003 EXstream 431 The group took the old Charter and turned it into a Values, Beliefs and Principles document that basically says where we stand and what we think is important for the college. (new sense from OED's)

churning $v b l$. $n$.

1987 T. BIG I.3 184 Instead there is a lot of recycled income or income churning among middle income earners. 1990 DSW. The Cost of Welfare Options 5 Overseas experience is that in the absence of an expansion of the labour market such measures tend to produce "churning" of unemployment; that is to say that they produce a turnover in which persons at any particular time are unemployed but do not produce much reduction in the aggregate number of unemployed.

(new sense from OED's)

coalface $n$.

1996 NZL 10.027 Locally, they have vanished; nationally, they have distanced themselves from the grub of the coalface, directing enquiries to the clutter of recycled executives who run the health services. 1997 NZL 26.07 36 Yet, when one excludes the consumers and providers working at the coalface of welfare delivery, the range narrows.

(OED has only the literal sense from mining)

\section{collectivity $n$.}

1987 T. BIG I Annex 410 It is further true that the legal system can allow collectivities to act as 'legal people' and thus to establish legal rights.

(OED has the singular form only, last citation 1884; new sense)

compete $v . t$.

1984 T. BIG II.11 237 Controls on interest rates are likely to have restricted the ability of these activities to compete resources away from declining activities. $1987 \mathrm{~T}$. $B I G$ I.1 27 By exploiting all the economies available this firm may be able to compete other firms out of the market.

(OED has as v.i. only) 


\section{creep $n$.}

1990 T. BIG 680 Preventing "Expenditure Creep" (heading). New policies approved during the year are one of the main sources of "expenditure creep". (new sense)

cutback $n$. and attrib.

1991 Boston et al 10 The central features or "doctrines" of the NPM can be summarized as follows: .... and a stress on cost-cutting, efficiency, and cutback management.

(4, OED has as $n$., last citation 1965 , not in attrib. use)

\section{dead weight attrib.}

1987 T. BIG I.4 233 In the case of non-commercial activities, where the benefits are difficult to measure, it is particularly important that the administrative and financing costs (including dead weight losses of adding to the tax burden, current and future) be taken into consideration when this evaluation is made.

$(4$, new comb.)

delivery $n$. and attrib.

1987 T. BIG II. 12 The third concern points to the need for institutional arrangements which give greater emphasis to accountability, and provide incentives for efficient delivery, including timely response to changing demand. 1987 T. BIG II.1 4 Their main concerns have been to obtain more resources via the present delivery systems, to extend or improve existing programmes and to resist changes in the present delivery system.

(new sense)

devolved ppl. adj.

1987 T. BIG I Annex 468 There needs to be a clear and publicly understood process by which state employees or organisations working under devolved authority from the state can be monitored and corrected.

(OED has as v.t., last citation 1884 , not as adj.)

disable v.t. 
1987 T. $B I G$ I: 17 Instead of empowering the poor, the programmes are disabling of taxpayers, restrict the choice of the users of social services and empower the public servants involved in their delivery. 1987 T. BIG II:5 146... any inwardness in the educational source is potentially disabling of students. ... It will be most disabling for those who do not come pre-equipped with an understanding of the relationship between education and economic life chances.

(Not in OED with this following construction)

\section{downwards adj.}

1984 T. BIG II.3 141 These need to be addressed by better macro and micro policies which must achieve a downwards adjustment in our cost structure (productivity adjusted) relative to our trading partners.

(in OED as adv. only)

\section{draw-down attrib.}

1984 T. BIG II.5 163 Restrictions are imposed on direct inward and outward investment flows, short-term overseas borrowing, draw-down periods and debtservicing repayments, individual outward portfolio investment, the timing of repatriation of proceeds of current account transactions, foreign currency holdings, and currency transactions between residents.

(new sense)

\section{driver $n$.}

2001 T. $A R 109$ The Treasury will assist the Government by developing a greater understanding of the drivers of the current account, its sustainability, the extent of the vulnerability it leaves us open to and the possible solutions.

(new sense)

ease $n$.

1987 T. BIG I.4 It is easy to bias the policy stance toward excessive ease, in which case no significant sustained disinflation takes place, because the caution is motivated by a desire to avoid erring in the side of being too tight.

(new sense) 
easing $v b l . n$.

1987 T. BIG I.4 222 At the same time, transactions with the public account could clear through the Databank network as expeditiously as possible without any fear of creating excessive monetary easing.

(new sense)

enabler $n$.

2001 T. AR 15 Since July 1999, our focus has been on three key enablers:

(1825, postdating by 176 years, not in OED in the fig. sense)

expenditures $n . p l$.

1984 T. BIG II.3 135 Taxes have not kept pace with government current expenditures during the last decade so that a growing proportion of current expenditures has been financed by borrowing. In addition, the Government has had to borrow in order to finance both its own capital expenditures and its lending activities. 1990 T. BIG 110 Different policy choices will be appropriate to different types of problem, especially in the area of social expenditures.

(OED has only as a mass $n .$, sing.)

front v.i.

1996 NZL 10.027 Not even the squadrons of PR people who front the health system can convince us otherwise.

(OED sense 7 (a) is literal and physical only; this is a fig. use)

greens $n . p l$.

1992 James 264 There is a broad division between 'purist' greens who focus primarily or exclusively on ecology, the physical environment, and those who 'seek fundamental changes in social and political institutions and stand for a new alternative, social-radical democratic paradigm', called by some 'dark' and 'light' greens. ... That happened with the Values Party, for example, which adopted a socialist outlook on economic and social issues - but it did so at the cost of the darker greens, suspicious of too deep an involvement in the power structures, splitting off.

(OED sense B 17, 1986, but without any pre-modifying adjectives) 
grouper $n$.

1990 MoH. R.3.28.6 The need for this work arose in response to increasing interest in the use of casemix classification in board performance comparisons and the malfunctioning of the DRG grouper currently available within New Zealand. .... Use of DRGs depends on the use of software ('grouper') to assign patient records to DRGs. The only DRG grouper currently available in New Zealand is that installed on the Paxus Health IBM mainframe. This grouper is based on 1985 Medicare DRG codes.

(new sense)

\section{half-way house $n$.}

1987 T. BIG I:5 346 In the light of such changes, rights to use the language that may seem a reasonable maximum at one point in time, may turn out to be half-way houses towards more extensive practical recognition.

(not in OED in the fig. sense)

\section{hatchet man $n$.}

$198904.03 N Z L 19$ A lot of people in forestry knew that I'd been associated with Weyerhaeuser, restructuring and downsizing. 'Ballard,' they said, 'they know he's a good hatchet man.'

(OED has the sense of a critical journalist only, not of a change manager)

\section{impacted $a d j$.}

1984 T. BIG II.1 107 Our poorly targeted interventions are a threat to the economy both because they distort the sectors immediately impacted and because they collectively disrupt resource allocation.

(OED has impacting as the only ppl. adj. in this sense 36)

\section{importables $n \cdot p l$.}

1984b T. BIG 214 However, as the Syntec Report (1984) concluded, it cannot be presumed that production of importables (import substitutes) is always highly assisted or that production for the export market is always lightly assisted.

(OED has as adj. only in sense 2) 
inflexibilities $n . p l$.

1987 T. BIG II.4 99 Losses in effectiveness and efficiency may be due to capture of resources by particular interest groups (providers, bureaucrats, advantaged parents) or to inflexibilities or waste resulting from public sector management unable or unwilling to respond to demand from consumers or the aims of government intervention.

(OED has as an uncountable noun only)

\section{kneecap v.t.}

1993 Kelsey 64 This allowed Treasury effectively to kneecap policies from other departments and agencies.

(not in OED in the fig. sense)

lag $n$.

1987 T. BIG I.6 381 The March quarter 1987 was influenced by the effect of GST on new house prices which enter with a 3-month lag.

(new sense)

point-to-point (econ.) adj.

1987 T. BIG I.6 364 A surprisingly high June quarter CPI movement took the annual point-to-point rate of consumer price inflation to 18.7 percent.... With inflation (point-to-point) forecast to be in single digits by December 1987, the likelihood is that interest rates will decline steadily over 1988/89 and impart a positive influence on consumption.

(new sense)

\section{privatisation $n$.}

1992 James 213 In particular, the World Bank and the International Monetary Fund have independently cited New Zealand as a country which has benefited from properly executed privatisations. 1996 Evans et al 1873 By February 1995 this had fallen to 21,600 , largely reflecting SOE work force reductions and privatizations. 1998 Evans 19 Foreign ownership has been permitted for New Zealand privatisations, but it has remained politically controversial and it is therefore worthy of further comment. 
(OED has as an uncountable noun only, not as n.pl.)

ratchet $n$. attrib.

1984 T. BIG II.8 195 A notable feature of this trend in government expenditure as a proportion of GDP has been a "ratchet' mechanism whereby increases in spending in election years have not been fully reversed in subsequent years.

(in OED as $n$. but not in attrib. use)

real $n$.

1997 Easton 19 The individual projects rarely attained a return of 10 percent real without some massaging of the numbers.

(new use)

receivable $n$.

1991 T. AR 19 The balance outstanding to the Treasury for GST is shown as a separate receivable within the Statement of Financial Position.

(In OED as $n . p l$. but not in sing.)

regulated $\mathrm{ppl}$. adj.

199707.08 The Daily Telegraph Meanwhile the economy is stagnant, exports flat and news bulletins led by stories about wheels dropping off aeroplanes in an underregulated sector.

(new comb.)

rigidity $n$.

1984 T. BIG II.1 108 The more that rigidities are allowed to slow down this reallocation the greater is the corresponding lack of income. 1984 T. BIG II.1 119 Some are poorly targetted, the level of subsidy tends to represent a high proportion of the wage, the programmes are generally offered within the award structure (which may itself be an important rigidity) and it is unclear how successful participants are in obtaining unsubsidised work when the subsidy terminates. 1987 T. BIG I.6 392 Barriers to trade are considered too high and rigidities in the labour market too great. (OED has as an abstract quality and uncountable noun only, not as a count noun or $n$. pl.) 
roll $n$.

1987 T. BIG II.1 11 Primary rolls doubled between 1945 and 1966. 1987 T. BIG II.1 13 The main determinants of state education expenditure are student rolls, pupil/teacher ratios and the level of teacher salaries.

(linked to senses I 3 (a) and 4, but more removed from the literal sense than either of these)

\section{rollout $n$.}

2001 T. AR 48 Completed the rollout to the SWIFT international payments system and progressed the establishment of an electronic link between the NZDMO's system and the SWIFT international payment system.

(OED does not have this fig. sense)

stand-down attrib.

1990 T. $B I G$ 8a 98 This can be achieved using instruments like partial user charges in health and stand-down periods for benefits.

(OED has military sense only)

stocktake $n$.

1994 T. AR 5 The Post-Election Briefing represented a stocktake of the economic and fiscal outlook facing the incoming Government.

(OED has literal sense only)

\section{subsidisation $n$.}

1984b T. BIG 217 It is possible for example, that because of high levels of subsidisation in the past (when the fertiliser subsidies were a much higher proportion of applied costs than they are now) super phosphate was applied in a wasteful manner from the national perspective.

(a different sense from the OED's last 1907 citation)

\section{sunset $a t t r i b$.}

1987 T. BIG I.4 260 A sunset clause could also generate considerable uncertainty each time the sunset period drew near.

(OED has sunset industry 1983. These are new combs.) 
tradeables $n$. pl. and attrib.

1984 T. BIG II.14 299 Intervention in Sectors Producing Non-Tradeables (heading)

1984 T. BIG II.14 313 The argument has been advanced that there is considerable scope for continuing reform in the non-tradeables area... With respect to tradeables, an acceleration in the pace of import protection reform would appear desirable. 1996 Evans et al 1870 These pressures aggravated difficulties for the tradeables sector - as predicted in the sequencing literature. 1996 Evans et al 1885 However, his data suggest that low productivity growth continues in certain nontradeables.

(OED has as adjective only, not as $n$. or pl. attrib.)

\section{trend adj.}

1984 T. BIG II.4 145 As suggested above, the appropriate intermediate objectives for controlling trend inflation rates are trend growth rates in money and credit aggregates. 1984 T. BIG II.7 180 For example, if real GDP had only grown at its 0.6 percent trend value in 1983/84 (instead of the actual 2.1 percent growth rate), the methodology suggests the deficit would have been even larger at 9.6 percent of GDP. 1984 T. BIG II.7 192 In years of cyclical upturns for example, GDP would be above trend and unemployment benefits would be reduced and tax revenues increased relative to the trend case. The cyclical effect... would then be to reduce the actual fiscal deficit below its structural (or trend) level. Trend GDP is calculated in each year from the 0.6 percent per annum average compounded growth rate in real GDP during the 19781983 period. 1990 T. BIG 226 The effects on the trend rate of growth of the economy as a result of structural reforms.

(OED has $n$. and $v$. only)

\section{vertical $a d j$.}

1984 T. BIG II.10 212 Considerations of vertical equity suggest that those on high incomes should pay higher amounts of tax, but do not necessarily provide a justification for marginal tax rates increasing with income. This refinement of the vertical equity principle depends upon the notion that an additional dollar of income is worth less to a relatively high income person than to a person on a lower income....Unless a tax system is horizontally equitable, it cannot be vertically equitable. 1984 T. BIG II.10 215 If income is not defined comprehensively, horizontal and vertical inequities arise which reduce the effectiveness of personal tax as a social 
instrument. 1987 T. BIG I.1 19 When a firm vertically integrates (or buys a supplier of services), it may be attempting an organisational innovation that reduces the costs of contracting.

(all new senses and combinations)

visioning vbl. n. (attrib.)

2003 EXstream 431 The college is just midway through a new visioning process, which we hope will set the direction for the college for the next five years. We began with a visioning team that was composed of Board members, staff and a parent representative.

(OED has as verbal noun only, not used attrib.) 


\section{APPENDIX VI}

\section{POST-DATINGS FOR THE OED}

Finding post-datings for the $O E D$ was not a primary focus of this study, however many were come across incidentally during the course of the research. As stated in section 2.5.2 of Chapter 2 above, after consulting with a senior lexicographer and editor at Oxford who advised that all postdatings for the $O E D$ would be useful and welcome, nevertheless for practical purposes a gap of two different decades was settled on as making their collection worthwhile. Therefore, for example, a 1984 citation for the compound noun crawling peg was discarded, as the OED's most recent citation for this lexical item dates from 1970; a 1987 citation for regulative was not included either, as the $O E D$ has a 1973 citation for this item, and so on. The postdatings in this list therefore range from $13-520$ years.

An exception to this two-decade rule of inclusion was made however, for lexical items which appear in the dataset in an orthographical form different from that in which they appear in the $O E D$. For example the entry in this appendix for white paper, which is not included here as a particularly worthwhile $O E D$ postdating (it is a postdating by nine years only), but is included because its citation is as a lower case open compound, whereas the $O E D$ 's citations all have capital initials. The reader is referred to the discussion of how new lexical items appear to move through stages of acceptance into the language, in Chapter 3 section 3.2.2.1 (i).

For the purposes of this appendix the online version of the Oxford English Dictionary has been used as it includes the most up to date revisions to the second edition: the "Additions Series". The information in brackets after each citation refers to the definition number and sense letter (if any) of the word in the online version (for entries which have multiple senses), then the date of the $O E D$ 's most recent citation for the word in this sense.

In the list that follows, the reader's attention is particularly drawn to the following entries. 
i. labelled nonce-wd. in the $O E D$

The word educatee is labelled as a nonce-word in the $O E D$, where it has just two citations. The citation in this dataset is a later occurrence by 130 years.

ii. labelled obs. in the $O E D$

- bundle as a transitive verb

- defeasance

- grow as a transitive verb in the sense of "to cause to increase, to enlarge"

- refit as a transitive verb, in the sense of "to make fit or ready again"

- scope as a transitive verb

The discovery of these five words in this study is notable because in these senses, they have been labelled obsolete by the $O E D$. Their citations in this appendix represent postdatings by $297,439,520,125$ and 185 years respectively.

iii. labelled arch. in the $O E D$

- enable as a transitive verb in the sense it is here cited has been labelled obsolete or archaic by the $O E D$.

iv. labelled rare in the $O E D$

- disemployment

- disprepare (v.t.)

- exportables

- scope (v.t.)

- transact (v.i.)

The $O E D$ has only two citations for disemployment, and just one single citation for disprepare and scope. Exportable as a noun is also labelled rare, and its occurrence here is a postdating by 123 years. Transact as an intransitive verb is last cited in the $O E D$ from 1872 and is labelled therein "now rare".

v. having a single source or a single citation in the $O E D$

The entry for distortive in this appendix supplies another occurrence of a word which has just two citations, but from a single source, in the $O E D$. The entry for lagged (adj.) supplies a second occurrence for the single citation from 1602 in the $O E D$. 
vi. postdatings of three centuries or more

- disjuncture

- disprepare

- defeasance

- grow as a transitive verb in the sense of "to cause to increase, to enlarge"

- lagged as an adjective

The occurrences of these five words in the dataset of this study furnish postdatings for their entries in the $O E D$ by $308,336,439,520$ and 385 years respectively.

abatement $n$.

1987 T. BIG I:4 306 It can be argued instead that relatively rapid abatement will on balance produce a less distortionary outcome.

(abatement 1 sense 2,1878 , postdating by 109 years)

ad valorem $a d v . p h r$.

1984 T. $B I G 652$ A simpler, and perhaps better, alternative would be a uniform ad valorem rate of subsidy.

(1866, postdating by 118 years)

advantage $v . t$.

1987 T. BIG I:4 305 A low initial tax-rate (and zero-rate thresholds) advantage most those on incomes above the range over which it applies.

(1 (a), 1871 , postdating by 116 years)

afforested ppl.a.

1992 T. $A R 80$ Adding to the complexity of the sale was the need to put in place environmental and social safeguards to protect the land, the supply of wood to Timberland's existing customers, and Maori claims to afforested land.

(1873, postdating by 119 years)

aggregate v.t.

1984 T. BIG II:9 206 Treasury should aggregate these forecasts and convert them to nominal prices.

$(1,1865$, postdating by 119 years) 


\section{aggregative adj.}

1987 T. $B I G$ I:4 271 Recent advances in the understanding of labour market arrangements have allowed this traditional approach, which tends to be somewhat aggregative, to be enhanced by better microeconomic perspectives on the nature of employment relationships, and of the adjustment processes which may generate unemployment.

(1, 1833, postdating by 154 years)

\section{alienate $v . t$.}

1987 T. BIG I:5 339 This would mean that within those fisheries that had not been freely alienated the tribes concerned would have a negotiable claim to take advantage of modern fishing technology. ... However, where the Maori owners had freely alienated a fishery, it may reasonably be assumed that the new owners would be the ones who could benefit from new technology.

$(2,1855$, postdating by 132 years)

\section{annex $n$.}

1994 T. AR 5 - preparation of the Budget Speech and Annexes, and the Budget tables; (3 (a), 1878, postdating by 116 years)

\section{appreciate $v \cdot i$.}

1984 T. BIG II:3 139 By exercising monetary discipline (which in practice, generally requires small fiscal deficits), an economy can in principle achieve, beyond any shortrun disturbances, a domestic rate of inflation less than that of its trading partners in conjunction with an appreciating exchange rate.

$(5,1882$, postdating by 102 years)

\section{appropriation $n$.}

1987 T. BIG I:2 79 Once budget allocations have been determined, the Government requests that Parliament ratify these allocations through the appropriation process.

(3, 1858, postdating by 129 years)

a priori $a d j$. phr. 
1987 T. $B I G$ I:1 3 In most cases, there can be no a priori assumption that particular functions will always be best served through one form or another. 1987 T. BIG Annex 425 We might instead say that we have a right to an a priori expectation of health status (possibly differing for differing age groups). 1987 T. BIG II:1 9 There is, in fact, no a priori reason why government intervention should take this form.

(2, 1882, postdating by 105 years)

\section{arbitrage $n$.}

1987 T. BIG I:4 299 This approach provides some scope for limiting tax avoidance and arbitrage opportunities.

$(3,1882$, postdating by 105 years $)$

arbitral adj.

1995 Glyn Davis and Margaret Gardner. In Boston, J. (ed.) 142 To this end, Jobsback! proposed a significant winding-back of arbitral institutions.

(1, 1911, postdating by 84 years)

avail v.t.

1987 T. BIG I:4 305 High rates induce the switching of income to presently untaxed or lightly-taxed forms, other avoidance and evasion activities (availed mostly by highincome earners) and generally put pressure on difficult-to-measure boundaries such as those between private and business expenditure and between capital and current income.

(5 (b), 1838, postdating by 149 years)

backbencher $n$.

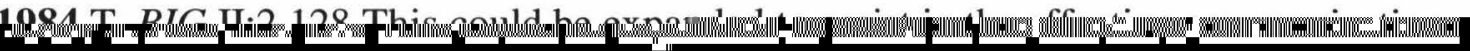

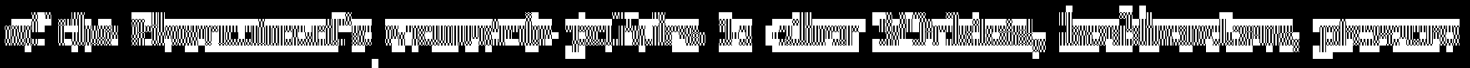

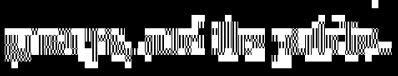

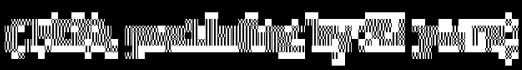

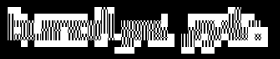

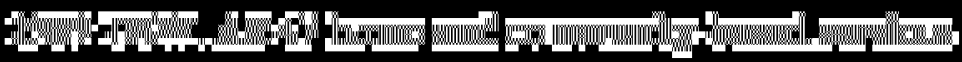

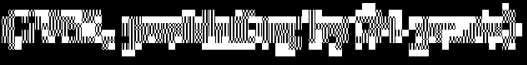




\section{benchmark $n$.}

1994 T. $A R 5$ Reports were prepared on the scope to enhance the medium-term fiscal performance by setting benchmarks for prudent fiscal policy and monitoring performance by timely and comprehensive fiscal reporting.

(1 (b), 1963, postdating by 31 years)

\section{bicultural $a d j$.}

1987 T. BIG I:5 340 Also, positive examples of bicultural co-operation can be pointed to, as in the case of some mining agreements.

(1963, postdating by 24 years)

bounded $p p l$. adj.

1987 T. BIG I.3 133 The contract will aim to be mutual, binding, bounded and based on the resources and information available.

(c, 1865 , postdating by 122 years)

brain washing $v b l . n$.

1987 T. BIG II:4 94 Thus, value neutrality does not appear readily achievable and, in practice, the implementation of value clarification techniques in the classroom has a strong resemblance to techniques of brain washing.

(1968, postdating by 19 years)

\section{brief $n$.}

1987 T. BIG I Annex 405 Through this paper, and the chapters of the brief, much of the analysis is couched in terms of the well-being of individual people.

(7 (b), 1949, postdating by 38 years)

\section{brokerage $n$.}

1984 T. $B I G$ I:4 77 The level of administration charges is expected to fall by $\$ 5$ million because of the change in the calculation of brokerage paid on retail stock issues.

$(2,1884$, postdating by 100 years $)$

\section{bundle $n$.}


1987 T. BIG I.4 268 The bundle of skills which a professional has may be of excessive quality or range for the majority of tasks he or she actually faces.

(1863, postdating by 124 years)

bundle $v . t$.

1987 T. BIG II:6 178 Government intervention, however, if it arbitrarily bundles research or entrepot funding with educational funding may prevent the most efficient and effective providers of the non-educational functions being allowed to compete or develop. 1987 T. BIG II:10 271 Such a contract will bundle together four core elements: who chooses, who pays, who benefits and who is accountable for delivery of the service.

(2, 1690, labelled Obs., postdating by 297 years)

\section{bundling $v b l . n$.}

1987 T. BIG II:2 35 However, in intervening to counter disjunctions with one or more of the contractual elements described above, the Government will itself break up the bundling together of the four elements in the contract.

(1878, postdating by 109 years)

\section{cabotage $n$.}

1994 T. AR 5 The Treasury also worked with the Ministry of Transport on CER border issues such as passenger facilitation, pre-clearance options and cabotage. $(2,1960$, postdating by 34 years $)$

cake $n$.

1984 T. BIG I:6 94 While the share of the national cake going to the household sector has not significantly altered over the period reviewed, marked changes in the distribution of income have occurred within the household sector.

(7 (b), 1958, postdating by 26 years)

\section{capitation $n$.}

1984 DoH. AR 4 Funded now on a "capitation" rather than a "fee-for-service" basis, hospital boards are beginning to realise that they have a vested interest in the health of their catchment population and not just in episodes of illness requiring hospital care. 
(1796, postdating by 188 years)

capture v.t. $\quad$ (fig.)

1996 NZL 14.097 The report also accepted Treasury's argument that the middle classes had captured higher education for their own benefit.

(1 (a), 1882, postdating by 114 years)

\section{carry over $n$.}

1987 T. BIG I:6 388 This assumes little carry over of the effects of the US dairy herd buyout scheme into the $1986 / 87$ September year...

((b), 1955, postdating by 32 years)

causal adj.

1984 T. BIG II:3 140 Imposing controls on prices simply means that the costs of the underlying causal policies are experienced in different ways: for example in queues and shortages and through the incurrence of greater risks and transaction costs in coping with and/or circumventing the regulations.

$(2,1881$, postdating by 103 years)

ceased ppl.a.

1987 DSW. AR 66 A table based on ceased benefits comparable to years to $31 \mathrm{March}$ 1986 and earlier is available on request.

(1927, postdating by 60 years)

\section{ceiling $n$.}

1987 T. BIG II:8 230 The retention rates from form 3 to form 5 are of special interest because, while a ceiling of 90 percent enrolment appears to have operated for nonMaori students, for Maori students there has been an effective ceiling of less than 70 percent.

(6 (d), 1958, postdating by 29 years)

\section{centripetal $a d j$.}

1987 T. BIG II:4 100 This will reinforce centripetal tendencies in decision making in the state sector. 
(1 (b), 1870, postdating by 117 years)

channel v.t.

1984 T. BIG II:2 132 While other departments will have a role in advising the Government on policies of this type (such as market promotion or technology development), the allocation of responsibility to one agency for advice on major proposals which involve the channelling of public assistance to private sector beneficiaries could facilitate a more rigorous and consistent approach to decisionmaking.

(3, 1958, postdating by 26 years)

cif $n .$, abbrev.

1984 T. BIG I:3 62 A positive/negative number indicates an increase/decrease in fob export volumes relative to cif import volumes.

(1958, postdating by 26 years)

\section{civism $n$.}

1987 T. BIG II:7 205 The public domain and vertical state component are necessarily integrated to maintain the "civism" required for a viable state to prosper politically and economically.

(1 (b), 1880, postdating by 107 years)

clawback $n$.

1994 T. AR 5 The Treasury continued to monitor the clawback arrangements that arose from the sale of Synfuel to Fletcher Challenge Limited in 1990. Revenue from the clawbacks amounted to $\$ 35.262$ million in $1993 / 94$.

$(2,1970$, postdating by 24 years $)$

\section{commercialisation $n$.}

1999 NZL 31.0754 Commercialisation is the theory that business practice is best, even for non-businesses.

(1889, postdating by 110 years)

commercialise $v . t$. 
1984 T. BIG II:13 281 This can be accomplished either by using some mechanism quite separate from state owned enterprises to achieve equity or by "commercialising" the objective for the State owned enterprise by paying a subsidy. 1984 T. BIG II:13 284 The social objectives which remain with State trading enterprises should be "commercialised", for instance by paying a subsidy to cover the extra costs involved. (1888, postdating by 96 years)

\section{commercialism $n$.}

1997 Easton The Commercialisation of New Zealand 222 Collectively the government adopted a policy of commercialism, and that policy was fundamentally antiintellectual because it pursues no higher goal than material prosperity. (1889, postdating by 198 years)

\section{concessionary adj.}

1984 T. BIG II:10 220 Other notable examples are the capital write-off provisions in farming, mining and forestry, and the concessionary taxation of life insurance.

(A, 1885, postdating by 99 years)

\section{contract $v . i$.}

1987 T. $B I G$ I:4 188 The more flexibly people are able to contract with each other in as unconstrained a manner as possible the more equitable the outcomes are likely to be.

(2 (a), 1891, postdating by 96 years)

contract $v . t$.

1984 T. BIG II:7 182 "The Macroeconomic Effects of Contracting the Deficit" (III 9 (b), 1878, postdating by 106 years)

\section{contract out v.t.}

1990 DoH. BIG II.35 - increasing competition among health care providers by allowing boards to contract-in and contract-out for services; 1996 Evans et al 1894 New Zealand accomplished government contracting out, the wholesale elimination of agricultural subsidies, import licensing, and many tariffs, and the privatization of its national telecommunications provider without instituting industry-specific regulation. 
(2 (e), 1959, postdating by 136 years)

contraction $n$.

1984 T. BIG II:5 158 An excess of demand over supply of foreign exchange (for example) will result in an external deficit, with a consequent domestic monetary contraction.

(6 (a), 1848, postdating by 136 years)

contractual adj.

1987 T. $B I G$ II:10 273 The long-term investment nature of many of the benefits of education, as against the predominantly short-term costs, means that the feedback loop on educational decisions is weak whatever party is the decision maker, hence the difficulties associated with the four elements of the contractual package mentioned earlier are reinforced.

(1884, postdating by 103 years)

correspondence school $n$.

1987 T. BIG II.6 179 The Correspondence School provides school certificate and other courses available to adults who now make up the majority (60 percent) of its total roll;

(1933, postdating by 54 years)

cost-plus attrib.

1990 T. BIG 439 Other policies led to cost-plus practices and less concern for productivity or quality.

(1949, postdating by 41 years)

\section{credit squeeze $n$.}

1984 T. BIG II:3 139 Sooner or later, however, the resulting balance of payments deterioration drains cash out of the economy, imposing a credit squeeze until the domestic cost structure is restored relative to that of foreign competitors.

(1962, postdating by 22 years)

\section{Crown $n$.}


1991 DSW. AR 28 The Department of Social Welfare is wholly owned by the Crown. $(4,1844$, postdating by 147 years)

\section{dead letter $n$.}

1987 T. BIG I Annex 430 Though the debate about rationality has raged for many years, as the debate is usually cast it is now a dead letter.

(1 (c), 1926, postdating by 61 years)

\section{de-bug v.t.}

1990 T. BIG 13 Experience shows that significant policy change takes a long time to design, implement, observe in action and "de-bug" before the full benefits come through.

$(2,1970$, postdating by 20 years $)$

\section{decentralise $v . t$.}

1987 DSW. AR 13 The department is following a policy of decentralising its activities and providing a service more readily accessible to the public.

(1875, postdating by 112 years)

\section{defeasance $n$.}

1990 T. AR 56 The Government and the Corporation entered into a deed to allow the defeasance of Railways' debt off its balance sheet.

(1551, labelled Obs., postdating by 439 years)

\section{deflationary adj.}

1987 T. BIG I:4 217 The higher interest rates that result have a deflationary impact on spending, which in turn has a restraining effect on prices.

(1963 (1959 in econ. sense), postdating by 24 years)

\section{depoliticize $v . t$.}

1995 Martin, J. in Boston, J. (ed.) 42 Finally, we should acknowledge that the purpose of much contracting in the New Zealand public sector has been to 'depoliticize' activities of government...

(1970, postdating by 25 years) 
deregulated $a d j$.

1997 NZL 31.1050 In a deregulated climate, it is inevitable that finance houses and banks will stiffen their credit criteria to protect themselves.

(1964, postdating by 33 years)

\section{determinant $n$.}

1984 T. BIG II:3 141 Jointly, monetary and exchange rate policies are the key determinants of the long-run inflation rate.

(B 2 (a), 1894, postdating by 90 years)

\section{determination $n$.}

1984 T. BIG II:5 164 Nominal Exchange Rate Determination - The Options

(6 (b), 1857, postdating by 127 years)

\section{devolution $n$.}

1987 T. BIG I:3 131 The process of devolution must be constructed on a mutual understanding by the Government and the iwi of the obligations, interests and rights of both parties.

$(5,1875$, postdating by 112 years $)$

\section{disaggregation $n$.}

1984 T. BIG II:2 14 The above data have been disggregated into the main industries within the pastoral sector and the results of that disaggregation are given below.

$(2,1890$, postdating by 94 years)

\section{disemployment $n$.}

1987 T. I:4 288 Empirical evidence on the disemployment effects of minimum wages is mixed, and depends to some extent on the particular study method used. (1893, labelled rare, only two citations, postdating by 94 years)

\section{disestablish v.t.}

1996 NZL 10.027 ...they were incensed by the latest "restructuring" - charge nurses were to be "disestablished" and replaced by a new tier of under-managers.

((a), 1886 , postdating by 110 years) 


\section{disinflation $n$.}

1990 T. BIG 447 Disinflation and faster growth will be assisted by measures to break down "indexation linkages".

$(2,1955$, postdating by 35 years $)$

\section{disinflationary adj.}

1987 T. BIG I:4 214 The swings in the exchange rate since the float have, to a considerable extent, reflected fluctuations in the degree of disinflationary pressure being applied by monetary policy.

$(2,1957$, postdating by 30 years $)$

\section{disjunction $n$.}

1987 T. BIG II:2 34 Hence the basis for government intervention in education cannot securely rest on an hypothetical distinction between individual and social benefits and costs from education but can rest on disjunctions between individuals.

( 1,1864 , postdating by 123 years)

\section{disjuncture $n$.}

1987 T. BIG I:3 126 The disjuncture of choice, payment, benefit and accountability means that social policy should always be scrutinised closely to ensure that social goals are achieved as fairly and efficiently as possible.

$(1,1679$, postdating by 308 years $)$

\section{disprepare $v . t$.}

1987 T. BIG II:10 280 The school, if it treats the individual as the customer looking for immediate benefits from its services, will create a relationship that disprepares individuals.

(1651, labelled rare, one single citation, postdating by 336 years)

\section{distortive $a d j$.}

1984 T. BIG II:2 16 However, where intervention by assistance has only an economic objective, it is particularly important to ensure that a net advantage can be expected from the intervention and that the method of delivery is the least distortive.

(1823, a single source with only two citations, postdating by 161 years) 
distributional adj.

1984 T. BIG II:10 211 Pursuit of particular allocative or distributional objectives should be effected through specific tax measures only if they are clearly the most efficient instrument.

(1963, postdating by 21 years)

downstream adj.

1984 T. BIG II:3 34 There are several policies designed to compensate forest growers for the downstream benefits they provide through the protection of land prone to erosion.

(1963, postdating by 21 years)

drag $n$.

1990 T. $B I G$ 8a 95 The taxes required to pay for social services create a drag on the economy's ability to create jobs. The resulting unemployment adds further to tax burdens, creating a further drag on the economy.

(3 (d), 1968, postdating by 22 years)

drive v.t.

1987 T. BIG I.4 231 Driving these trends has been growth in transfer payments and debt servicing.

(2 (a), 1892, postdating by 95 years)

driven $p a$. pple.

1987 T. BIG II:6 183 Funding is roll-driven and compartmentalised.

$(1,1887$, postdating by 100 years)

dull v.i.

1987 T. BIG I:2 63 This would provide sufficient time for an appointee to achieve results, but not be so long that motivation could dull.

(II 6 (a), 1871, postdating by 116 years)

educatee $n$. 
1987 T. BIG II:2 31 Society can suffer costs to the economy from the loss to the labour market of the skills and time spent on education both by educators and educatees.

(1857, labelled nonce-wd. with only two citations, postdating by 130 years)

\section{empower v.t.}

1987 T. BIG II:2 42 In attempting to redress the situation and safeguard the life chances of our young people and New Zealand's future the key element, as will be discussed in the following chapters, is empowering, through choice and through maximising information flows, the family, parent or individual as the customer of educational sources.

(2, 1869 , postdating by 118 years)

enable v.t.

1987 T. BIG II;2 39 By contrast, enabling intervention will be more positively received by those groups or individuals whom it enables.

(3 (a), 1888, labelled “obs. or arch.”, postdating by 99 years)

\section{enhance $v . t$.}

1984 T. $B I G$ II:2 133 For example, some announced criteria for governing the conduct of monetary policy would have the advantage of giving the public regular information on the Government's success in meeting its objectives (and thereby enhance the impact of policy on inflationary expectations).

(3 (a), 1873, postdating by 111 years)

\section{entrepot $a t t r i b$.}

1987 T. BIG II:10 283 They may act as the repository of and agent for knowledge and culture with the community as a whole: the entrepot function.

$(1,1871$, postdating by 116 years)

\section{estate duty $n$.}

1984 T. BIG II:10 218 The only wealth-based taxes imposed in New Zealand are land tax and estate and gift duties.

(1896, postdating by 88 years) 
expansionary adj.

1984 T. BIG I:1 2 Interest rates will therefore remain high and adversely affect business investment, exchange rates and the financial position of major LDC debtors unless the United States authorities are successful in unwinding their expansionary fiscal position.

(1969, postdating by 15 years)

exportables $n \cdot p l$.

1996 Evans et al 1885 In primary exportables the rate of total factor productivity grew at 6.3 percent per annum between 1985 and 1994, faster than at any other time during his study (starting in 1960).

(B, 1873, labelled rare, postdating by 123 years)

extractive adj.

1990 T. BIG III:33 New Zealand lacks the energy and mineral resources to acquire substantial wealth through extractive industries...

$(2,1962$, postdating by 28 years)

\section{featherbedding $n$.}

1987 T. BIG I:1 43 Opportunism in the context of central government decision making and planning may exhibit itself in the form of political favours, featherbedding and waste of public resources.

(1958, postdating by 29 years)

\section{feedlot $n$.}

1987 T. BIG I:6 388 This assumes little carry over of the effects of the US dairy herd buyout scheme into the 1986/87 September year, and increasing cows retained on US feedlots because of lower grain prices;

(1964, postdating by 23 years)

\section{floor $n$.}

1990 T. BIG 448 By placing a floor under the wages which people will accept, benefits can also reduce the number of jobs on offer.

(1 (b), 1959, postdating by 31 years) 


\section{foreshore $n$.}

1987 T. BIG I:5 324 ...conflict is unavoidable where, for example, the Treaty assigns ownership rights over fisheries to various tribes but, even in 1840 , there was a common law assumption of Crown ownership of harbours and foreshores.

(1894, postdating by 93 years)

\section{formulary $n$.}

1993 DoH. AR 38 Owing to a reassessment of ministerial priorities, the Department of Health distributed copies of the British National Formulary (BNF) to general practitioners as a means of providing unbiased information on medicine, rather than proceeding with a New Zealand Formulary as originally planned.

(A, 1877, postdating by 116 years)

forward $a d j$.

1987 T. $B I G$ I:4 212 A further important aspect of the development of an effective foreign exchange market has been the development of an efficient forward market. (1962, postdating by 25 years)

\section{foster home $n$.}

1988 DSW. AR 46 Over $50 \%$ of children in departmental care are in the care of foster families in private foster homes or in one of the 164 departmental Family Homes. (1886, postdating by 102 years)

\section{framework $n$.}

1984 T. BIG II.1 111 This includes such matters as the legal framework for the conduct of commercial affairs.

(1 (b), 1959, postdating by 25 years)

\section{friendly society $n$.}

1994 T. AR 3 This Office is also responsible for scrutinising the activities of friendly societies and credit unions.

$(8,1863$, postdating by 131 years $)$

\section{fringe benefit $n$.}


1987 T. $B I G$ I:4 293 ...the personal income tax base was extended by removing a number of unjustified concessions and by the introduction of the fringe benefit tax;

$(3,1969$, postdating by 18 years $)$

\section{functionality $n$.}

1994 T. AR 7 During the year, the Treasury's Document system was reviewed, and a decision was made to replace the system with a product that would provide better functionality, complete with a user-friendly Windows interface.

(1879, postdating by 115 years)

gimme attrib.

1992 James 277 One set of changes, the claiming of independence, the attempt to do better by minorities and the pursuit of equalisation of the imbalances in society generally, the greater moral and civil freedoms and the greening of policy, was predictable from the preoccupations of most young political activists in the 1960s, the formative political years of the gimme generation.

(1963, postdating by 29 years)

\section{ginger $v . t$.}

$2001 \mathrm{~T}$. AR $21 \mathrm{In}$ addition to these formal projects, a number of 'cluster groups' have been formed to ginger our thinking, for example on sustainable development and on competition policy.

(2 (b), 1897, postdating by 104 years)

\section{globalisation $n$.}

1996 The Sydney Morning Herald 13.04 6s Gordon Preece, lecturer in ethics at Ridley College in Melbourne, says the nature of globalisation enables companies to leave their morals at home.

(1962, postdating by 34 years)

$\operatorname{good} n$. countable and uncountable

1987 T. BIG I: 118 For instance if the quality of a good or service is hard to measure then it will be easier for one party to cheat another. 1987 T. BIG I:2 96 That is, 
consumers can be easily identified and the amount of good or service consumed accurately assessed and charged for on a full cost recovery basis.

(C III 8 (a), 1968, postdating by 19 years)

grow v.t.

2001 T. DFR 20 Grow an Inclusive, Innovative Economy for the Benefit of All.

(II 14 (e), 1481, labelled obs., postdating by 520 years)

\section{half-pie $a d j$.}

1992 Colin James 161 The National Government is attempting to drive the model further into private sector practices, creating half-pie state-owned enterprises (with a social as well as a commercial objective) out of the area health boards to run hospitals

(1955, postdating by 37 years)

\section{hamstring $v . t$.}

1984 T. BIG II: 106 The interest rate controls hamstring the monetary policy action which should be counteracting that threat.

$(2,1858$, postdating by 126 years)

\section{$\operatorname{hardwood} n$.}

1990 T. BIG 333 Harvesting of forests on the scale of the hardwood extraction in the Amazon Basin would probably be unacceptable to New Zealanders.

(1 (a), 1968, postdating by 22 years)

\section{hedge $n$.}

2001 T. AR 46 These financial investments are in foreign currencies, which are held as hedges against long-dated foreign-currency debt that cannot be bought back from investors.

$(5,1959$, postdating by 42 years $)$

\section{house parent $n$.}


1984 DSW. AR 57 A new salary subsidy programme was introduced from 1 October 1983 for a limited number of approved organisations employing house parents to run accommodation for street kids.

(1964, postdating by 20 years)

\section{impact on $v . i$.}

1984 T. $B I G$ II:4 153 It is likely, for instance, that the increased financial sophistication required to arrange for first, second and perhaps third mortgages, all possibly having to come from different sources, represents an obstacle which impacts more heavily on the less wealthy and the less knowledgeable.

(3 (b), 1956, postdating by 28 years)

\section{imprest adj.}

1991 DoH. AR 26 Under Mode A appropriation the Department reported trust and imprest accounts that are not part of the balance sheet when reporting as a Mode B appropriated department.

(2 attrib., 1893, postdating by 98 years)

\section{incurrence $n$.}

1984 T. BIG II:3 140 Imposing controls on prices simply means that the costs of the underlying causal policies are experienced in different ways: for example in queues and shortages and through the incurrence of greater risks and transaction costs in coping with and/or circumventing the regulations.

(1892, postdating by 92 years)

\section{inflow $n$.}

1984 T. BIG II: 105 This boost to the deficit contributed to the monetary growth in 1983 (which was augmented by a private capital inflow).

(1897, postdating by 87 years)

\section{injunctive adj.}

1987 T. $B I G$ I:4 265 There are many situations in which measures such as the granting of appropriate private property rights or the imposition of pollution taxes can 
lead to much more cost-effective control of pollution than the injunctive remedies which are common in this area.

(1853, postdating by 134 years)

\section{in-kind $a d j$.}

1990 T. BIG 8a 97 The form of assistance: governments may make cash available to purchase goods or services or can offer those goods and services directly (i.e., "inkind").

$(15,1862$, postdating by 128 years $)$

\section{in loco parentis prep.}

1987 T. BIG II:10 280 Similarly, on the agency concern the state may intervene to act in loco parentis for the individual who is in transition from childhood to adulthood... (1854, postdating by 133 years)

\section{inshore $a d j$.}

1987 T. BIG I:4 256 For instance the problem of depletion in the inshore fishery arose because the rights to the resource had not been allocated and hence fishermen individually had poor incentives to conserve the fish stocks.

(B (a), 1885, postdating by 102 years)

\section{intervention $n$.}

1987 T. BIG II:4 99 The general problems of government intervention, discussed in Chapter 2, demonstrate the substantial potential costs to state intervention, especially where its purposes are not clearly identified.

(1 (a), 1868, postdating by 119 years)

\section{ironsand $n$.}

1987 T. BIG I:5 324 Other conflicts of this nature have developed since 1840 through various legislative enactments reserving river beds, inland waters such as Lake Taupo and minerals such as petroleum, ironsands and geothermal energy to the exclusive ownership of the Crown.

(1963, postdating by 24 years) 


\section{kindergarten $n$.}

1987 T. BIG II:1 9 For most people, the choice is greatest at pre-school where there is a variety of options including kindergarten, play centres and private day care.

(1, 1968, postdating by 19 years)

lagged $\mathrm{ppl}$. adj.

1987 T. BIG I.4 288 The effects are lagged, and often the time lags can be long. 1987 T. BIG I.6.364 The two main influences on the June quarter movement were further lagged effects of GST and rises in housing costs which occurred in the March quarter but which were reflected in the June CPI result. 1987 T. BIG I.6.383 - lagged migration: the considerable outflows of people which occurred during 1985/86 tend now to be reflected in increased inflows;

$(4,1602$, single citation, postdating by 385 years)

lay off $v . t$.

1990 T. BIG 4.48 Given the difficulties of negotiating changes in work practices within enterprises, employers have often responded to increased competition and slow growth in domestic demand by laying-off workers.

(54 (f), 1972, postdating by 18 years)

layoff $n$.

1996 Evans et al 1874 This decline was due to a combination of SOE layoffs and privatization.

(1973, postdating by 23 years)

\section{liberalisation $n$.}

1984 T. BIG II.5 164 Adjustments to the nominal exchange rate could be expected to make a positive contribution to the process of trade liberalisation, facilitating shifts in resources between sectors.

(1961, postdating by 23 years)

\section{liberalise $v . t$.}

1984 T. BIG II.14 300 Domestic aviation has been liberalised in the same manner.

(1 (d), 1955, postdating by 29 years) 
lift $n$.

1984 T. BIG I 24 The major driving influences behind the lift in output currently underway are the expansionary fiscal and monetary policies and the growth in export demand.

(2 (a), 1897 , postdating by 87 years)

\section{loanable adj.}

1984 T. BIG II.4 143 In general, then, competition between financial institutions will result in the provision of a range of savings opportunities for their customers who deposit funds with them, and will force institutions to allocate their loanable funds in the most efficient manner.

(1885, postdating by 99 years)

locate $v . i$.

1987 T. BIG I.4 248 The manufacturing industries which produce goods for local consumption, tend to locate more heavily in the urban centres to take advantage of lower distribution costs. Export industries on the other hand, tend to locate close to their natural resource base which is often in provincial areas.

$(4,1887$, postdating by 100 years $)$

\section{loophole $n$.}

1987 T. BIG I.4 297 This is possible because of weaknesses and loopholes in the tax law and deficiencies in its administration.

$(3,1888$, postdating by 99 years $)$

\section{rebate $n$}

1987 T. BIG II.3 62 An additional rebate of up to \$200 (the maximum corresponds to $\$ 607$ or more of expenditure) may be claimed through the provision for charitable donations and school and pre-school fees.

$(1,1965$, postdating by 22 years $)$

receiving $v b l$. $n$.

1984 DSW. AR 81 Theft, attempted theft, receiving.

$(1,1956$, postdating by 28 years) 
refit $v . t$.

1987 T. BIG II. 4 The demands on the education system to fit and refit people for work are increasing enormously.

(3, labelled obs., 1862, postdating by 125 years)

\section{repatriation $n$.}

1984 T. BIG II.5 163 Restrictions are imposed on direct inward and outward investment flows, short-term overseas borrowing, draw-down periods and debtservicing repayments, individual outward portfolio investment, the timing of repatriation of proceeds of current account transactions, foreign currency holdings, and currency transactions between residents.

$(1,1879$, postdating by 105 years $)$

ring-fence $v . t$.

1987 T. BIG I.2 117 It would clearly ring-fence the operation of the activities and in so doing confer numerous advantages.

(1903, postdating by 84 years)

safeguard $v . t$.

1987 T. BIG II.4 112 Subsequent to identification, the school may be regarded as a key partner in the co-ordinated endeavours of state agencies to help the child and to continue to safeguard his or her safety and future.

((a), 1889, postdating by 98 years)

scope v.t. and scoping $v b l$. $n$. attrib.

1991 Boston et al 46 The Government introduced the 'scoping' exercise which is a process of investigation largely carried out by Treasury with assistance from outside consultants prior to the decision to sell an enterprise. 1992 James 214 Private sector consultants 'scope' the enterprise, assessing its present value, the degree to which its value would be enhanced by potential private owners whom they identify and assess whether its market value exceeds its theoretical value.

(scope v.t. labelled obs. rare, 2, 1807, single citation; scoping vbl. n. not in the OED)

\section{shipment $n$.}


1987 T. BIG I.6 388 This is a consequence of the effects of industrial action in the previous year, which saw shipments to the UK curtailed during the normal seasonal peak in prices;

$(2,1900$, postdating by 87 years $)$

short-run attrib.

1987 T. BIG I.4 198 As long as government intentions are clear and credible, short run effects will be less significant.

(4 (B) 1979 with hyphen only, not as open compound)

smoothed ppl. adj.

1987 T. BIG I.6 364 On a smoothed, seasonally adjusted basis the current account deficit was \$103 million for June 1987 compared with deficits of \$107 million for May 1987 and $\$ 173$ million for June 1986. The balance on merchandise trade (smoothed, seasonally adjusted) for June 1987 was in surplus by $\$ 121$ million, an improvement of \$5 million over May 1987.

(2 (b), 1964, postdating by 23 years)

\section{soft-landing $n$.}

1990 T. BIG 229 It appears possible that the 'soft-landing' hoped for in Australia slowing growth, declining inflation, and an improving current account position could tip over into recession.

(1 (b), 1973, postdating by 17 years)

\section{softwood $n$.}

1990 T. BIG 333 It is one of the world's most efficient producers of pastoral products and has a comparative advantage in growing softwood.

(1 (a), 1977, postdating by 13 years)

spot price $n$.

1984 T. BIG I 7 While disturbances in the Persian Gulf may cause short-term increases in spot prices, the overall outlook is for continued downward pressure on real oil prices.

(IV 13 (d), 1882, postdating by 102 years) 
stigmatise $v . t$.

1987 T. BIG I Annex 444 It also depends on the ability to deliver assistance in a way which does not stigmatise its recipients.

(2 (a), 1875 , postdating by 112 years)

$\operatorname{sum} v . i$.

1984 T. BIG II.10 227 Over the years a complex patchwork of special assistance has been built up by means of a wide variety of concessions in all the major taxes, summing to an annual fiscal cost of some $\$ 1500$ million.

(1 (b), 1966, postdating by 18 years)

sum v.t.

1987 T. BIG I Annex 437 Any such approach would rapidly collapse in the face of the generally recognised impossibility of measuring or summing utility.

(1 (f), 1828, postdating by 159 years)

sweep $n$.

1987 T. BIG I.3 122 These examples give an idea of the sweep of elements involved in the overall well-being of society.

(II 14,1877 , postdating by 110 years)

taxable adj.

1984 T. BIG II.8 201 Major weaknesses in the definition of taxable business income arise from the exclusion of capital profits...

$(2,1908$, postdating by 76 years $)$

\section{thorough-going adj.}

1984 T. BIG II.8 202 More thorough-going reforms in the direct and business tax areas offer the prospect of a significant improvement in the tax system overall. (1888, postdating by 96 years)

\section{touchstone $n$.}

1990 T. BIG 16 With Cabinet commitment this provides touchstones for decisionmaking. 
(1 (b), 1871, postdating by 113 years)

\section{transact $v \cdot i$.}

1987 T. BIG I.3 124 Given this set of constraints on the pursuit of well-being, it seems likely that an appropriate role for the state in many areas is to define a clear set of rights for people and to permit individuals to voluntarily transact between one another in order to pursue their own well-being.

(1 (a), 1872, labelled "now rare", postdating by 115 years)

trend v.i.

1993 T. BIG 125 The fiscal outlook is trending in a favourable direction. 1996 Evans et al 1868 Even so, government noninterest expenditure, after an initial fall, trended upwards through to 1991.

(4 (b), 1901, postdating by 95 years)

\section{tuck shop $n$.}

1984 DoE. BIG Sec.2.23 Extensions to secondary school gymnasiums are funded entirely by local effort as are tuck shops and cafeterias.

(1885, postdating by 99 years)

uncalled $\mathrm{ppl}$. adj.

$1991 \mathrm{~T}$. $A R 72$ This capital is uncalled creating a contingent liability of $\$ 200,000$.

$(4,1882$, postdating by 109 years $)$

\section{underpin v.t.}

1995 Glyn Davis and Margaret Gardner in Jonathan Boston (ed.). The State Under Contract 141 At issue is the logic which underpins the Coalition's industrial relations policy.

(1 (b), 1884, postdating by 111 years)

\section{underpinning $v b l . n$.}

1995 Davis and Gardner in Boston (ed.) 141 The Liberal proposal is clear about its underpinning: employment is a contract arrangement between consenting parties reached in private. 
(2 (b) fig., 1894, postdating by 101 years)

underpricing $v b l . n$. (two different senses)

1984 T. BIG II.14 303 The result has been substantial underpricing of these fuels and an effective subsidy (amounting to several hundred million dollars per annum) to consumers.

$(1,1756$, postdating by 228 years $)$

1984 T. BIG II.13 277 The wider effects of underpricing include the possible forcing out of production of private sector producers which may have been more efficient than the State owned enterprise;

$(2,1890$, postdating by 94 years $)$

unincorporated $\mathrm{ppl}$. adj.

1984 T. BIG II.10 219 Taxable income, defined as above, is taxed under the personal tax system in the case of unincorporated businesses but, in the case of companies, at both the company tax rate and shareholders' marginal tax rates when profits are distributed as dividends (the "classical" system of company taxation).

$(2,1884$, postdating by 100 years $)$

untied $p p l$. adj.

1984 T. BIG II.12 253 The more doubt is attached to the proposition, the stronger the case for either not intervening at all or for delivering untied assistance - i.e. for redistributing income rather than providing particular services or regulating individuals' decisions.

$(1,1888$, postdating by 96 years $)$

unwind $v \cdot i$.

1990 T. $B I G 224$ Dairy and meat exports are likely to grow strongly, as temporary factors which depressed exports in 1989/90 (including delays in dairy shipments) unwind.

(3, 1860 , postdating by 130 years)

unwind $v . t$. 
1984 T. BIG I. 2 Interest rates will therefore remain high and adversely affect business investment, exchange rates and the financial position of major LDC debtors unless the United States authorities are successful in unwinding their expansionary fiscal position.

(1 (b) fig., 1908, postdating by 76 years)

\section{user-charge $n$.}

1996 NZL 7 To enable students to meet these user-charges, under-25-year-olds from low-income families were to receive allowances; everyone else a readily available loan...

(1976, open compound, postdating by 20 years)

\section{value-added $n$.}

1987 T. BIG II.5 124 However, as described, educational qualifications are used as signalling devices in the labour market - they do not, in themselves, directly provide value-added in the way that a piece of new machinery may. In fact, much educational investment by individuals appears to be a defensive expenditure to protect the individual's market share in the labour market rather than to achieve net value-added to the economy. Whether value-added is achieved, that is, whether that particular level of qualification is necessary to that particular job, may be fortuitous. (1951, in quotation marks, single citation, postdating by 36 years)

\section{white paper $n$.}

1987 T. BIG I.2 117 The exact mechanism for achieving this would require careful consideration and would perhaps best be discussed in a white paper along with the complementary question of who should own the shares in the corporation.

(1978, with capital initials, postdating by 9 years)

\section{wind-up $n$.}

2001 T. $A R 103$ The final dividend from the wind-up of Government Property Services has been delayed into 2001/02.

(A.1, 1869, postdating by 132 years)

\section{woodpulp $n$.}


1984 T. BIG I.3 59 This is supported by higher than previously forecast export volumes of sawn timber and woodpulp.

(1866, open compound, and also hyphenated, postdating by 118 years) 


\section{APPENDIX VII}

WORDS FROM TE REO MAORI used by the New Zealand Treasury in its Briefings to Incoming Governments, Annual Reports and Corporate Plans, 1984 - 1994.

hapu $n$.

iwi $n$.

kaiarahi reo $n$.

kaumatua $n$.

kiwi $n$.

kohanga reo $n$.

kura kaupapa $n$.

Maatua Whangai $n$. (name of programme)

mana $n$.

mana motuhake $n$.

Maori $n$.

Maoritanga $n$.

marae $n$.

pakeha $n$.

rangatiratanga $n$.

taha Maori $n$.

taha Pakeha $n$.

tangata whenua $n$.

tangi $n$.

tangihanga $n$.

taonga $n$.

te reo Maori $n$.

Te Urupare Rangapu $n$.

utu $n$.

wairua $n$.

wananga $n$.

whanau $n$.

(27) 


\section{APPENDIX VIII}

WORDS FROM TE REO MAORI used by the New Zealand Department of Social Welfare in its Briefings to Incoming Governments, Annual Reports and Corporate Plans, 1984 - 1994.

hapu $n$.

hui $n$.

iwi $n$.

kai tiaki $n$.

kaumatua $n$.

kaupapa $n$.

koha $n$.

(Te) kohanga reo $n$.

Komiti Whakahaere $n$.

kowhaiwhai $n$.

Maatua Whangai $n$. (name of programme)

Maori $n$.

Maoridom $n$.

Maoritanga $n$.

marae $n$.

mokopuna $n$.

pakeha $n$.

Puao-te-Ata-tu $n$. (name of influential 1986 report)

Putea Manaaki $n$. (name of programme)

roopu $n$.

runanga $n$.

taha Maori $n$.

Tainui $n$.

tangata whenua $n$.

tangi $n$.

tangihanga $n$.

Te Kakano o te Whanau $n$. (name of collective)

Te Koputu Taonga $n$. Te Urupare Rangapu $n$. Tihei Mauriora! (Behold there is life!) tikanga Maori $n$. Tuhonohono $n$. (name of programme) whakapakari $n$. whanau $n$. whanaunga $n$. whanaungatanga $n$. 


\section{APPENDIX IX}

WORDS FROM TE REO MAORI used by the New Zealand Department of Health in its Briefings to Incoming Governments, Annual Reports and Corporate Plans, 1984 1994. Numbers in the right-hand column are the tokens, i.e. the frequency of occurrence of each lexeme within this dataset.

Aotearoa $n$.

hauora $n$. (health, spirit of life) 10

hapu $n$. 8

He Kete Maatauranga (a Maori health resource kit) 2

hikoi $n$.

hui $n$.

Hui Whakaoranga $n$. (a 1984 DoH report)

Ihi $n$.

iwi $n$.

kai $n$.

kaiawhina $n$. (counsellor, support worker)

Kaitiaki

kaumatua $n$.

kaupapa $n$.

Kia Piki Te Ora (name of a research report)

Kohanga Reo $n$.

Kokiri $n$.

Ko tou rourou, ko taku rourou, Ka ora ai te tangata (With your and my contribution, skill and knowledge, the wellbeing of man will be assured) 1

mana $n$.

Manatu Maori $n$.

Maori $n$.

Maoridom $n$.

Maoritanga $n$.

marae $n$.

Matua Whangai $n$. 
Minita $n$.

Nga Ringa Aroha $n$. (a DoH programme to train community health workers) 5

ora 1

$\begin{array}{lr}\text { Oranga Maori } n \text {. } & 8\end{array}$

$\begin{array}{ll}\text { pakeha } n . & 7\end{array}$

rongoa $n$. (herbal medicine) 2

roopu $n$.

roopu-a-iwi 1

$\begin{array}{ll}\text { tangata whenua } n . & 10\end{array}$

tane 1

taonga $n$. 1

tapu $n$. (sacred thing) 1

Tautoku kia whaia Te Ao Marama (Support the pursuit for a healthy world) 1

Te Hui Whakaoranga $n$. 5

Te Kakano o Te Whanau $n$. 2

Te Kohanga Reo $n$. 11

$\begin{array}{ll}\text { Te Koputu Taonga } n . & 7\end{array}$

Te Puni Kokiri $n$. (The Ministry of Maori Development) 2

te reo Maori $n$. 2

Te Roopu (Maori) Takawaenga Tohutohu ki te Minita Hauora $n$. (Ministerial Advisory Committee on Maori Health) 9

Te Roopu Tautoko $n$. 3

te Taha Hinengaro $n$. (mental well-being) 3

$\begin{array}{ll}\text { Te Taha Maori } n . & 2\end{array}$

Te Taha Tinana $n$. (physical well-being) 3

Te Taha Wairua $n$. (spiritual well-being) 4

Te Taha Whanau $n$. (family well-being) 3

Te Tira Ahu Iwi (Iwi Transition Agency) $n$. 1

Te Tirohanga Rangapu $n . \quad 2$

Te Urupare Rangapu $n . \quad 13$

Te Waiora o Aotearoa $n$. (name of Trust) 6

Te Wananga Hauora Maori $n$. (the Dept's Maori Health Unit) 2

Te Wananga o Raukawa $n$. 3

$\begin{array}{ll}\text { tikanga (Maori) } n . & 7\end{array}$ 
tino rangatiratanga $n$.

tohunga $n$. (traditional Maori healer)

Tu Tangata $n$.

Waiora $n$. - name of programme

wananga

Whakarongo Mai $n$. - name of a report

whanau $n$.

Whare Rapuora $n$.

whenua $n$.

(67 lexemes)

In addition, the following phrases were used in this dataset:

E nga mana, e nga reo, e nga hau e wha, tena koutou, tena koutou, tena koutou katoa. 


\section{APPENDIX X}

WORDS FROM TE REO MAORI used by the New Zealand Department of Education in its Briefings to Incoming Governments, Annual Reports and Corporate Plans, 1984 - 1994. Numbers in the right-hand column are the tokens, i.e. the frequency of occurrence of each lexeme within this dataset.

(te) Ao Maori (the Maori world)

Aotearoa

aroha

atawhai

hapu

He Huarahi (name of a major report produced by NACME in 1980) 1

He Tangata (name of a report produced by IAGNE)

He Tohu Matauranga (the Maori attestation scheme which endorses candidates for teacher training)

hui

iwi

Ka Awatea (the Government's Maori Affairs policy)

kaiarahi (i te) reo 29

kaiawhina

kaitiaki

kakapo

karakia

kaumatua

kaupapa

(Te / Nga) Kohanga Reo

kuia

kura

Kura Kaupapa (Maori)

manaaki

Manatu Maori

Maori

Maoridom 
$\begin{array}{ll}\text { Maoriness } & 2\end{array}$

Maoritanga 2

$\begin{array}{ll}\text { marae } & 71\end{array}$

matua 1

$\begin{array}{lr}\text { mihi } & 8\end{array}$

mihimihi 1

mokopuna 3

nga taonga katoa (possessions) 1

nga toi 1

oranga 1

$\begin{array}{ll}\text { Pakeha } & 70\end{array}$

rangatiratanga 2

$\begin{array}{ll}\text { runanga } & 6\end{array}$

Runanga Matua (an independent advisory body to the Minister of Education on Maori

$\begin{array}{lr}\text { policy matters) } & 14\end{array}$

$\begin{array}{ll}\text { Taha Maori } & 60\end{array}$

tamariki 1

$\begin{array}{ll}\text { tangata whenua } & 17\end{array}$

Tangata Whenua Whakahaere Matua (the name of a course) 3

taonga 2

Te Atakura (the training course for secondary school teachers of Maori) 26

te hinengaro (health, as a school subject) 1

Te Kete Raukura (a programme of Maori perspectives within the Forms 1 - 4 Social

$\begin{array}{ll}\text { Studies syllabus) } & 2\end{array}$

Te Ohu Whakatapu (the Ministry of Women's Affairs) 1

$\begin{array}{ll}\text { te pangarau (mathematics) } & 6\end{array}$

Te Puni Kokiri 3

$\begin{array}{ll}\text { te putaiao (science) } & 6\end{array}$

$\begin{array}{ll}\text { te reo (Maori) } & 68\end{array}$

Te Ropu Whakahaere 6

Te Ropu Whanui (a group of Maori in Education which sets the agenda for Te Ropu

$\begin{array}{ll}\text { Whakahaere) } & 2\end{array}$

$\begin{array}{ll}\text { Te Tahuhu o te Matauranga (the Ministry of Education) } & 13\end{array}$

$\begin{array}{ll}\text { te taiao (technology, as a school subject) } & 1\end{array}$ 
te tikanga-a-iwi 1

te tinana 1

Te Tira Ahu Iwi 1

Te Tiriti o Waitangi 2

Te Urupare Rangapu (the Government's policy statement) 16

Te Wahanga Maori (a division of the DoE) 25

te (iwi) wairua 3

$\begin{array}{ll}\text { Te Wananga o Raukawa } & 6\end{array}$

Te Whariki (the early childhood national curriculum) 5

$\begin{array}{ll}\text { (nga / te) tikanga (Maori) } & 12\end{array}$

tino rangatiratanga 4

tuatara 1

$\begin{array}{ll}\text { Tu Tangata } & 5\end{array}$

wananga 41

whakahaere 1

$\begin{array}{ll}\text { Whakapakari (a training programme) } & 2\end{array}$

whakapapa 1

$\begin{array}{ll}\text { Whakatu Wahine (Women's Suffrage) } & 1\end{array}$

$\begin{array}{ll}\text { whanau } & 22\end{array}$

whare kura 1

$\begin{array}{ll}\text { whare wananga } & 19\end{array}$

wharenui 2

He Purapura ) 1

Te Rangatahi ) a series of booklets for schools 1

Te Tautoko ） 1

$\begin{array}{ll}\text { Te Wharekura ) } & 1\end{array}$

(83 lexemes)

In addition, the following phrases were used in this dataset:

He aha te mea nui te ao? He tangata, he tangata, he tangata.

(What is the most important thing in the world? It is the people.) 
Hutia te rito o te harakeke: kei hea te komako, e ko?

(If the central shoot of the flax is removed, where will the bellbird sing?)

Ka rere te manuka, tomokia. (The challenge is upon us now.)

Kia pai te whakatere e te waka,

Kei pari paria e te tai te monenehu o te kura.

(Caution, as you launch the canoe,

Lest the tide buffet it about, and spoil the plumage on the prow.)

Ko te pae tawhiti, whaia kia tata.

Ko te pae tata, whakamaua kia tina!

Ko te reo te mauri o te tangata. (The language is the soul of the people.)

Naku noa, na.

Nga Tikanga Tekau o te Tatai mo te Akoranga Maori 5

$\begin{array}{ll}\text { Noho ora mai koutou katoa } & 2\end{array}$

Rau rangatira ma. 1

Tena kotou katoa (Greetings to one and all.) 3

Tenei te Tahuhu o te Matauranga e mihi atu ana ki a koe. 2 


\section{APPENDIX XI}

ABBREVIATIONS AND ACRONYMS used by the New Zealand Treasury in its Briefings to Incoming Governments, Annual Reports and Corporate Plans, 1984 1994.

AAVA Authority for Advanced Vocational Award

ACTML Advisory Committee on Teaching of the Maori Language

ADB Asian Development Bank

AGA Annual General Adjustment

AHB Area Health Board

ANZCERTA Australia and New Zealand Closer Economic Relations Trade Agreement

CBU Completely Built Up (pre-assembled)

CCMAU Crown Company Monitoring Advisory Unit

CER Closer Economic Relations

CHE Crown Health Enterprise

CIES Chatham Islands Electricity System

cif cost, insurance, plus freight

CKD Completely Knocked Down (unassembled)

CPI Consumers Price Index

CRI Crown Research Institute

CROC Crown-Owned Company

DPB Domestic Purposes Benefit

DR WHO Direct Recording of Work Hours and Output (a system)

DSW Department of Social Welfare

EC Electricity Corporation

ECS Early Childhood Services

EDRU Electricity Distribution Reform Unit

EFTS Equivalent Full-time Students

EMDTI Export Market Development Taxation Incentive

EMTR Effective Marginal Tax Rate

EPTI Export Performance Taxation Incentive 
ERA Effective Rate of Assistance

ESA Electricity Supply Authority

FAUSA Federation of Australian University Staff

FMR Financial Management Reform

GAAP Generally Accepted Accounting Practice

GATT General Agreement on Tariffs and Trade

GDP Gross Domestic Product

GFS Government Financial Statistics

GMFI Guaranteed Minimum Family Income

GST Goods and Services Tax

HEIS Household Expenditure and Income Survey

HMO Health Maintenance Organisation

HSC Higher Salaries Commission

IMF International Monetary Fund

IRD Inland Revenue Department

ITA Iwi Transition Agency

ITQ Individual Transferable Quota

JOS Job Opportunities Scheme

LATA Local Authority Trading Activity

M3 Broad Measure of Money Supply

Mbd million barrels per day

MEF Maori Education Foundation

MTN Multilateral Trade Negotiation

MTR Marginal Tax Rate

NAFMAC National Fisheries Management Advisory Committee

NPF National Provident Fund

NWASCO National Water and Soil Conservation Organisation

NZARE New Zealand Association for Research in Education

NZDMO New Zealand Debt Management Office

NZEI New Zealand Educational Institute (primary teachers' union)

NZFKU New Zealand Free Kindergarten Union

NZIER New Zealand Institute of Economic Research

OECD Organisation for Economic Cooperation and Development

OET Overseas Exchange Transaction 
PAT Progressive Achievement Test

PPTA Post-Primary Teachers' Association

PR Position of Responsibility

PSBR Public Sector Borrowing Requirement

PSU Pupil Session Unit

QES Quarterly Employment Survey

RAR Reserve Asset Ratio

REAP Rural Education Assistance Programme

RERC Rural Electricity Reticulation Council

RMLR resource management law reform

RST Retail Sales Tax

SCI Statement of Corporate Intent

SEPS Southland Electric Power Supply

SES Socio-Economic Status

SMP Supplementary Minimum Price

SOE State Owned Enterprise

SSC State Services Commission

TAC Total Allowable Catch

TCD Transferable Certificate of Deposit

TPEB Trans Power Establishment Board

UE University Entrance

UGC University Grants Committee

VAT Value Added Tax 


\section{APPENDIX XII}

ABBREVIATIONS AND ACRONYMS used by the New Zealand Department of Social Welfare in its Briefings to Incoming Governments, Annual Reports and Corporate Plans, 1984 - 1994.

AAI Adult Adoption Information

ADG Assistant Director-General

AISU Adoption Information and Services Unit

AWEC Area Welfare Executive Committee

COGS Community Organisations Grants Scheme

CBT Computer Based Training

CWIF Community Welfare Initiatives Fund

CYP \& F Children Young Persons and Their Families

CYPFIS Children, Young Persons and Their Families Information System

DEC District Executive Committee

DPB Domestic Purposes Benefit

EMA Emergency Maintenance Allowance

EEO Equal Employment Opportunity

ECHO Embargo Classification (Head Office) (system)

EMG Executive Management Group

FAMIS Financial Management Information System

FB Family Benefit

FGC Family Group Conference

FVPCC Family Violence Prevention Co-ordinating Committee

GCS Government Computing Service

GMFI Guaranteed Minimum Family Income

GOAB Government Office Accommodation Board

GPS Government Property Services

GRI Guaranteed Retirement Income

ICA Independent Circumstances Allowance

IHC Intellectually Handicapped Children

IMC Institutional Management Committee

ISSP Information Systems Strategic Plan 
ITSC The Information Technology Centre (An Inventory of the

LPC Liable Parent Contribution

MSU Ministerial Services Unit

NCIWR National Collective of Independent Women's Refuges

OMS Operations Management System

OSH Occupational Safety and Health

PIT Parentally Income Tested (also Aust.)

POBOC Payments on Behalf Of the Crown (also used in the Cook Islands, only)

RMC Residence Management Committee

SB Sickness Benefit

SCAN System for Computerised Accounting Networking

SNG Special Needs Grant

SSC State Services Commission

SSRFC Social Sciences Research Fund Committee

SWC Social Welfare Commission

SWIFTT Social Welfare Information for Tomorrow Today

UB Unemployment Benefit

VOSP Vocational Opportunities Support Programme 


\section{APPENDIX XIII}

ABBREVIATIONS AND ACRONYMS used by the New Zealand Department of Health in its Briefings to Incoming Governments, Annual Reports and Corporate Plans, 1984 - 1994.

A \& R Assessment and Rehabilitation

ABR automatic brainstem response

ACC Accident Compensation Corporation

ACHBF Advisory Committee on Hospital / Area Health Board Funding

ACOSH Advisory Council on Occupational Safety and Health

ADT admission, discharge, transfer

AHB Area Health Board

AIDS Acquired Immune Deficiency Syndrome

ALAC Alcoholic Liquor Advisory Council

ANHA Annual National Health Assessment

ANZCERTA Australia New Zealand Closer Economic Relations Trade Agreement

ANZECC Australian New Zealand Environment and Conservation Council

APACHE Acute Physiology Assessment and Chronic Health Education

APG ambulatory patient group

ARU Alcohol Research Unit

ATAB Ambulance Transport Advisory Board

AVG ambulatory visit group

BNF British National Formulary

BPCS Business Performance Accounting System

BTS Blood Transfusion Services

CAU census area unit

CCI Construction Cost Index

CDC Communicable Disease Control

CETSS Council for Education and Training in the Social Services

CER Closer Economic Relations

CHIFS Community Health Initiatives Funding Scheme

CIS cervical carcinoma insitu 
CIT Central Institute of Technology

CMG Corporate Management Group

CORD chronic obstructive respiratory disease

CPI Consumer Price Index

CPR cardio-pulmonary resuscitation

CRR cohort remainder rate (used of retention of nurses in the workforce)

CSOM chronic suppurative otitis media

DAC Drugs Advisory Committee

DMFT decayed, missing and filled teeth

DP Data Processing (Division)

DPB Domestic Purposes Benefit

DPMC Department of the Prime Minister and Cabinet

DRG Diagnostic Related Group

DSW Department of Social Welfare

EEC European Economic Community

EEO equal employment opportunities

EFTS equivalent full-time students

EIA Environmental Impact Assessment

ENT ear, nose and throat

ERMA Environmental Risk Management Authority

FAREX Financial Authority, Requisition and Expenditure Scheme

FIALS Field Information and Licensing System

FLOG Food Legislation Overview Group

FMTP Family Medicine Training Programme

FSC Food Standards Committee

FTE full-time equivalent

GHDPB Geriatric Hospital Daily Patient Benefit

GHSAS Geriatric Hospital Special Assistance Scheme

GMP good manufacturing practices

GMS General Medical Services (benefit)

GP General Practitioner

HACCP Hazard Analysis and Critical Control Point

HBA Hospital Boards' Association

HEAPS Health Education and Promotion System 
HEQ health and equity

HIV human immuno-deficiency virus

HMIS Health Management Information System

HOMES Homes Ongoing Monitoring Evaluation System

HPV human papilloma virus

HRC Health Research Council

HRD Health Reforms Directorate

HRM human resource management

HSEODU Health Services Equal Employment Opportunities Development Unit

HSMDU Health Services Management Development Unit

HSPC Health Service Personnel Commission

HSRDU Health Services Research and Development Unit

HSU Health Science Unit

IADRRS Intensified Adverse Drug Reactions Reporting Scheme

IARC International Agency for Research on Cancer

ICBDMS International Clearinghouse for Birth Defects Monitoring System

ICC Interagency Co-ordinating Committee

ICN International Council of Nurses

ICU Intensive Care Unit

IDC Inter-departmental Committee on Substance Abuse Funding

IDCCHA Interdepartmental Co-ordinating Committee on HIV/AIDS

ISP Independent Service Provider

IUCD intra-uterine contraceptive device

IV intravenous

IWDA Industrial Welfare Deposit Account

LGC Local Government Commission

MAF Ministry of Agriculture and Fisheries

MAPS Management Accounting and Performance System

ME myalgic encephalo-myelitis

MEDLARS Medical Literature Analysis and Retrieval System

MFAT Ministry of Foreign Affairs and Trade

$\mathrm{MOH} \quad$ Ministry of Health

MOT Ministry of Transport

MRC Medical Research Council 
MRSA methicillin-resistant staphylococcus aureus

MRT medical radiation technologist

MSCA Medical and Scientific Committee on AIDS

MSRU Management Services and Research Unit

MWD Ministry of Works and Development

MWWL Maori Women's Welfare League

MWS Medical Warning System

NAC National Audiology Centre

NACAIDS the (Australian) National Advisory Committee on AIDS

NACCHS National Advisory Committee on Core Health Services

NACHRI National Association of Children's Hospitals and Related Institutions

NAG National Action Group

NCSP national cervical screening programme

NECAL National Environmental Chemistry and Acoustics Laboratory

NHI National Health Index

NHSC National Health Statistics Centre

NIPB National Interim Provider Board

N/L no limit (used of government ministers in salary guidelines)

NMDP National Management Development Programme

NMDS National Minimum Dataset

NMPI National Master Patient Index

NPPS Nationwide Pay / Personnel Systems

NRL National Radiation Laboratory

NRMAC National Resource Management Advisory Committee

NWH National Women's Hospital

NZCDC New Zealand Communicable Disease Centre

NZCETSS New Zealand Council for Education and Training in the Social Services

NZHIS New Zealand Health Information Service

NZMA New Zealand Medical Association

NZMI New Zealand Medical/Health Index

NZNA New Zealand Nurses' Association

NZODA New Zealand Official Development Assistance

NZSP New Zealand Society of Physiotherapists

ODAP Official Development Aid Programme 
OECD Organisation for Economic Cooperation and Development

OIA Official Information Act

OLS old long stay

OME otitis media with effusion

PAHs polycyclic aromatic hydrocarbons

PAP Priority Areas Programme (Scheme)

PBFF population-based funding formula

PCBs polychlorinated biphenyls

PDP performance development plan

PEC Public Expenditure Committee

PHARMAC Pharmaceutical Management Agency

PHC Public Health Commission

PHCIG Public Health Commission Implementation Group

PHN public health nursing

PKU phenylketonuria

PMDRG Paediatric Modified Diagnostic Related Group

PMG Project Management Group

PMS Patient Management System

PSA Public Service Association

QMF Query Management Facility

R and W Religious and Welfare (as in ownership status of Rest Homes)

RDRG Refined Diagnostic Related Group

RHA Regional Health Authority

RMLR Resource management law reform

RHMU Residual Health Management Health Unit

RPAC Radiation Protection Advisory Committee

RPIEN Review of the Preparation and Initial Employment of Nurses

RSI Relative Stay Index

RSI Repetitive Strain Injury

RUS Resource Utilisation System

SACHSO Special Advisory Committee on Health Services Organisations

SAMO Special Area Medical Officer

SANZ Standards Association of New Zealand

SES Senior Executive Service 
SFR Standardised Fertility Ratio

SMR Standardised Mortality Ratio

SOS Stop Ourselves Smoking

SPC South Pacific Commission

SRHSS Special Rest Home Subsidy Scheme

SSC State Services Commission

STD sexually transmitted disease

TELARC Testing Laboratory Registration Council

THAW The Health Alternative for Women

TSB Toxic Substances Board

WAM Workforce Analysis and Management System

WHO World Health Organisation

WIMS Works Information Management System

(176) 


\section{APPENDIX XIV}

ABBREVIATIONS AND ACRONYMS used by the New Zealand Department of Education in its Briefings to Incoming Governments, Annual Reports and Corporate Plans, 1984 - 1994.

AAVA Authority for Advanced Vocational Awards

ACAP Australian Co-operative Assessment Programme

AEC Australian Education Council

APEC Asian Pacific Economic Co-operation

APEID Asian Programme of Educational Innovation for Development

APNZ Association of Polytechnics of New Zealand

APSU Aotearoa Polytechnics Student Union

APTEP Advisory Panel on Training and Employment Policy

ARP Adult Retraining Programme

ARLA Adult Reading and Learning Assistance Federation

ASEAN Association of South East Asian Nations

ASTE Association of Staff in Tertiary Education

ASTU Advanced Studies for Teachers Unit

ATE Aotearoa Trainees in Education

ATTI Association of Teachers in Technical Institutes

AUS Association of University Staff

AUT Association of University Teachers

CAC Central Advisory Committee

CAI computer aided instruction

CCDU computer courseware development unit

CCS Crippled Children's Society

CEC Collective Employment Contract

CECUA Combined Early Childhood Union Aotearoa

CEIS Community Education Initiatives Scheme

CERI Centre for Educational Research and Innovation

CILANZ Committee for Independent Learning Aotearoa

CIT Central Institute of Technology

CLANZ Committee for Community Learning Aotearoa/New Zealand 


\begin{tabular}{|c|c|}
\hline CPSW & community pre-school worker \\
\hline CRRISP & Curriculum Review Research in Schools Project \\
\hline CTA & Combined Teachers' Association \\
\hline CWC & Cabinet Works Committee \\
\hline DACOTE & District Advisory Committee on Transition Education \\
\hline DAEs & Dynamic Asian Economies \\
\hline DCC & District Consultative Committee \\
\hline DEET & (Australian) Department of Employment, Education and Training \\
\hline DOSLI & Department of Survey and Land Information \\
\hline EAP & Employee Assistance Programme \\
\hline EBA & Education Boards Association \\
\hline ECAC & Early Childhood Advisory Committee \\
\hline ECDU & Early Childhood Development Unit \\
\hline EDC & Education Development Conference \\
\hline EDI & Education Development Initiative \\
\hline EDUMIS & Education Management Information System \\
\hline EEO & Equal Employment Opportunities \\
\hline EFTS & equivalent full-time student \\
\hline EOD & education of the deaf \\
\hline $\mathrm{EOH}$ & education of the handicapped \\
\hline EOTC & Education Outside the Classroom \\
\hline ERO & Education Review Office \\
\hline ESL & English as a second language \\
\hline ETSA & Education and Training Support Agency \\
\hline FAST & Future Aspirations, Subjects and Training \\
\hline HASE & Health and Safety in Employment Act \\
\hline IAGNE & Interim Advisory Group on Non-Formal Education \\
\hline IEA & International Association for the Evaluation of Educational Achievement \\
\hline IHC & Intellectually Handicapped Children \\
\hline IST & in-service training \\
\hline ITO & Industry Training Organisation \\
\hline \multicolumn{2}{|c|}{ MCEETYA Ministerial Council for Education, Employment, Training, and Youth } \\
\hline & Affairs \\
\hline MEF & Maori Education Foundation \\
\hline
\end{tabular}


MERC Multicultural Educational Resource Centre

MERT Ministry of External Relations and Trade

NACBE National Advisory Committee on Bilingual Education

NACME National Advisory Committee on Maori Education

NACOTE National Advisory Committee on Transition Education

NACTSWL National Advisory Committee on Transition from School to Working Life

NACWE National Advisory Committee on Women in Education

NCAE National Council of Adult Education

NEQA National Education Qualifications Authority

NQF National Qualifications Framework

NZARE New Zealand Association for Research in Education

NZCER New Zealand Council for Educational Research

NZCTE New Zealand Council of Teacher Education

NZEI New Zealand Educational Institute

NZFKU New Zealand Free Kindergarten Union

NZJEP New Zealand Japan Exchange Programme

NZPPTA New Zealand Post Primary Teachers' Association

NZQA New Zealand Qualifications Authority

NZSC New Zealand School Certificate

NZSTCA New Zealand School Transport Contractors' Association

NZTCB New Zealand Trades Certification Board

NZTCI New Zealand Technical Correspondence Institute

NZTISA New Zealand Technical Institute Students' Association

NZVCC New Zealand Vice-Chancellors' Committee

NZWEA New Zealand Workers' Educational Association

OECD Organisation for Economic Cooperation and Development

PAC Parent Advocacy Council

PACIFICA Pacific Allied (Women's) Council

PAFT Parents as First Teachers

PCC Pacific Circle Consortium

PCET post-compulsory education and training

PECC Pacific Economic Co-operation Conference

PIERC Pacific Island Educational Resource Centre 
PIPEF Pacific Islands Polynesian Education Foundation

POBOC payment on behalf of the Crown

POD Property Occupancy Document

PSA Public Service Association

PSAC Public Sector Accounting Concepts

PSRA Public Scholarship and Research Agency

PSU Pupil Session Unit

RBDU Resources Business Development Unit

REAC Regional Employment and Access Council

REAP rural education activities programme

REMTA Risk Management, Training and Assessment

SCC School Consultative Committee

SCEB School Certificate Examination Board

SCORITE Standing Committee on Relationships in Tertiary Education

SEAMEO South East Asian Ministers of Education Organisation

SEAPREAMS South East Asia and Pacific Region Educational Administrators and Managers Symposium

SEPIT Special Education Policy Implementation Team

SES socio-economic status

SES Special Education Service

SFC Sixth Form Certificate

SGM Salaries Grant for Management

SIGMA System of Integrated Government Management Accounting

SMG Strategic Management Group

SOSRIS Social Science Research Index

SPANZ Secondary Principals’ Association of New Zealand

SSRFC Social Science Research Fund Committee

STA School Trustees’ Association

STEPS School Leavers Training and Employment Preparation Schemes

STJC Senior Teacher of Junior Classes

TAG Tertiary Assistance Grant

TCA Teachers College Association

TCC Tertiary Consultative Committee

TIA Technical Institutes Association 
TIAG Tertiary Institutes Advisory Group

TIASA Technical Institute Allied Staff Association

TOP Training Opportunities Programme

TOPIA Transfer of PCET Institution Assets

TRB Teacher Registration Board

TRL Technical Refresher Leave

TSG Teacher Salaries Grant

TTU Tutor Training Unit

TUEL Trade Union Education Leave

TUPES Trade Union Postal Education Service

UE University Entrance

UNESCO United Nations Educational, Scientific and Cultural Organisation

URICA Universal Real-Time Information Control and Access (the DoE library system)

VEETAC Vocational Education, Employment and Training Advisory Committee

VPU visual production unit

WACE Womens' Advisory Committee on Education

YLC Youth Learning Centre

YPTP Young Persons Training Programme 


\section{DATA SOURCES}

\section{COMPOSITION OF CORPUS}

\section{NEW ZEALAND TREASURY BRIEFINGS TO INCOMING GOVERNMENTS}

New Zealand Treasury. 14 July 1984a. Economic Management. www.treasury.govt.nz/briefings/

New Zealand Treasury. 30 July 1984b. Economic Management: Land Use Issues. www.treasury.govt.nz/briefings/

New Zealand Treasury. 1987. Government Management: Brief to the Incoming Government 1987. www.treasury.govt.nz/briefings/

New Zealand Treasury. 1990. Briefing to the Incoming Government 1990. www.treasury.govt.nz/briefings/

New Zealand Treasury. 1993. Briefing to the Incoming Government 1993. www.treasury.govt.nz/briefings/

\section{NEW ZEALAND TREASURY ANNUAL REPORTS}

New Zealand Treasury. 1990. "Report for Year Ended 31 March 1988". Appendix to the Journals of the House of Representatives of New Zealand 1987 - 90. Vol. IV B. Wellington: Government Printer. pp. B.27 1 - 31 .

New Zealand Treasury. 1990. "Report for Year Ended 31 March 1989". Appendix to the Journals of the House of Representatives of New Zealand 1987 - 90. Vol. IV B. Wellington: Government Printer. pp. B.27 1 - 37. 
New Zealand Treasury. 1994. "Report for the Six Months Ended 31 December 1990". Appendix to the Journals of the House of Representatives of New Zealand 1991 - 93. Vol. IX B. Wellington: Government Printer. pp. B.27 HY 1 - 44.

New Zealand Treasury. 1994. "Report for Year Ended 30 June 1991". Appendix to the Journals of the House of Representatives of New Zealand 1991 - 1993. Vol. IX B. Wellington: Government Printer. pp B.27 1 - 74 .

New Zealand Treasury. 1994. "Report for Year Ended 30 June 1992”. Appendix to the Journals of the House of Representatives of New Zealand 1991 - 1993. Vol. IX B. Wellington: Government Printer. pp. B.27 1-111.

New Zealand Treasury. 1994. Annual Report for the year ended 30 June 1994. http://www.treasury.govt.nz/pubs/corp/annrepl.htm

New Zealand Treasury. 1999. "Report of the Treasury for the year ended 30 June 1993". Appendix to the Journals of the House of Representatives of New Zealand 1993 - 96. Vol. XVII B. Wellington: Government Printer. pp. B.27 1- 102.

\section{NEW ZEALAND TREASURY CORPORATE PLANS}

New Zealand Treasury. 1990. The Treasury Corporate Plan 1990 - 1991. Wellington: Treasury, unpublished manuscript.

New Zealand Treasury. 1991. The Treasury Corporate Plan 1991 - 92. Wellington: Treasury, unpublished manuscript.

New Zealand Treasury. 1992. The Treasury Corporate Plan 1992/93. Wellington: Treasury, unpublished manuscript.

New Zealand Treasury. 1993. The Treasury Corporate Plan 1993 - 94. Wellington: Treasury, unpublished manuscript. 
NEW ZEALAND DEPARTMENT OF SOCIAL WELFARE BRIEFINGS TO INCOMING GOVERNMENTS

New Zealand Department of Social Welfare. 1984. Briefing Notes of 22 July 1984 Minister of Social Welfare. Wellington: Department of Social Welfare, unpublished manuscript.

New Zealand Department of Social Welfare. 1987. Briefing Papers for Incoming Minister of Social Welfare, 1987. Wellington: Department of Social Welfare, unpublished manuscript.

New Zealand Department of Social Welfare. 1990. An Inventory of the Department and its Programmes: Briefing Paper for the Minister of Social Welfare. Wellington: Government Printer.

New Zealand Department of Social Welfare. 1990. Fraud Abuse and Waste: A Briefing Paper for the Minister of Social Welfare October 1990. Wellington: Government Printer.

New Zealand Department of Social Welfare. 1990. Key Issues for Benefit Reform Implementation: A Briefing Paper for the Minister of Social Welfare October 1990. Wellington: Government Printer.

New Zealand Department of Social Welfare. 1990. Key Issues for Social Welfare: A Briefing Paper for the Minister of Social Welfare October 1990. Wellington: Government Printer.

New Zealand Department of Social Welfare. 1990. The Cost of Welfare Options and Cost Containment: A Briefing Paper for the Minister of Social Welfare October 1990. Wellington: Government Printer.

New Zealand Department of Social Welfare. 1993. Social Welfare in New Zealand: Briefing Material February 1993 for Hon. Jenny Shipley, Minister of Social Welfare New Zealand. Wellington: Government Printer. 
New Zealand Department of Social Welfare. 1984. Report of the Department of Social Welfare for the year ended 31 March 1984. Wellington: Government Printer.

New Zealand Department of Social Welfare. 1985. Report of the Department of Social Welfare for the year ended 31 March 1985. Wellington: Government Printer.

New Zealand Department of Social Welfare. 1986. Report of the Department of

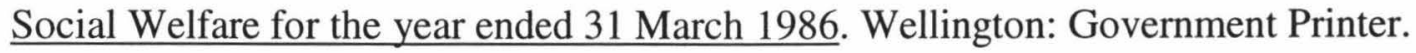

New Zealand Department of Social Welfare. 1987. Report of the Department of Social Welfare for the year ended 31 March 1987. Wellington: Government Printer.

New Zealand Department of Social Welfare. 1988. Report of the Department of Social Welfare for the year ended 31 March 1988. Wellington: Government Printer.

New Zealand Department of Social Welfare. 1989. Report of the Department of Social Welfare for the year ended 31 March 1989. Wellington: Government Printer.

New Zealand Department of Social Welfare. 1990. Report of the Department of Social Welfare for the year ended 30 June 1990. Wellington: Government Printer.

New Zealand Department of Social Welfare. 1991. Report of the Department of Social Welfare for the year ended 30 June 1991. Wellington: Government Printer.

New Zealand Department of Social Welfare. 1992. Department of Social Welfare New Zealand Fiscal 1992. Wellington: Government Printer.

New Zealand Department of Social Welfare. 1993. Annual Report Department of Social Welfare Te Tari Toko I Te Ora Fiscal 1993. Wellington: Government Printer.

New Zealand Department of Social Welfare. 1994. Department of Social Welfare Te Tari Toko I Te Ora Fiscal 1994 Annual Report. Wellington: Government Printer. 
New Zealand Department of Social Welfare. 1986. DSW Management Plan 1986. Wellington: Department of Social Welfare.

New Zealand Department of Social Welfare. July 1987. Management Plan 1987. Wellington: Government Printer.

New Zealand Department of Social Welfare. 1988. Department of Social Welfare Corporate Management Plan 1988. Wellington: Department of Social Welfare.

New Zealand Department of Social Welfare. 1989. Department of Social Welfare 1989/90 Corporate Plan. Update to 1988 Corporate Management Plan. Wellington: Department of Social Welfare.

New Zealand Department of Social Welfare. 1990. DSW Corporate Plan 1990 1991. Wellington: Department of Social Welfare.

New Zealand Department of Social Welfare. 1991. DSW Corporate Plan 1991 1992. Wellington: Department of Social Welfare.

New Zealand Department of Social Welfare. 1993. DSW Corporate Plan Fiscal 1993. Wellington: Department of Social Welfare.

New Zealand Department of Social Welfare. 1994. Corporate Plan Fiscal 1994. Wellington: Department of Social Welfare.

New Zealand Department of Social Welfare. 1995. Department of Social Welfare Te Tari Toko i te Ora Fiscal 1995 Corporate Plan. Wellington: Department of Social Welfare.

NEW ZEALAND DEPARTMENT OF HEALTH BRIEFINGS TO INCOMING GOVERNMENTS 
New Zealand Department of Health. July 1984. General Briefing Notes for the Minister of Health. Wellington: Department of Health, unpublished manuscript.

New Zealand Department of Health. August 1987. General Briefing Notes for the Minister of Health. Wellington: Department of Health, unpublished manuscript.

New Zealand Department of Health. January 1989. Briefing Notes for the Minister of Health. Wellington: Department of Health, unpublished manuscript.

New Zealand Department of Health. 1990. The Department and The Health Sector Today. (BIG Volume I) Wellington: Department of Health, unpublished manuscript.

New Zealand Department of Health. 1990. The Department and The Health Sector Today - Appendix. Wellington: Department of Health, unpublished manuscript.

New Zealand Department of Health. 1990. Health in the 1990s - Issues, Options and Opportunities. (BIG Volume II) Wellington: Department of Health, unpublished manuscript.

New Zealand Department of Health. 1990. Issues, Options and Opportunities Briefing Papers. Wellington: Department of Health, three ringbinders of typed looseleaf papers, unpublished manuscript.

New Zealand Department of Health. November 1993. Post Election Briefing Ministry of Health Volume I: Strategic Issues in the Health Sector. Wellington: Department of Health, unpublished manuscript.

New Zealand Ministry of Health. 1993. Post Election Briefing Ministry of Health Volume II. Wellington: Ministry of Health, unpublished manuscript. 
New Zealand Department of Health. 1984. The Public Health: Report of the Department of Health for the year ended 31 March 1984. Wellington: Government Printer.

New Zealand Department of Health. 1985. The Public Health: Report of the Department of Health for the year ended 31 March 1985. 1985. Wellington: Government Printer.

New Zealand Department of Health. 1986. The Public Health: Report of the Department of Health for the year ended 31 March 1986. Wellington: Government Printer.

New Zealand Department of Health. 1987. The Public Health: Report of the Department of Health for the year ended 31 March 1987. Wellington: Government Printer.

New Zealand Department of Health. 1988. The Public Health: Report of the Department of Health for the year ended 31 March 1988. Wellington: Government Printer.

New Zealand Department of Health. 1989. The Public Health: Report of the Department of Health for the year ended 31 March 1989. Wellington: Government Printer.

New Zealand Department of Health. 1990. The Public Health: Half-Yearly Report of the Department of Health for the six months ended 31 December 1989. Wellington: Government Printer.

New Zealand Department of Health. 1990. The Public Health: The Report of the Department of Health for the transitional quarter, April - June 1989. Wellington: Government Printer. 
New Zealand Department of Health. 1990. The Public Health: The Annual Report of the Department of Health for the year ended 30 June 1990. Wellington: Government Printer.

New Zealand Department of Health. 1991. The Public Health: The Half-Yearly Report of the Department of Health for the period 1 July - 31 December 1990. Wellington; Government Printer.

New Zealand Department of Health. 1991. The Public Health: Report of the Department of Health for the year ended 30 June 1991. Wellington: Government Printer.

New Zealand Department of Health. 1992. Department of Health: Half-Yearly Report for the six months ended 31 December 1991. Wellington: Government Printer.

New Zealand Department of Health. 1992. Department of Health: Annual Report for the year ended 30 June 1992. Wellington: Government Printer.

New Zealand Department of Health. 1993. Department of Health: Annual Report for the year ended 30 June 1993. Wellington: Government Printer.

New Zealand Department of Health. 1994. Ministry of Health: Annual Report for the Year Ended 30 June 1994. Wellington: Government Printer.

NEW ZEALAND DEPARTMENT OF HEALTH CORPORATE PLANS

New Zealand Department of Health. 1986. Department of Health Corporate Plan 1986/87. Wellington: Department of Health, unpublished manuscript.

New Zealand Department of Health. 1987. The Health Management Plan 1987 - 88. Wellington: Government Printers.

New Zealand Department of Health. 1988. Statement of corporate intent 1988. Wellington: Government Printers. 
New Zealand Department of Health. 1990. Department of Health Te Tari Ora Corporate Plan 1990 - 91. Wellington: Government Printers.

New Zealand Department of Health. 1991. Corporate Plan 1991/92 Department of Health Te Tari Ora. Wellington: Government Printers.

New Zealand Department of Health. Corporate Plan 1992/93 Department of Health Te Tari Ora. Wellington: Government Printers.

New Zealand Ministry of Health. 1993. Corporate Plan 1993/94. Wellington: Government Printers.

\section{NEW ZEALAND DEPARTMENT OF EDUCATION BRIEFINGS TO INCOMING GOVERNMENTS}

New Zealand Department of Education. July 1984. Briefing Papers Provided to Hon. Russell Marshall Minister of Education July 1984. Wellington: Department of Education, unpublished manuscript.

New Zealand Department of Education. August 1987. Briefing Papers Provided to Rt. Hon. David Lange Minister of Education August 1987: Current Issues. Wellington: Department of Education, unpublished manuscript.

New Zealand Ministry of Education. October 1990. Quality Education for All According to their Needs: Brief For the Incoming Government. Wellington: Ministry of Education, unpublished manuscript.

New Zealand Ministry of Education. November 1993. Education in New Zealand: A Briefing for the Incoming Government. Wellington: Ministry of Education, unpublished manuscript.

NEW ZEALAND DEPARTMENT OF EDUCATION ANNUAL REPORTS 
New Zealand Department of Education. 1985. Report of the Department of Education for the year ended 31 March 1984. Appendix to the Journals of the House of Representatives of New Zealand 1984 - 85. Vol. V. Wellington: Government Printers. pp. E. $11-58$.

New Zealand Department of Education. 1985. Report of the Department of Education for the year ended 31 March 1985. Appendix to the Journals of the House of Representatives of New Zealand 1984 - 85. Vol. V. Wellington: Government Printers. pp. E.1 $1-55$.

New Zealand Department of Education. 1987. Report of the Department of Education for the year ended 31 March 1986. Appendix to the Journals of the House of Representatives of New Zealand 1986 - 87. Vol. V. Wellington: Government Printers. pp. E. $11-64$.

New Zealand Department of Education. 1987. Report of the Department of Education for the year ended 31 March 1987. Appendix to the Journals of the House of Representatives of New Zealand 1986 - 87. Vol. V. Wellington: Government Printers. pp. E. $11-60$.

New Zealand Department of Education. 1990. Report of the Department of Education for the year ended 31 March 1988. Appendix to the Journals of the House of Representatives of New Zealand 1987 - 90. Vol. VI. Wellington: Government Printers. pp. E.1 1 - 44.

New Zealand Department of Education. 1990. Report of the Department of Education for the year ended 31 March 1989. Appendix to the Journals of the House of Representatives of New Zealand 1987 - 90. Vol. VI. Wellington: Government Printers. pp. E. $11-48$.

New Zealand Department of Education. 1989. Report of the Department of Education Transitional Quarter 1 April - 30 June 1989. Wellington: Department of Education, unpublished manuscript. 
New Zealand Department of Education. 1990. Report of the Department of Education (Disestablished 30 September 1989) 1 July - 30 September 1989. Appendix to the Journals of the House of Representatives of New Zealand 1990. Vol. IV. Wellington: Government Printers. pp. E.1 1 - 28.

New Zealand Ministry of Education. 1990. Report of the Ministry of Education Te Tahuhu o te Matauranga for the 3 months to 31 December 1989. Appendix to the Journals of the House of Representatives of New Zealand 1990. Vol. IV. Wellington: Government Printers. pp. E.1 $1-41$.

New Zealand Ministry of Education. 1990. Report of the Ministry of Education Te Tahuhu o te Matauranga for the 9 months from 1 October 1989 to 30 June 1990. Wellington: Ministry of Education, unpublished and unbound manuscript.

New Zealand Ministry of Education. 1993. Report of the Ministry of Education Te Tahuhu o te Matauranga for the 6 months from 1 July 1990 to 31 December 1990. Appendix to the Journals of the House of Representatives of New Zealand 1991 - 93. Vol. XIII. Wellington: Government Printers. pp. E.1 1 - 59.

New Zealand Ministry of Education. 1993. Report of the Ministry of Education Te Tahuhu o te Matauranga for the 12 months from 1 July 1990 to 30 June 1991. Appendix to the Journals of the House of Representatives of New Zealand 1991 - 93. Vol. XIII. Wellington: Government Printers. pp. E.1 1 - 93.

New Zealand Ministry of Education. 1993. Report of the Ministry of Education Te Tahuhu o te Matauranga for the 6 months from 1 July 1991 to 31 December 1991. Appendix to the Journals of the House of Representatives of New Zealand $1991-93$. Vol. XIII. Wellington: Government Printers. pp. E.1 1 - 65.

New Zealand Ministry of Education. 1993. Report of the Ministry of Education Te Tahuhu o te Matauranga for the 12 months from 1 July 1991 to 30 June 1992. Appendix to the Journals of the House of Representatives of New Zealand 1991 - 93. Vol. XIII. Wellington: Government Printers. pp. E.1 1 - 92. 
New Zealand Ministry of Education. 1996. Report of the Ministry of Education Te Tahuhu o te Matauranga for the 12 months from 1 July 1992 to 30 June 1993. Appendix to the Journals of the House of Representatives of New Zealand 1993 - 96. Vol. XXII. Wellington: Government Printers. pp. E.1 1 - 75.

New Zealand Ministry of Education. 1996. Report of the Ministry of Education Te Tahuhu o te Matauranga for the year ended 30 June 1994. Appendix to the Journals of the House of Representatives of New Zealand 1993 - 96. Vol. XXII. Wellington: Government Printers. pp. E.1 1 - 108.

\section{NEW ZEALAND DEPARTMENT OF EDUCATION CORPORATE PLANS}

New Zealand Department of Education. 1988. Statement of Intent 1988/89. Wellington: Department of Education, unpublished manuscript.

New Zealand Department of Education. 1989. Statement of Intent 1 April - 30 September 1989. Wellington: Department of Education, unpublished manuscript.

New Zealand Ministry of Education. 1989. Ministry of Education Te Tahuhu o Te Matauranga Corporate Plan 1989/1990 (1 October - 30 June). Wellington: Ministry of Education, unpublished manuscript.

New Zealand Ministry of Education. 1990. Corporate Plan 1990/91. Wellington: Ministry of Education.

New Zealand Ministry of Education. 1991. Corporate Plan 1991/92. Wellington: Ministry of Education.

New Zealand Ministry of Education. 1992. Corporate Plan 1992/93. Wellington: Ministry of Education.

New Zealand Ministry of Education. 1993. Ministry of Education Corporate Plan 1993/94. Wellington: Ministry of Education. 
New Zealand Ministry of Education. 1994. Ministry of Education Corporate Plan 1994/95. Wellington: Ministry of Education. 


\section{REFERENCES AND BIBLIOGRAPHY}

Aijmer, Karin and Bengt Altenberg (eds.). 1991. English Corpus Linguistics: Studies in Honour of Jan Svartvik. London and New York: Longman.

Algeo, John. 1994. "Problems in New-Word Lexicography". Dictionaries 15: pp 3946.

Allan, Keith and Kate Burridge. 1991. Euphemism and Dysphemism: Language Used as Shield and Weapon. New York: Oxford University Press.

Allen, Robert. 1999. “Lumping and Splitting”. English Today 15,4: 61 - 63.

Andersen, Johannes C. 1946. "Maori Words Incorporated into the English Language". Journal of the Polynesian Society 55,2: pp 141-162.

"Attitudes to New Zealand English: A Listener Correspondence (1961)". (No author given). 1990. New Zealand English Newsletter 4: pp 35-38.

Avis, Walter S. ed.). 1991. A Dictionary of Canadianisms on Historical Principles. Toronto: Gage.

Ayto, John. 1990. The Longman Register of New Words. Volume Two. Harlow: Longman.

Ayto, John. 1999. 20 ${ }^{\text {th }}$ Century Words: The Story of the New Words in English over the Last Hundred Years. Oxford: Oxford University Press.

Bailey, Richard W. (ed.). 1989. Dictionaries of English: Prospects for the Record of Our Language. $2^{\text {nd }}$ ed. Cambridge: Cambridge University Press.

Baker, S. J. 1941. New Zealand Slang: A Dictionary of Colloquialisms. Christchurch: Whitcombe \& Tombs.

Baker, Sidney J. 1945. The Australian Language. Sydney: Angus and Robertson.

Bardsley, Dianne. 2001a. "Keeping company in the country: collocations, compounds, and phrasal verbs in the rural lexicon". New Zealand English Journal 15: pp 20-28.

Bardsley, Dianne. 2001b. "On first looking into Kiwi ruralspeak". New Zealand Words 5: pp 1-3.

Bardsley, Dianne. 2003. The Rural New Zealand English Lexicon 1842-2002. Unpublished doctoral dissertation. School of Linguistics and Applied Language Studies, Victoria University of Wellington. 
Bardsley, Dianne. 2005. “A Specialist Study in New Zealand English Lexis: The Rural Sector”. International Journal of Lexicography 19:1: pp 41 - 72.

Bauer, Laurie. 1980. "Something Old, Something New, Something Borrowed: An Essay on Loan Words". In Norton and Robinson, 1980.

Bauer, Laurie. 1983. English Word-Formation. Cambridge: Cambridge University Press.

Bauer, Laurie. 1984. Perspectives on Words. Wellington: Victoria University of Wellington.

Bauer, Laurie. 1987. "Approaching the Grammar of New Zealand English". New Zealand English Newsletter 1: pp 12-15.

Bauer, Laurie. 1994. "English in New Zealand". In Robert Burchfield (ed.). The Cambridge History of the English Language. Volume V. Cambridge: Cambridge University Press.

Bauer, Laurie. 1998. Vocabulary. London and New York: Routledge.

Bauer, Laurie. 1999. "A Note on Rhyming Slang in New Zealand English". New Zealand English Journal 13: pp 5-7.

Bauer, Laurie. 2002. An Introduction to International Varieties of English. Edinburgh: Edinburgh University Press.

Bauer, Laurie and Winifred Bauer. 2000. "Nova Zelandia est Omnis Divisa in Partes Tres”. New Zealand English Journal 14: 7-17.

Bauer, Laurie and Christine Franzen (eds.). 1993. Of Pavlova, Poetry and Paradigms: Essays in Honour of Harry Orsman. Wellington: Victoria University Press.

Bayard, Donn. 1988. "Variation in and Attitudes Toward New Zealand English: A Quantitative Approach”. New Zealand English Newsletter 2: pp 13-16.

Bejoint, Henri. 1994. Tradition and Innovation in Modern English Dictionaries. Oxford: Clarendon Press.

Bejoint, Henri. 2000. Modern Lexicography: An Introduction. $2^{\text {nd }}$ ed. Oxford: Oxford University Press.

Bell, Allan and Janet Holmes (eds.). 1990. New Zealand Ways of Speaking English. Wellington: Victoria University Press.

Bell, A. and K. Kuiper (eds.). 2000. New Zealand English. Wellington: Victoria University Press.

Bennett, J.A.W. 1970. "English as it is Spoken in New Zealand”. In Ramson, 1970. 
Benson, Morton, Evelyn Benson and Robert Ilson. 1986. Lexicographic Description of English. Studies in Language Companion Series (SLCS) Vol. 14. Amsterdam: John Benjamins.

Benson, Philip. 1993. "Localised vocabulary in Hong Kong and Australian English". In Pemberton and Tsang, 1993.

Berg, Donna Lee. 1993. A Guide to the Oxford English Dictionary. Oxford: Oxford University Press.

Biber, Douglas, Susan Conrad and Randi Reppen. 1998. Corpus Linguistics: Investigating Language Structure and Use. Cambridge: Cambridge University Press.

Biber, Douglas, Stig Johansson, Geoffrey Leech, Susan Conrad and Edward Finegan. 1999. Longman Grammar of Spoken and Written English. Harlow: Pearson Education Ltd.

Boston, Jonathan. 1989. "The Treasury and the Organisation of Economic Advice: Some International Comparisons”. In Easton, 1989.

Boston, Jonathan. 1991a. "Reorganizing the Machinery of Government: Objectives and Outcomes". In Boston et al, 1991.

Boston, Jonathan. 1991b. "The Theoretical Underpinnings of Public Sector Restructuring in New Zealand”. In Boston et al, 1991.

Boston, Jonathan. 1992. "The Treasury: its Role, Philosophy and Influence”. In Gold, 1992.

Boston, Jonathan (ed.). 1995. The State Under Contract. Wellington: Bridget Williams Books.

Boston, Jonathan, John Martin, June Pallot and Pat Walsh (eds.). 1991. Reshaping the State: New Zealand's Bureaucratic Revolution. Auckland: Oxford University Press.

Boston, J., J. Martin, J. Pallot and P. Walsh. 1996. Public Management: The New Zealand Model. Auckland: Oxford University Press.

Brook, G.L. 1963. English Dialects. London: Andre Deutsch.

Burchfield, Robert (ed.). 1987. Studies in Lexicography. Oxford: Clarendon Press.

Burchfield, R.W. 1988. "Some Unedited New Zealand Words". In Burton and Burton, 1988.

Burridge, K. and J. Mulder. 1998. English in Australia and New Zealand: An Introduction to Its History, Structure, and Use. Melbourne: Oxford University Press.

Burton, T.L. and Jill Burton (eds.). 1988. Lexicographical and Linguistic Studies: Essays in Honour of G.W.Turner. Cambridge: D.S.Brewer. 
Cameron, Lynne. 1999. "Identifying and describing metaphor in spoken discourse data". In Cameron and Low, 1999.

Cameron, Lynne and Graham Low (eds.). 1999. Researching and Applying Metaphor. Cambridge: Cambridge University Press.

Cameron, Lynne J. and Juurd H. Stelma. 2004. "Metaphor clusters in discourse". Journal of Applied Linguistics 1,2: pp 107 - 136.

Carter, Ronald. 1987. Vocabulary: Applied Linguistic Perspectives. London: Allen and Unwin.

Cassidy, Frederic G. (ed.). 1985. The Dictionary of American Regional English. Cambridge (Mass.) and London: Harvard University Press.

Cavana, R.Y. "Restructuring the New Zealand railway system: 1982 - 1993". Transport Reviews, 1995, Vol. 15, No.2, pp. 119 - 139. In Privatisation: Lessons from New Zealand.

Clark, Margaret. 2004. "Something like a cult". New Zealand Books 14, 1, 62: p 17.

Connor, Cherie. 2010. A Diachronic Exploration of the Contribution of the Harvesting of the Marine Environment to a Distinctive New Zealand English Lexicon, 1796 - 2005. Unpublished doctoral dissertation. School of Linguistics and Applied Language Studies, Victoria University of Wellington.

Cortazzi, Martin and Lixian Jin. 1999. "Bridges to learning". In Cameron and Low, 1999.

Cruse, D.A. 1986. Lexical Semantics. Cambridge: Cambridge University Press.

Cryer, M. 2002. Curious Kiwi Words. Auckland: Harper Collins.

Crystal, David (ed.). 1980. Eric Partridge in his own words. London: Andre Deutsch.

Crystal, David. 1995. The Cambridge Encyclopedia of the English Language. Cambridge: Cambridge University Press.

Davy, Derek. 1988. "Surveying New Zealand English". New Zealand English Newsletter 2: pp 4-8.

De Bres, Julia. 2006. "Maori lexical items in the mainstream television news in New Zealand”. New Zealand English Journal 20: pp 17-34.

Deignan, Alice. 1999. “Corpus-based research into metaphor”. In Cameron and Low, 1999.

Delbridge, Arthur and P.H. Peters. 1988. "Dictator, Gatekeeper, Tally Clerk or Harmless Drudge?" In Burton and Burton, 1988. 
DeMaria, Robert, Jr. 1986. Johnson's Dictionary and the Language of Learning. Chapel Hill and London: The University of North Carolina Press.

Deverson, Tony. 1984. “'Home Loans': Maori Input into Current New Zealand English”. English In New Zealand 33: pp 4-10.

Deverson, Tony. 1990. "Considering Kiwi: A Survey of Teachers' Attitudes to New Zealand English”. New Zealand English Newsletter 4: pp 10-15.

Deverson, T. 2000. "Handling New Zealand English Lexis". In Bell and Kuiper, 2000 .

Deverson, Tony. 2001. "New Zealand, New Zealand English and the dictionaries". In Bruce Moore (ed.). Who's Centric Now?: The Present State of Post-Colonial Englishes. Melbourne: Oxford University Press.

Deverson, Tony and Graeme Kennedy (eds.). 2005. The New Zealand Oxford Dictionary. Melbourne: Oxford University Press.

Eagleson, R. D. 1988. "Legislative Lexicography”. In Stanley and Hoad, 1988.

Easton, Brian. 1989a. "The Commercialisation of the New Zealand Economy: From Think Big to Privatisation". In Easton, 1989b.

Easton, Brian (ed.). 1989b. The Making of Rogernomics. Auckland: Auckland University Press.

Easton, Brian. 1994. "How did the Health Reforms Blitzkrieg Fail?" Political Science 46, 2: pp $215-233$.

Easton, Brian. 1997. The Commercialisation of New Zealand. Auckland: Auckland University Press.

Evans, Lewis. 1998. "The Theory and Practice of Privatisation". In Privatisation: Lessons From New Zealand.

Evans, Lewis, Arthur Grimes, Bryce Wilkinson and David Teece. 1996. "Economic Reform in New Zealand 1984 - 95: The Pursuit of Efficiency".Journal of Economic Literature XXXIV: pp 1856 - 1902. In Privatisation: Lessons from New Zealand.

Foreman, J. B. (ed.). 1966. The New Zealand Contemporary Dictionary. Christchurch: Whitcombe and Tombs.

Gannon, Martin J. (ed.). 2001. Cultural Metaphors: Readings, Research Translations, and Commentary. Thousand Oaks: Sage Publications.

Gibbs, Raymond W. Jr. 1999. "Researching metaphor". In Cameron and Low, 1999.

Gilman, E. Ward. 1990. "Dictionaries as a Source of Usage Controversy". Dictionaries 12: pp 75-84. 
Gold, Hyam (ed.). 1992. New Zealand Politics in Perspective. $3^{\text {rd }}$ ed. Auckland: Longman Paul.

Gordon, Elizabeth. 1988. "New Zealand English and the New Zealand Listener". New Zealand English Newsletter 2: pp 9-12.

Gordon, Elizabeth and Tony Deverson. 1985. New Zealand English: An introduction to New Zealand speech and usage. Auckland: Heinemann.

Gordon, Elizabeth and Tony Deverson. 1989. Finding A New Zealand Voice: attitudes towards English used in New Zealand. Auckland: New House Publishers.

Gordon, Elizabeth and Tony Deverson. 1998. New Zealand English and English in New Zealand. Auckland: New House Publishers.

Gordon, Elizabeth and Margaret Maclagan. 1995. "Making a Virtue of Necessity: combining teaching and research in the study of New Zealand English". New Zealand English Newsletter 9: pp 27-31.

Gordon, I. 1980. A Word In Your Ear. Auckland: Heinemann Educational Books.

Gordon, Ian A. (ed.). 1982. The New Collins Concise Dictionary of the English Language; New Zealand Edition. Auckland: Collins.

Gordon, Ian A. 1988. "British Regional Survivals in New Zealand English". In Burton and Burton, 1988.

Grant, Lynn and Paul Nation. 2005. "How many idioms are there in English?" (in press)

Green, Jonathan. 1996. Chasing The Sun. London: Pimlico.

Gregory, Robert. 2000. "Getting better but feeling worse? Public sector reform in New Zealand”. International Public Management Journal 3: pp 107-123.

Gregory, Robert. 2002. "Governmental Corruption in New Zealand: A View Through Nelson's Telescope?” Asian Journal of Political Science Vol.10 No.1: pp 17-38.

Hanks, Patrick. 2004. "The Syntagmatics of Metaphor and Idiom". International Journal of Lexicography Vol. 17 No.3: pp 245-274.

Hartmann, R.R.K. (ed.). 1983. Lexicography: Principles and Practice. London: Academic Press.

Hartmann, R.R.K. (ed.). 1986. The History of Lexicography. Amsterdam: John Benjamins.

Hartmann, R.R.K. 2001. Teaching and Researching Lexicography. Harlow: Longman. 
Hartmann, R.R.K. and Gregory James. 1998. Dictionary of Lexicography. London and New York: Routledge.

Hayward, N. and T. Hayward. 1976. New Zealandeze: A Traveller's Guide to the Kiwi Language. Nelson: Hayward Publications.

Henderson, David. 1996. Economic Reform: New Zealand in an International Perspective. Wellington: New Zealand Business Roundtable.

Hirsh, Walter. 1989. New Zealand English - Alive and Very Well. Auckland, Wellington and Christchurch: The Office of the Race Relations Conciliator.

Holder, R. W. 1995. A Dictionary of Euphemisms. Oxford: Oxford University Press.

Holmes, Janet, Maria Stubbe and Bernadette Vine. 1999. “Analysing New Zealand English in the Workplace”. New Zealand English Journal 13: pp 8-12.

http://www.govt.nz/

http://www.oed.com/

http://www.ssc.govt.nz/

http://www.treasury.govt.nz/annualreport/

http://www.treasury.govt.nz/soi/

Hudson, Kenneth. 1977. The Dictionary of Diseased English. London: Macmillan.

Hull, C. 1957. Talking of Words. Auckland: Unity Press.

Hurley, Desmond. 2000. "The Dump of Words". New Zealand English Journal 14: pp 34-40.

Ilson, Robert F. (ed.). 1985. Dictionaries, Lexicography and Language Learning. Oxford: Pergamon Press.

Ilson, Robert (ed.) 1986. Lexicography: An emerging international profession. Fulbright Papers Vol.1. Manchester: Manchester University Press.

Isaac, Peter. 2004. The New Gobbledygook: a New Zealand dictionary and guidebook. Wellington: transpress New Zealand.

Ivir, Vladimir. 1988. "Collocations in Dictionaries Monolingual and Bilingual". In Burton and Burton, 1988.

Jackson, Howard. 1985. “Grammar in the Dictionary”. In Ilson, 1985.

Jackson, Howard. 1988. Words And Their Meaning. London and New York: Longman. 
Jackson, Howard. 2002. Lexicography: An Introduction. London: Routledge.

Jackson, Howard and Etienne Ze Amvela. 2000. Words, Meaning and Vocabulary: An Introduction to Modern English Lexicology. London and New York: Cassell.

James, Colin. 1992. New Territory: The transformation of New Zealand 1984-92. Wellington: Bridget Williams Books.

Jesson, Bruce. 1989. Fragments of Labour: The Story Behind the Labour Government. Auckland: Penguin.

Johnston, Jeanette and Adrienne von Tunzelmann. 1982. The State in Business: Public Enterprise in New Zealand. Wellington: New Zealand Planning Council.

Katamba, Francis. 1994. English Words. London and New York: Routledge.

Kelsey, Jane. 1993. Rolling Back the State: Privatisation of Power in Aotearoa/New Zealand. Wellington: Bridget Williams Books.

Kelsey, Jane and Mike O'Brien. 1995. Setting the Record Straight: Social Development in Aotearoa/New Zealand. Wellington: Association of Non Government Organisations of Aotearoa.

Kennedy, G. D. 1978. "Conceptual Aspects of Language Learning". In Jack C. Richards (ed.). Understanding Second and Foreign Language Learning: Issues and Approaches. Rowley: Newbury House.

Kennedy, Graeme. 1998. An Introduction to Corpus Linguistics. London: Longman.

Kennedy, Graeme. 1999. "New Zealand Words and Meanings”. New Zealand English Journal 13: p 13.

Kennedy, Graeme. 2008. "Phraseology and language pedagogy: Semantic preference associated with English verbs in the British National Corpus". In Fanny Meunier and Sylviane Granger (eds.). Phraseology in Foreign Language Learning and Teaching. Amsterdam and Philadelphia: John Benjamins Publishing Company.

Kennedy, Graeme and Shunji Yamazaki. 1999. "The Influence of Maori on the New Zealand English Lexicon". In John M. Kirk (ed.). Corpora Galore: Analyses and Techniques in Describing English. Amsterdam and Atlanta: Rodopi.

Knowles, Elizabeth and Julia Elliott (eds.). 1997. The Oxford Dictionary of New Words. Oxford: Oxford University Press.

Kovecses, Zoltan. 2005. Metaphor in Culture: Universality and Variation. Cambridge: Cambridge University Press.

Krebs, W.A. 1988. "Horses for Courses: The Design of Smaller Dictionaries for Particular Users". In Burton and Burton, 1988. 
Kuiper, Koenraad. 1984. “Our Native Language: A Book Review”. English In New Zealand 33: pp 46-48.

Kuiper, Koenraad. 1987. "The Study of New Zealand English: A brief position paper". New Zealand English Newsletter 1: pp 3-5.

Kuiper, K. and A. Bell. 2000. "New Zealand and New Zealand English". In Bell and Kuiper, 2000.

Lakoff, George. 1987. Women, Fire, and Dangerous Things: What Categories Reveal about the Mind. Chicago and London: The University of Chicago Press.

Lakoff, George and Mark Johnson. 1980. Metaphors We Live By. Chicago and London: The University of Chicago Press.

Lakoff, George and Mark Johnson. 2001. "Metaphors We Live By”. In Gannon (ed.), 2001.

Landau, S. I. 2001. Dictionaries: The Art and Craft of Lexicography. $2^{\text {nd }}$ ed. Cambridge: Cambridge University Press.

Larson, Myq. 2006. Increasing rates of word compounding in English: A preliminary measurement. Unpublished MS. In author's possession.

Leek, Robert. 1997a. "New English Speakers, the Lexicon and Socialisation". New Zealand English Journal 11: pp 37-44.

Leek, Robert. 1997b. "Standard and Non-Standard Pronoun Use by Two Generations of New Zealand Speakers: An Auckland Mini-Project”. New Zealand English Journal 11: pp 26-34.

Leland, L. S., Jr. 1980. A Personal Kiwi-Yankee Dictionary. Dunedin: John McIndoe.

Lewis, Gillian. 1996. "The Origins of New Zealand English: A Report on Work in Progress”. New Zealand English Journal 10: pp 25-30.

Lipka, Leonhard. 1990. An Outline of English Lexicology: Lexical Structure, Word Semantics, and Word-Formation. Tubingen: Niemeyer.

Lloyd, S. M. (ed.). 1984. Roget's Thesaurus of English Words and Phrases. Harmondsworth: Penguin.

Lodwig, Richard R. and Eugene F. Barrett. 1967. The Dictionary and the Language. New York: Hayden Book Company.

Looser, Diana. 1999. “'Boob jargon': the language of a women's prison”. New Zealand English Journal 13: pp 14-37.

Low, Graham. 1999. "Validating metaphor research projects". In Cameron and Low, 1999. 
Lyons, John. 1977. Semantics. Cambridge: Cambridge University Press.

Macalister, John. 1999. "Trends in New Zealand English: some observations on the presence of Maori words in the lexicon". New Zealand English Journal 13: pp 38-49.

Macalister, John. 2000. "The changing use of Maori words in New Zealand English". New Zealand English Journal 14: pp 41-47.

Macalister, John. 2001. "Introducing a New Zealand newspaper corpus". New Zealand English Journal 15: pp 35-41.

Macalister, John Sinclair. 2003. The Presence of Maori Words in New Zealand English. Unpublished doctoral dissertation. School of Linguistics and Applied Language Studies, Victoria University of Wellington.

Macalister, John (ed.). 2005. A Dictionary of Maori Words in New Zealand English. Melbourne: Oxford University Press.

Macalister, John. 2007. "Weka or woodhen? Nativization through lexical choice in New Zealand English”. World Englishes 26:4 pp 492-506.

Malmkjaer, K. (ed.). 1991. The Linguistics Encyclopedia. London: Routledge.

Martin, John. 1991. “Devolution and Decentralization”. In Boston et al, 1991.

Mascarenhas, R.C. 1991. "State-Owned Enterprises”. In Boston et al, 1991.

Mathews, M.M. 1933. A Survey of English Dictionaries. London: Oxford University Press.

Matthews, R.J. 1983. "New Zealand English: A Case Study". World Language English 2, 2: pp 75-80.

Matthews, R.J.H. 1990. "New Zealand English: An Antipodean View”. New Zealand English Newsletter 4: pp 27-30.

McArthur, Tom. 1981. Longman Lexicon of Contemporary English. Harlow: Longman.

McArthur, Tom. 1998. Living Words: Language, Lexicography and the Knowledge Revolution. Exeter: University of Exeter Press.

McArthur, Tom. 2002. The Oxford Guide to World English. Oxford: Oxford University Press.

McEnery, Tony and Andrew Wilson. 1996. Corpus Linguistics. Edinburgh: Edinburgh University Press.

McGill, David. 1988. A Dictionary of Kiwi Slang. Wellington: Mills Publications. 
McGill, David. 1989. The Dinkum Kiwi Dictionary. Wellington: Mills Publications.

McGregor, G. and M. Williams (eds.). 1991. Dirty Silence: Aspects of Language and Literature in New Zealand. Auckland: Oxford University Press.

Moon, Rosamund. 2002. "Dictionaries and Metaphor, Metaphor and Dictionaries". In Gottlieb, H., J.E. Mogensen and A. Zettersten (eds.). 2005. Symposium on Lexicography XI: Proceedings of the Eleventh International Symposium on Lexicography, May $2-4,2002$, at the University of Copenhagen. Lexicographica Series 115. Tubingen: Max Niemeyer Verlag.

Morris, Edward E. 1898. Austral English: A Dictionary of Australasian Words. London: Macmillan and Co.

Mugglestone, Lynda (ed.). 2000. Lexicography and the OED. Oxford: Oxford University Press.

Murray, James A.H. 1900. The Evolution of English Lexicography (Romanes Lecture). Reprinted 1970 College Park, Maryland: McGrath Publishing Company.

Murray, K.M.Elisabeth. 1977. Caught in the Web of Words. New Haven and London: Yale University Press.

Newman, John. 2002. "A corpus-based study of the expression good as gold". New Zealand English Journal 16: pp 24-32.

New Zealand Business Roundtable. 1992. "The Public Benefit of Private Ownership: The Case for Privatisation". In Privatisation: Lessons from New Zealand.

New Zealand Department of Social Welfare. February 1998. Public Discussion Document. Wellington: New Zealand Department of Social Welfare.

New Zealand Listener. 12 March 1988.

New Zealand Ministry of Health. 1997. Purchasing for Your Health 1995/96. Wellington: New Zealand Ministry of Health.

New Zealand Ministry of Justice. 1996. Justice Sector Information Strategy. Wellington: New Zealand Ministry of Justice.

New Zealand Planning Council. 1979. The Welfare State? Social Policy in the 1980s. Wellington: New Zealand Planning Council.

New Zealand Treasury. 2001a. Departmental Forecast Report. www.treasury.govt.nz/dfr/2001/

New Zealand Treasury. 2001b. Annual Report. www.treasury.govt.nz/annualreport/2001/ 
New Zealand Treasury. 2005/2006. Statement of Intent. www.treasury.govt.nz/soi/2006/

Norton, David and Roger Robinson (eds.). 1980. Views of English 2. Wellington: Victoria University, Department of English.

Oliver, W. Hugh. "The Labour Caucus and Economic Policy Formation, 1981 to 1984”. In Easton, 1989b.

Onions, C. T. (ed.). 1973. The Shorter Oxford English Dictionary. Oxford: Oxford University Press.

Opitz, K. 1983. “On dictionaries for special registers". In R.R.K.Hartmann (ed.). Lexicography: Principles and Practice. London: Academic Press.

Orsman, E. and H. Orsman (eds.). 1994. The New Zealand Dictionary. Auckland: New House Publishers.

Orsman, Harry. 1980. "Early New Zealand English Vocabulary and the Australian Connection (Some Data and Notes)”. In Norton and Robinson, 1980.

Orsman, Harry. 1987. "A New Zealand National Dictionary”. New Zealand English Newsletter 1: pp 10-11.

Orsman, Harry. 1995. "The Dictionary of New Zealand English - A Beginning and (almost) an end". New Zealand English Newsletter 9: pp 9-12.

Orsman, H. W. (ed.). 1997. The Dictionary of New Zealand English: A Dictionary of New Zealandisms on Historical Principles. Auckland: Oxford University Press.

Orsman, Harry (ed.). 1999. A Dictionary of Modern New Zealand Slang. Auckland: Oxford University Press.

Ortony, Andrew. 2001. "Why Metaphors are Necessary and Not Just Nice". In Gannon (ed.), 2001.

Palmer, Harold E. 1933. Second Interim Report on English Collocations. Tokyo: Kaitakusha.

Partridge, E. 1963. The Gentle Art of Lexicography. London: Andre Deutsch Limited.

Pemberton, Richard and Elza S.C. Tsang (eds.). 1993. Studies in Lexis: Working Papers from a Seminar. Hong Kong: The Hong Kong University of Science and Technology Language Centre.

Privatisation: Lessons from New Zealand. ( Undated). Wellington: Victoria University of Wellington, Faculty of Commerce and Administration. (Unpublished collection of papers, no editor given). 
Quigley, Katherine. 2004. "Ministry-Speak: Research at the NZDC on the Language of Public Sector Reform in New Zealand, 1981 - 2001". NZ Words 8: $10-11$.

Quigley, Katherine. 2005. "Keeping Company in The City: compounds in the lexicon of the New Zealand Treasury". New Zealand English Journal 19: 26 - 35.

Quigley, Katherine. 2006. "Coinings in the Treasury". In Marianna Kennedy, Stephanie Schnurr and Agnes Terraschke (eds.). Proceedings of the 2nd International Postgraduate Conference in Linguistics and Literary Studies. Wellington: School of Linguistics and Applied Language Studies, Victoria University of Wellington.

Quigley, Katherine. 2007. "The Metaphors of Economic Change”. Wellington Working Papers in Linguistics 18: 1 - 30.

Ramachandran, Vilayanur S. 2003. "The Emerging Mind”. Reith Lecture Series. Available online at http://www.bbc.co.uk/radio4/reith2003/

Ramson, W.S. 1966. Australian English: An Historical Study of the Vocabulary 17881898. Canberra: Australian National University Press.

Ramson, W.S. (ed.). 1970. English Transported: Essays on Australasian English. Canberra: Australian National University Press.

Ramson, W.S. 1988a. "Some South Australian Words”. In Burton and Burton, 1988.

Ramson, W.S. (ed.). 1988b. The Australian National Dictionary. Melbourne: Oxford University Press.

Reddick, Allen. 1990. The Making of Johnson's Dictionary: 1746-1773.

Cambridge: Cambridge University Press.

Riggs, Fred. 1989. "Terminology and Lexicography: Their Complementarity". International Journal of Lexicography 2,2: pp 89-110.

Robinson, Richard. 1950. Definition. Oxford: The Clarendon Press.

Schick, Allen. 1996. The Spirit of Reform: Managing the New Zealand State Sector in a Time of Change. Wellington: State Services Commission.

Schmitt, Norbert (ed.). 2002. An Introduction to Applied Linguistics. London: Arnold.

Schneider, Edgar W. 2007. Postcolonial English: Varieties around the world. Cambridge: Cambridge University Press.

Scott, Rosie. 1999. "Dangerous Lies: The Language of Economic Rationalism". In Rosie Scott. The Red Heart. Auckland: Random House.

Scroder, J. H. E. 1969. The Ways of Words. Christchurch: Pegasus Press. 
Simpson, J. 1988. “The New Vocabulary of English”. In Stanley and Hoad, 1988.

Simpson, J.A. and E.S.C. Weiner (eds.). 1989. The Oxford English Dictionary. Vols. 1-20. $2^{\text {nd }}$ ed. Oxford: Clarendon Press.

Sledd, James and Wilma R. Ebbitt. 1962. Dictionaries and That Dictionary. Chicago: Scott, Foresman and Company.

Stanley, E.G. and T.F. Hoad (eds.). 1988. Words. For Robert Burchfield's Sixty-Fifth Birthday. Cambridge: D.S. Brewer.

Stein, Gabriele. 1973. English Word-Formation over Two Centuries. In Honour of Hans Marchand on the Occasion of his Sixty-Fifth Birthday. Tubingen: Tubinger Beitrage zur Linguistik.

Stein, Gabriele. 1985. "Word-Formation in Modern English Dictionaries". In Ilson, 1985.

Taylor, Dennis. 1990. "The Writer, the Lexicographer, and Lexical Change". Dictionaries 12: pp 1-14.

The American Heritage Dictionary. $4^{\text {th }}$ ed. 2000. Houghton Mifflin. http://www.thefreedictionary.com/

“The Public Finance Act”. 1989. Reprinted Statutes of New Zealand, Vol. 33, 1995, pp.419-520. Wellington: New Zealand Government Printers.

"The State-Owned Enterprises Act". 1986. Reprinted Statutes of New Zealand, Vol. 33, 1995, pp. 813-906. Wellington: New Zealand Government Printers.

“The State Sector Act”. 1988. Reprinted Statutes of New Zealand, Vol. 33, 1995, pp. 715-812. Wellington: New Zealand Government Printers.

Trebilcock, Michael J. “Can Government Be Reinvented?” In Boston, 1995.

Turner, G. W. 1966. The English Language in Australia and New Zealand. London: Longman.

Turner, G.W. 1970. “New Zealand English Today”. In Ramson, 1970.

Urdang, L. (ed.). 1979. Collins English Dictionary. London and Glasgow: Collins.

Wall, A. 1936. The Mother Tongue in New Zealand. Dunedin: Reed.

Wall, A. 1958. The Queen's English: A Commentary for New Zealand. Christchurch: Pegasus Press.

Wall, A. 1959. New Zealand English: a guide to correct pronunciation. 3rd ed. Christchurch: Whitcombe and Tombs Ltd.

Walsh, Pat. 1991. “The State Sector Act 1988”. In Boston et al, 1991. 
Wattie, N. (ed.). 2001. The Reed Dictionary of New Zealand English. $3^{\text {rd }}$ ed. Auckland: Reed Books.

Whitcombe, Judy. 1992. "The Changing Face of the New Zealand Public Service". In Gold, 1992.

Wileman, B. and R. Wileman (eds.). 1987. New Zealand Spelling Dictionary. Bundalong: Wileman Publications.

Wilkes, G.A. 1986. Exploring Australian English. Sydney: ABC Enterprises.

Wilkes, G.A. 1988. "Shakespeare and Australian English”. In Burton and Burton, 1988.

Williams, Geoffrey. "Review of John M. Sinclair, Susan Jones and Robert Daley. English Collocation Studies: The OSTI Report. London and New York: Continuum. 2004.” International Journal of Lexicography Vol.18 No.3: pp 391-393.

Willinsky, John. 1994. Empire of Words: The Reign of the OED. Princeton: Princeton University Press.

Winchester, Simon. 1998. The Surgeon of Crowthorne. Harmondsworth: Penguin.

Winchester, Simon. 2003. The Meaning of Everything: The Story of the Oxford English Dictionary. Oxford: Oxford University Press.

Wray, Alison. 2002. Formulaic Language and the Lexicon. Cambridge: Cambridge University Press.

Xiao, Richard and Tony McEnery. 2006. "Collocation, Semantic Prosody, and Near Synonymy: A Cross-Linguistic Perspective.” Applied Linguistics 27,1: pp 103-129.

Zgusta, Ladislav. 1971. Manual of Lexicography. The Hague: Mouton. 